\title{
From rags to richness: A structuration perspective on interactional richness and its impact on customer evaluations of online experiences
}

Citation for published version (APA):

van Oppen, C. A. M. L. (2007). From rags to richness : A structuration perspective on interactional richness and its impact on customer evaluations of online experiences. [Doctoral Thesis, Maastricht University]. Maastricht University. https://doi.org/10.26481/dis.20070704co

Document status and date:

Published: 01/01/2007

DOI:

10.26481/dis.20070704co

Document Version:

Publisher's PDF, also known as Version of record

Please check the document version of this publication:

- A submitted manuscript is the version of the article upon submission and before peer-review. There can be important differences between the submitted version and the official published version of record.

People interested in the research are advised to contact the author for the final version of the publication, or visit the DOI to the publisher's website.

- The final author version and the galley proof are versions of the publication after peer review.

- The final published version features the final layout of the paper including the volume, issue and page numbers.

Link to publication

\footnotetext{
General rights rights.

- You may freely distribute the URL identifying the publication in the public portal. please follow below link for the End User Agreement:

www.umlib.nl/taverne-license

Take down policy

If you believe that this document breaches copyright please contact us at:

repository@maastrichtuniversity.nl

providing details and we will investigate your claim.
}

Copyright and moral rights for the publications made accessible in the public portal are retained by the authors and/or other copyright owners and it is a condition of accessing publications that users recognise and abide by the legal requirements associated with these

- Users may download and print one copy of any publication from the public portal for the purpose of private study or research.

- You may not further distribute the material or use it for any profit-making activity or commercial gain

If the publication is distributed under the terms of Article 25fa of the Dutch Copyright Act, indicated by the "Taverne" license above, 


\section{From Rags to Richness}

A Structuration Perspective on Interactional Richness and its Impact on Customer Evaluations of Online Experiences

Claudia van Oppen 
(C) 2007, Claudia A.M.L. van Oppen, Maastricht

All rights reserved. No part of this publication may be reprinted or utilized in any form or by any electronic, mechanical, or other means, now known or hereafter invented, including photocopying and recording or in any information storage or retrieval systems, without written permission of the copyright owner.

ISBN: 978-90-5681-256-0

Cover design: Regien Lemmens

Printed by: Oce Business Services Maastricht 


\section{From Rags to Richness}

A Structuration Perspective on Interactional Richness and its Impact on Customer Evaluations of Online Experiences

\section{PROEFSCHRIFT}

Ter verkrijging van de graad van doctor aan de Universiteit Maastricht, op gezag van de Rector Magnificus, prof. mr. G.P.M.F. Mols volgens het besluit van het College van Decanen, in het openbaar te verdedigen op woensdag 4 juli 2007 om 14.00 uur

door

Claudia Anna Maria Leonardus van Oppen 


\section{Promotor}

Prof. Dr. J.C. de Ruyter

\section{Copromotor:}

Dr. G. J. Odekerken-Schröder

\section{Beoordelingscommissie}

Prof. Dr. J. G. A. M. Lemmink (Voorzitter)

Prof. Dr. W. H. Gijselaers

Prof. Dr. J. C. Hoekstra 
Voor Sander, Dries, Mam \& Pap 


\section{Acknowledgements}

Het schrijven van een proefschrift is een vak apart. Voor buitenstaanders is het vaak moeilijk te begrijpen wat het eigenlijk precies inhoudt en waarom het ruim 4 jaar duurt. Hoewel het op zich een zeer individueel proces is, zijn er een heleboel mensen die op wat voor een manier dan ook een steentje hebben bijgedragen aan de tot standkoming van dit proefschrift. Aan hen richt ik in dit voorwoord dan ook graag een woord van dank.

Gaby, je titel als copromoter ofwel dagelijkse begeleider heb je meer dan eer aangedaan. Als het nodig was, stond je dagelijks voor me klaar. Je had altijd een luisterend oor, dacht actief mee, las mijn teksten zeer grondig en gaf me gedetailleerde feedback. Je bent een echte inspirator met een nuchtere kijk op de zaken. Niet alleen stond je altijd voor me klaar wat het proefschrift betreft, maar was je ook altijd oprecht geïnteresseerd en leefde je mee met alle belangrijke en bijzondere gebeurtenissen in mijn leven. Dat waren er nogal wat de afgelopen jaren; de koop en de verbouwing van ons huis, samenwonen, onze bruiloft, de zwangerschap en de geboorte van Dries. Onze reguliere en de speciale bijeenkomsten zoals "de mama-lunch" zijn momenten waar ik met veel plezier naar terugkijk en ik hoop dat we deze plezierige bijeenkomsten in de toekomst zullen voortzetten. Gaby, hartelijk bedankt voor de goede begeleiding de afgelopen jaren!

Ko, jij had als promotor de helicopter view over het gehele proces. Met je objectieve visie, je kritische houding en je creatieve ideeën zette je me steeds weer aan het denken en wist je telkens de lat weer wat hoger te leggen ten bate van het eindresultaat. Bedankt voor de fijne samenwerking.

Martin, je bent een rondlopende encyclopedie op het gebied van analyses, die ik dikwijls geraadpleegd heb. Ik heb veel geleerd van jouw expertise, bedankt!

Mark, je hebt me samen met Sebastiaan wegwijs gemaakt in een wereld van html-codes en andere "technische" zaken. Daarnaast heb je altijd een luisterend oor en een objectieve kijk op de zaak. Ik wil je bedanken voor het meedenken, al je hulp en het feit dat je paranimf wilt zijn.

De leden van de commissie, Prof. Dr. Janny Hoekstra, Prof. Dr. Wim Gijselaers en Prof. Dr. Jos Lemmink, wil ik heel hartelijk bedanken voor het beoordelen van mijn proefschrift en hun constructieve feedback.

Mijn collega's van het departement marketing wil ik graag bedanken voor de prettige werksfeer en hun behulpzaamheid.

Tevens wil ik een woord van dank richten aan alle bedrijven die aan mijn onderzoeksprojecten hebben meegewerkt zoals, Adversitement, Samsung, Mocreate en Elitech. Deze samenwerking maakte het uitvoeren van het onderzoek zeer uitdagend en 
boeiend voor me. Daarnaast wil ik ook de scriptiestudenten bedanken die aan deze onderzoeksprojecten hebben meegewerkt.

Regien, heel hartelijk bedankt voor het schitterende ontwerp van de kaft van het proefschrift. Mieke, je bent net aan je AIO-schap begonnen. Ik vind het leuk dat je als paranimf bij de afronding van mijn AIO-schap aanwezig wilt zijn.

Familie oet Sjömmert en vrung, bedank veur euch interesse en de gezellige dinger die veer same gedoan höbbe. Opa en Oma Sjömmert bedankt voor jullie betrokkenheid en de goede zorgen voor Dries.

Pap en Mam, ik wil jullie graag heel hartelijk bedanken voor alles wat jullie voor me gedaan hebben. Jullie hebben de keuzes die ik in mijn leven gemaakt heb altijd gerespecteerd en me gesteund. Mam, bedankt voor al je goede zorgen. Pap, ik had nooit gedacht dat je zo'n goede babysitter zou zijn. Bedankt voor alles!!!

Dries, het is geweldig om je mama te zijn. Je hebt ons zoveel vreugde en geluk gebracht en ons leven enorm verrijkt. Je ben echt het zonnetje in huis. Ik ben trots op je!

Sander, even in termen van mijn onderzoek, de interactie rijkheid in onze relatie maakt het tot een zeer waardevolle ervaring wat resulteert in loyaliteit. Ik wil je bedanken voor je begrip, hulp en liefde!

Claudia

Schimmert, 2007 


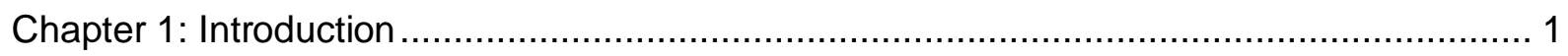

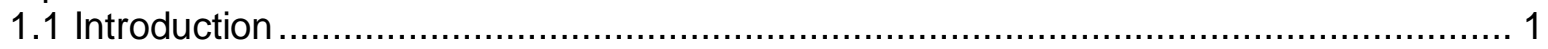

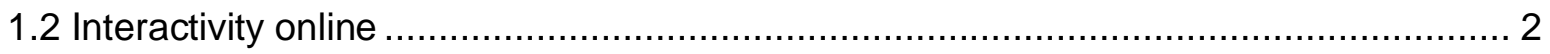

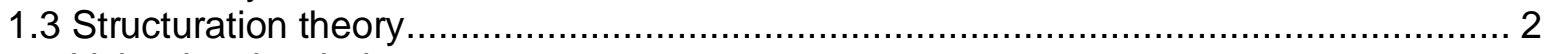

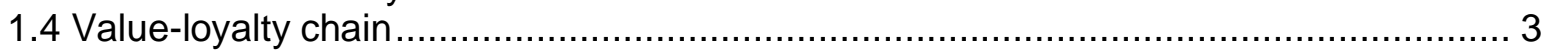

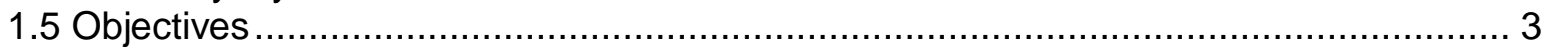

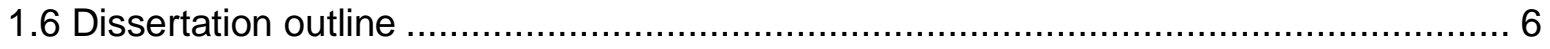

Chapter 2: Building a Theoretical Framework from a Structuration Perspective................... 10

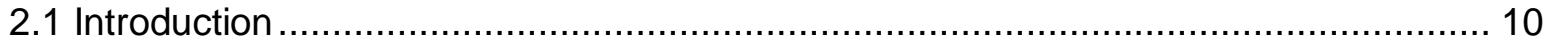

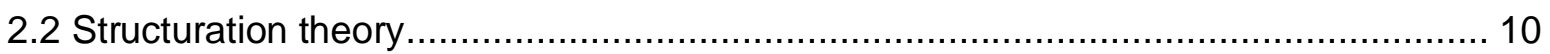

2.2.1 Structuration theory in an online context ...................................................... 11

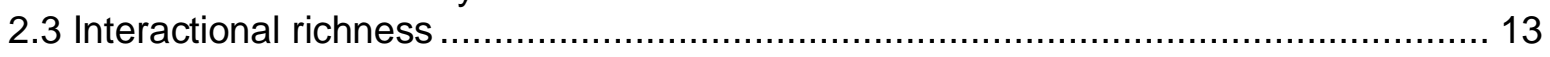

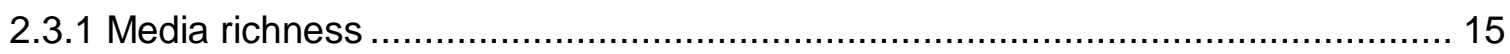

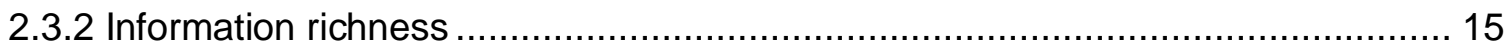

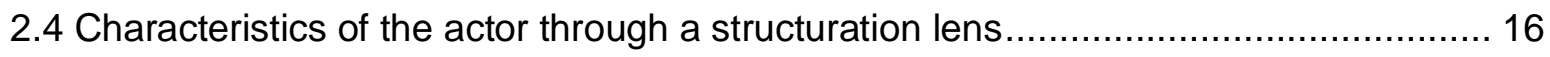

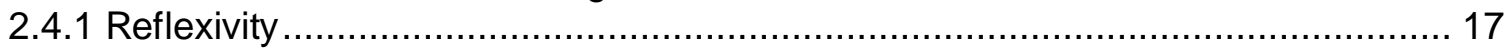

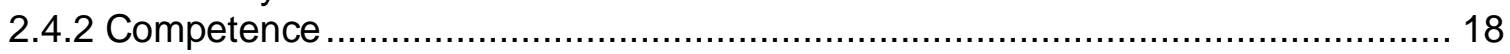

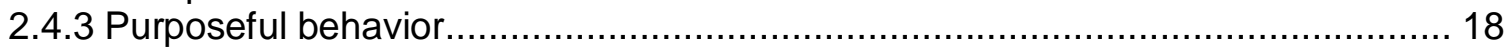

2.5 Outcome variables ........................................................................................ 19

2.6 Hypotheses related to media and information richness and purposeful behavior ....... 19

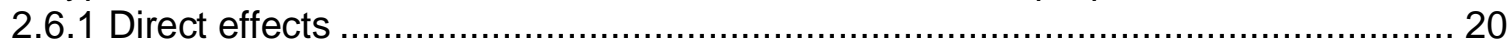

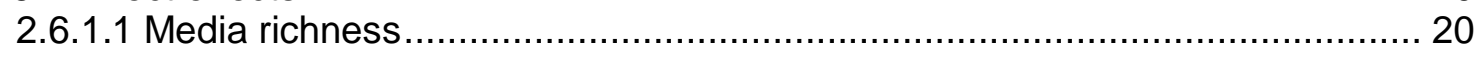

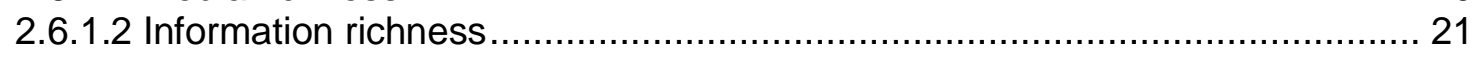

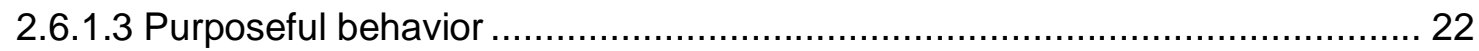

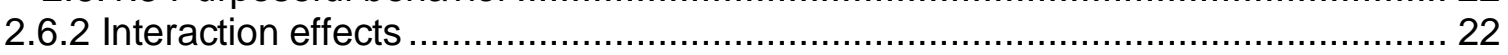

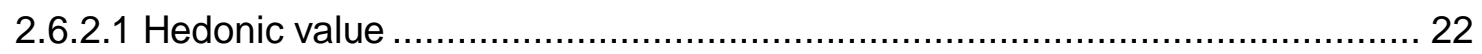

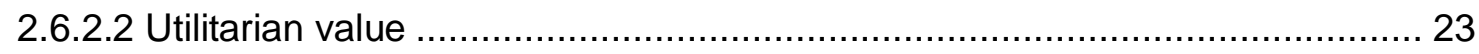

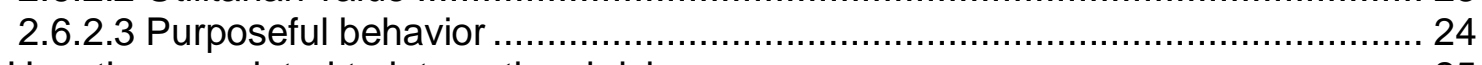

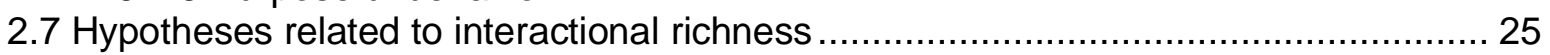

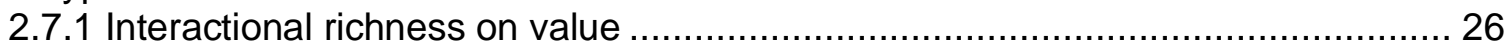

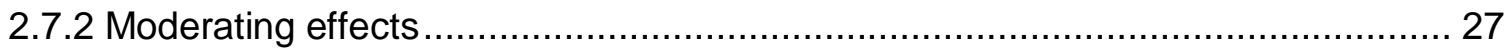

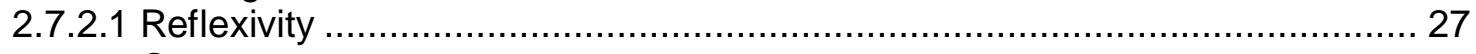

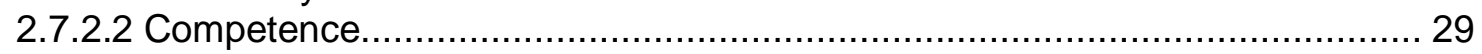

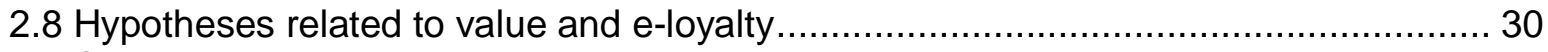

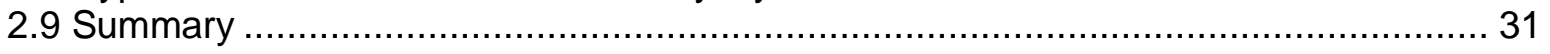

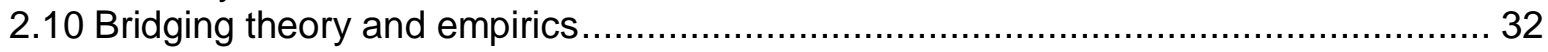

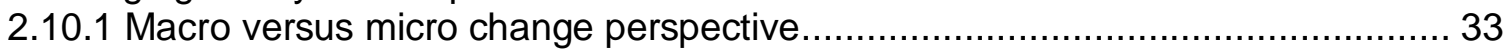

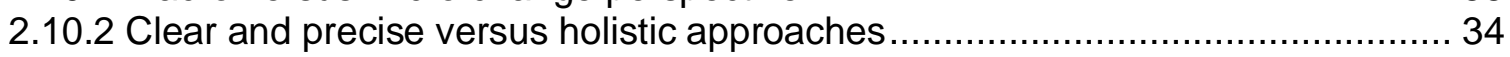

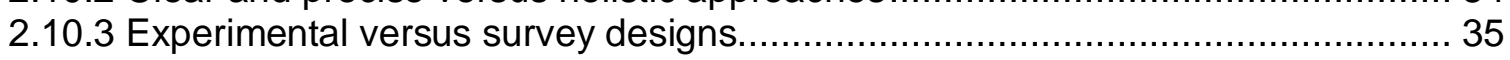

Chapter 3: Measures to Assess Customer Evaluations of the Online Experience................ 36

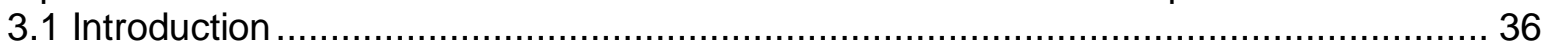

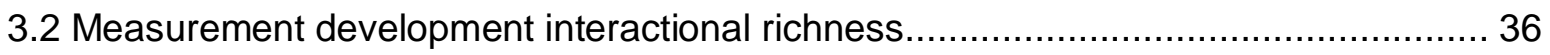

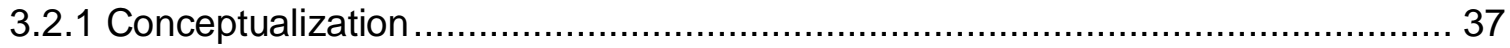

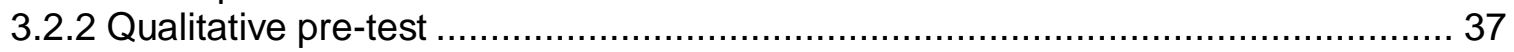

3.2.3 Development and qualitative pre-test of questionnaire .................................. 38

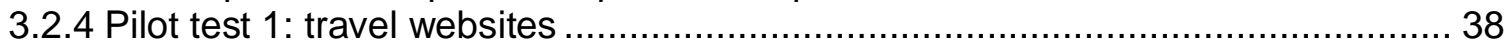

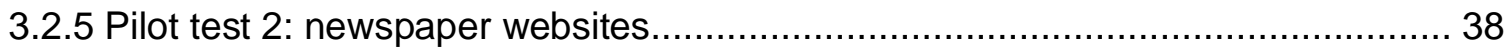

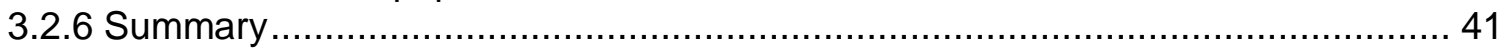

3.3 Measurement development utilitarian and hedonic value .................................. 41

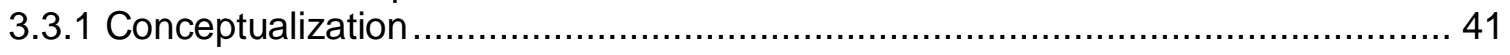


3.3.2 Research setting: Books and CDs websites ................................................ 44

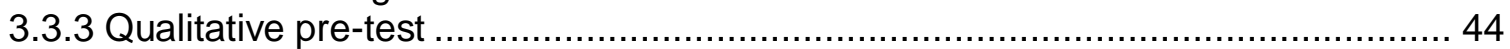

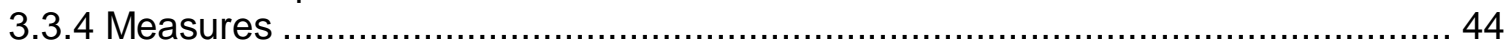

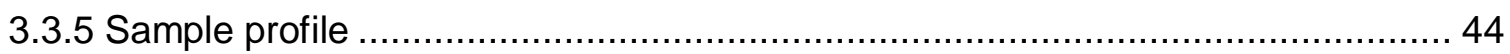

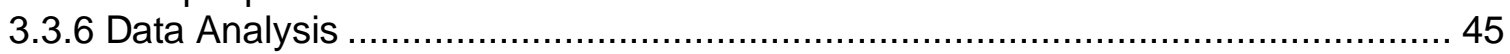

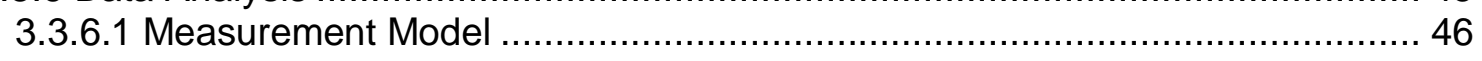

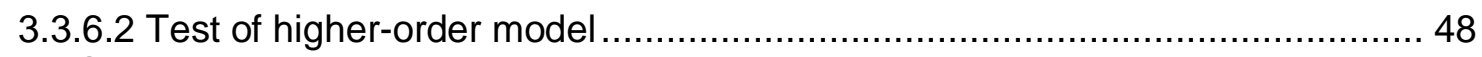

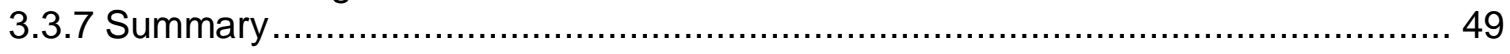

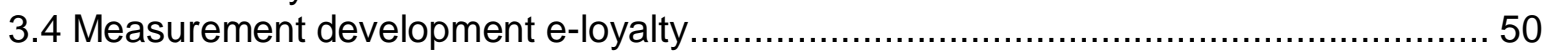

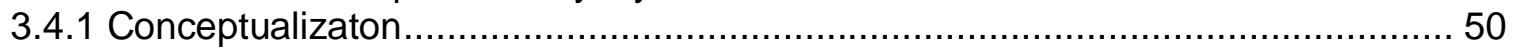

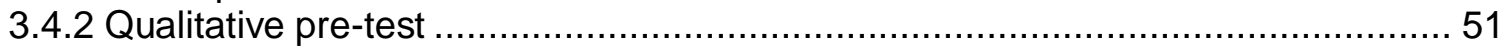

3.4.3 Quantitative test: Newspaper websites ...................................................... 51

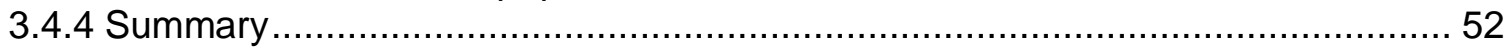

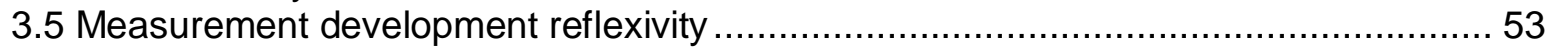

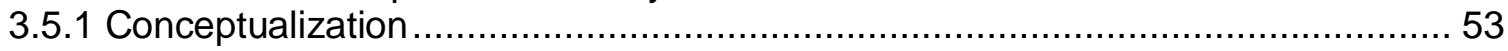

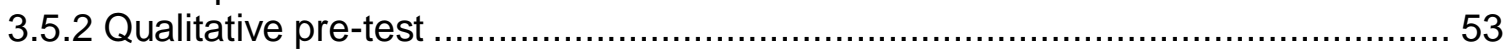

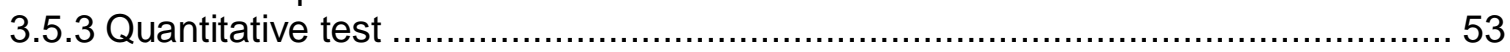

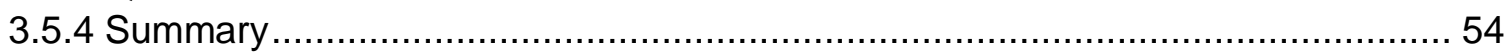

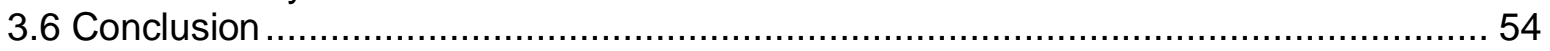

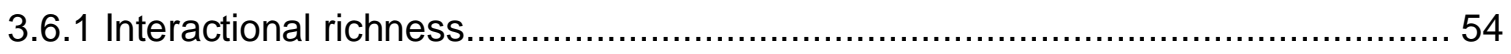

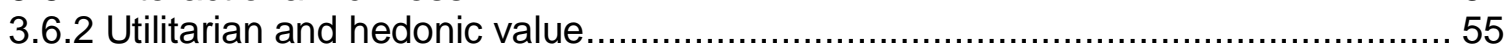

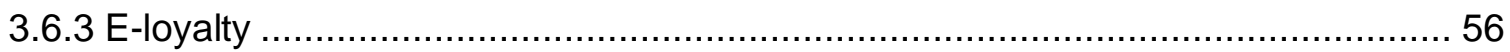

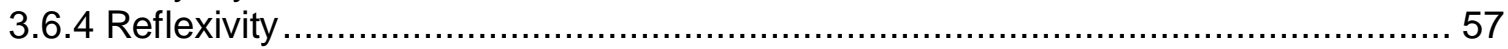

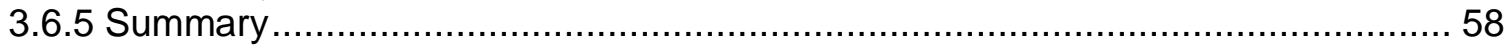

Chapter 4: Media Richness and Information Richness: Two Complementary Factors ......... 59

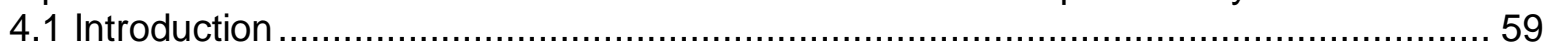

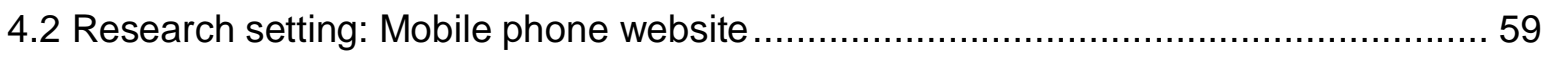

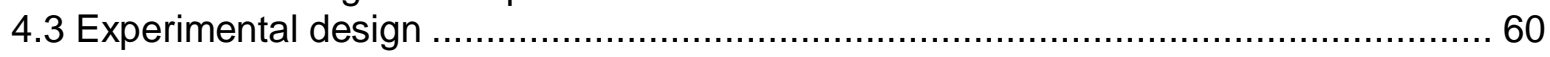

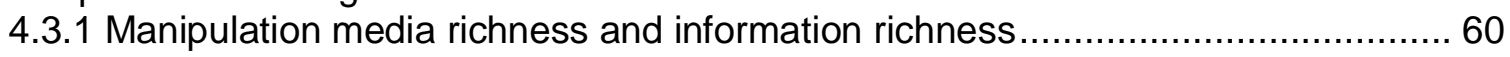

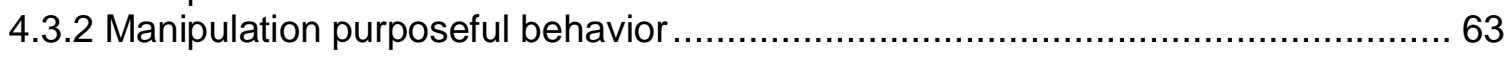

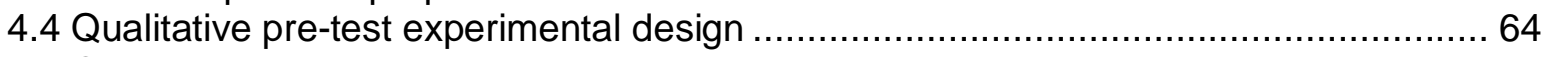

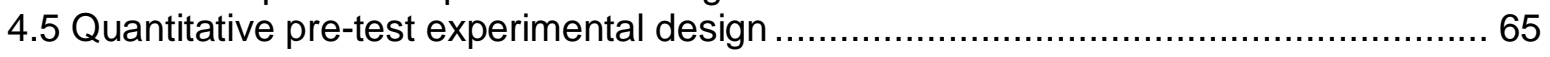

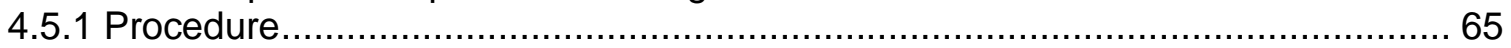

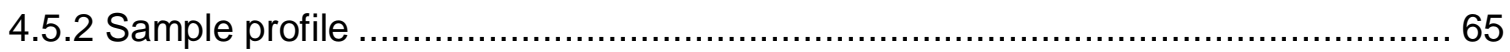

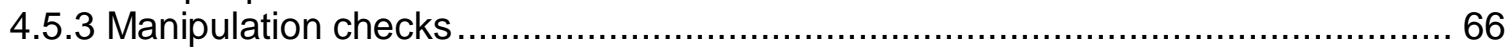

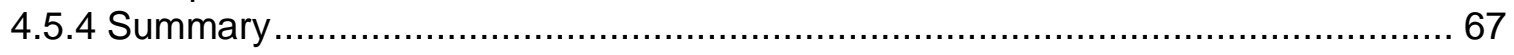

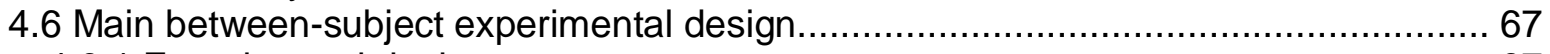

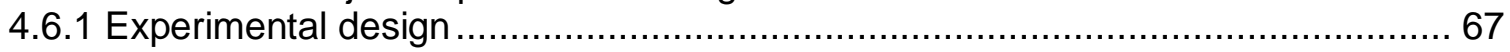

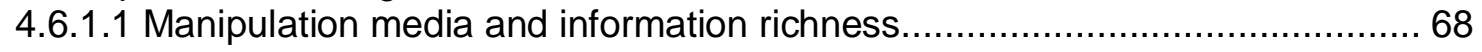

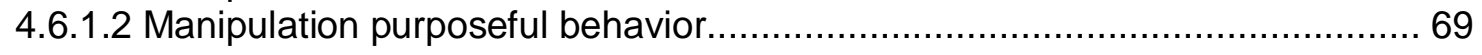

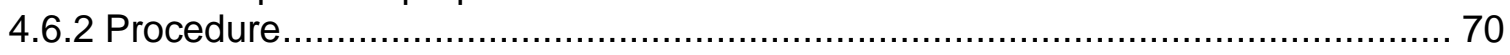

4.6.3 Measures outcome variables

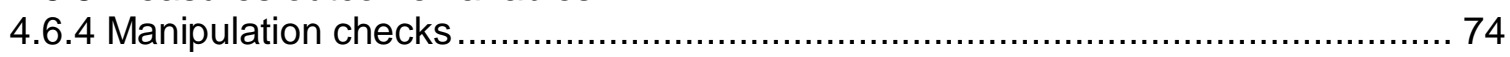

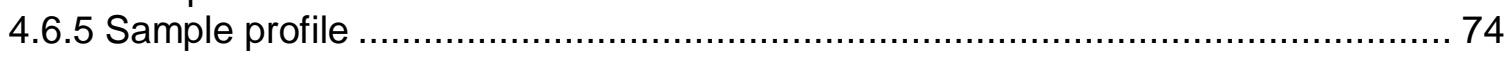

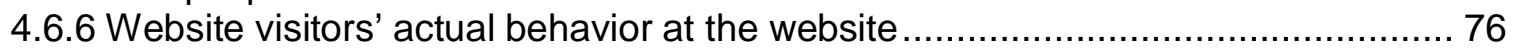

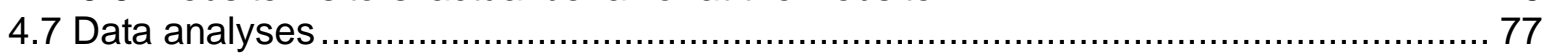

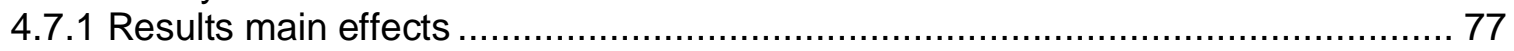

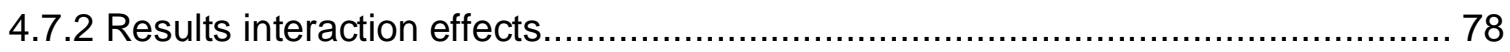

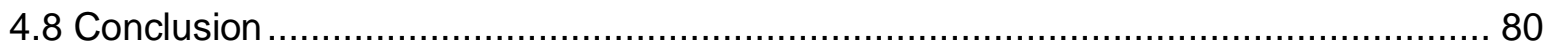

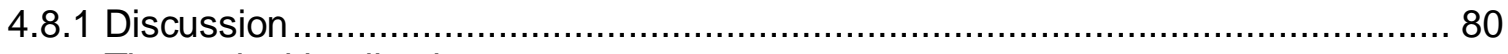

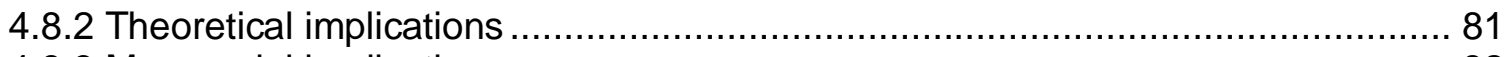

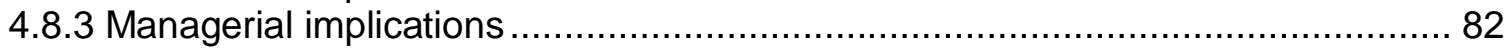


Chapter 5: The Impact of Interactional Richness on Customer Evaluations of Online Experiences .

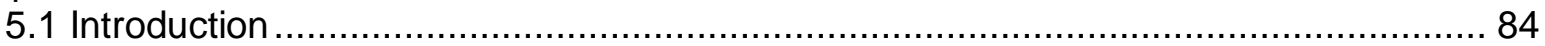

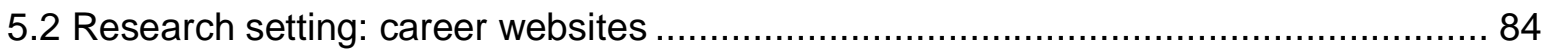

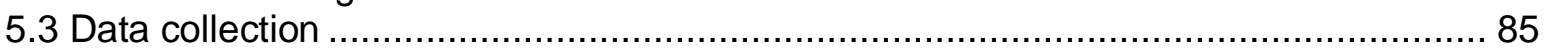

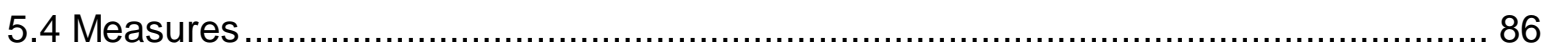

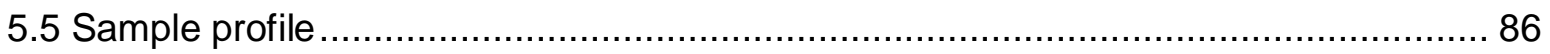

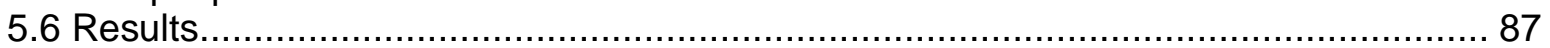

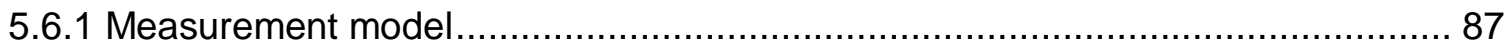

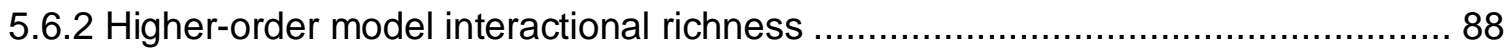

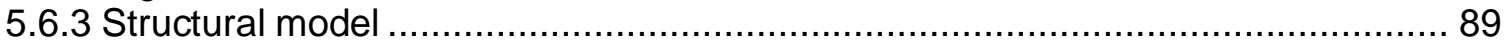

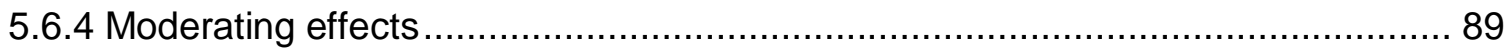

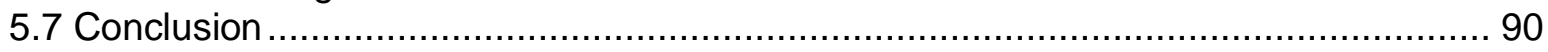

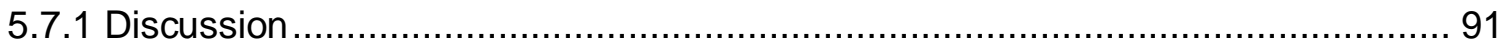

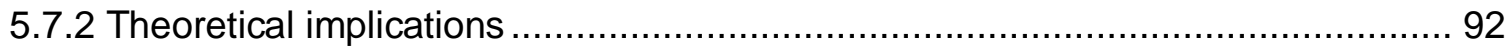

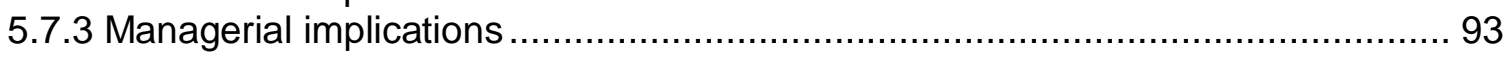

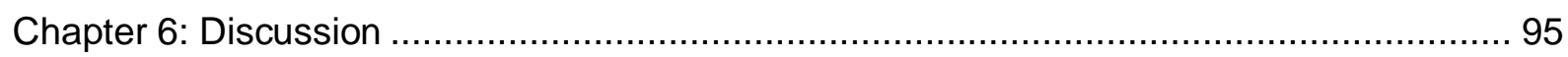

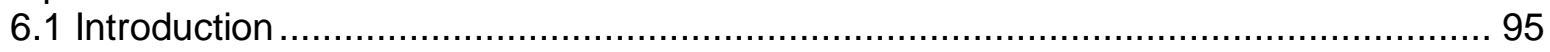

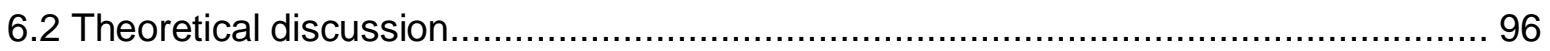

6.2.1 A structuration perspective on the online interaction process .......................... 96

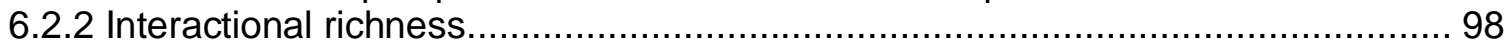

6.2.3 Assessing customers' evaluations of the online interaction experience ............... 98

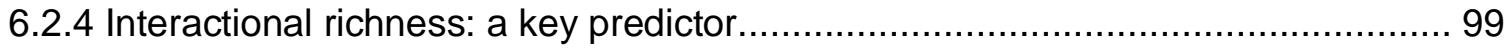

6.2.5 The role of website visitors' idiosyncratic characteristics.................................100

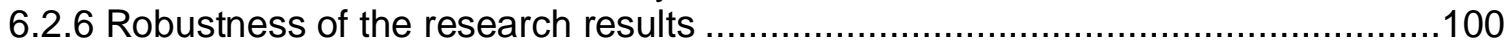

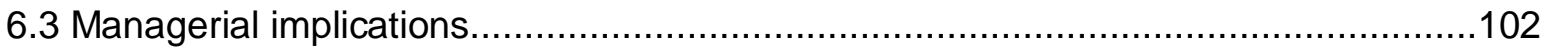

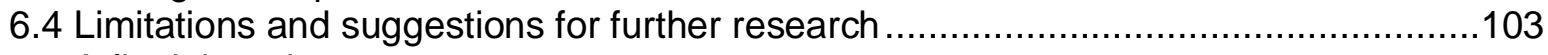

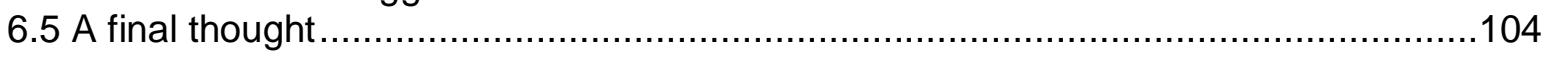

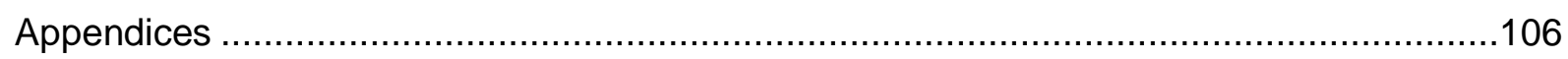

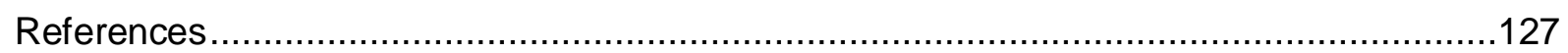

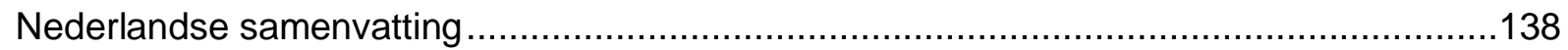

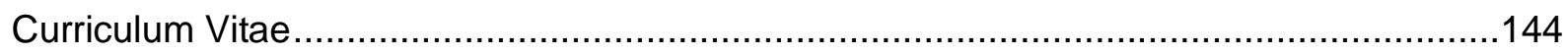




\section{List of Figures}

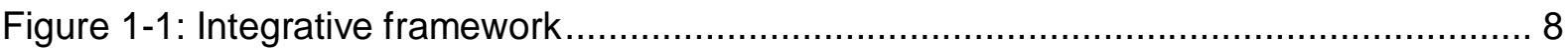

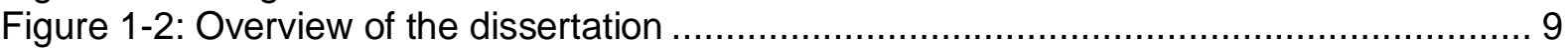

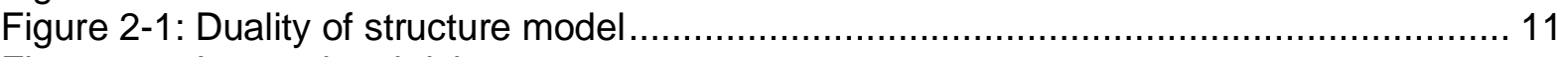

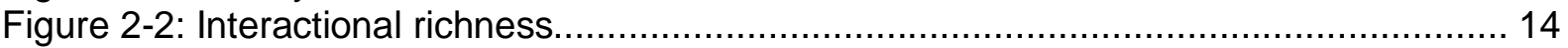

Figure 2-3: Higher-order model interactional richness ............................................... 16

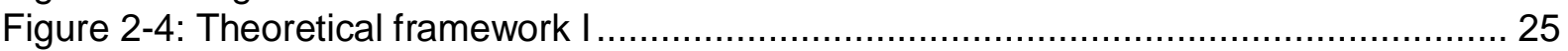

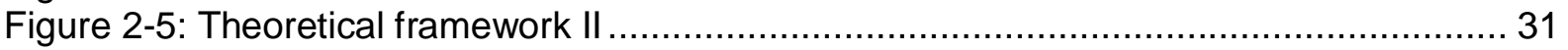

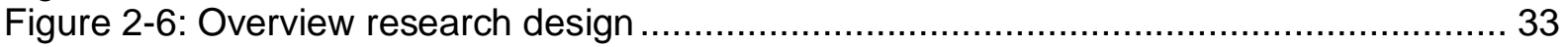

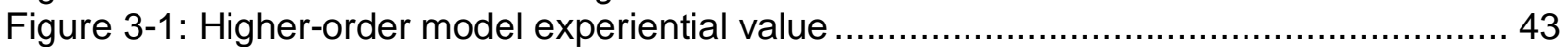

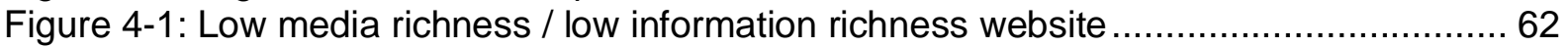

Figure 4-2: High media richness / high information richness website ................................. 62

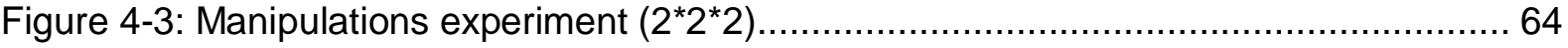

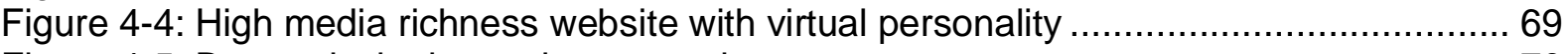

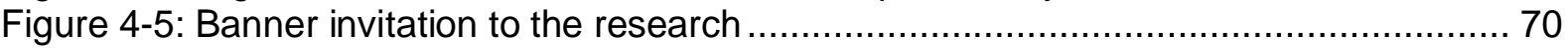

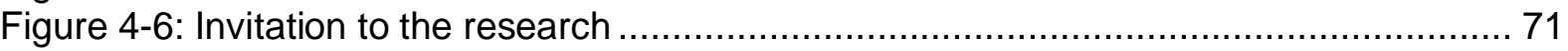

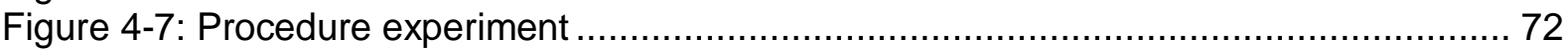

Figure 4-8: Interaction effect media and information richness on hedonic value .................. 79

Figure 4-9: Interaction effect media and information richness on utilitarian value ............... 80

Figure 5-1: Invitation to participate in the research on career websites............................. 85

Figure 6-1: The duality of structure model applied to an online interaction process ............ 97 


\section{List of Tables}

Table 3-1: Interactional richness: psychometric properties of first-order constructs ............ 40

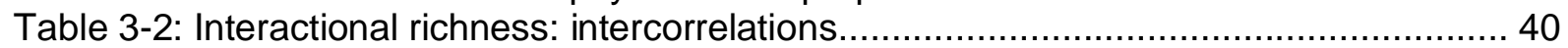

Table 3-3: Sample profile: books and CDs websites............................................... 45

Table 3-4: Experiential value: psychometric properties for first-order constructs.................47

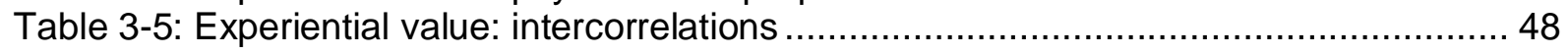

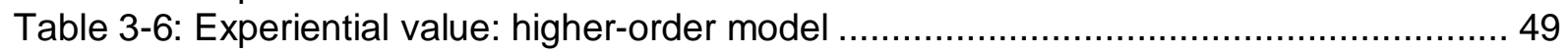

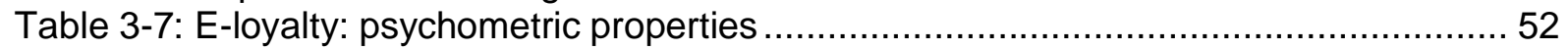

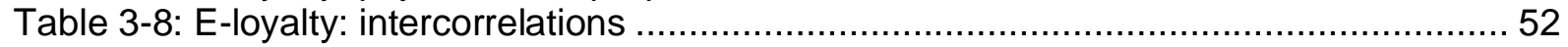

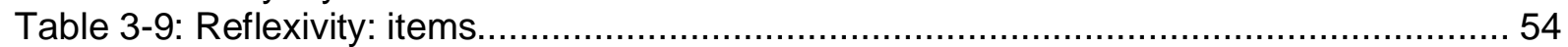

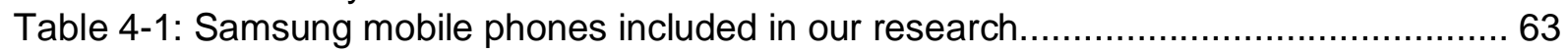

Table 4-2: Sample profile: quantitative pre-test experimental design ................................ 66

Table 4-3: Higher-order model experiential value for mobile phone context......................... 73

Table 4-4: Sample profile: main between-subjects experimental design ............................ 75

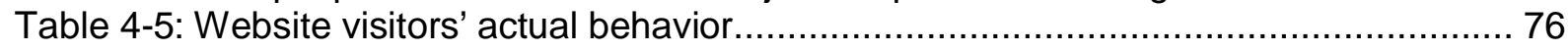

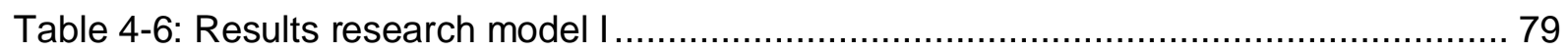

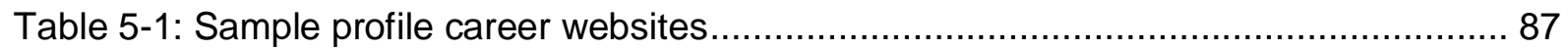

Table 5-2: Composite reliability, average variance extracted, and correlations .................... 88

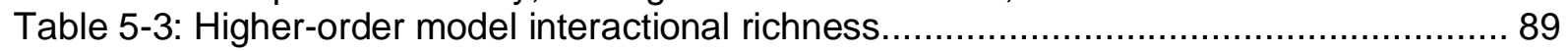

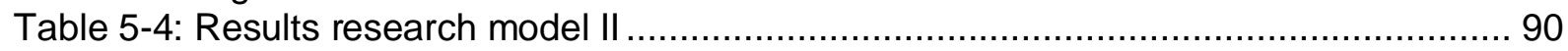

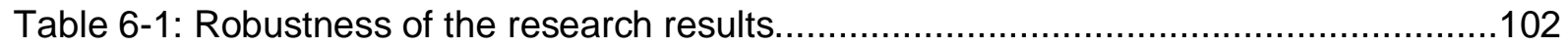


"True interactivity is not about clicking on icons or downloading files, it's about encouraging communication."

(Schlossberg 1998)

\section{Chapter 1: Introduction}

\subsection{Introduction}

The introduction of new media such as the Internet has profoundly changed how people communicate and search for information. On a regular day, approximately one billion people access the Internet to gather information, to communicate with others, to entertain themselves or to buy products or services online (Fallows 2004). Moreover, the proliferation of high speed broad band internet connections, drive the use of a variety of features that enhance the richness and interactivity of the online interface. One of the key characteristics of the Internet is interactivity, a feature that influences how websites are designed and also determines users' attitudes and behaviors towards these websites. Due to its increasingly interactive nature, the Internet has the potential to approach real life experiences and create virtual environments in which users become part of another world, e.g. SecondLife.com. SecondLife.com is a 3-D virtual world entirely built and owned by its residents (www.SecondLife.com, 2007). Companies such as Philips, IBM and ABN AMRO participate in SecondLife.com to communicate with their customers (www.mdweekly.nl). However, these companies also extensively use their corporate websites for communication purposes. Nowadays, most companies use their website as full-blown alternative channel to interact with their customers. Although the advent of the Internet has fundamentally changed and still is changing the communication process between companies and their customers, it also plays a vital role in company performance. Therefore, from a marketing perspective it is very interesting to examine how companies interact with their customers via their websites. The interactions between companies and consumers are heavily influenced by the features and capabilities of the websites. Interactive features at a website facilitate, for example, communication, customization of information and entertainment (Fiore et al. 2005b). Across widely diverging industries, well-known companies, such as Lands' End, MSN and Miller Beer, now incorporate interactive functionalities at their websites to enhance their customers' online experience. For instance, Millerbeer.com uses virtual service representatives who communicate with customers in real time, in natural language, providing customized and personalized information. Consequently, knowing how different website characteristics influence consumers' perceptions of a website can provide managers with powerful insights how to develop and manage their websites effectively. Therefore, this dissertation aims to enhance the understanding of the impact of different website characteristics on consumers' 
perceptions of a website and how it influences their attitudes and behaviors towards this website.

The next sections of this chapter briefly introduce the main concepts and theoretical framework of our research. Next, we discuss our research objectives. Finally, we provide an outline of the dissertation.

\subsection{Interactivity online}

Recent technological developments are a driving force behind a substantial increase in the use of interactive features on websites such as, intelligent agents, chat rooms, threedimensional virtual tours, communities, and games (Rayport et al. 2005). For instance, Nike.com offers their customers the possibility to develop their own running shoes in line with their personal style. The rationale for the use of such technology-enhanced interactivity is the assumed positive impact on customer value perceptions in online encounters. Every online experience involves an interaction between a website and a website visitor (Addis and Holbrook 2001). In this interaction, from an abstract perspective, website and website visitor contribute differently to the visitor's online experience. The website represents certain features or objective characteristics, while the website visitor is a personality who subjectively assesses the objective characteristics and reacts accordingly. While anecdotal evidence of the fact that interactivity enhances the consumer's online value experience is abundant (e.g. Yadav and Varadarajan 2005a), this assumption has yet to be substantiated by empirical research.

\subsection{Structuration theory}

In order to account for the complex and dynamic interaction process between websites and website visitors, we adopt structuration theory (Giddens 1979). Structuration theory, originally used to describe social behavior, has been used extensively in an information technology context to examine how new technology (structure) is influenced, created and appropriated by individuals (actors) who interact with this technology (Orlikowski 2000; Peters 2006). Nevertheless, structuration theory has only recently been introduced and adopted in an online interactive marketing context (van Dolen et al. 2007; Stewart and Pavlou 2002). Central to structuration theory is the conceptualization of the interactions between structures and actors as a duality, whereby structures and actors are highly interdependent and coevolve. Structuration theory is often referred to as a "meta-theory" as it offers general guidance for conducting research, leaving issues specific to each research open for interpretation for the researchers themselves (Poole and DeSanctis 2004). We feel that, applying structuration theory may strengthen our understanding of the dynamic online interaction process between companies and consumers. In line with a structuration view, we 
conceptualize website visitors in this research as actors interacting with websites (structure), where visitors can be characterized in various ways. More specifically, and according to earlier work in structuration theory, website visitors may be viewed as competent, reflexive and purposeful actors (Sarason et al. 2006), while websites are considered as a set of features like relevant information, interactivity and pictures. Furthermore, structuration refers to the reciprocal interaction process between websites and their visitors, which signifies that websites are influenced and adapted in terms of their structural features in line with the individual or mutual goals of companies and consumers (Stewart 2005). Companies frequently exploit the website to provide value to their consumers ultimately leading to company value in terms of consumers' e-loyalty (Payne and Frow 2005). All in all, employing a structuration lens to examine the dynamic process of online interactions between websites and website visitors presents the value-loyalty chain as the result of website-visitors interactions.

\subsection{Value-loyalty chain}

In a structuration view, value and loyalty represent consumers' and companies' respective goals that play a critical role in the online interaction process. In previous studies, value has often been operationalized as a tradeoff between quality and price (Bolton and Drew 1991; Overby and Lee 2006). However, we argue in line with more recent studies that value is mainly based on consumers' experiences (Addis and Holbrook 2001; Grewal et al. 2003; Mathwick et al. 2001) rather than a simple tradeoff between quality and price and as such is a crucial driver of online loyalty (Novak et al. 2000). Mathwick et al. (2001) were the first to introduce, develop, and test a scale of experiential value in an online context. Their experience-based value concept theoretically represents a hierarchical model that consists of the underlying extrinsic (utilitarian) and intrinsic (hedonic) value dimensions (cf. Holbrook and Hirschman 1982). Hoffman and Novak (1996) claim that the hedonic versus utilitarian distinction is especially important online, because for many consumers, the hedonic value of the online experience is more crucial than the final utilitarian outcome. Consequently, for companies to accomplish their goals in terms of customer loyalty, it is important to deliver a valuable experience to fulfill their customers' goals in terms of both hedonic and utilitarian value. Gradually, several researchers started to support a positive impact of hedonic and utilitarian value (consumer goals) on e-loyalty (company goals) (Childers et al. 2001; Chiu et al. 2004).

\subsection{Objectives}

The overall purpose of this dissertation thus is to create a comprehensive understanding of the reciprocal online interaction process that occurs between websites and their visitors by 
applying structuration theory in an online context. So far, structuration theory has been used in various fields, such as technology and information systems (Orlikowski 2000), accounting (Macintosh and Scapens 1990) and strategic management (Pozzebon 2004) and it has been interpreted and applied in different ways. However, in an online interactive marketing context, structuration theory has only recently been introduced (van Dolen et al. 2007; Stewart and Pavlou 2002). We think that structuration theory is especially relevant to interactive communications between websites and their visitors, as this interaction can be characterized as a recursive process in which the website and its visitors are highly interdependent and coevolve. Thus, our assumption is that website features are not deterministic, but are assessed by website visitors' subjective perceptions and changed by their respective inputs. For instance, the website msn.com offers its visitors a variety of features such as news, e-mail, chat etc. Visitors can customize the msn-homepage to their own interests and needs. Our study contributes to the literature as it offers crucial insights into the determinants of consumers' perceptions of websites and how these perceptions develop over time as a result of the ongoing interaction process and website visitors' idiosyncratic characteristics.

Within structuration theory, actors' perceptions of the structure and interaction process play a vital role. In order to assess consumers' (actor) perceptions of a website (structure), there is a need for an appropriate measure that captures this. Our first objective is to introduce and conceptually develop the construct of interactional richness in order to comprehensively capture the full range of aspects involved in consumers' perceptions of the website. In the marketing literature, numerous studies have explored "laundry lists" of website attributes to assess their direct impact on various outcome variables such as satisfaction and loyalty (e.g. Novak et al. 2000; Srinivasan et al. 2002; Szymanski and Hise 2000). In the information systems research, medium features and content of the information have been introduced and examined as separate drivers of outcome variables (DeLone and McLean 2004). Although the characteristics of the medium and characteristics of the information content can conceptually and operationally be regarded as distinct from each other (Yadav and Varadarajan 2005b), we argue that customers' perceptions of the website are a composite evaluation of the perceptions of both. Therefore, we recognize the need for including both characteristics of the medium as well as of the information exchanged resulting in our higherorder conceptualization of interactional richness and we test this higher-order construct of interactional richness empirically.

In order to completely examine consumers' perceptions of the online interaction process, we also need appropriate measures to assess consumers' perceptions of value, their idiosyncratic characteristics such as reflexivity, and their responses towards the website in terms of loyalty. Hence, our second objective is to develop or refine appropriate multi-item measures to examine the online interaction process between websites and their visitors. The 
online value that visitors perceive is created as a result of their interaction with websites and can be both utilitarian and hedonic in nature. Consequently, in order to assess website visitors' utilitarian and hedonic value perceptions of their online interaction experience, we develop measures for both utilitarian and hedonic value using Mathwhick, Malhotra and Rigdon's (2001) experiential value scale as a basis. Mathwick et al. (2001) provide conceptual support for a higher-order model of experiential value, consisting of both utilitarian and hedonic value (Mathwick et al. 2001). However, their empirical study does not test the fourth-order model. We consider this lack of empirical evidence as an opportunity to advance existing literature. By providing empirical support for the fourth-order multidimensional model of experiential value, we acknowledge that hedonic and experiential value are dissimilar but interdependent phenomena, rather than bipolar ends of a unidimensional continuum.

Moreover, from a structuration perspective, we argue that website visitors' value perceptions of the online interaction experience are influenced by their personal characteristics such as reflexivity. However, so far in the online interactive marketing literature there is no proper measure for reflexivity available. In order to develop a measure for website visitors' reflexivity related to an online context, we propose a refined scale based on an existing scale for reflexivity in an offline team context. Furthermore, in response to their utilitarian and hedonic value perceptions, website visitors may exhibit different types of loyalty either more cognitive or affective in nature. Yet, existing e-loyalty measures did not make a clear difference between these different loyalty stages. Hence, we propose a refined e-loyalty measure based on extant scales along the four stages loyalty framework as initiated by Oliver (1999). Third, using a multi-method approach we empirically test whether interactional richness impacts online value perceptions and whether these in turn predict online loyalty. Value and loyalty represent respectively consumer and company goals, which in a structuration perspective are the result of the reciprocal interaction process between a website and its visitors. Moreover, online value is commonly seen as an intermediate goal, whereas customer loyalty is the ultimate company objective. The link between perceived value and customer loyalty is relatively established in both the offline (Bolton and Drew 1991; Cronin et al. 2000; Parasuraman and Grewal 2000) and online contexts (Chiou 2004). Nevertheless, interactional richness has not yet been considered as an explanatory predictor of this causal chain.

An important aspect of structuration theory is that, the interpretation of the recursive relationship between structure and actor is not only determined by the structural features but is also highly dependent on the idiosyncratic characteristics of the actors' such as reflexivity, competence and purposefulness (Pozzebon 2004). In addition, recent empirical assessments of consumer behavior in both offline and online settings have revealed cross- 
sectional heterogeneity among users as a result of diverging subject-related factors (Bolton and Drew 1991; Brady and Robertson 1999). Therefore, our fourth objective focuses on the contingency of website visitors related factors such as reflexivity, competence and purposeful behavior, on our causal chain of interactional richness, value, and e-loyalty. In this study, reflexivity expresses a website visitor's critical evaluation of his/her own information search process online. Websites are complex and evolving and depending on the level of critical assessment of search behavior, the resulting perceived value of the online interface will vary. We also acknowledge the importance of a person's competence. Recent studies in the online environment demonstrated that consumers' familiarity with the Internet or with the interactive environment in general, attenuates their attitudes and behaviors online (Gefen and Straub 2003). In the current study, we include competence, reflecting consumers' perceptions of their own capabilities to search the Internet for information. We reason, that the level of expertise in searching the internet will affect the impact of interactional richness on the perceived value. In addition, we recognize that a visitors' perception of value resulting from a website visit might depend on whether website visitors visit a website either to search or to browse. Consequently, we also include purposeful behavior in this research.

Finally, our fifth objective is to determine the robustness of our research results. Therefore, we investigate whether our findings related to the interaction process between websites and their visitors are robust when employing different methods across various research samples in a variety of contexts to demonstrate the reliability and generalizability of our research findings.

\subsection{Dissertation outline}

In this dissertation the reciprocal online interaction process between companies (structure) and consumers (actors) is studied through a theoretical lens of structuration theory (see figure 1-1). Within structuration theory, the interactions between structure and actors are signified as a duality as they are highly interdependent and mutually influence each other (Poole and DeSanctis 2004). Three main empirical studies are conducted that focus on particular aspects of structuration theory employing different contexts and various data collection methods and data analyses techniques. Although the focus and methods of these three studies differ, they are clearly linked and built upon each other. In study one, we focus on signification structures, which refer to the attributes of a website that visitors use to interpret a website. Consequently, we introduce and develop the construct interactional richness as a measure for visitors' (actors) perception of the website features (structure) in an information services context. Once companies know how to develop interactional rich websites, the question becomes whether consumers want to re-visit their websites, which relates to the structures of domination and legitimation. Subsequently, we incorporate the 
construct of interactional richness in study two and three. In these studies, we focus on the discrete actions and interpretations of individual website visitors in the recursive online interaction process referring to analyses on a micro level. More specifically, in study two, we examine domination structures. This means that we investigate how website visitors draw on asymmetries in website technology (interactional richness) to facilitate their goal attainment (value) and whether they subsequently decide to adopt the website. Accordingly, we conduct both a survey and an experimental research in an experiential services context to examine, between subjects, the impact of different levels of media and information richness on visitors' value perceptions and ultimately their e-loyalty.

In study three, we focus on website visitors' justification of their loyal versus non-loyal online behavior based on evaluative criteria or norms such as value representing legitimation structures. Furthermore, in study three we also focus on website visitors' idiosyncratic characteristics, e.g. competence and reflexivity, which attenuate the relationship between interactional richness and visitors' value perceptions, referring to domination structures.

Moreover, we use a multi-method approach allowing us to capture and understand the reciprocal interactions and co-evolution between website visitors (actors) and websites (structure) over time (macro change perspective). In addition, we employ this multi-method approach to demonstrate the reliability and generalizability of our research findings across different samples in various online services contexts. 


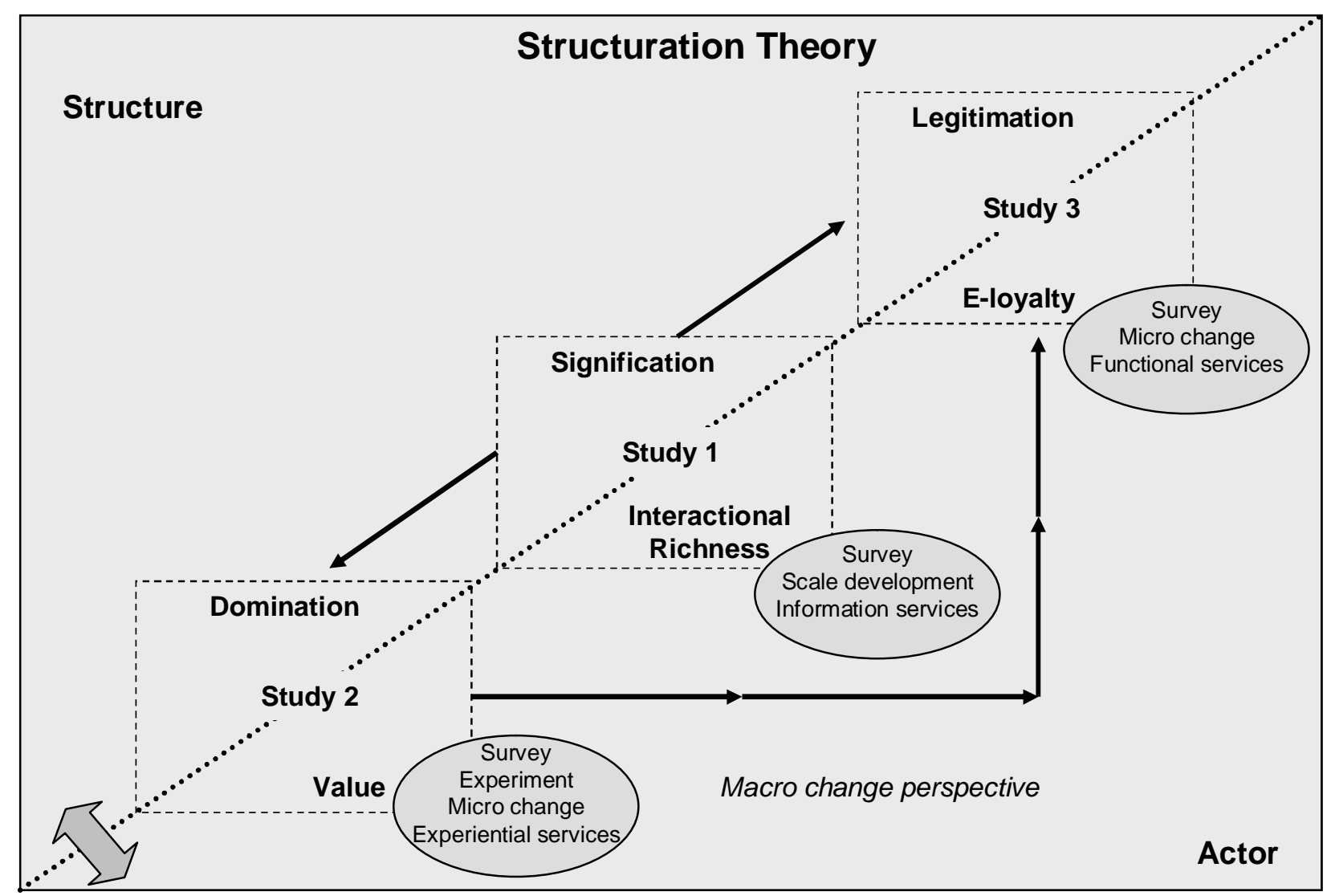

Figure 1-1: Integrative framework

These three empirical studies are reported in the remainder of this dissertation. In chapter two, we build two theoretical frameworks and present the related hypotheses. Next, we describe the development of measures incorporated in our theoretical frameworks in chapter three. In chapter four, we describe our experimental research and its results, while chapter five describes the methodology and results of our survey research. Finally, we conclude this dissertation (chapter six) with a summary of our main findings, and outline the theoretical and managerial implications and guidelines for future research. Figure 1-2 provides an overview of the dissertation. 


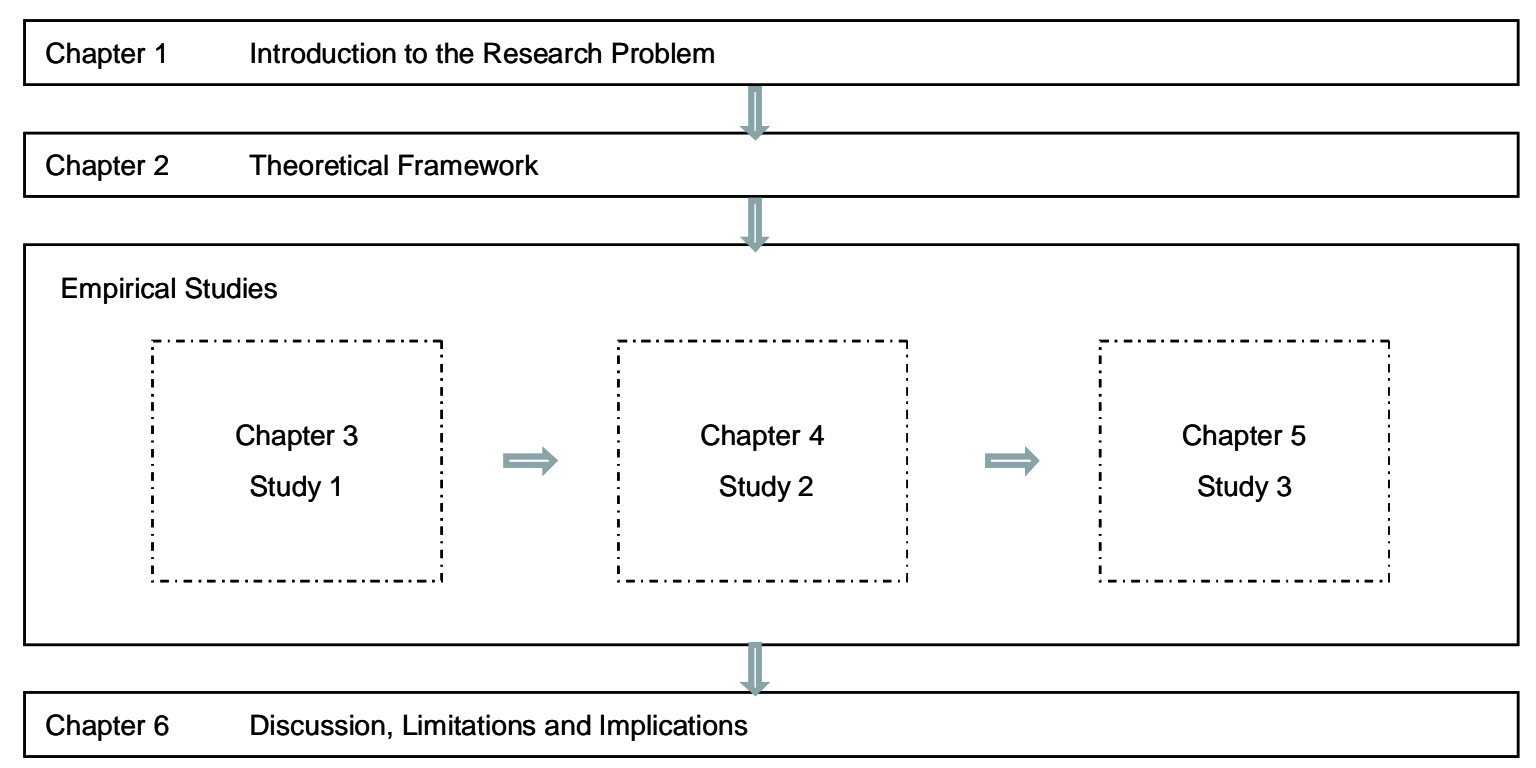

Figure 1-2: Overview of the dissertation 


\section{Chapter 2: Building a Theoretical Framework from a Structuration Perspective}

\subsection{Introduction}

The general objective of this chapter is to develop a theoretical framework as a basis for the investigation of the reciprocal online interaction process between websites (structure) and their visitors (actors). Consequently, in section 2.2, we discuss structuration theory as it theorizes reciprocal relationships between structure and actor and we apply it to an online context (section 2.2.1). Subsequently, in section 2.3, we introduce interactional richness as a measure to assess visitors' perceptions of the website (structure) and describe a higherorder model for the interactional richness construct. In section 2.4 we focus on the actor and introduce, based on a structuration view, subject-related factors such as reflexivity, competence, and purposeful action. Next, in section 2.5 we focus on the outcomes of the structuration process, customer and company goals, respectively value and loyalty.

In section 2.6 we develop hypotheses that describe the assumed relationships between different levels of information richness and media richness and purposeful behavior on hedonic and utilitarian value. Subsequently, we describe in section 2.7 the assumed relationships between interactional richness and hedonic and utilitarian value and how these relationships are attenuated by idiosyncratic characteristics of website visitors. We hypothesize the relationships between value and e-loyalty in section 2.8. In section 2.9 we provide a brief summary of this chapter. Finally, in section 2.10 we attempt to bridge our theoretical frameworks with the empirical methods used.

\subsection{Structuration theory}

The sociologist Giddens (1984) in "The Constitution of Society" describes the established principles of structuration theory. Structuration theory bridges two extreme schools of thoughts, functionalism (structure) and interpretivism (agency/actors) which so far were believed to be incompatible (Poole and DeSanctis 2004; Rose 1998). Functionalism assumes that social structures are not determined by actors, but are solely inherent to institutions or technologies. Interpretivism claims the opposite by arguing that actors have a dominant role as they cognitively form the structures that mainly exist in the actor's mind (Poole and DeSanctis 2004; Rose 1998). Combining these two philosophies, the central idea of structuration theory is that structures subsist in the actions of actors as they continually produce and reproduce structures over time (Poole and DeSanctis 2004). Or in other words, structures and actors are mutually dependent, which is depicted in the duality of structure model (Giddens 1984; Poole and DeSanctis 2004). The duality of structure is one of the basic premises of structuration theory, referring to the reciprocal and mediated relationships between structure and interaction with actors. Figure 2-1 displays Giddens' (1984) duality of 
structure framework with its key elements, using the original terminology: structure, modality and interaction. Structure consists of signification, domination and legitimation, which represent respectively attributes, resources and criteria that actors use in their interactions. Modality represents how actors employ structure within an interaction (e.g., for interpretation or facilitation). Finally, interaction refers to communication, power and sanctions that produce and reproduce structure and guide actors' behavior (Poole and van de Ven 1989; Stewart and Pavlou 2002). Moreover, as illustrated in figure 2-1, the key elements and the underlying dimensions of the duality of structure model are highly related and mutually influence each other (Joseph 2006; Macintosh and Scapens 1990). We will discuss the interrelationships between these dimensions along the three different types of structures that can be identified within structuration theory: signification structures, domination structures and legitimation structures. Signification structures focus on the interpretive processes and facilitate the interpretation of rules and sharing of meaning. Domination structures facilitate actions by actors to accomplish their goals through control over different resources. Legitimation structures provide the evaluation criteria that legitimate or sanction the actors' actions (Joseph 2006; Sarason et al. 2006). The process whereby the duality of structure evolves and is reproduced over time is called structuration (Rose 1998). This structuration process is contingent on the actors' reflexivity, purposefulness, and competence (Pozzebon 2004; Sarason et al. 2006). In summary, structuration theory is based on three main principles, duality of structure, change over time, and idiosyncratic characteristics of the actors.

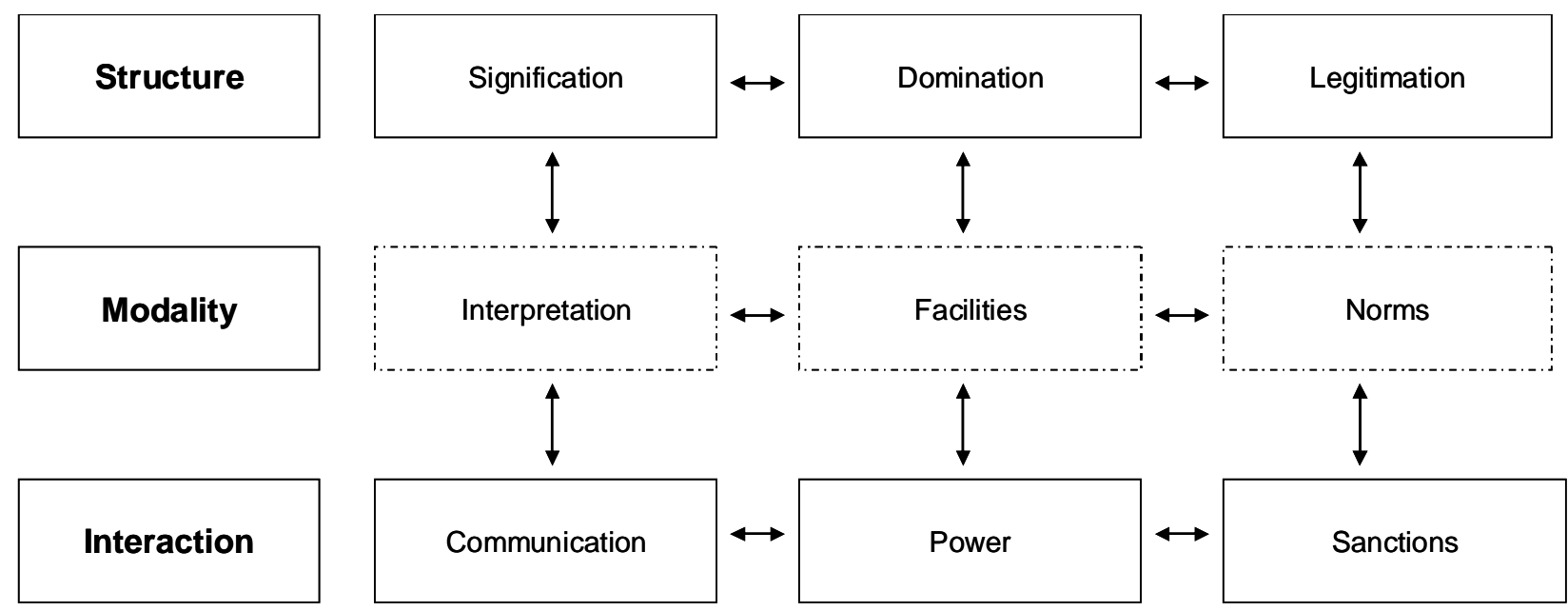

Figure 2-1: Duality of structure model

Source: Giddens (1984)

\subsubsection{Structuration theory in an online context}

We argue that structuration theory is applicable to an online interaction process, as structuration theory emphasizes the interdependence between actor (website visitor) and 
structure (website). The central idea of structuration theory, when applied to an online context, is that the characteristics of a website (structure) enable and shape the online interaction and exchange of information with website visitors (actors), whereas the continuous interactions between websites and their visitors concurrently help companies to customize their websites (Stewart and Pavlou 2002). When companies want to develop a pleasant online experience for their website visitors, they should not solely develop a sophisticated website, but they should also monitor how consumers use their website, respond to it, and subsequently improve their interactions with their consumers via their website in order to serve both their own and consumers' goals (Stewart 2005). For example, YouTube.com a popular, user friendly website enables visitors to upload, share, and view video clips. Registered visitors can upload an unlimited number of videos on the website, whereas unregistered visitors can solely watch these videos. Recently, the website enabled visitors to respond and subscribe to any registered visitors. In addition, visitors are engaged to actively participate in and provide feedback about the trial runs of the new YouTube features via the "test Tube" at the YouTube website, clearly demonstrating the vital role consumers fulfill in their interaction with a website. Thus, the focus of structuration theory is on the reciprocal interactions between companies and website visitors, rather than on the behavior of both parties separately. Furthermore, websites are neither a stable nor objective phenomenon, but they are constantly evolving as a result of the interactions with their visitors. This is reflected in the duality of structure model. In this research, we propose that signification structures refer to the attributes, e.g., website characteristics that make up meaning and facilitate a visitor to interpret a website. Moreover, interactional richness is introduced as a measure to assess visitors' perceptions of a website as it focuses on both the features of the website (media richness) and the content of the information (information richness). Visitors' perceptions of a website (interactional richness) are based on their own interpretive schemes and driven by their individual goals. Consequently, each visitor's interpretation of a website is unique and simultaneously shapes their online communication (interaction).

Moreover, domination structures are concerned with the power of website visitors to acquire and employ resources such as idiosyncratic competence, purposeful behavior, capacity for reflection, and website technology to achieve their goals. These resources are facilities that empower website visitors to fulfill their goals, e.g. to get hedonic and/or utilitarian value.

Finally, legitimation structures involve website visitors' evaluative criteria or norms, e.g. value, which justify their online behavior in terms of loyalty versus switching ((non)sanctions). Besides, previous research (see chapter one) has already shown that, value judgments (both utilitarian and hedonic) are indeed important drivers of online loyalty. 
In the following section, we will focus on signification structures and introduce interactional richness as a measure to assess visitors' interpretation of the website (structural) features.

\subsection{Interactional richness}

Recently, Yadav and Varadarajan (2005b) provided an overview of interactivity in an online context and argued that online interactivity should be operationalized as consumer perceptions, focusing on the reciprocal interaction process between companies and consumers. They also indicate that structuration theory can add to our understanding of interactivity between websites and website visitors. Despite these valuable efforts in organizing the existing knowledge, they do not introduce a concept to measure online interactivity. Stewart and Pavlou (2002) indicate that existing measures of the online interaction between website visitors and websites mainly focused on the responses and behavior of website visitors, whereas the interaction itself has been neglected as a focus for measurement development. They reason that a potential explanation for this gap might be found in the multidimensional nature of interactivity which is difficult to assess with a single unidimensional measure. Consequently, there is a need to develop a comprehensive measure that captures the dynamic reciprocal interaction process between websites and their visitors. Therefore, we introduce interactional richness as a multidimensional construct to measure visitors' holistic perceptions of the website. In addition, the inclusion of interactional richness as a measure to assess visitors' perceptions of a website draws heavily on structuration theory, which proposes that in an online interaction process, structural features or in other words website characteristics determine visitors' perceptions and appropriation of the website.

Barry and Crant (2000) were among the first authors who clearly introduced a concept to capture dyadic communication (interactivity) in the offline context of organizational communication, and defined interactional richness as consisting of two distinct dimensions being information and media richness. In the past, several authors did not make such a clear distinction between information richness and media richness and even used these two constructs interchangeably (Daft and Lengel 1986; Dennis and Valacich 1999), simply neglecting their theoretical distinctiveness. Another existing problem mainly apparent in the information richness theory (Daft and Lengel 1986) is the unique focus on characteristics of the medium to assess the richness of the information, which has been criticized openly by Chen and Tan (2004). Barry and Crant (2000) overcome these problems by defining (p. 651) interactional richness as "the extent to which communication within the dyad at a given point in time is efficient (high in symbolic content), coordinated (characterized by synchronous interaction), and accurate (symbolic meaning is shared and appropriately interpreted)". More specifically, media richness is described as "the information and symbol carrying capacity of 
the communication channel" (Barry and Crant 2000 p. 651), whereas information richness describes "the informational depth of transmitted data" (Barry and Crant 2000 p.651). Although Barry and Crant (2000) do identify both underlying dimensions (media and information richness), they do not clearly specify how these dimensions of interactional richness relate to the theory of information and media richness (Daft and Lengel 1986). Based on their descriptions of media and information richness, we argue that the components of efficiency and coordination in the definition of interactional richness refer to media richness since both symbolic content and synchronous interaction are enabled by the carrying capacity of the medium. On the contrary, accuracy represents information richness, as the correct interpretation of information depends on the content of the information exchanged. So far, the initial construct of interactional richness has only been defined and used to describe the communication process in an organizational context (Barry and Crant 2000) and its empirical validation has been neglected.

In relation to Barry and Crant (2000), we introduce and empirically validate the construct of interactional richness to assess consumers' perceptions of the website. We define interactional richness as consumers' perceptions (actor) of the extent to which the website (structure) at a given point in time provides relevant, accurate, comprehensible, and comprehensive information presented in multiple ways, facilitating user control and two-way communication in real time (interaction). Hence, as illustrated in figure 2-2, we will evaluate the richness of the website by investigating both its features and the content of the information and subsequently build upon and extend the traditional information and media richness theories (Daft and Lengel 1986).

Information Richness

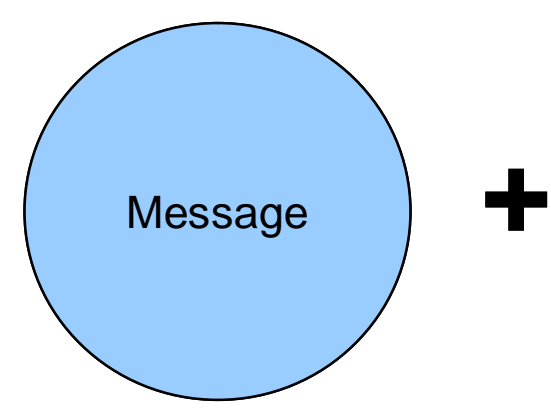

Media Richness

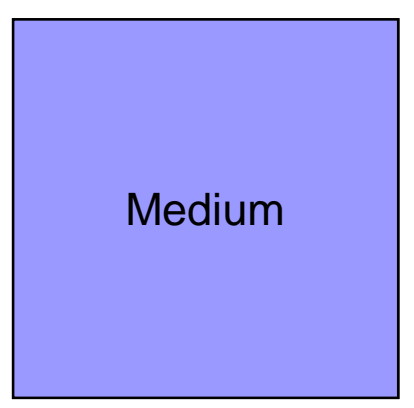

Interactional Richness

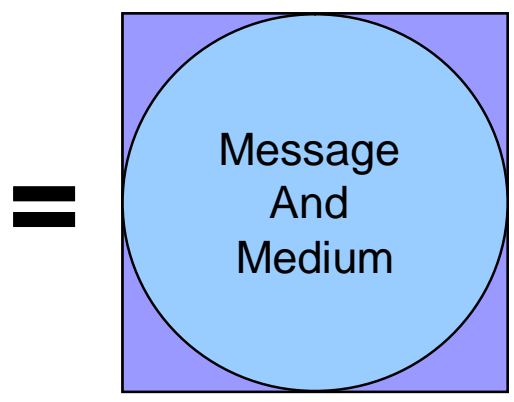

Figure 2-2: Interactional richness

Moreover, websites nowadays differ considerably in their level of sophistication (Palmer 2002). Consequently, we express the degree of interactional richness along a continuum ranging from low to high, emphasizing the extent of richness rather than its mere presence because we assume that higher levels of interactional richness create more favorable 
consumer perceptions. Besides, one should note that consumers' richness perceptions of both the medium and the information can vary depending on consumers' competence and reflexivity and on the situational context they face. Consequently, consumers can have different richness perceptions for specific information content or for a particular medium and these richness perceptions might also change over time (Carlson and Zmud 1999). The higher-order concepts of interactional richness, media richness, and information richness comprise in turn several first-order constructs, which will be discussed in detail in the following sections.

\subsubsection{Media richness}

Based on existing literature, we argue that consumers' perceptions of the richness of a website (medium) are based on various factors. The first factor that can be distinguished is synchronicity. Synchronicity reflects the exchange of information via two-way communication which can either be in real-time (e.g., chatting) with other website users or it can be delayed (e.g., sending an e-mail to the company or putting a message in a message board) (Liu and Shrum 2002). Faster exchange of information might increase customers' perceptions of the richness of the medium.

The second factor is control. Customers might perceive a website to be rich when it allows them to manage their own online interaction. More specifically, they might feel in charge when they are able to choose how to get information (e.g., as text only or with animations) (Dholakia et al. 2000). Finally, multiplicity of presentation refers to the presentation of the information in various ways (e.g., video clips, product demonstrations) in which companies might facilitate a meaningful online interaction with their customers and consequently enhance customers' media richness perceptions (D'Ambra et al. 1998). Accordingly, we define medium richness in this research as the consumers' perceptions of the extent to which a website facilitates user control (control), two-way communication between organizations and users and among users in real time (synchronicity), and uses multiple ways, e.g. text, pictures, sound, video, to present the information (multiplicity of presentation).

\subsubsection{Information richness}

Similar to media richness, the other dimension of interactional richness, information richness, also consists of various underlying dimensions. Recently, various studies have identified several dimensions and measures that can be used to evaluate the information apart from the website carrying this information (McKinney et al. 2002). In the traditional management information systems (MIS) literature, commonly accepted dimensions of the content of information are relevance, accuracy, comprehensibility, and comprehensiveness (e.g. DeLone and McLean 2004). In line with their conceptualization, we define information 
richness in an online marketing context as consumers' perceptions of the extent to which information is relevant, accurate, comprehensible, and comprehensive. Relevance refers to the degree to which users perceive the information on the website to meet their needs. The second dimension, accuracy, expresses the extent to which users perceive the information on the website to be correct or in other words information that is free of errors, precise, and reliable. The degree to which website users consider the information easy to understand is defined as comprehensibility. Finally, comprehensiveness refers to users' perceptions of the completeness of the information on the website (Muylle et al. 2004). Figure 2-3 depicts a third-order model of interactional richness consisting of the second-order constructs media richness and information richness, which encompass several first-order constructs.

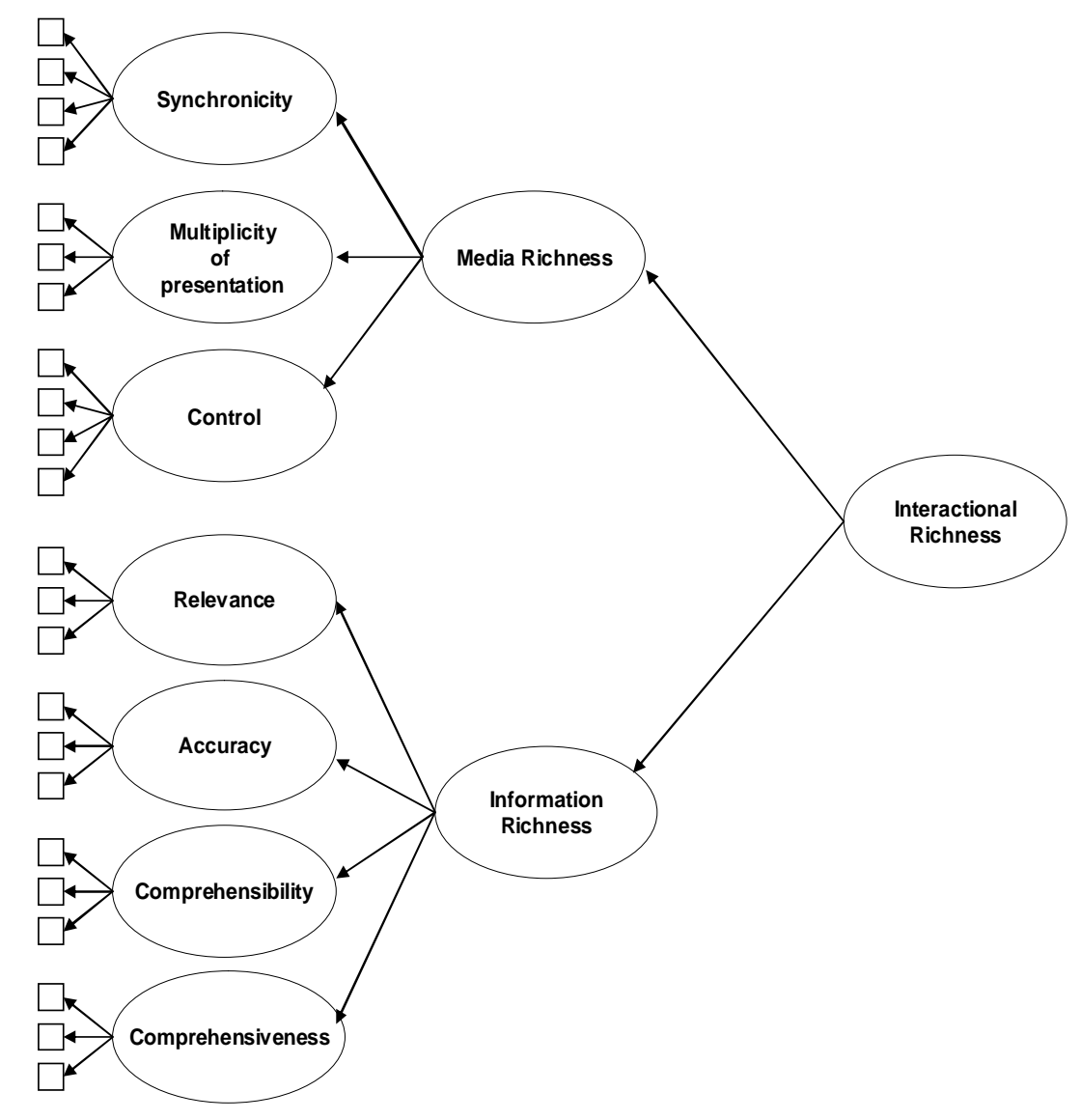

Figure 2-3: Higher-order model interactional richness

\subsection{Characteristics of the actor through a structuration lens}

In this chapter, we have so far only focused on the characteristics of websites (structure) to the neglect of the crucial role that actors (website visitors) play in the online interaction process. 
Within structuration theory, website visitors (actors) are viewed as reflexive, competent, and purposeful individuals that co-evolve with websites (structures) over time (Pozzebon and Pinsonneault 2001; Sarason et al. 2006). These three idiosyncratic characteristics provide website visitors with the power to attain their goals in terms of hedonic and utilitarian value, which relates to domination structures in the duality of structure model.

In accomplishing their goals, not only visitors' critical evaluations of website features play a dominant role, but also their individual characteristics. Anticipating on the next sections where we elaborate on each of the characteristics individually, we briefly justify the link to structuration theory in this section.

First, reflexivity refers to the extent to which website visitors' critically reflect upon their own information search process. Their reflexivity enables website visitors to provide feedback to the website, ultimately resulting in an adjustments or adaptation of their own actions and also of the website (Sarason et al. 2006). Second, competence refers to website visitors' capacity to search for information online. In structuration theory literature, competent individuals are assumed to have the power to make a difference (e.g. Rose 1998). In an online context, this means that competent website visitors will be able to judge a website and as a result of their assessment provide input to the website. This input represents another influence from actor (visitor) to structure (website) in structuration terminology.

Third, purposeful behavior is the extent to which individuals are task oriented during their online visit. Their purposeful behavior or goal orientation implies a critical attitude of website visitors who want to accomplish a task. This critical attitude is required in the duality of structure model (Sarason et al. 2006) assuming that the website visitor has an impact on the website.

Therefore, we argue that the structurationist way of interpreting the interactions between websites and their visitors along the lines of the duality of structure model requires reflexive, competent, and purposeful visitors.

\subsubsection{Reflexivity}

In a structuration view, reflexivity refers to subjects' ability to monitor and comprehend what they are doing, while they are doing it (Sarason et al. 2006). In this study, we focus on consumers' reflexivity in an online context and specifically on consumers' reflection upon their own information search process. We propose that especially in an online environment where consumers are confronted with a broad range of potential choices and unlimited information sources, it is crucial to reflect upon one's own information search process if consumers intend to effectively fulfill their information needs. Only then, consumers will be able to learn from their online interaction experiences and to determine if the online interaction is valuable for them and whether it is meaningful to become a loyal website 
visitor. The construct of reflexivity is rooted in philosophy where it refers to consciousness or awareness. Reflexivity has been used in various other disciplines such as management teams (Schippers 2003) and marketing education (Peltier et al. 2005,2006). In our research, reflexivity refers to individuals' capacity to critically monitor and evaluate their own information search process while they are searching for information online. More specifically, if they reflect during their online information search, they question themselves regularly what their information needs are (self-questioning), whether they are searching for the right information, and what the long-term consequences of their search activities are (selfanalysis). Individuals' self-questioning and self-analysis are thus central to reflexivity and can stimulate both challenging one's own information search process and gaining a better understanding of the online interface (Peltier et al. 2005).

\subsubsection{Competence}

In line with structuration theory, we argue that to completely understand the online reciprocal interaction process, one should not only investigate the role of website visitors' reflexivity but also the role of website visitors' competence. While reflexivity is a relatively stable individual characteristic, individuals' competence can change over time as it can be actively learned and improved (Hoegl and Parboteeah 2006). Competence represents individuals' perceptions of their own search capabilities related to the Internet as a medium and the interactive environment in general (Hoffman et al. 2000; Mathwick and Rigdon 2004) and it is largely a function of the experience individuals have gained using the Internet (Lehto et al. 2006; Zhou 2002). Similar to self-efficacy, competence is not directly related to individuals' objective skills to perform a task, but relates to individuals' perceptions of their ability to perform a task (e.g., searching for information online) (Bandura 1986). Previous research has already indicated that website visitors' competence comprise some of the variance in website visitors' online experiences (Hampton-Sosa and Koufaris 2005).

\subsubsection{Purposeful behavior}

We draw on structuration theory and propose that actors can engage to a certain degree in purposeful behavior ranging from non-purposeful to purposeful behavior (Sarason et al. 2006). Previous research has indicated that website visitors primarily engage in two types of behavior when visiting the Internet: searching and/or browsing (Hoffman and Novak 1996; Schlosser 2003). Searching reflects purposeful, goal-directed, task-specific behavior and is aimed at finding specific information. Searchers try to find the information efficiently without investing too much effort (Lee et al. 2006). In contrast, browsing refers to non-purposeful behavior and nonlinear search, or in other words surfing a website for entertainment or out of curiosity or fun (experiential behavior) (Hoffman and Novak 1996; Kuo et al. 2004; Schlosser 
2003). Browsers enjoy the experience of visiting interesting and entertaining websites (Lee et al. 2006). While some view searching and browsing as two different types of online behaviors (Hoffman and Novak 1996), others characterize these two constructs as ends of a continuum (Hong et al. 2004). Moreover, in line with Babin et al. (1994) we argue that the extent to which a website visitor exhibits purposeful behavior influences his/her perceptions of value either directly or as a consequence of interactional richness.

\subsection{Outcome variables}

A structuration view proposes that companies and their customers are highly interdependent and co-evolve in line with each party's individual and/or mutual goals. Consequently, in this study we investigate the dynamic online interaction process between websites and their visitors and incorporate value (customer goal) and loyalty (company goal) as the result of the website-visitor interaction. In line with structuration theory, we view visitors' perceptions of value as norms that legitimate website visitors' behavior which corresponds to legitimation structures.

We define value in this research as the consumer's perception of the outcome of the online interaction experience, which can be divided into utilitarian and hedonic value. In an Internet context, utilitarian and hedonic value dimensions seem to be most common (Overby and Lee 2006). Utilitarian value is relevant for task-specific use of the website while hedonic value reflects website visitors' appreciation of the online experience (Babin et al. 1994). Previous research has already indicated that visitors' utilitarian and hedonic value perceptions are both important in influencing their loyalty towards a website (e-loyalty) (Fiore et al. 2005b). In order to create a valuable online interface for subjects, companies have to know to what extent their subjects perceive that the online interface provides both hedonic and utilitarian value (Novak et al. 2000), resulting ultimately in e-loyalty. In line with commonly accepted definitions of (e)-loyalty, we define e-loyalty as a belief reflecting a preference for a particular website (cognitive) that based on satisfied usage might lead to a favorable attitude towards a website (affective) resulting in behavioral intentions e.g. to recommend the website to others or visiting the website again (conative) and repeat actual behavior (action) (e.g. Anderson and Srinivasan 2003; Oliver 1997; Srinivasan et al. 2002).

In the next section, we develop our hypotheses describing the assumed relationships between media richness, information richness, and purposeful behavior and the value-loyalty chain.

\subsection{Hypotheses related to media and information richness and purposeful behavior}

In the first set of hypotheses we focus on the impact of different levels of media and information richness on website visitors' perceptions of hedonic and utilitarian value. 
Furthermore, we hypothesize the impact of the interaction effect of media and information richness on both types of value. Finally, we examine the direct and interaction effect of purposeful behavior on website visitor's hedonic and utilitarian value perceptions (see figure 2-4).

\subsubsection{Direct effects}

\subsubsection{Media richness}

In line with structuration theory, we propose that website characteristics (structural features) influence visitors' value perceptions (actors' perceptions). A website visitor perceives utilitarian value when $\mathrm{s} /$ he accomplishes her/his tasks (e.g., s/he finds the information s/he was searching for or receives the service s/he needed) (Babin and Attaway 2000; Bourdeau et al. 2002). Websites with high levels of media richness or more specifically high levels of synchronicity, multiplicity of cues, and control, provide an environment that supports website visitors in their task fulfillment and consequently enhance their perceptions of utilitarian value. Website features such as search engines facilitate navigation and evaluation of information and thereby offer website visitors utilitarian benefits such as saving time and effort (Kim et al. 2007). For example, when a website visitor searches for a new mobile phone, 3-d pictures of a mobile phone which the website visitor can turn around by simply clicking on the picture facilitate the comparison of different types of phones and at last visitor's choice for a particular phone. Moreover, a website that is well organized and designed provides the visitor with greater control, which minimizes the required effort for fulfilling a task (Heeter 1989 in Dholakia et al. 2000). Thus, we hypothesize:

$H_{1 a}$ Media richness has a positive influence on utilitarian value.

However, consumers' perceptions of the online interaction are not only related to fulfilling one's goals but also to the enjoyment of the online interaction itself (Backström and Johansson 2006; Cotte et al. 2006). Consumers might perceive hedonic value when the online interaction experience itself is pleasant and enjoyable (Babin and Attaway 2000; Babin et al. 2004). Shih (1998) argues that through interaction with the website, visitors will experience positive affects because this medium offers ample opportunity to go beyond mere task orientation. For instance, if the website is responsive and includes attractive features, e.g. video and sounds, it is likely that website visitors enjoy their visit. Several studies indicate that appealing site designs including attractive features promote customer excitement and create an enjoyable online interaction for their customers (e.g. De Wulf et al. 2006; Liu and Arnett 2000). Nowadays, more and more companies use video-content at their website for promoting their products and/or services, which increases the aesthetic elements 
and visual appeal of their website (Ranganathan and Ganapathy 2002), representing components of hedonic value. Recent studies on online atmospherics showed a positive effect from website design on pleasure experienced in an online fashion (Mummalameni 2005) and retailing context (Eroglu et al. 2003). In a similar vein, travel websites (e.g. gobest.nl) offer website visitors the possibility to look around in the hotel of their stay, increasing the visual appeal of their holiday destination resulting in a high level of perceived online hedonic value. In addition, many companies are implementing chat applications on their website to facilitate website visitor interactions with company representatives or other customers, resulting in hedonic value. Koufaris (2002) argues that many websites offer their visitors search engines, enhancing visitors' control and convenience, resulting in higher perceptions of hedonic value. Based on this, we hypothesize;

$H_{1 b}$ Media richness has a positive influence on hedonic value.

\subsubsection{Information richness}

Chen and Dubinsky (2003) argue that one of the most important reasons why consumers use the Internet is to fulfill a need or a goal, such as acquiring information about particular products or services, as this is abundant and readily available online. Therefore, the Internet can lower consumers' costs of information search (Bakos 1991 in Ranganathan and Ganapathy 2002). However, a major drawback of the Internet is that it often provides visitors with information overload (Huang 2000), as it is a real challenge for consumers to find appropriate information that is relevant, accurate, comprehensive, and complete. A website that provides rich information content reduces the effort needed to acquire knowledge on products or services and thereby enables website visitors to make better informed decisions (Ballantine 2005), ultimately increasing their perceptions of utilitarian value. For instance, when website visitors are searching for a job at a career website and find information about the employment conditions and the required level of education and skills, they are able to judge whether they want to apply for the job, creating utilitarian value. In a similar vein, consumers can book a trip online when the website provides them with information about the price, time tables and availability of their flights resulting in higher perceptions of utilitarian value. Therefore, we hypothesize the following:

$\mathrm{H}_{2 a}$ Information richness has a positive influence on utilitarian value.

Huizingh (2000) argues that providing information about the product or service a consumer is looking for is the basic goal of a website. However, information is not necessarily goal-related but can refer to different aspects of the online visit such as company background and noncommercial information such as geographic location or technology (Huizingh 2000). In the example of a holiday site, travel agencies provide basic information about the 
accommodation and availability, but additionally also provide information about the local attractiveness of the area, which increases visitors' excitement about their trip, leading to perceived hedonic value. Furthermore, we consider information richness as a prerequisite for experiencing hedonic value (De Wulf et al. 2006). No matter how attractive the website is in terms of its media richness, e.g. multimedia and responsiveness, if the required information is not available or not accurate, website visitors might become irritated instead of pleased or excited. Therefore, we hypothesize:

$H_{2 b}$ Information richness has a positive influence on hedonic value.

\subsubsection{Purposeful behavior}

Research in an online shopping context suggests that the main reason why consumers visit a website is to search for specific information to accomplish their goals (Wolfinbarger and Gilly 2001). Nevertheless, only focusing on goal-directed behavior and task fulfillment does not reflect website visitors' whole online experience, as they may also visit a website out of curiosity or fun (Forsythe et al. 2006). Moreover, several authors suggest that the online experience offers website visitors both utilitarian and hedonic value (Childers et al. 2001; Hoffman and Novak 1996). According to Holbrook (1986), individual differences, e.g. a search or browse task, may influence the type of value that is experienced. In addition, several authors argue that in a shopping context, goal-directed or search behavior involves the propensity to experience utilitarian value, whereas experiential or browse behavior involves the propensity to experience hedonic value (Babin et al. 1994; Lee et al. 2006). For instance, consumers with an intention to buy a mobile phone visit a mobile phone website to search for specific information in order to accomplish their goals and are consequently more likely to experience utilitarian value than browsers who visit the website out of curiosity. Consumers without plans to buy a mobile phone visit the mobile phone website primarily for the experience and browse the website for curiosity and are subsequently more likely to experience hedonic value than searchers who visit a website to accomplish their goals. Thus; H3 Purposeful behavior has a positive influence on (a) utilitarian value and a negative influence on (b) hedonic value.

\subsubsection{Interaction effects}

\subsubsection{Hedonic value}

Building on hypothesis $1 \mathrm{~b}$ where we argued that media richness contributes to hedonic value, we now elaborate on situations of low versus high media richness and the compensating role of information richness. In practice, we observe that several websites can be viewed in different versions depending on the website visitor's bandwidth and corresponding download time, ranging from text-based versions (low media richness) to 
multimedia versions (high media richness). Consequently, we constitute media richness on a continuum ranging from low to high (Griffith et al. 2001). Moreover, in line with Dennis and Kinney (1998), we argue that differences in media richness cues determine the role website visitors attach to information richness. In other words, if a website demonstrates a high level of media richness, website visitors need information richness to a lesser extent to perceive hedonic value (conform hypothesis $1 \mathrm{~b}$ ). However, if the perceived level of media richness is low, a high level of information richness can compensate this deficiency and still lead to hedonic value. Several authors already acknowledged the role of providing information on the one hand and site design on the other hand in creating a satisfying online experience (e.g. De Wulf et al. 2006; McKinney et al. 2002; Szymanski and Hise 2000; Wolfinbarger and Gilly 2001). Ranganathan and Ganapathy (2002) even argue that business to consumer websites should pay serious attention to the important role of providing information in order to create a pleasant online experience for website visitors. So, for website visitors to perceive hedonic value if media richness is low, they will more heavily depend on an accurate, relevant, complete, understandable, and attractive description of the information they are looking for. Therefore, we hypothesize the interaction effect of media richness and information richness on hedonic value as follows:

$\mathrm{H}_{4}$ In situations of high media richness the impact on hedonic value is equal for websites with high and low information richness, whereas in situations of low media richness the impact on hedonic value is stronger for websites with high (versus low) information richness.

\subsubsection{Utilitarian value}

Comparable to the formation of media richness, we also conceptualize information richness on a continuum ranging from low to high. Building on hypothesis $2 \mathrm{a}$ where we argued that information richness contributes to utilitarian value, we now elaborate on situations of low versus high information richness and the compensating role of media richness. When a website is less informative, it is difficult for the website visitor to fulfill his/her task. However, non-text elements enhance the task accomplishment by facilitating website visitors to retrieve and attach meaning to the information presented (Huizingh 2000). In a similar vein, Marsico and Levialdi (2004) argue that media richness elements of a website can overcome difficult accessibility and interpretation of information. For instance, if a website visitor from Europe wants to purchase American food items s/he can consult the website www.americangoodies.nl which is based on graphical and visual representations of the food items lacking a detailed nutritional and size description. Nevertheless, thanks to the provided pictures and the convenient website layout, website visitors may still be able to accomplish 
their shopping task. Hence, we hypothesize the interaction effect of information richness and media richness on utilitarian value as follows:

$\mathrm{H}_{5}$ In situations of high information richness the impact on utilitarian value is equal for websites with high and low media richness, whereas in situations of low information richness the impact on utilitarian value is stronger for websites with high (versus low) media richness.

\subsubsection{Purposeful behavior}

As described in hypotheses 1 and 2, website features (structure) such as information and media richness directly influence visitors' (actor) perceptions of value in an online interaction process (De Wulf et al. 2006; Kim et al. 2007). Moreover, as posited in hypothesis 3, purposeful behavior plays an important direct role in experiencing value of an interaction with a website as searchers and browsers have a tendency to experience different types of value (e.g. Babin et al. 1994; Lee et al. 2006). In addition to the direct influence of a visitor's search (purposeful behavior) or browse (non-purposeful behavior), we also assume a moderating role of purposeful behavior on the relationship between website features and utilitarian and hedonic value.

With respect to utilitarian value, several studies in the shopping behavior literature demonstrated a difference between shoppers who exhibit purposeful behavior (searchers) and people who do not demonstrate purposeful behavior (browsers) (e.g. Bellenger and Korgaonker 1980; Dawson et al. 1990; Kaltcheva and Weitz 2006; Reynolds and Beatty 1999; Westbrook and Black 1985). These studies share the common understanding that purposeful shoppers mainly shop to acquire a product and do not consider shopping as enjoyable but as a necessity. Individuals who visit a website to aim at a specific purpose are mainly interested in an efficient online experience resulting in goal attainment. Therefore, if these purposeful individuals perceive the website as a facilitator in their task accomplishment, the effect of website features on utilitarian value will be strengthened. Therefore, we hypothesize:

$H_{6}$ The influence of purposeful behavior will

(a) strengthen the relationship between media richness and utilitarian value.

(b) strengthen the relationship between information richness and utilitarian value.

(c) strengthen the relationship between media richness, information richness and utilitarian value.

In terms of hedonic value, the studies mentioned in the shopping behavior literature argue that purposeful or goal-oriented shoppers do not experience shopping as a pleasant use of their time but rather want to complete their shopping task (e.g. Bellenger and Korgaonker 
1980; Dawson et al. 1990; Kaltcheva and Weitz 2006; Reynolds and Beatty 1999; Westbrook and Black 1985). So, these goal oriented individuals do not derive hedonic value from the mere presence of appealing website features, as they mainly want to achieve intended outcomes such as acquiring needed information (e.g., Dawson et al. 1990; Babin et al. 1994). Therefore, we hypothesize:

$H_{6}$ The influence of purposeful behavior will

(d) weaken the relationship between media richness and hedonic value.

(e) weaken the relationship between information richness and hedonic value.

(f) weaken the relationship between media richness, information richness and hedonic value.

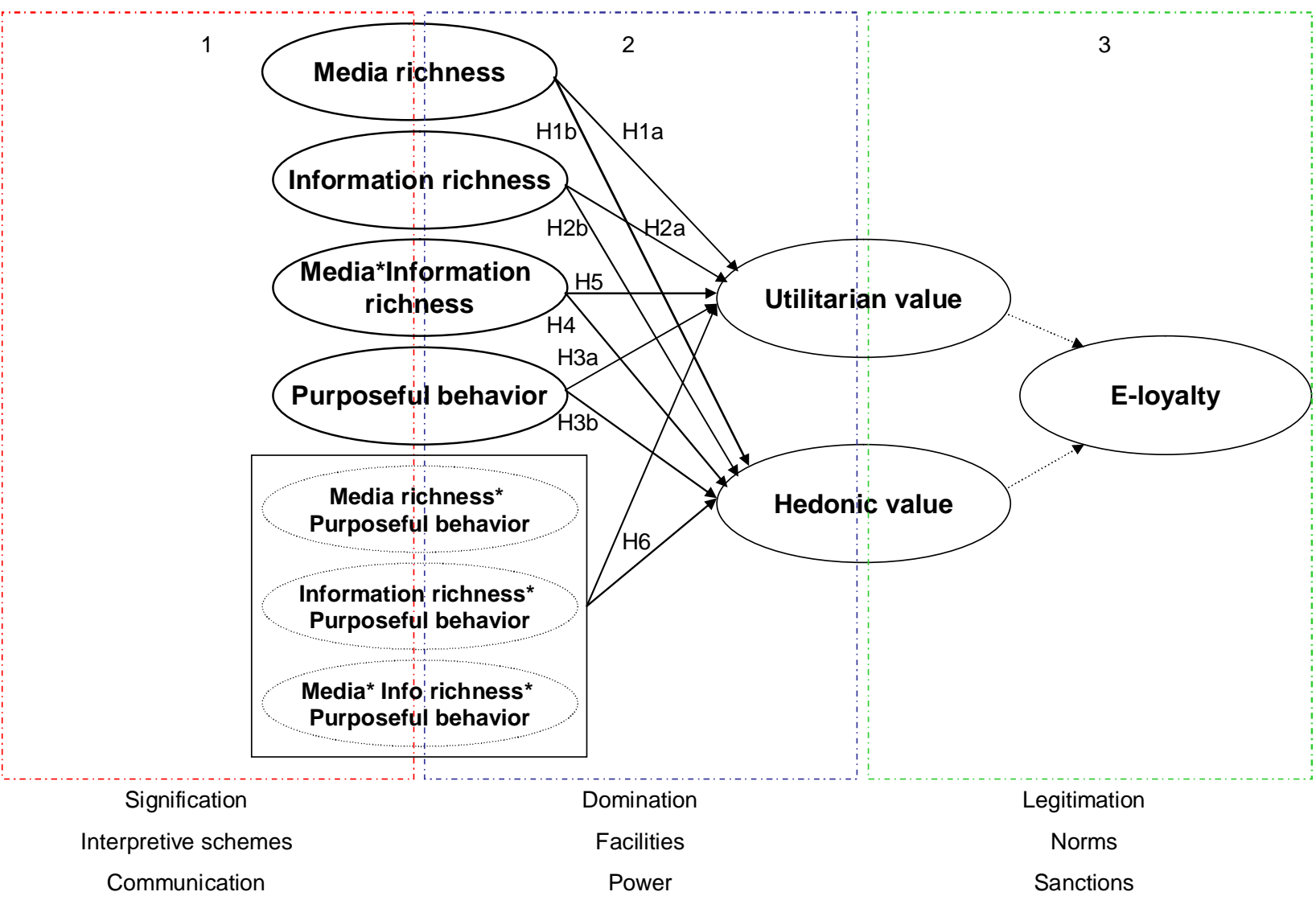

Figure 2-4: Theoretical framework I

\subsection{Hypotheses related to interactional richness}

In the previous part, we developed theoretical framework I (see figure 2.4) in order to examine the interaction process between websites and their visitors. This framework emphasizes the clear and precise impact of the separate dimensions of media richness and information richness on outcomes of the interaction process (utilitarian and hedonic value), rather than emphasizing the holistic perspective of interactional richness as a representation 
of an overall phenomenon. The holistic perspective of interactional richness will be represented in theoretical framework II. This second theoretical framework focuses on the impact of the multidimensional construct of interactional richness on website visitors' perceptions of both utilitarian and hedonic value and ultimately visitors' loyalty towards the website (see figure 2-5). By considering interactional richness as a holistic perspective, we emphasize the comprehensive evaluation of the website, stressing the overall picture consumers form after their website visit. These frameworks together offer a rich understanding of interactional richness by presenting both clear and precise as well as holistic insights.

\subsubsection{Interactional richness on value}

Ranganathan and Ganapathy (2002) acknowledge that both the design of the website as well as its content are equally important for an effective website. In their study at online bookstores, Liang and Lai (2002) take a six stage consumer decision making process resulting in a transaction and post sales behavior. They argue that the quality of a website's design refers to both appropriate information as well as media richness factors. They provide empirical evidence for the positive effect of design quality on consumer choice. This finding supports our assumption that interactional richness contributes to task fulfillment. An interactional rich website thus provides visitors with both medium and information characteristics which facilitate them to accomplish their tasks. For example, a career website presents rich information about vacancies and the corresponding companies by means of text complemented by pictures and short video films. Moreover, this website offers visitors the opportunity to consult a career coach online and practice job assessments. All these information and media features will facilitate their job search and consequently enhance their perceptions of goal accomplishment.

$\mathrm{H}_{7 a}$ High levels of interactional richness have a positive impact on utilitarian value.

Website visitors' perceptions of hedonic value are based on how appropriate the combination of both media and information features at the website is (Babin et al. 2004). For instance, if website visitors believe that the rich information content provided via a rich website is sufficient and presented in an attractive way, they are more likely to enjoy the website visit or in other words experience hedonic value (Childers et al. 2001; De Wulf et al. 2006). In contrast, if website visitors perceive low levels of interactional richness they might become frustrated and will not perceive the website visit as pleasant or enjoyable. For example, if consumers visit a holiday website but cannot find basic information about prices and availability of destinations and feel out of control because they do not get a synchronous response to their questions, consumers become frustrated and consequently do not enjoy 
the website visit. De Marsico and Levialdi (Marsico De and Levialdi 2004) already acknowledged that in order to create a pleasant and attractive medium the website should exhibit a combination of informative characteristics and appealing presentation methods. Therefore, we hypothesize;

$H_{7 b}$ High levels of interactional richness have a positive impact on hedonic value.

\subsubsection{Moderating effects}

In line with a structuration view, we argue that different website visitors do not value the same website attributes, as each website visitor has unique characteristics that influence their value perceptions as a result of interactional richness. In the following paragraphs, we will discuss how the relationships between interactional richness and value are contingent upon the website visitors' reflexivity and competence.

\subsubsection{Reflexivity}

According to structuration theory, websites (structures) and their visitors (actors) are highly entangled and co-evolve over time as they continuously influence each other. To fully comprehend how website features trigger visitors (actors), we have to examine the recursive and dynamic interaction process between websites and their visitors and simultaneously assess the distinctiveness among different types of structural features, such as website characteristics and individual traits.

In line with trait activation theory (Tett and Guterman 2000), we assume that trait relevant cues such as website characteristics stimulate visitors' traits. Visitors' traits in turn influence the relationship between visitors' perceptions of website characteristics and resulting value perceptions. In this study, we consider reflexivity as a relevant trait because structuration theory proposes that website visitors (actors) are reflexive (Pozzebon and Pinsonneault 2001; Sarason et al. 2006). In addition, reflexivity is especially relevant in an online information search context because it refers to visitors' capacity to critically monitor and evaluate their own information search process while they are searching for information online. Personality traits such as reflexivity are hidden potentials inherent in the individual (Tett and Burnett 2003). Understanding what activates visitors' relevant personality traits is critical for understanding the role of reflexivity in visitor's interaction process with websites. However, whether such a trait is expressed depends on the trait-relevance of situational cues (Tett and Burnett 2003). A situation is considered relevant to a trait when the provided situational cues stimulate a particular response that indicates an individual's standing on a specific trait. The whole process of personality trait expression as a reaction to relevant situational cues is referred to as the principle of trait activation (Tett and Burnett 2003). In this study, we follow this principle of trait activation and subsequently express reflexivity as a 
response to a bundle of trait-relevant situational cues such as interactional richness. Peltier et al. (2005) suggest that an outstanding experience triggers an individual's reflection process. Consequently, we propose that website visitors' reflexivity is stimulated when they perceive high levels of interactional richness at a website. Thus, we hypothesize;

$H_{8 a}$ Interactional richness has a positive impact on reflexivity.

A structuration perspective suggests that the idiosyncratic characteristics of website visitors (e.g. reflexivity) have an important impact on the interaction process between website features and the resulting value perceptions (Poole and DeSanctis 2004). As stated earlier, reflexivity refers to an individual's critical evaluation of his/her own information search process online. The corresponding reflection process consists of three stages; awareness, critical evaluation, and change (Peltier et al. 2005). In this study, awareness refers to visitors' consciousness of their own information search process that they subsequently critically evaluate. As a result of their critical evaluation, the relationship between website visitors' perceptions of interactional richness and ultimately their perceptions of value change. In an education context, Biggs (Biggs 1987 in Peltier et al. 2005) argued that students who have a reflexive approach to learning are interested in the task itself and aim at completing the task (utilitarian value). Or in other words, website visitors engaging in deep reflection of their own online information search process are focused on their task fulfillment. Subsequently, we expect that website visitors who critically evaluate their own online information search process are more likely to accomplish their goals online as a result of their enhanced awareness of interactional rich cues at the website. Therefore, we propose

$H_{8 b}$ The relationship between interactional richness and utilitarian value is stronger for website visitors with high levels of reflexivity.

In contrast, we expect that reflexivity will not moderate the relationship between perceived levels of interactional richness and hedonic value perceptions. From a structuration perspective actors are assumed to exhibit self reflection which refers to the capacity to critically evaluate what they are doing, while they are doing it (Rose 1998). Schippers (2003) already argued that reflexivity is most relevant in settings with high information processing requirements and less related to hedonic aspects. The rational behind this can be seen in an education context. It is proposed that reflexive learning consists of two elements; a state of doubt which activates the thinking process and the search to find information to resolve the doubt (Dewey 1933 in Peltier et al. 2005). Also in organizational behaviour, reflexivity is seen as the degree to which teams focus on task-related (utilitarian) issues such as evaluation of the process leading to task fulfillment as well as an evaluation of finished tasks (Schippers 2003). In other words, reflexivity comprises thinking and fulfilling ones information needs, 
which is merely utilitarian in nature. Summarizing, we do not expect that critical evaluation of visitors' own search process (reflexivity) will influence the relationship between interactional richness and hedonic value as hypothesized in $7 \mathrm{~b}$.

Hence, we hypothesize;

$H_{8 c}$ The relationship between interactional richness and hedonic value is the same for website visitors with either high or low levels of reflexivity.

\subsubsection{Competence}

In line with structuration theory, we also focus on the effect of websites (structures) on their visitors (actors). Thus, to evaluate website visitors' perceptions of their ability to search for information online (competence), we have to consider the impact of structural features such as interactional richness. Lehto et al. (2006) argue that competence depends on website visitors' experience with the Internet. In line with this, we regard competence as an incremental skill that can continuously be enhanced by visiting challenging interactional rich websites and thereby gaining experience and acquiring knowledge (Wood and Bandura 1989 in $\mathrm{Yi}$ and Hwang 2003). Furthermore, Yi and Hwang (2003) argue that consumers perceive challenges as a chance to develop competence. In a similar vein, we expect that website visitors appreciate the challenge of an interactional rich website and develop self-confidence in searching the internet for information. For instance, when a mobile phone provider includes interactional rich features at its website such as an application to compare different types of mobile phones, website visitors may welcome the challenge of using such an application to inform themselves and subsequently become more confident in their ability to search the internet for information. Hence, we hypothesize;

$H_{9 a}$ Interactional richness has a positive effect on competence.

As in the case of reflexivity, we expect that website visitors' competence will moderate the effect of perceived level of interactional richness on website visitors' value perceptions. Being a competent website visitor could affect the relationship between website visitors' perceptions of interactional richness and their perceptions of utilitarian and hedonic value in either way. Some website visitors who exhibit strong competence are more likely to fulfill their tasks (utilitarian value) as a result of the perceived interactional richness, because based on their previous experiences these website visitors are better equipped to apply website and information features to accomplish their goals (Lehto et al. 2006). However, other competent website visitors may find the website too simplistic or too boring and are consequently not encouraged to accomplish their tasks. Hammond et al. (1998) argue that experienced website visitors, or in other words highly competent internet searchers, are not only more skilled in navigating websites but also more enthusiastic about websites. Website 
visitors who indicate stronger competence are more experienced online and, because of their enthusiasm online, more willing to recognize the hedonic aspects as a result of perceived interactional richness. In contrast, other competent website visitors may not enjoy the interaction with an interactional rich website because they are neither interested nor appreciate the variety of features and information available to them. Hence, we hypothesize;

$\mathrm{H}_{9}$ The relationship between interactional richness and (b) utilitarian and (c) hedonic value is stronger for website visitors with high levels of competence.

\subsection{Hypotheses related to value and e-loyalty}

The final set of hypotheses focus on the outcomes of the online interaction process, value (consumer goal) and e-loyalty (company goal). It is commonly accepted that website visitors will be more likely to become loyal if the interaction with the website enables them to accomplish their tasks (Babin et al. 2004). Eroglu et al. (2003) for instance, argue that the instrumental qualities of the online interaction experience such as convenience and functionality influence visitors' loyalty. For example, if a visitor is able to accomplish his/her task at a website, this automatically reduces his or her need to switch to an alternative website (Anderson and Srinivasan 2003). In a similar vein, Koufaris (2002) argues that website visitors will be more likely to return to a website if it enhances their shopping productivity or in other words their ability to accomplish their tasks. Hence, we hypothesize;

$H_{10 a}$ Utilitarian value has a positive impact on e-loyalty.

Several authors argue that an online interaction experience which is valuable in terms of its enjoyment, enhances the intention to visit the website again (Baumgartner et al. 2006; Fiore et al. 2005a; Koufaris 2002; Menon and Kahn 2002). In an online shopping environment, Lee et al. (2006) recently provided empirical evidence for the hypothesis that shopping enjoyment influences consumers' attitudes towards the online store positively. De Wulf et al. (2006) demonstrated across online settings that website pleasure results in visitors' commitment or loyalty. In a similar vein, Chen et al. (2002) suggest that the level of entertainment at a website is an important driver of visitor's attitude towards a website. In line with these ideas, we hypothesize;

$H_{10 b}$ Hedonic value has a positive impact on e-loyalty. 


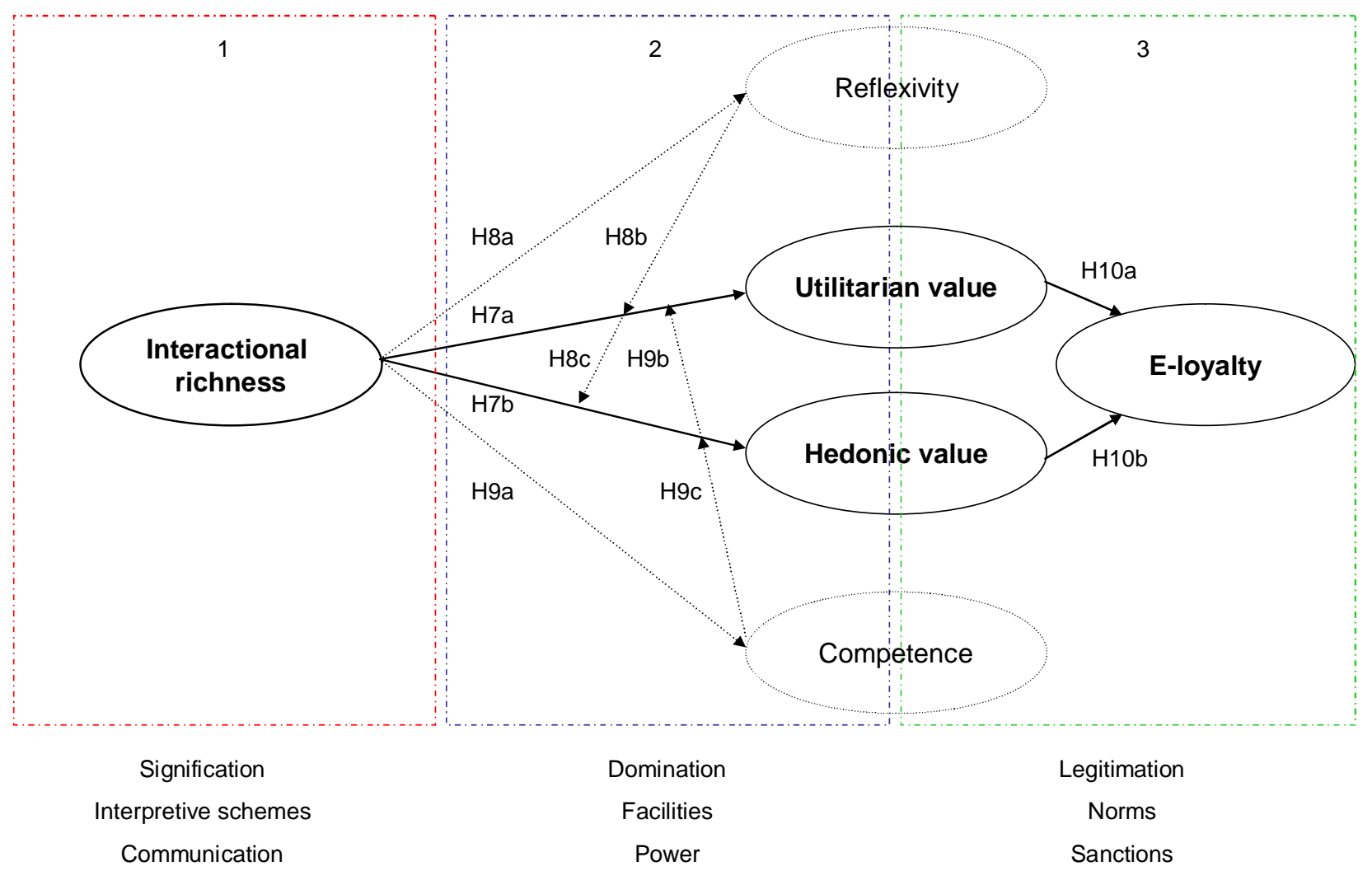

Figure 2-5: Theoretical framework II

\subsection{Summary}

In this chapter, we applied structuration theory as a theoretical lens to develop a theoretical framework as a basis for the investigation of the recursive online interaction process between websites (structures) and their visitors (actors). We discussed the main principles of structuration theory, duality of structure, change over time, and idiosyncratic characteristics of the actors and applied them to an online context. Next, we developed our theoretical frameworks and related hypotheses along the lines of the duality of structure model inherent in structuration theory.

We first focused on signification structures, which refer to the attributes of a website that facilitate website visitors to interpret a website, e.g. media and information richness. However, based on previous research (e.g. McKinney et al. 2002) we argued that a website does not consist of either media or information features but is merely a combination of both. Subsequently, we proposed besides an impact of either media richness or information richness also an impact of the interaction effect of media and information on website visitors' perceptions of utilitarian and hedonic value. In addition, to comprehensively capture the impact of both types of website features we introduced and conceptualized the higher-order construct interactional richness. Furthermore, we hypothesized that interactional richness has a positive influence on website visitors' value perceptions. 
Next, we focused on domination structures and proposed how asymmetries in both media and information richness and website visitors' idiosyncratic characteristics (e.g. reflexivity, competence, and purposeful behavior) facilitate website visitors' goal attainment, or in other words website visitors' perceptions of value. We hypothesized that different levels (high vs. low) of media and information richness influence website visitors' perceptions of value. We also assumed that the extent to which website visitors exhibit purposeful or non-purposeful behavior influences their value perceptions. Moreover, we assumed that the relationship between interactional richness and website visitors' value perceptions is contingent upon their reflexivity and competence.

Finally, we focused on legitimation structures and adopted website visitors' perceptions of value as norms which legitimate their loyal vs. non-loyal behavior respectively as a sanction or non-sanction. In line with previous studies we hypothesized a positive impact of utilitarian and hedonic value on e-loyalty.

\subsection{Bridging theory and empirics}

This section is the link between the theoretical frameworks described in this chapter and the empirical studies outlined in the next chapters. The purpose of this section is to motivate our choice for applying a multi-method approach to investigate the dynamic online interaction process between websites and their visitors, which is in line with structuration methodology. The justification of our study design will be explained at three different levels ranging from abstract to concrete: (1) macro versus micro change perspective, (2) clear and precise versus holistic approaches, and (3) experimental versus survey designs (see figure 2-6). 


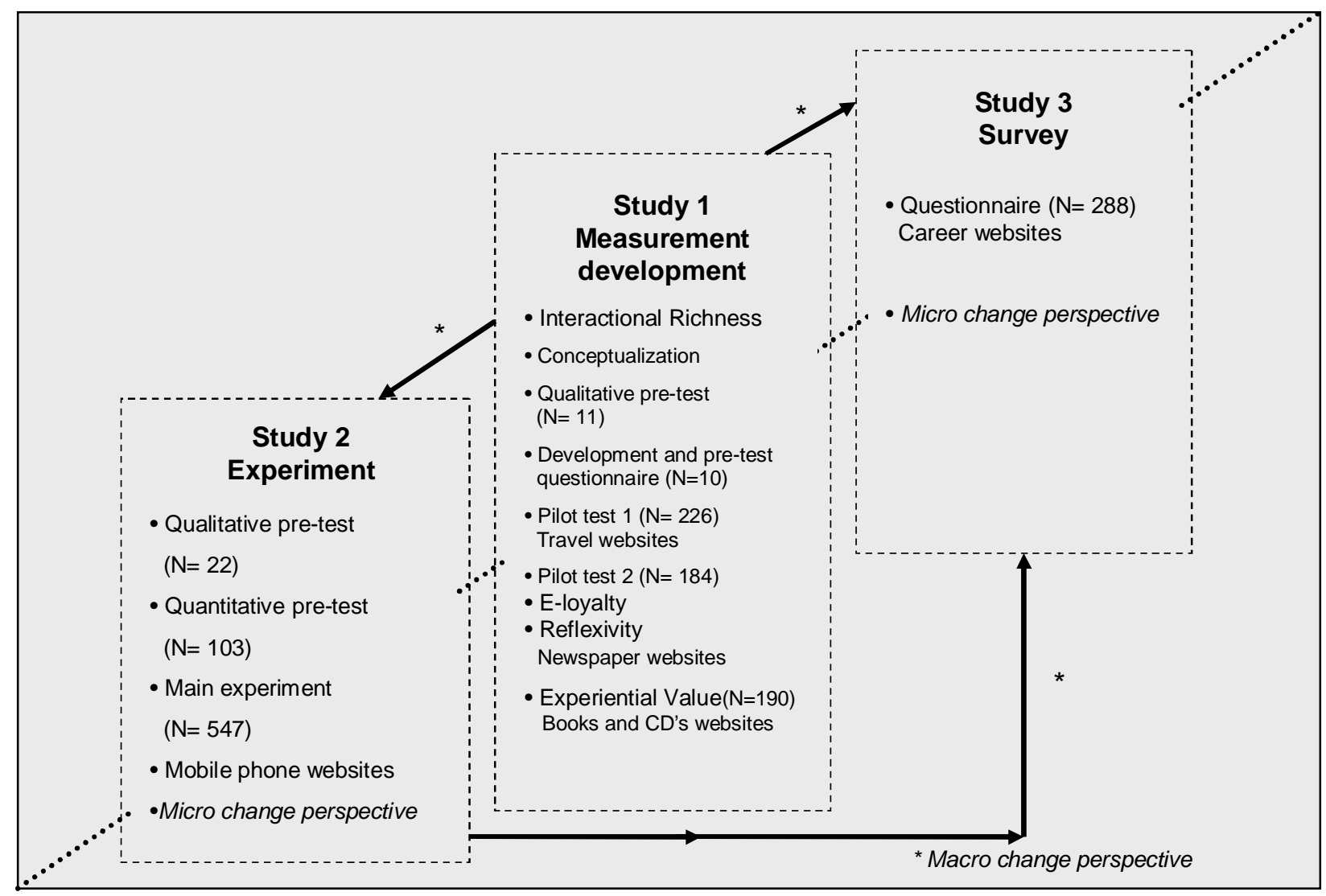

Figure 2-6: Overview research design

\subsubsection{Macro versus micro change perspective}

The interdependencies between the different studies we conducted can be considered as the underlying macro change perspective. Insights from one study will be used to shape the next study, thereby benefiting from a learning process, as subsequently conducting interrelated studies captures the changes over time.

Taking this macro perspective, the online interaction process between websites and their visitors is an aggregate of both company and customer initiated actions, reciprocal interactions, and visitors' interpretations of websites (Pozzebon 2004). While several researchers recommended conducting longitudinal research to identify the structural changes over time, we used a multi-method approach, in line with a recent trend in structuration methodology (Poole and DeSanctis 2004). A multi-method approach employs a combination of research methods to compensate for the weaknesses of a single method and to enhance the reliability and validity of the research findings (Wood et al. 1999). In this research, we conducted a multi-method approach because a combination of complementary research methods (e.g., qualitative research, surveys and experiments) results in a better understanding of the reciprocal interaction process, high interdependence, and co-evolution between websites and their visitors over time. As illustrated in Figure 2-6, the complementary research designs have been integrated in a coherent framework. 
Finally, we will apply this multi-method approach within different research contexts (e.g., experiential vs. functional services) using different types of samples (e.g., student vs. nonstudent samples) to assess the robustness of the results (Wood et al. 1999). Assessing the stability of our research results with different methods across different samples in various contexts validates the reliability and generalizability of our findings.

In addition to the aggregate macro change perspective, the final study within our multimethod research design is a comprehensive survey stressing the importance of individual website visitors. Within structuration theory, gaining an understanding of visitors' (actors') perception of the dynamic interaction with a website (structure) is important (Poole and DeSanctis 2004). Nevertheless, to fully comprehend the recursive relationship between websites and their visitors one should also take into consideration the discrete actions and interpretations of individual website visitors. We refer to the investigation of the impact of different idiosyncratic characteristics of website visitors as the micro change perspective.

\subsubsection{Clear and precise versus holistic approaches}

In our research design which will be further specified in 2.10.3, we investigate the impact of multidimensional constructs (higher order constructs) as well the impact of their underlying dimensions. Multidimensional constructs have largely been introduced to capture underlying dimensions in a single theoretical concept (e.g. service quality, relationship quality, job satisfaction). The value of multidimensional constructs versus their underlying dimensions has been a starting point for challenging debates (Edwards 2001). Researchers in favor of multidimensional constructs advocate the holistic representation of complex phenomena (e.g. Hanisch et al. 1998). Another research camp argues that multidimensional constructs are conceptually ambiguous. These researchers favor the precision and clarity of the dimensions that constitute the construct. Edwards (2001) explicitly argues that the conflicting objectives (clear and precise versus holistic) cannot be realized by following one side of the debate. Therefore, the different stages of our research design address these apparently conflicting objectives subsequently. After the first study that focuses on measurement development, we proceed with study two by manipulating the dimensions of interactional richness separately in an experimental design, resulting in clear and precise findings on the level of the underlying dimensions that constitute interactional richness. These findings can easily be applied by business practice. In the third study finally, we incorporate the multidimensional construct of interactional richness in a survey research to emphasize the holistic representation of website features. 


\subsubsection{Experimental versus survey designs}

In chapter 3 (study one) we develop and refine measurements of interactional richness, hedonic and utilitarian value, e-loyalty, and reflexivity. These newly developed or refined scales will be incorporated in the experimental design (study two) and our survey research (study three).

In chapter 4 (study two), we describe the design and results of the experimental research. We used the items and dimensions that constitute our multidimensional interactional richness scale as a basis for the manipulation of both media and information features on the company's website. A major advantage of our experimental design is that through the manipulation of the dimensions media and information richness (structural features), we can clearly and precisely compare the effect of media and information richness dimensions simultaneously. Another advantage of our experimental design is the fact that we control for extraneous variables that might offer an alternative explanation to our experimental findings. We will use random assignment of individuals to experimental groups. As a result of this random assignment, extraneous variable will be presented equally in each of the treatment conditions. Furthermore, applying controlled experiments also results in high internal validity and theory confirmation (Wood et al. 1999). In addition, recent research has stressed the added value of conducting experiments in an online context as so far most studies in an online context have been conceptual or survey based (Shankar et al. 2002).

Subsequently, in chapter 5 (study three) we will describe the methodology and results of our survey research. While study two emphasizes the impact of the underlying dimensions of interactional richness, offering clear and precise implications, in study three we take the holistic perspective of interactional richness representing a complex conceptual phenomenon. Commonly accepted advantages of surveys methods are the high external validity, the potential for theory development, and their relative ease of use and low costs (Wood et al. 1999). An advantage of our survey research is that it will provide valid insight into the actors' views of their interactions with websites because we focus on the micro change perspective. For these reasons the survey research may be used as a complement to our experimental study. We manipulate the website features, information and media richness in the experimental design, we assess visitors' perceptions of the website by including our multidimensional, higher-order interactional richness construct in the survey research. 


\section{Chapter 3: Measures to Assess Customer Evaluations of the Online Experience}

\subsection{Introduction}

This chapter describes the measurement development procedure of the constructs incorporated in our theoretical frameworks. The development or refinement of multi-item measures to examine the online interaction process between websites and their visitors is of vital importance to empirically assess customers' perceptions of the online experience. So far, existing measures of consumers' perceptions of a website only focused on parts of the website e.g., level of interactivity or information quality. Consequently, to comprehensively assess customers' perceptions of the website we develop, in section 3.2, a new scale for interactional richness following established scale development procedures (e.g. Churchill 1979). However, where possible we adapt the wording of items for the dimensions of our interactional richness measure from existing scales. This measurement development for interactional richness is in line with signification structures in the duality of structure model, which refers to the attributes of the website that visitors use to interpret a website.

For the other constructs involved in our theoretical framework, scales were available in the literature. In section 3.3, we introduce the experiential value concept of Mathwick et al. (Mathwick et al. 2001). We empirically assess that their construct consists of the underlying dimensions of utilitarian and hedonic value in order to subsequently employ their scale for measuring both our utilitarian and hedonic value constructs. Moreover, the existing scales of e-loyalty and reflexivity were not appropriate for a direct re-application in our research, as the existing e-loyalty scales refer only to attitudinal and behavioral dimensions (Srinivasan et al. 2002) and the existing reflexivity scale has to the best of our knowledge only been developed in a team context (Schippers 2003). Therefore, in section 3.4, we generate items for our eloyalty construct based on existing loyalty scales and furthermore describe how these items were refined. Subsequently, in section 3.5, we focus on the refinement of the reflexivity scale. Finally, we provide a conclusion in section 3.6.

\subsection{Measurement development interactional richness}

Within the duality of structure model of structuration theory (Giddens 1984), signification structures refer to website characteristics that make up meaning and facilitate visitors' interpretation of websites. In our research, the construct interactional richness is introduced as a measure to assess visitors' perceptions of websites. Consequently, in the first research phase we developed a scale for our higher order conceptualization of interactional richness. This scale was developed following established procedures (e.g. Churchill 1979), which are described in detail in the subsequent part. 


\subsubsection{Conceptualization}

Based on an extensive review of the literature of different research streams such as the marketing (e.g. Stewart and Pavlou 2002), information system (e.g. Muylle et al. 2004) and communication literatures (e.g. Barry and Crant 2000), the construct of interactional richness and its dimensions were defined. In addition, a large pool of items was generated by collecting items from similar constructs in published studies (e.g. information relevancy, accuracy, comprehensibility, comprehensiveness (Muylle et al. 2004); synchronicity (Liu 2002); media richness (Carlson and Zmud 1999)).

\subsubsection{Qualitative pre-test}

First of all, we conducted a qualitative pre-test with an academic expert who was knowledgeable about the objective of this study. This scholar reviewed the conceptual definitions and evaluated the appropriateness and wording of the items. Some of the remarks were incorporated in the formulation of the definitions of the constructs and the items. Next, qualitative pre-tests with expert judges were conducted to gather critical feedback about the conceptual definitions and the initial pool of items, and to enhance discriminant and content validity. This group consisted of nine PhD-students in marketing and one practitioner, a webmaster. At the start of the qualitative pre-test the experts received a written document with the definitions of interactional richness and its dimensions. After reviewing the conceptual definitions, the experts received a list with the items intended to measure each of the dimensions of interactional richness and some additional items not related to interactional richness. The experts were asked to evaluate the items and assign them to one or more dimensions or to the answer option "other" (see appendix A). Furthermore, the experts were asked whether the scale was complete or whether elements were missing. Based on their feedback a number of definitions and items were slightly modified or new items were developed to enhance content validity. For instance, some respondents also indicated that they had problems with the definition of the construct control as they found it hard to imagine that control implied creating their own online experience. However, they could imagine that website visitors feel in control when they are able to do what they want i.e., determine their own information search process. Consequently, we redefined control as the extent to which website visitors perceive that they are able to manage their own online interaction. As an indicator of discriminant validity, we used the number of items, at least eight, that is "correctly" assigned to a dimension of interactional richness. Furthermore, by examining the pattern of correct and incorrect divisions of the items to the dimensions we could assess which items might decrease content validity (De Wulf and Odekerken-Schröder 2003). We provide an overview of the results of this assignment in Appendix B. Next, we validated our 
preliminary set of items for interactional richness empirically by conducting two pilot tests that are described in the following sections.

\subsubsection{Development and qualitative pre-test of questionnaire}

Based on the results of the qualitative pre-test, a first version of the questionnaire was developed. The items of the different dimensions of interactional richness were presented in a mixed order. All measures used a seven-point Likert scale, with "strongly disagree" and "strongly agree" as the anchors. A group of five PhD-students in Marketing and five international business students were asked to pretest the written questionnaire, as all were Internet users and familiar with the context. These respondents filled in this questionnaire and provided us with feedback with respect to layout, instructions and item wording, sequence and difficulty. Based on their qualitative feedback problematic instructions and items were reformulated. After this pre-test of the questionnaire, two quantitative pilot tests were conducted.

\subsubsection{Pilot test 1: travel websites}

To determine reliability and validity of the interactional richness scale we conducted a quantitative pilot-test with 226 undergraduate business economics students. A pencil-andpaper survey was used to assess students' experiences with travel Websites (see appendix C). We selected the travel industry as many students are already familiar with visiting, searching for information, and buying from travel websites as this service industry has already quite a long presence online (Shankar et al. 2000; Shankar et al. 2003) and students are known to be rather mobile. To motivate participation a chocolate-bar was offered to the students that completed the questionnaire.

The measure for interactional richness was purified by examining first the item-total correlation. Ten items with an item-total correlation of less than 0.4 were deleted. Second, to assess internal consistency we calculated Cronbach's Alphas, which were adequate as they ranged from 0.61 to 0.81 (synchronicity 0.811 ; multiplicity of presentation 0.710 ; control 0.6055 ; relevance 0.727 ; accuracy 0.780 ; comprehensibility 0.726 ; completeness 0.784 ). Third, we conducted Principal Component Analysis. We accepted items that minimally loaded 0.6 on the hypothesized component. The results of the Principal Component Analysis indicated that some additional items had to be deleted or reformulated. Overall, this resulted in a scale reduction, from 45 to 23 items measuring interactional richness.

\subsubsection{Pilot test 2: newspaper websites}

A second pilot test was conducted to purify the interactional richness measure consisting of 23 items further. Again a pencil-and-paper survey was employed with a student sample to 
assess students' experiences with online newspaper websites (see appendix D). We have chosen online newspapers as the context for this research because nowadays most newspapers have an online presence (Schultz 1999) and are increasing in popularity (Neuberger et al. 1998) particularly among younger age groups like students. 184 business economics graduate students participated in this survey research. We also varied the incentive to take part in the study. All students that completed the questionnaire had the chance of winning one of 25 vouchers of $10 €$. Cronbach's alpha for the dimensions of interactional richness were all adequate (>.60), except for control. Two items of control were removed to increase Cronbach's alpha (synchronicity 0.722 ; multiplicity of presentation 0.710 ; control 0.6266 ; relevance 0.673 ; accuracy 0.831 ; comprehensibility 0.657 ; completeness 0.752 ).

We used PLS Graph 3.0 (Chin 2001) in this online newspaper context to estimate the parameters in the measurement model. We assessed the adequacy of the measurement model through examination of convergent validity, composite scale reliability, and discriminant validity. Convergent validity was assessed by examining the loadings of the measures on the respective constructs. All loadings were higher than 0.5 (Hulland 1999), while most loadings were higher than 0.7 (see table 3-1). The composite reliability for all firstorder factors of interactional richness compellingly exceeded the cut-off value of 0.7 proposed by Fornell and Larcker (1981). Moreover, the average variance extracted for all factors were above the recommended cut-off value of 0.5 ranging from 0.59 to 0.75 . 
Table 3-1: Interactional richness: psychometric properties of first-order constructs

\begin{tabular}{|c|c|c|c|c|}
\hline Construct & Item & Loading & CR & $A V E$ \\
\hline Synchronicity & $\begin{array}{l}\text { This website enables me to ask questions and obtain } \\
\text { answers as they arise } \\
\text { I feel as if this website talks back to me while I am navigating } \\
\text { This website is effective in gathering visitors' feedback } \\
\text { This website makes me feel it wants to listen to its visitors }\end{array}$ & $\begin{array}{l}0.56 \\
0.71 \\
0.82 \\
0.86\end{array}$ & 0.83 & 0.59 \\
\hline $\begin{array}{l}\text { Multiplicity of } \\
\text { presentation }\end{array}$ & $\begin{array}{l}\text { This website communicates its information in various ways } \\
\text { such as text, pictures, symbols etc. } \\
\text { This website expresses in multiple ways what it wants to say } \\
\text { by using pictures, symbols, numbers, text etc. } \\
\text { This website presents the information in } \\
\text { various ways such as pictures, video, text etc. }\end{array}$ & $\begin{array}{l}0.86 \\
0.84 \\
0.78\end{array}$ & 0.87 & 0.69 \\
\hline Control & $\begin{array}{l}\text { When I am on this website, I can choose freely what I want } \\
\text { to see } \\
\text { When surfing this website, I can do what I want }\end{array}$ & $\begin{array}{l}0,87 \\
0,85\end{array}$ & 0,85 & 0,73 \\
\hline Relevance & $\begin{array}{l}\text { The information on the website is relevant } \\
\text { The information on the website is to the point } \\
\text { The information on the website relates to my needs }\end{array}$ & $\begin{array}{l}0.79 \\
0.80 \\
0.75\end{array}$ & 0.82 & 0.61 \\
\hline Accuracy & $\begin{array}{l}\text { I can rely on the information on this website } \\
\text { The information on this website reflects reality } \\
\text { The information on this website is correct }\end{array}$ & $\begin{array}{l}0.85 \\
0.87 \\
0.86\end{array}$ & 0.90 & 0.75 \\
\hline Comprehensibillity & $\begin{array}{l}\text { The information on this website is easy to understand } \\
\text { The information on this website is clear to me } \\
\text { The information on this website is presented clearly }\end{array}$ & $\begin{array}{l}0.67 \\
0.86 \\
0.79\end{array}$ & 0.82 & 0.60 \\
\hline Completeness & $\begin{array}{l}\text { This website provides sufficient information on news events } \\
\text { The information on this website is complete } \\
\text { The information on this website is sufficiently detailed }\end{array}$ & $\begin{array}{l}0.79 \\
0.84 \\
0.82\end{array}$ & 0.86 & 0.67 \\
\hline
\end{tabular}

Notes: $\alpha=$ coefficient alpha; $C R=$ composite reliability; and AVE = average variance extracted.

As shown in table 3-2, we found support for discriminant validity as the square root of the average variance extracted exceeds the intercorrelations of the factors with the other factors in the model.

Table 3-2: Interactional richness: intercorrelations

\begin{tabular}{lccccccc}
\hline Construct & $\mathbf{1 .}$ & $\mathbf{2 .}$ & $\mathbf{3 .}$ & $\mathbf{4 .}$ & $\mathbf{5 .}$ & $\mathbf{6 .}$ & $\mathbf{7 .}$ \\
& 0.75 & & & & & & \\
1. Synchronicity & 0.24 & 0.83 & & & & & \\
2. Multiplicity of presentation & 0.27 & 0.18 & 0.85 & & & & \\
3. Control & 0.27 & 0.30 & 0.21 & 0.78 & & & \\
4. Relevance & 0.08 & 0.02 & 0.10 & 0.62 & 0.86 & & \\
5. Accuracy & 0.02 & 0.30 & 0.37 & 0.44 & 0.34 & 0.78 & \\
6. Comprehensibillity & 0.19 & 0.17 & 0.16 & 0.71 & 0.59 & 0.32 & 0.82 \\
7. Completeness & & & & & & &
\end{tabular}

Notes: Square root of the AVE on the diagonal. 
As only two items for control remained after the assessment of the Cronbach's alpha, we added two new items in order to assure the richness of the content of our control measure. These two control items "While surfing this website, I can control the sequence of my information search" and "While surfing this website, I can control my interactions with the site" were derived from an existing measure for control (Zhang and Dran 2001). Moreover, we adapted the formulation of the other two remaining control items a bit. Satisfied by its reliability and validity, the interactional richness scale including 21 items (+ 2 new items for control) was incorporated in the subsequent studies.

\subsubsection{Summary}

In this first phase of measurement development, we developed a scale for our higher-order construct interactional richness. We first defined our conceptual domain and generated items, then we conducted a qualitative pre-test $(\mathrm{N}=11)$ and two quantitative pilot-tests in an online travel $(\mathrm{N}=226)$ and newspaper $(\mathrm{N}=184)$ context, which resulted in our 23 items scale of interactional richness.

\subsection{Measurement development utilitarian and hedonic value}

From a structuration perspective, value represents consumer goals, which play a critical role in an online interaction process. In this section, we use Mathwick et al.'s (Mathwick et al. 2001) higher-order construct of experiential value as a basis for our measurement development of utilitarian and hedonic value.

\subsubsection{Conceptualization}

Several researchers have recognized that value is the outcome of an experience and composed of both utilitarian and hedonic value dimensions (Babin et al. 1994; Holbrook 1994; Van der Heijden 2004). According to Hoffman and Novak (1996) the distinction between hedonic and utilitarian value is especially important in an online context, because for many consumers, the hedonic value component is even more important than the final utilitarian outcome of their online experience. Mathwick et al. (2001) were the first to introduce, develop, and test a scale of experiential value in an online context. They define online experiential value as "a perceived, relativistic preference for product attributes or service performances arising from interaction within a consumption setting that facilitates or blocks achievement of customer goals or purposes" (Mathwick et al. 2002 p. 53). Moreover, they base their conceptualization of experiential value on Holbrook's (1994) work and distinguish between intrinsic (hedonic) and extrinsic (utilitarian) value components on the one hand and active versus reactive sources of value on the other. With respect to the active and 
reactive sources of value, Holbrook (1994 p. 43) defines the active dimension as "a manipulation of the environment," such as occurs when people play video games. In the reactive dimension, the consumer mainly acts as a viewer and receiver rather than as an active participant.

Mathwick et al. (2001) also distinguish playfulness, aesthetics, customer return on investment (CROI), and service excellence as sources of value. Playfulness and aesthetics experienced while navigating a website are both sources of hedonic (intrinsic) value, because they offer immediate pleasure for its own sake (Holbrook 1994). In contrast, CROI and service excellence offer utilitarian (extrinsic) value because they serve as a means to an end (Holbrook 1994). Moreover, in an online context, playfulness refers to the absorbing capacity of a Website, which makes the consumer an active coproducer of value, whereas aesthetics reflect the consumer's reactive appreciation of the visual appeal and entertainment of the site (Mathwick et al. 2001). Their return on investment denotes consumers' active investment of resources that might generate a benefit for them, whereas service excellence refers to reactive consumer responses in appreciation for the delivered service (Mathwick et al. 2001). These second-order concepts in turn comprise several firstorder constructs. Playfulness involves enjoyment and escapism, aesthetics is composed of visual appeal and entertainment, and CROI is made up of economic value and efficiency; these authors do not define any first-order concepts of service excellence (Mathwick et al. 2001) (see figure 3-1). 


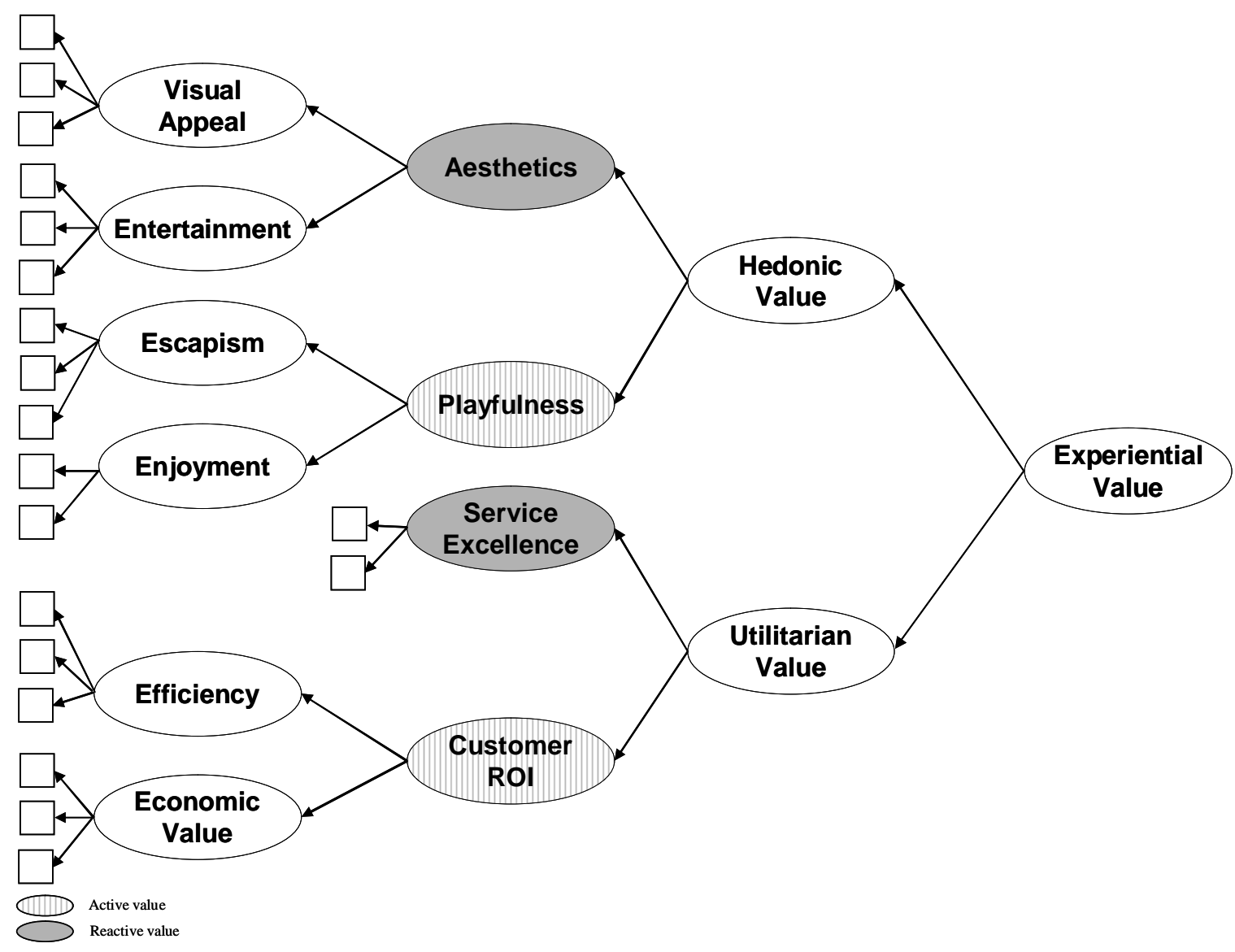

Figure 3-1: Higher-order model experiential value

Mathwick et al.'s $(2001,2002)$ conceptual work is based on the idea that an online experience can be assessed by means of experiential value. Although for practitioners it might be more helpful to gain knowledge about the differential impacts of hedonic and utilitarian value on e-loyalty, research on experiential value also might be extended by an empirical demonstration of the existence of a fourth-order model of experiential value, especially because experiential value has been hypothesized to offer both hedonic and utilitarian value concurrently (Babin et al. 1994; Mano and Oliver 1993). Moreover, empirical support of a fourth-order model would provide support for the conceptual ideas developed by Mathwick et al. $(2001,2002)$ and indicate that an online experience consists of both utilitarian and hedonic dimensions. We apply this experiential value scale of hedonic and utilitarian value in an online context, because Mathwick (2001, 2002) also applied this scale in an online context in contrast to previous offline scales (e.g. Babin et al. 1994). Moreover, the experiential value scale provides clear guidelines to adjust website features, as the first order concepts relate to specific elements of the online experience that practitioners can easily fine-tune. 


\subsubsection{Research setting: Books and CDs websites}

We use PLS path modeling to test our higher order model of experiential value in the context of online $C D$ and book retailers. This context provides an appropriate test environment for several reasons. First, research indicates that CDs and books are among the most frequently purchased items online (Kim and Stoel 2004; Kwak et al. 2002). Second, by addressing both product categories, our study is not limited to only one dimension of online experiential value but can address both hedonic and utilitarian value components. Kwak et al. (2002) offer preliminary evidence for this assumption with their indication that to purchase books online, a high degree of information is required, whereas CDs/music require only a low degree of information.

\subsubsection{Qualitative pre-test}

Before the actual research was conducted, five graduate students pre-tested the questionnaire, paying specific attention to question content, wording, sequence, format and layout, question difficulty, and instructions. During this pretest, we observed the respondents to monitor their reactions and attitudes toward the questionnaire. On the basis of the problems identified by the respondents, we made several improvements to the questionnaire.

\subsubsection{Measures}

The online questionnaire consisted of previously published multi-item scales with favorable psychometric properties. As argued in section 3.3.1, we used Mathwick et al. (2001) experiential value scale. In order to reduce potential halo-effects within the experiential value scale, we applied an e-loyalty scale used by Srinivasan et al. (2002) (see table 3-4). All the items were measured on a seven-point Likert scale, ranging from "strongly disagree" to "strongly agree". Finally, we collected some socio-demographic information about the respondents' gender, age, nationality, and profession.

\subsubsection{Sample profile}

We selected a sample of 1,000 individuals from a large online research panel, and then sent an e-mail invitation, containing an embedded URL link to the Website hosting the survey, to each potential respondent. To increase the response rate, we raffled off five cash incentives worth $\$ 12.50$, which resulted in a total of 308 respondents. As a screening question, we asked whether the respondent had ever visited or purchased from an online retailer selling both books and CDs, such as Amazon.com or Barnesandnoble.com. If not, we did not include these respondents in our sample, but 190 respondents indicated they had visited or purchased from the Web site of an online book and CD retailer before. Next, we asked these 
remaining respondents to complete the questionnaire about their most frequently visited online book and CD store to evaluate their online experiences.

As table $3-3$ shows, of the participants, $57.6 \%$ were women and $42.4 \%$ were men, $9.6 \%$ were younger than 20 years of age, $63.9 \%$ were between 20 and 25 years, $19.5 \%$ between 26 and 30 years, and $7 \%$ were older than 30 years. Of the total sample population, $73.8 \%$ considered themselves students, $21.9 \%$ as being employed, and $4.3 \%$ as "other."

Table 3-3: Sample profile: books and CDs websites

\begin{tabular}{lrl}
\hline $\mathbf{N}=\mathbf{1 9 0}$ & Percentage (\%) \\
\hline \multirow{2}{*}{ Gender } & & \\
& Male & 42.4 \\
Age & Female & 57.6 \\
& $<20$ & 9.6 \\
& $20-25$ & 63.9 \\
& $26-30$ & 19.5 \\
Profession & $>30$ & 7.0 \\
& Students & 73.8 \\
& Employee & 21.9 \\
& Other & 4.3 \\
& & \\
\hline
\end{tabular}

\subsubsection{Data Analysis}

Higher-order models can be specified as an alternative to group-factor models (Guinot et al. 2001; Rindskopf and Rose 1988). Basically, a higher-order model imposes an alternative structure on the pattern of correlations (covariances) among lower-order factors. As such, the higher-order model represents a restriction of the group-factor model, which allows for correlation of the lower-order factors (Rindskopf and Rose 1988). Obviously, this hierarchical model can be extended to higher-order factors, such as third-order factors (cf. Marsh and Hocevar 1985). Hierarchical models using latent variables can be estimated using structural equation modeling (SEM). Both covariance- and component-based SEM, or partial least squares (PLS), can be employed to estimate the parameters in a hierarchical model (Guinot et al. 2001), though covariance-based SEM involves various restraints regarding the distributional properties (multivariate normality), measurement level, sample size, model complexity, identification, and factor indeterminacy (Fornell and Bookstein 1982).

Essentially, PLS path modeling allows for the conceptualization of higher-order factors through the repeated use of manifest variables (Guinot et al. 2001; Tenenhaus et al. 2005). A higher-order factor thus can be created by specifying a latent variable that represents all the manifest variables of the underlying lower-order factors. This approach easily can be 
extended to higher-order factors as well and therefore we have employed this approach to empirically test our higher-order model.

\subsubsection{Measurement Model}

We used PLS Graph 3.0 (Chin 2001) to estimate the parameters in the hierarchical and substantive models with PLS estimation. To assess the psychometric properties of the measures, we initially specified a null model for the first-order constructs, in which we included no structural relationships. To assess the reliability of the measures, we calculated the composite scale reliability (CR, Fornell and Larcker 1981) and average variance extracted (AVE, Fornell and Larcker 1981). For the first-order factors CR exceed 0.70, and the AVE of all measures compellingly exceeds the cut-off value of 0.50 proposed by Fornell and Larcker (Fornell and Larcker 1981) (see table 3-4). In addition, the CRs and AVE of the measures in the second-, third-, and fourth-order models also offer CRs equal to or greater than 0.80 and AVE greater than 0.65 , which provides evidence of reliable measures (see table 3-4). 
Table 3-4: Experiential value: psychometric properties for first-order constructs

\begin{tabular}{|c|c|c|c|c|}
\hline Construct & Item & Loading & CR & $A V E$ \\
\hline \multicolumn{5}{|c|}{ EXPERIENTIAL VALUE (Mathwick et al. 2001) } \\
\hline \multirow[t]{3}{*}{ Visual appeal } & 1 The way $X$ displays its products is attractive & 0.82 & 0.90 & 0.75 \\
\hline & $2 \mathrm{X}$ 's Internet site is aesthetically appealing & 0.88 & & \\
\hline & 3 I like the way X's Internet site looks & 0.90 & & \\
\hline \multirow{3}{*}{$\begin{array}{l}\text { Entertainment } \\
\text { value }\end{array}$} & 1 I think X's Internet site is very entertaining & 0.79 & 0.88 & 0.70 \\
\hline & $\begin{array}{l}2 \text { The enthusiasm of X's Internet site is catching, it picks } \\
\text { me up }\end{array}$ & 0.88 & & \\
\hline & $3 \mathrm{X}$ doesn't just sell products - it entertains me & 0.84 & & \\
\hline \multirow[t]{3}{*}{ Escapism } & $\begin{array}{l}1 \text { Shopping from X's Internet site "gets me away from it } \\
\text { all" }\end{array}$ & 0.76 & 0.85 & 0.65 \\
\hline & $\begin{array}{l}2 \text { Shopping from X makes me feel like I am in another } \\
\text { world }\end{array}$ & 0.80 & & \\
\hline & $\begin{array}{l}3 \text { I get so involved when I shop from } X \text { that I forget } \\
\text { everything else }\end{array}$ & 0.85 & & \\
\hline \multirow[t]{2}{*}{ Intrinsic enjoyment } & $\begin{array}{l}1 \text { I enjoy shopping from X's Internet site for its own } \\
\text { sake, not just for the items I may have purchased }\end{array}$ & 0.88 & 0.87 & 0.76 \\
\hline & $\begin{array}{l}2 \text { I shop from X's Internet site for the pure enjoyment of } \\
\text { it }\end{array}$ & 0.87 & & \\
\hline \multirow[t]{2}{*}{ Excellence } & 1 When I think of $X, I$ think of excellence & 0.87 & 0.86 & 0.76 \\
\hline & $2 I$ think of $X$ as an expert in the merchandise it offers & 0.87 & & \\
\hline \multirow[t]{3}{*}{ Efficiency } & $\begin{array}{l}1 \text { Shopping from } X \text { is an efficient way to manage my } \\
\text { time }\end{array}$ & 0.80 & 0.84 & 0.64 \\
\hline & 2 Shopping from X's Internet site makes my life easier & 0.78 & & \\
\hline & 3 Shopping from X's Internet site fits with my schedule & 0.82 & & \\
\hline \multirow[t]{3}{*}{ Economic value } & $1 \mathrm{X}$ products are a good economic value & 0.81 & 0.87 & 0.67 \\
\hline & 2 Overall, I am happy with X's prices & 0.87 & & \\
\hline & $\begin{array}{l}3 \text { The prices of the product(s) I purchased from X's } \\
\text { Internet site are too high, given the quality of the } \\
\text { merchandise }\end{array}$ & 0.80 & & \\
\hline \multicolumn{5}{|c|}{ E-LOYALTY (Srinivasan et al. 2002) } \\
\hline \multirow[t]{3}{*}{ Attitudinal loyalty } & $1 \mathrm{I}$ like using this website & 0.73 & 0.85 & 0.66 \\
\hline & $\begin{array}{l}2 \text { To me this is the best retail website to do business } \\
\text { with }\end{array}$ & 0.84 & & \\
\hline & 3 I believe that this is my favorite retail website & 0.87 & & \\
\hline \multirow[t]{3}{*}{ Behavioral loyalty } & 1 I seldom consider switching to another website & 0.82 & 0.82 & 0.61 \\
\hline & $\begin{array}{l}2 \text { As long as the present service continues, I doubt that } \\
\text { I would switch to another website }\end{array}$ & 0.78 & & \\
\hline & $\begin{array}{l}3 \text { I try to use this website whenever I need to make a } \\
\text { purchase }\end{array}$ & 0.74 & & \\
\hline
\end{tabular}

Notes: $\alpha$ = coefficient alpha; $C R=$ composite reliability; and AVE = average variance extracted.

Moreover, as we show in table 3-5, the square root of the AVE exceeds the intercorrelations of the construct with the other constructs in the model, in support of discriminant validity (Fornell and Larcker 1981). 
Table 3-5: Experiential value: intercorrelations

\begin{tabular}{llllllllll} 
Construct & 1. & 2. & 3. & 4. & 5. & 6. & 7. & 8. & 9. \\
\hline 1. Visual appeal & 0.87 & & & & & & & & \\
2. Entertainment & 0.65 & 0.84 & & & & & & & \\
3. Escapism & 0.31 & 0.62 & 0.81 & & & & & & \\
4. Enjoyment & 0.27 & 0.57 & 0.70 & 0.87 & & & & & \\
5. Excellence & 0.59 & 0.56 & 0.37 & 0.38 & 0.87 & & & & \\
6. Efficiency & 0.32 & 0.26 & 0.21 & 0.20 & 0.46 & 0.80 & & & \\
7. Economic value & 0.34 & 0.21 & 0.05 & -0.03 & 0.41 & 0.32 & 0.82 & & \\
8. Attitudinal loyalty & 0.62 & 0.56 & 0.49 & 0.42 & 0.63 & 0.43 & 0.34 & 0.81 & \\
9. Behavioral loyalty & 0.34 & 0.41 & 0.45 & 0.34 & 0.43 & 0.35 & 0.32 & 0.63 & 0.78
\end{tabular}

Notes: Square root of the AVE on the diagonal.

\subsubsection{Test of higher-order model}

We used nonparametric bootstrapping as implemented in PLS Graph 3.0, with 500 replications and individual sign preprocessing (Chin 2001) to obtain estimates for the standard errors of the estimates of parameters in the measurement (outer) model and the structural (inner) model (hierarchical and substantive model). The loadings of the first-order factors on the second-order factors exceed 0.8 (aesthetics: 0.91 [visual appeal] and 0.91 [entertainment]; playfulness: 0.95 [escapism] and 0.90 [enjoyment]; CROI: 0.81 [efficiency] and 0.83 [economic value]). Similarly, the loadings of the second-order factors on the thirdorder factors are equal to or exceed 0.80 . Finally, the loading of hedonic value on experiential value equals 0.926 , and the loading of utilitarian value on experiential value is 0.780 , in support of the fourth-order model of experiential value. Our results indicate that all loadings are significant at $\alpha=0.05$ (see table 3.6). 
Table 3-6: Experiential value: higher-order model

\begin{tabular}{|c|c|c|c|c|}
\hline \multicolumn{5}{|c|}{ Second-Order Model } \\
\hline & Aesthetics & Playfulness & $\begin{array}{l}\text { Service } \\
\text { Excellence }^{b}\end{array}$ & Customer ROI \\
\hline $\begin{array}{l}\text { CR } \\
\text { AVE }\end{array}$ & $\begin{array}{l}0.92 \\
0.86\end{array}$ & $\begin{array}{l}0.92 \\
0.86\end{array}$ & $\begin{array}{l}\text { n.a. } \\
\text { n.a. }\end{array}$ & $\begin{array}{l}0.80 \\
0.67\end{array}$ \\
\hline $\begin{array}{l}\text { Visual appeal } \\
\text { Entertainment } \\
\text { Escapism } \\
\text { Enjoyment } \\
\text { Efficiency } \\
\text { Economic value }\end{array}$ & $\begin{array}{l}0.91^{* *} \\
0.91^{* *}\end{array}$ & $\begin{array}{l}0.95^{\star *} \\
0.90^{* *}\end{array}$ & $\begin{array}{l}\text { n.a. } \\
\text { n.a. } \\
\text { n.a. } \\
\text { n.a. } \\
\text { n.a. } \\
\text { n.a. }\end{array}$ & $\begin{array}{l}0.81^{\star *} \\
0.83^{\star \star}\end{array}$ \\
\hline \multicolumn{5}{|c|}{ Third-Order Model } \\
\hline & $\begin{array}{l}\text { Hedonic } \\
\text { Value }\end{array}$ & $\begin{array}{l}\text { Utilitarian } \\
\text { Value }\end{array}$ & & \\
\hline $\begin{array}{l}\text { CR } \\
A V E\end{array}$ & $\begin{array}{l}0.86 \\
0.76\end{array}$ & $\begin{array}{l}0.86 \\
0.76\end{array}$ & & \\
\hline $\begin{array}{l}\text { Aesthetics } \\
\text { Playfulness }\end{array}$ & $\begin{array}{l}0.90^{* *} \\
0.84^{* *}\end{array}$ & & & \\
\hline $\begin{array}{l}\text { Excellence } \\
\text { Customer return } \\
\text { on investment }\end{array}$ & & $\begin{array}{l}0.80^{\star *} \\
0.94^{\star *}\end{array}$ & & \\
\hline
\end{tabular}

\section{Experiential}

Value

Fourth-Order Model

$\begin{array}{ll}\text { AVE } & 0.93 \\ C R & 0.78\end{array}$

Hedonic value $\quad 0.93^{* *}$

Utilitarian value $\quad 0.78^{* *}$

\footnotetext{
${ }^{* *} p<0.01$

b Service excellence is specified as a first-order factor in the null- model. However, in the hierarchical model, service excellence constitutes second-order factor.
}

\subsubsection{Summary}

We assessed website visitors' perceptions of utilitarian and hedonic value with Mathwick et al.'s (2001) experiential value scale. However, so far Mathwick et al. (2001) only theoretically supported that experiential value comprised the underlying dimensions utilitarian and hedonic value. Consequently, we empirically tested and found empirical evidence for a higher-order model of experiential value emphasizing its utilitarian and hedonic value components. 


\subsection{Measurement development e-loyalty}

In the previous section we have focused on the measurement development of utilitarian and hedonic value, which from a structuration perspective represent customer goals. In this section, we will focus on the development of a measure representing a company goal eloyalty.

\subsubsection{Conceptualizaton}

The importance of loyalty in an online context is supported by the common knowledge that a decrease in customer switching creates value for companies in terms of higher revenues and lower costs (Keaveney and Parthasarathy 2001; Zeithaml et al. 2000). For example, in terms of revenues, loyal customers will be inclined to attract new customers through positive wordof-mouth, thereby increasing traffic on websites (Novak et al. 2000; Reichheld and Sasser 1990 ) and lowering marketing costs to acquire these new customers (Bolton and Bronkhorst 1995). Companies should exploit the interface to provide value to their customers ultimately leading to company value in terms of customers' e-loyalty (Payne and Frow 2005).

So far, most research on e-loyalty has only focused on the attitudinal and behavioral dimensions of loyalty (e.g. Srinivasan et al. 2002). Yet, Harris and Goode (2004) developed a measure of e-loyalty in an online retailing context based on the four stages loyalty framework as initiated by (Oliver 1997). Nevertheless, in our opinion their conative loyalty stage measures the superiority of the website instead of behavioral intentions, while the action loyalty stage reflects in fact more behavioral intentions than real behavior. As suggested by Harris and Goode (2004), we use the loyalty framework of Oliver (1997) to develop a scale for e-loyalty representing customer loyalty towards a website in an online services context. Moreover, based on the existing literature about both offline and online loyalty, we defined eloyalty and generated a set of items. In this research, e-loyalty is characterized as a belief reflecting a preference for a particular website (cognitive) that based on satisfied usage might lead to a favorable attitude towards a website (affective) resulting in behavioral intentions e.g. to recommend the website to others or visiting the website again (conative) and repeat actual behavior (action) (Anderson and Srinivasan 2003; Oliver 1999; Srinivasan et al. 2002). For the e-loyalty measure we used items from several existing loyalty scales (Mathwick et al. 2001; Srinivasan et al. 2002; Zeithaml et al. 1996) and we adapted these scales to ensure that they captured Oliver's loyalty phases (1999) in an online services context. However, we focused only on the first three stages of online loyalty, because it is hard to measure action loyalty with a scale. To measure action loyalty we need a more technical tool to gather clickstream data representing visitors' actual behavior at a website over time. 


\subsubsection{Qualitative pre-test}

In order to refine our e-loyalty scale, we first conducted a qualitative pre-test with five PhDstudents and one expert in marketing. We used a similar approach as in our qualitative pretest for the development of the interactional richness scale. Hence, the participants received a written document with the definitions of the dimensions of e-loyalty and the set of items. We asked participants to critically review these definitions and items and subsequently assign the items to the appropriate e-loyalty dimension(s). Participants could assign the items to more than one dimension and also to the category "other". After completing this assignment, respondents were asked whether there were items missing and whether they had suggestions for improvements concerning the formulation of items. We used the number of items that is "correctly" assigned to a dimension of e-loyalty as an indicator of discriminant validity. Moreover, we used the pattern of correct or incorrect assignment to assess which items might decrease content validity (De Wulf and Odekerken-Schröder 2003; De Wulf et al. 2001). An overview of the results of this assignment is provided in appendix E. Furthermore, respondents specified that items which referred to "I will" or "I intend" represented the intention loyalty stage. Whereas items stating "I like" and "it is pleasant" refer to the affective loyalty stage. In addition, respondents indicated that the cognitive loyalty stage was represented mainly by items stating "I belief, "first choice" or "preference".

\subsubsection{Quantitative test: Newspaper websites}

In order to refine the e-loyalty measure further, we incorporated the items of the preliminary e-loyalty scale of our qualitative pre-test in the second pilot test of the scale development procedure for interactional richness which was conducted in an online newspaper context (see appendix D). In this paper-and-pencil survey 184 business economic graduate students participated. Our e-loyalty measure was purified based on coefficient alpha and factor analysis. This resulted in a scale reduction from 31 to 14 items for e-loyalty (see table 3-7). Furthermore, we used PLS Graph 3.0 (Chin 2001) to estimate the parameters in the measurement model of e-loyalty.

We assessed convergent validity by examining the loadings of the measures on the respective constructs. The loadings were higher than 0.5 (Hulland 1999) except for one item of word-of-mouth, which was a reversed scale item. We decided not to delete this item yet, but to change the formulation of this item into "I do refer my acquaintances to this website" and incorporate it as such in our next study. Composite scale reliability ranged from 0.79 to 0.92 and exceeded the cut-off value of 0.7 (Fornell and Larcker 1981). Moreover, the average variance extracted was for all factors equal to or above the recommended cut-off value of 0.5 (Fornell and Larcker 1981). 
Table 3-7: E-loyalty: psychometric properties

\begin{tabular}{|c|c|c|c|c|}
\hline Construct ( $\alpha)$ & Item & Loading & $C R$ & AVE \\
\hline $\begin{array}{l}\text { Cognitive loyalty } \\
(0.877)\end{array}$ & $\begin{array}{l}\text { When I am searching for information about news events this } \\
\text { newspaper website is my first choice } \\
\text { When it comes to obtaining the latest news this newspaper } \\
\text { website is my first preference } \\
\text { I consider this online newspaper website my first choice to read } \\
\text { the news } \\
\text { In the future, this newspaper website is one of the first places I } \\
\text { will search when I want to read the latest news }\end{array}$ & $\begin{array}{l}0.87 \\
0.92 \\
0.84 \\
0.79\end{array}$ & 0.92 & 0.73 \\
\hline $\begin{array}{l}\text { Affective loyalty } \\
(0.678)\end{array}$ & $\begin{array}{l}\text { It is always a pleasant experience to visit this newspaper } \\
\text { website, that's why I continue to visit it } \\
\text { One of the reasons why I visit this newspaper website is because } \\
\text { I like it } \\
\text { I like visiting this newspaper website, and want to remain a visitor }\end{array}$ & $\begin{array}{l}0.81 \\
0.87 \\
0.81\end{array}$ & 0.87 & 0.69 \\
\hline $\begin{array}{l}\text { Word-of-Mouth } \\
(0.632)\end{array}$ & $\begin{array}{l}\text { I say positive things about this newspaper website to other } \\
\text { people } \\
\text { I recommend this newspaper website to anyone who seeks my } \\
\text { advice } \\
\text { I encourage friends to visit this newspaper website } \\
\text { I don't refer my acquaintances to this newspaper website* }\end{array}$ & $\begin{array}{l}0.80 \\
0.75 \\
0.76 \\
0.39\end{array}$ & 0.79 & 0.50 \\
\hline $\begin{array}{l}\text { Visit intention } \\
(0.712)\end{array}$ & $\begin{array}{l}\text { I intend to visit this newspaper website more in the next months } \\
\text { I will visit this newspaper website less in the next months } \\
\text { I intend to visit this newspaper website in the future }\end{array}$ & $\begin{array}{l}0.79 \\
0.76 \\
0.84\end{array}$ & 0.84 & 0.64 \\
\hline
\end{tabular}

Notes: $\alpha=$ coefficient alpha; $C R=$ composite reliability; and AVE = average variance extracted.

Furthermore, we found support for discriminant validity as the square root of the average variance extracted exceeds the intercorrelations of the constructs with the constructs in the model (see table 3-8).

Table 3-8: E-loyalty: intercorrelations

Construct

1. Cognitive loyalty

2. Affective loyalty

3. Word-of-Mouth

4. Visit intention
1.

0.86

0.37

0.43

0.42
2.

3.

4.

0.83

$0.45 \quad 0.69$

0.43

0.47

0.80

Notes: Square root of the AVE on the diagonal.

\subsubsection{Summary}

Based on existing (e-)loyalty scales and in line with Oliver's (1997) loyalty stages we develop a measure for e-loyalty representing customer loyalty towards a website in an online services context. Our loyalty scale consists of cognitive loyalty, affective loyalty, word-of-mouth and visit intentions. Word-of-mouth and visit intentions are behavioral intentions which represent Oliver's conative loyalty stage. 


\subsection{Measurement development reflexivity}

In the previous two sections, we have focused on the development of measures which from a structuration perspective represent customer and company goals, correspondingly value and loyalty. In line with a structuration view, we propose that customers' characteristics such as reflexivity influence their goal fulfillment in terms of hedonic and utilitarian value as a result of their website visit. Hence, in this section we will purify a measure for individuals' reflexivity in an online context.

\subsubsection{Conceptualization}

The reflexivity scale was originally developed to capture reflexivity in a team context. However, this scale was not appropriate for reapplication in this website context as we measure reflexivity at an individual level with respect to the information search process online. Consequently, to develop a measure for reflexivity with regard to an individual's online information search process we adapted the team reflexivity scale (Schippers 2003). However, we only adopted the items related to evaluation/learning and neglected the items related to discussing processes as these were not relevant to an individual's online information search process.

\subsubsection{Qualitative pre-test}

After we adapted the items of Schippers' (2003) reflexivity scale to an individuals' online information search process, we conducted a qualitative pre-test with five international business students and five PhD-students in marketing. We asked the participants to critically evaluate our reflexivity scale. Based on their feedback some items were modified (see appendix F). Moreover, the respondents also indicated that some items were not representative for the reflexivity construct that we intended to measure e.g. "While searching for information online I will discuss the problems I discover with other people" and "While searching for information online I reflect on the question of whether a pattern can be discerned in events". Hence, these items were deleted. In addition, respondents also had their doubts about the items that referred to the influence of changes in the environment on their online information search process. However, we decided not to delete these items yet and as a result incorporated 16 items for reflexivity in the quantitative test.

\subsubsection{Quantitative test}

To further refine our reflexivity scale, we incorporated the preliminary scale of reflexivity in a study in an online mobile phone context with 103 participants and conducted an exploratory factor analyses. Based on the results of our exploratory factor analyses we could identify three main factors within the reflexivity scale; reflexivity before, reflexivity during and 
reflexivity after an individuals' online information search. In our research reflexivity is defined as an individuals' capacity to critically monitor and evaluate his/her own information search process while searching for information online. Consequently, we adopted only the items that referred to an individual's reflexivity while searching (during search), which resulted in our 3 item reflexivity scale (see table 3-9). The Cronbach's alpha of our 3-item reflexivity scale was 0.679. Next, we included our 3-item reflexivity scale in a second study in an online mobile phone context and found a Cronbach's Alpha of 0.698 in support of the internal consistency of the measure.

Table 3-9: Reflexivity: items

\begin{tabular}{ll}
\hline \multicolumn{3}{c}{ Reflexivity } \\
\hline $\begin{array}{l}\text { In general, while searching for information } \\
\text { online, I..... }\end{array}$ & $\begin{array}{l}\text { stop for a moment to assess whether I am } \\
\text { searching for the right information } \\
\text { examine the long-term consequences of my search } \\
\text { activities } \\
\text { question myself regularly what my information } \\
\text { needs are }\end{array}$ \\
\hline
\end{tabular}

Scores shown between parentheses are Cronbach's alphas

\subsubsection{Summary}

We adopted Schippers et al.'s (2003) team reflexivity scale and adapted it to an individual level referring to an individual's critical evaluation of his or her online information search process. Furthermore, we conducted both a qualitative and two quantitative tests to further refine our reflexivity measure, which ultimately resulted in a three-item reflexivity scale.

\subsection{Conclusion}

The objective of this chapter was the development of the constructs that represent the online reciprocal interaction process between websites and their visitors.

\subsubsection{Interactional richness}

We introduced interactional richness as a comprehensive measure that captures both media and information richness dimensions to assess visitor's perceptions of a website. Previous studies in an information system context did not make a clear distinction between information richness and media richness and even caused ambiguity because they used these two constructs interchangeably (Daft and Lengel 1986; Dennis and Valacich 1999). Barry and Crant (2000) were among the first authors who defined interactions in an organizational communication context as consisting of both information and media richness components. Recent studies in Management Information Systems literature (McKinney, Yoon and Zahedi (2002) and DeLone and McLean (2004) recognized that visitors' perceptions of a website are 
based on both media and information features. So far, most studies in the marketing literature focused only on the impact of individual website features e.g. interactivity on visitors' perceptions of the website. Only recently De Wulf et al (2006) integrated several website features such as content, organization and technology in a multi-dimensional construct for evaluating visitors' perceptions of the website. However, they only examined how visitors' evaluation of the website influenced their level of pleasure experienced at the website to the neglect of visitors' level of functionality experienced at the website. Rather than focusing on website features that contribute either to visitors' perceptions of utilitarian or hedonic value, we developed a measure that encompassed both media and information richness dimensions and that simultaneously related to both visitors' utilitarian and hedonic value perceptions.

From a scientific perspective, our conceptualization and development of our interactional richness construct comprehensively captured the full range of aspects involved in visitors' perceptions of a website and consequently paves the way for researchers that want to assess website visitors' evaluations of the online experience. So far, extant measures of the online interaction between websites and their visitors mainly focused on the responses and behavior of website visitors, to the neglect of the online interaction process itself. Hence, our measure of interactional richness contributes to the literature as it emphasizes the multidimensional nature of the online interaction process.

Moreover, from a managerial perspective, in order to become and stay successful online, managers must continuously monitor visitors' perceptions of their website and acknowledge the distinct and complementary roles of both media and information features at their websites. Our measure of interactional richness helps companies to identify which aspects of the website e.g. information content or website design need attention in order to enhance customers' evaluations of their online interaction experience.

\subsubsection{Utilitarian and hedonic value}

We proposed that the online value that website visitors perceive is a result of the online reciprocal interaction process between websites and their visitors and can be both utilitarian and hedonic in nature. This is in line with Hoffman and Novak (1996) who claimed that the recognition of both hedonic and utilitarian value is particularly important online. Moreover, similar to a seminal research in marketing Vargo and Lusch (2004) we recognize the role of website visitors in creating their own online experiences while interacting with the website. As we focused on website visitors' value perceptions of their online interaction experience, we employed Mathwick, Malhotra and Rigdon's (2001) experiential value scale as a basis for our measurement development of both utilitarian and hedonic value. Mathwick et al. (2001) conceptualized experiential value as a higher-order construct comprising both utilitarian and 
hedonic value dimensions. However, so far this higher-order model has only been partially tested in empirical research. Our results go beyond existing research and provide strong empirical support for a higher-order latent model that emphasizes the utilitarian and hedonic value components of the online experience. Moreover, recent literature stresses the importance of both hedonic and utilitarian value dimensions in an online context because both value dimensions might affect website visitors' responses differently (Chiu et al. 2004). However, existing measures of utilitarian and hedonic value (Babin et al. 1994) did not represent customers' complementary value perceptions of the online experience. Hence, our effort to develop an appropriate measure to evaluate website visitors' value perceptions of the online experience contributes to the existing online marketing literature as it emphasizes the important role of measuring both hedonic and utilitarian value dimensions of the online experience concurrently. By emphasizing both the hedonic and utilitarian aspects of the online interaction we provide a comprehensive view on website visitors' evaluations of the online experience.

From a managerial perspective, it is important to recognize that valuable interactions in an online environment consist of both fun and task-related dimensions. So far, practitioners focused most on delivering utilitarian value to their website visitors. However, nowadays consumers do not only visit a website to simply acquire information but also to entertain themselves. For instance, many people participate in second life as they simply enjoy it to have a different live in a virtual environment. Consequently, we argue that practitioners should take into consideration the complementary roles of both hedonic and utilitarian value in order to create a valuable online experience for their website visitors.

\subsubsection{E-loyalty}

We developed a comprehensive multi-dimensional measure of e-loyalty consisting of cognitive, affective and conative loyalty dimensions. In previous research, e-loyalty has only been divided in the rough dimensions of attitude and behavior (e.g. Srinivasan et al. 2002), which is in line with common offline measures of loyalty (e.g. Dick and Basu 1994). Recently, Harris and Goode (2004) adopted a more extensive four stages e-loyalty scale in line with the framework Oliver (1997) developed for an offline context. However, by carefully analyzing Harris and Goode's (2004) e-loyalty scale, it becomes apparent that their conative loyalty stage refers more to the superiority of the website than to behavioral intentions. In addition, Harris and Goode's (2004) action loyalty stage seems to represent behavioral intentions rather than actual behavior. These developments indicated that there is currently no e-loyalty scale available that clearly distinguishes between cognitive, affective, conative and action loyalty representations. In an online experience, we especially consider the distinction between beliefs about a website (cognition), liking of the website (affect), and the resulting 
intentions to visit a website (conation) of utmost importance to advance theory on e-loyalty and to provide practitioners with a detailed view of what constitutes visitors' loyalty towards a website. In the end, practitioners will be interested in actual behavior (action loyalty), but this cannot be measured by a scale, but needs a more technical tool to gather clickstream data over time. Therefore, we went back to Oliver's (1997) basis for the development of a sophisticated multi-dimensional e-loyalty construct in an online services context, explicating the refined distinctions between cognition, affect and conation. Our e-loyalty scale allows researchers and practitioners to gain a better insight in the contribution of the underlying eloyalty representations to the overall perceived loyalty towards a website. These insights help practitioners to identify whether attention should be paid to a change in beliefs, affect or intentions in order to realize customer loyalty online. Moreover, our loyalty scale can be used to segment different customer groups according to differences in their loyalty states.

\subsubsection{Reflexivity}

Our final contribution in this chapter on measurement development refers to the introduction of reflexivity in an online context, which measures an individual's evaluation of his/her own online information search process, while searching. So far, reflexivity has mainly been used in a team context to represent the extent to which a team reflects upon and modifies its functioning (Schippers 2003). In a marketing education context, reflexivity has been investigated and refers to "a questioning of what is learnt, and may include a search for alternative explanations" (Peltier et al. 2006 p.6 ). However, to the best of our knowledge, in the online interactive marketing literature, no attention has yet been given to the measurement of reflexivity or the possible impact of individuals' reflexivity on their evaluation of their online interaction process. We argue that reflexivity does play an important role in the online interaction experience, as this construct makes a distinction between website visitors who do explicitly evaluate their online information search process and visitors who do not, possibly resulting in differences in their perceptions of the online interaction experience. Therefore, we applied and refined Schippers' (2003) team reflexivity scale to an online context, resulting in a concise and context-specific measure for reflexivity. Consequently, our scale enables researchers to integrate reflexivity in studies on online experiences, focusing on possible differences between individuals due to their unique evaluation characteristic. By including reflexivity in research on online interactions, we stress that not only the characteristics of the website play a vital role in creating a valuable online experience but also unique characteristics of website visitors such as reflexivity. Practitioners might benefit from our reflexivity scale by using this scale for example as a filter question while entering a website, directing reflexive versus non-reflexive website visitors to a different version of the website. Visitors who tend to reflect upon their information search process might appreciate a 
site map showing them where they are in the website's structure, which enables them to get an overview of which pages they have visited and which pages they still can consult.

\subsubsection{Summary}

Summarizing, this study contributes to the knowledge of the online interaction process between websites and their visitors from a structuration perspective as we developed several measures that enable us to assess customers' evaluations of their online interaction experience. We first developed a measure for interactional richness to assess visitors' perceptions of a website. Second, we developed a measure to assess visitors' perceptions of utilitarian and hedonic value concurrently. Third, we purified a measure for website visitors' e-loyalty specifying the underlying phases: cognitive, affective and conative e-loyalty. Finally, we refined a measure for reflexivity. Both academia and practitioners are likely to benefit from the clearly defined constructs and robust measurement scales, which we developed in this study and subsequently will significantly aid studies on this important topic.

In study two (experiment), we will use the dimensions and items of our newly developed measure of interactional richness as a basis for the manipulation of both media and information richness features at a website. In addition, we will examine how the main and interaction effects of media and information richness influence website visitors' perceptions of utilitarian and hedonic value and ultimately their loyalty towards a website. Hence, we will also incorporate our newly developed measures of utilitarian value, hedonic value and eloyalty. 


\section{Chapter 4: Media Richness and Information Richness: Two Complementary Factors}

\subsection{Introduction}

After the development and refinement of measures to assess consumers' evaluation of the online experience, in this experimental research we employ the newly developed measure of interactional richness as the basis for the manipulation of website features. Although substantial research has examined the impact of different website features on consumers' attitude and behavior towards the website (e.g. De Wulf et al. 2006), existing research does not provide insights into the impact of different levels of both information and media richness on website visitors' perceptions of the online interaction experience. Consequently, in this study we develop an experimental design in an online mobile phone context (section 4.2). To be more specific, in line with domination structures, we manipulate both media and information features to create asymmetries in website characteristics, such as high and low levels of synchronicity and also manipulate website visitors' purpose to visit the website either to search or to browse (section 4.3). Our approach corresponds with domination structures of structuration theory, as we investigate how consumers draw on asymmetries in website features to fulfill their goals (value). In addition, we conduct an extensive qualitative research (section 4.4) and a quantitative pre-test experiment (section 4.5) to optimize the manipulation of potentially important website and information features, which will subsequently be tested in a full-factorial design (section 4.6). Next, we describe the results of our data analyses in section 4.7 , followed by a conclusion in section 4.8 .

\subsection{Research setting: Mobile phone website}

A frequent criticism of experimental research is that it employs situations that are far from reality or unlikely to be faced by average individuals (Runco and Sakamoto in Burroughs and Mick 2004). However, this is not the case for visiting a website about mobile phones as most people are familiar with both mobile phones and the Internet. Previous research suggested that future studies should strive to make the experimental conditions as real and as fully functional as possible. One way to do this is to conduct research in cooperation with existing firms that are already engaged in web related activities (Fortin et al. 2002). Therefore, we cooperated with Samsung which was willing to invite their website visitors to participate in our research. The Samsung Fun Club website (SFC) is a community site from Samsung Mobile, especially designed for customers of mobile phones. Customers can view information on Samsung mobile phones and related information on the SFC-website. Furthermore, they can subscribe as a member of the Samsung Fun Club website and get a personal login name and password. When registered, the members can download photos, screensavers and wallpapers and exchange their Samsung Fun Club credits. Credits are 
earned while visiting the website, playing online games or when sending an e-mail with product information to a friend (tell a friend). For instance, every login is worth one credit and 10 credits can be used to download a photo. In addition, Samsung Fun Club members also receive a monthly newsletter. For customers, the incentive to register at the Samsung Fun Club website is their interest in Samsung mobile phones and the desire to exploit the offered benefits. In addition, Samsung receives valuable information about their customers by means of membership observation and member feedback.

In our opinion, Samsung's Mobile Inc. Fun Club Website is very appropriate to use for this experiment for several reasons. First of all, Samsung's Fun Club Website encompasses both hedonic (games, ring tones downloads etc.) and utilitarian features (product comparisons, detailed product descriptions) which might fulfill different visitors' needs. Furthermore, Samsung Fun Club has a large database with registered visitors (members) who have visited the Samsung Fun Club Website before. Based on their experiences with the original Samsung Fun Club Website, members can give a critical evaluation of their experience with the manipulated website as they can objectively compare this website with the original SFC website.

\subsection{Experimental design}

We used the original Samsung Fun Club (SFC) website as the basis for the development of our experimental website. Three out of five categories of the website (fun, showroom and club) were incorporated in our experimental SFC website. The fun category consisted of ring tones, pictures and games. The category showroom provided information about mobile phones, user manuals and accessories. News and information about events related to the SFC website were presented in the club category. Due to technical reasons, we excluded the two other categories personal and messages from our experimental SFC website. The category personal is related to an individual's Samsung Fun Club membership and provides, for example, information about a SFC member's credit account. The category messages, offers members possibilities to communicate with others via e-cards and SMS. Moreover, we also excluded a feature within the category showroom that automatically compared different types of Samsung mobile phones because of technical reasons. Furthermore, we left out the phone reviews (category showroom) as this feature was hardly used by SFC members. In addition, we did not provide information about all 30 Samsung mobile phones that were available at that time, but we limited ourselves to 10 different Samsung mobile phones.

\subsubsection{Manipulation media richness and information richness}

The underlying dimensions of interactional richness, media and information richness, were employed as a basis for the manipulation of our SFC-website. Media and information 
richness can both be conceptualized on a continuum from high to low. In order to create these two different levels of media and information richness (low versus high), we manipulated website features related to both media and information richness on each subpage of our SFC website. For example, text only presentation is a characteristic of low media richness, while multimedia presentations integrating pictures, video, sound and 3-d product visualizations are characteristics of high media richness. The two levels of information richness were operationalized, focusing on the relevance, accuracy, comprehensiveness and comprehensibility of the information. In the low information richness condition, the amount of information was limited, irrelevant, not correct or not understandable. For example, links to the wrong information content, spelling mistakes, parts of the information presented in a different language e.g. Chinese, incomplete information etc. The manipulation of both low and high levels of media and information richness resulted in four different versions of our experimental Samsung Fun Club website (2*2; low media-low info, low media- high info, high media-low info, high media - high info). The low media-low information richness website and the high media-high information richness website are illustrated in figure 4-1and figure 4-2. 


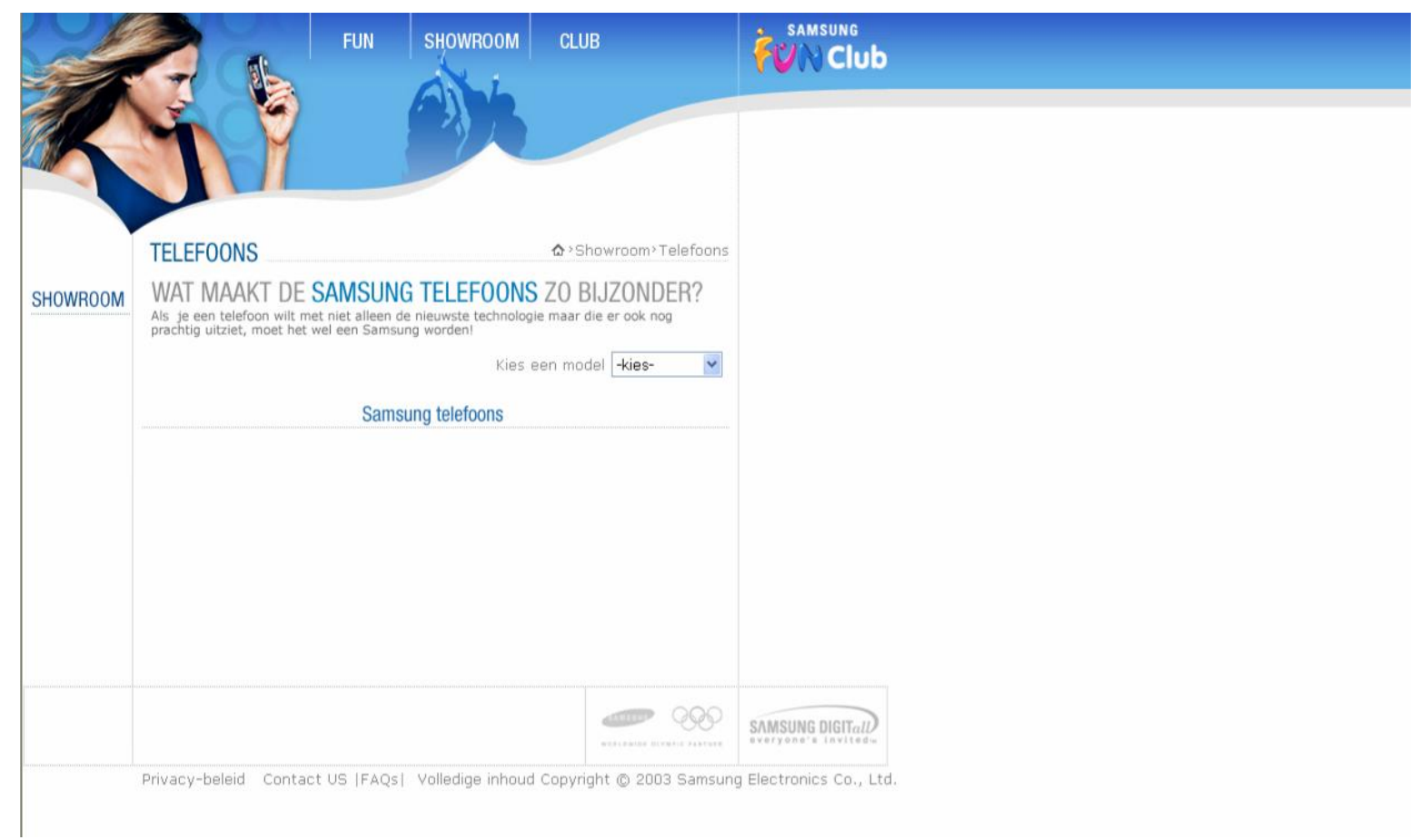

Figure 4-1: Low media richness / low information richness website

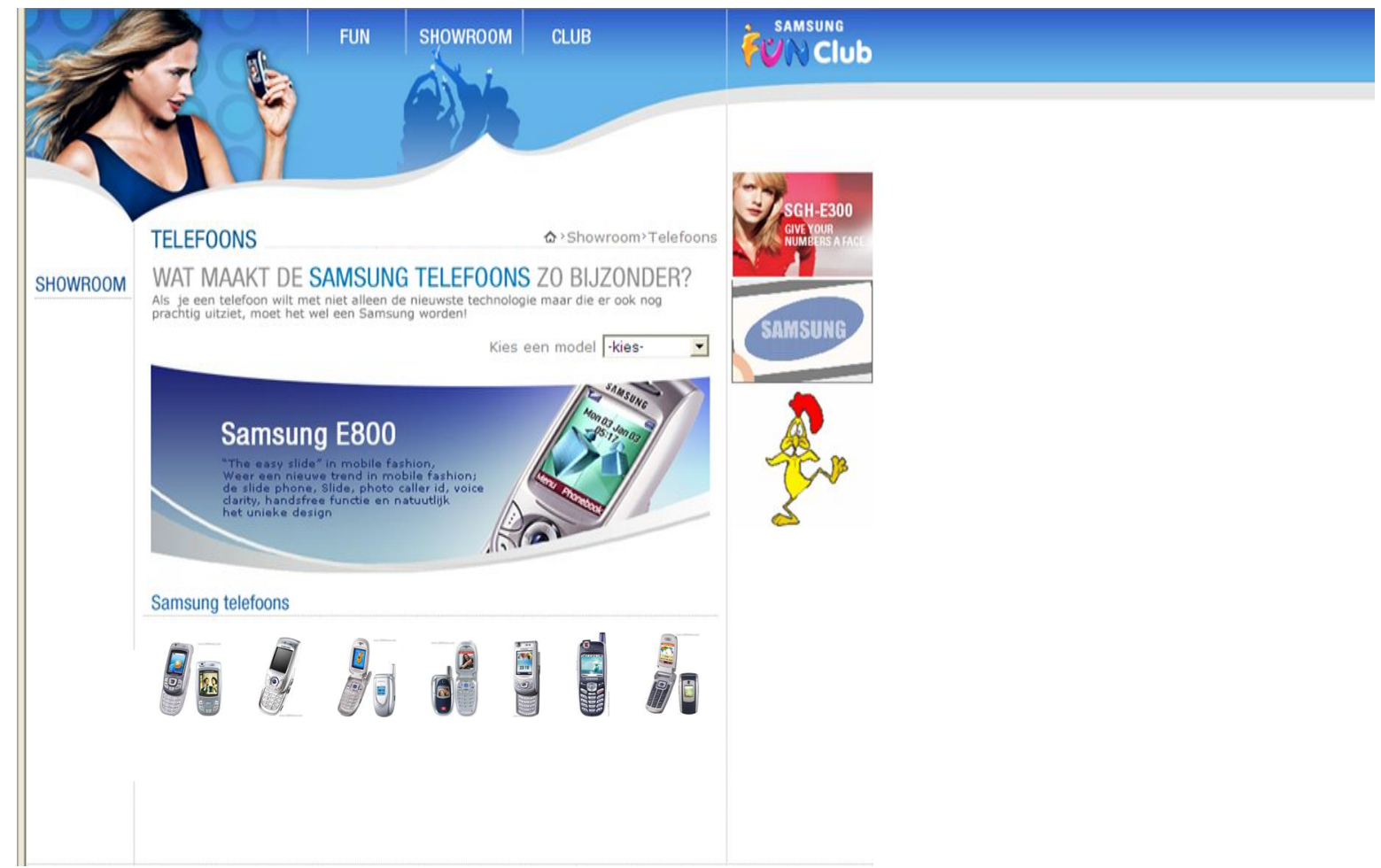

Figure 4-2: High media richness / high information richness website 


\subsubsection{Manipulation purposeful behavior}

In addition to the manipulation of media richness and information richness, the underlying dimensions of interactional richness, we also manipulated website visitors' purposeful behavior. In line with structuration theory, we propose that purposeful behavior ranges from non-purposeful to purposeful behavior respectively browse or search behavior. We manipulated purposeful behavior by giving participants a task to either search or browse the experimental SFC website. Participants assigned to the search scenario were asked to imagine that they needed a new mobile phone because their own mobile phone was broken. They were instructed to visit the Samsung Fun Club website with the goal of efficiently finding a mobile phone with four specific characteristics; low weight, high standby time, a photo-camera and a TFT color screen (see appendix G). These specific attributes were chosen based on the features of the Samsung mobile phones which were incorporated in our research (see table 4-1).

Table 4-1: Samsung mobile phones included in our research

\begin{tabular}{llccc}
\hline Standby-time (hours) & $\begin{array}{c}\text { Photo } \\
\text { camera }\end{array}$ & TFT-screen & $\begin{array}{c}\text { Weight } \\
\text { (grams) }\end{array}$ \\
\hline E310 & $160-220$ & yes & no & 85 \\
E810 & 150 & yes & yes & 85 \\
E820 & 130 & yes & yes & 85 \\
E300 & 150 & yes & no & 85 \\
Z105 & $176+217$ (\&extra 254+314) & yes & yes & 130 \\
D410 & 130 & yes & yes & 85 \\
E100 & $160-250$ & yes & yes & 116 \\
X600 & 200 & no & yes & 80 \\
E700 & $160-360$ & yes & no & 80 \\
E700 & 230 & yes & yes & 88 \\
& & & & \\
\hline
\end{tabular}

Furthermore, those assigned to the browse scenario, were asked to imagine that a friend had made them curious about the Samsung Fun Club website. Moreover, they were instructed to have fun and look at whatever they considered interesting and/or entertaining at the Samsung Fun Club website (see appendix G).

So, this manipulation of the purposeful behavior (search or browse) together with the manipulations of media richness and information richness resulted in eight different experimental conditions (see figure 4-3). 


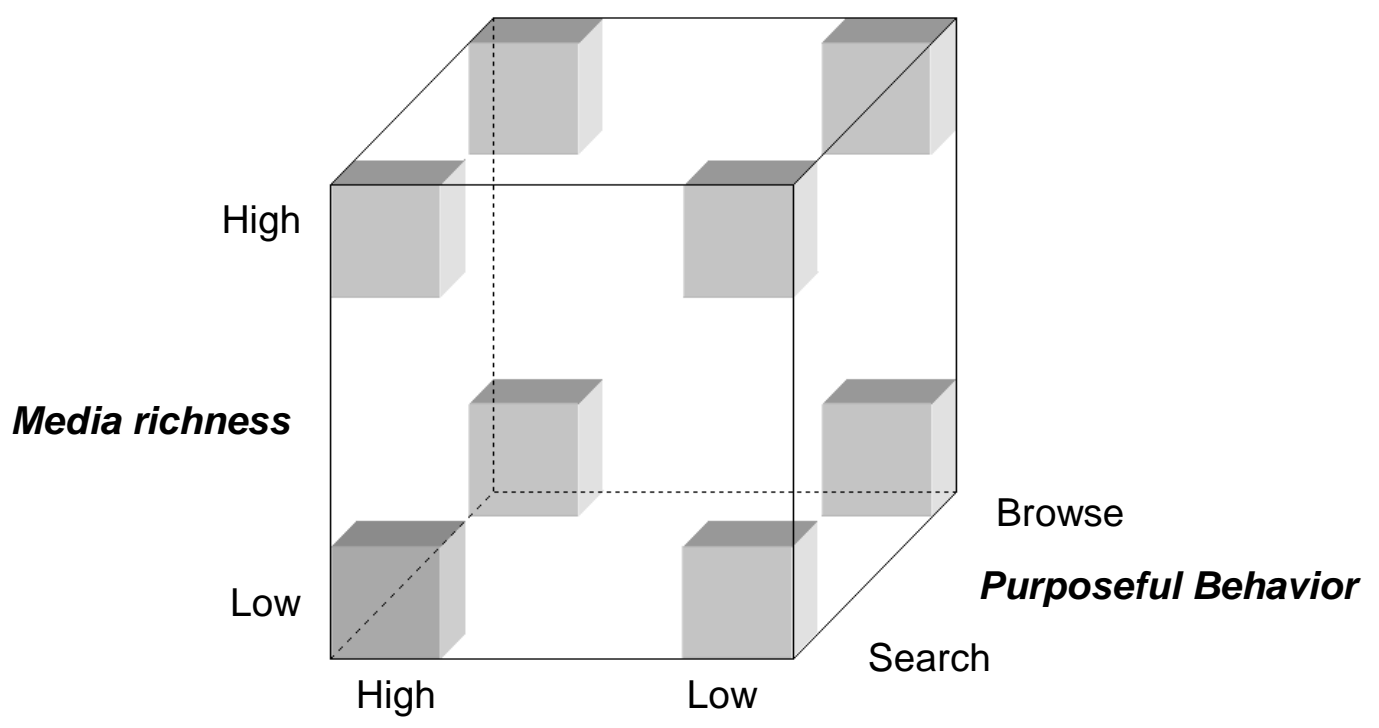

Information richness

Figure 4-3: Manipulations experiment $\left(2^{*} 2^{\star} 2\right)$

\subsection{Qualitative pre-test experimental design}

Twenty-two Master of Science students participated in the qualitative pre-test. Respondents qualified if they were experienced internet and mobile phone users. The goal of this qualitative pre-test was to check whether the stimulus materials were unambiguous and realistic. First, respondents were asked to read one of the two scenarios that described either a task to search for specific information or to browse at the experimental website. With this task in mind, they visited one of the four websites at which website and information features were manipulated. An experienced interviewer observed the respondents while visiting the website and asked them to say out loud what they did and why. Moreover, the interviewer asked respondents what their impression of the website was and which aspects of the website they considered good or bad. For instance, respondents with a task to search indicated that a disadvantage across all the different experimental SFC websites was that it lacked a tool which facilitated a direct comparison of different types of Samsung mobile phones. Moreover, respondents in high media richness situations indicated that they liked the pictures, ring tones, videos and the virtual reality tool to look at the phone from different sides. In contrast, respondents in the low media richness missed the pictures of the mobile phones and the option to listen to ring tones. Furthermore, respondents in the low information richness situation indicated that the provided information was often not complete or incorrect. Respondents' feedback helped to improve the selection and manipulation of appropriate website and information features in the subsequent full-factorial design. Second, 
respondents were asked to pre-test the written questionnaire including measures for utilitarian and hedonic value, reflexivity, e-loyalty and socio-demographic factors. Based on their qualitative feedback problematic instructions and items were reformulated. This qualitative pre-test was conducted in-person at the University and lasted approximately 45 minutes per individual test.

\subsection{Quantitative pre-test experimental design}

After the qualitative pre-test, the purpose of the quantitative pre-test was first to verify that the experimental procedure, instructions and questions were clear and understood. Second, we employed this quantitative pre-test to empirically check the effectiveness of the manipulations for all levels of media and information richness and purposeful behavior.

\subsubsection{Procedure}

Participants were invited to take part in the quantitative pre-test through an e-mail that was sent to members of an online University panel. Although these respondents were most likely not a member of the Samsung fun Club, which would be the focus in the ultimate experiment, they are appropriate to invite for participation in this research as they generally tend to be familiar with the internet and mobile phones. To encourage participation, a scratch-ticket and a prize draw for three MP3-players was offered as an incentive to each respondent that completed the questionnaire. Participants could access the research by clicking on an embedded URL link in the invitation e-mail. The participants were first shown an introduction page. This page provided respondents with an outline of the different parts of the research and some instructions. The research consisted of four parts: survey I, scenarios, website visit and survey II. Consumer characteristics were measured in survey I and perceptions of the online experience, attitudes and intentions were measured in survey II. Measures of realism and purposeful behavior at the website were used as manipulation checks in the pre-test so that corrections to the stimulus material could be made before the final experiment was conducted.

\subsubsection{Sample profile}

The effective sample size of the quantitative pre-test was 103 respondents (see table 4-2). The sample was almost equally divided between males (52.4\%) and females (47.6\%). Most of the respondents were between 21-30 years old (68\%), $22.3 \%$ were younger than 21 years old $3.9 \%$ were between $31-40$ years old and $5.8 \%$ were older than 40 . Moreover, most respondents were students (68.9\%) and $23.3 \%$ of the respondents was employee, 3.9 $\%$ were employer and $3.9 \%$ were unemployed. Additionally, $19.4 \%$ of the respondents used the internet about once a day and $77.7 \%$ several times a day. Only $1 \%$ uses the Internet a 
few times a month and $1.9 \%$ a few times per week. The time spent online per visit varied; $21.4 \%$ of the respondents spent on average 16-30 minutes per visit online, 38.8 \% 31-60 minutes, $30.1 \%$ more than an hour, $8.7 \%$ between $5-15$ minutes and only $1 \%$ less than 5 minutes.

Table 4-2: Sample profile: quantitative pre-test experimental design

\begin{tabular}{|c|c|}
\hline $\mathrm{N}=103$ & Percentage (\%) \\
\hline \multicolumn{2}{|l|}{ Gender } \\
\hline Male & 52.4 \\
\hline Female & 47.6 \\
\hline \multicolumn{2}{|l|}{ Age } \\
\hline$<21$ years & 22.3 \\
\hline 21-30 years old & 68.0 \\
\hline $31-40$ years old & 3.9 \\
\hline$>40$ years & 5.8 \\
\hline \multicolumn{2}{|l|}{ Education } \\
\hline Primary school & 2.9 \\
\hline Secondary school & 50.5 \\
\hline Intermediate vocational education & 5.8 \\
\hline Higher vocational education & 20.4 \\
\hline University & 20.4 \\
\hline Other & 0 \\
\hline \multicolumn{2}{|l|}{ Profession } \\
\hline Students & 68.9 \\
\hline Employee & 23.3 \\
\hline Employer & 3.9 \\
\hline Housewife/men & 0 \\
\hline Unemployed & 3.9 \\
\hline \multicolumn{2}{|l|}{ Frequency of Internet use } \\
\hline Never/almost never & 0 \\
\hline Less than once a month & 0 \\
\hline A few times a month & 1.0 \\
\hline A few times a week & 1.9 \\
\hline About once a day & 19.4 \\
\hline Several times a day & 77.7 \\
\hline \multicolumn{2}{|l|}{ Duration of session at the Internet } \\
\hline Less than 5 minutes & 1.0 \\
\hline 5 to 15 minutes & 8.7 \\
\hline 16 to 30 minutes & 21.4 \\
\hline 31 minutes to 1 hour & 38.8 \\
\hline More than 1 hour & 30.1 \\
\hline
\end{tabular}

\subsubsection{Manipulation checks}

We included some measures in our questionnaire to check the realism of the task descriptions (scenarios), website visitors' purposeful behavior and the manipulation of the website features. We employed Dabholkar and Bagozzi's (2002) two item realism check scale as a basis. In addition, we added two other items as we wanted to stress both that the described situation was realistic but also that participants were able to imagine themselves in 
this situation. Hence, the realism of the scenarios was assessed with four items; "The task was clear to me", "I could easily imagine the described situation", "The situation described was realistic" and "I had no difficulty imagining myself in the situation". These four items had a scale reliability of .90 (Cronbach alpha) and were averaged to form a composite score. This realism check showed that the scenarios were considered highly realistic, with a rating of 6.42 on a scale of 1 to 7 . Moreover, the manipulation check for purposeful behavior at the website was measured on a 7 -point Likert scale $(1=$ strongly disagree and $7=$ strongly agree $)$ and stated "I was searching for something specific during my website visit". This item showed a significant difference between respondents that had a task to search ( $\mu=4.84, N=63$ ) and those who had to browse $(\mu=2.73, N=40, p=.000$ ). Although respondents visited different websites (either high or low information/media richness), there was no significant difference in their grading of the website on a scale from 1 (lowest) to 10 (highest). These results indicated that we should modify the manipulations of the website for our main betweensubject experimental design.

\subsubsection{Summary}

The results of the manipulation checks of this quantitative pre-test of our experimental design indicated that respondents considered the scenarios as highly realistic. Moreover, the manipulation check for purposeful behavior also showed a significant difference between respondents with a task to search or to browse. Furthermore, we did not find a significant difference in respondents' grading of the website, although they visited websites that varied in level of media or information richness. Consequently, for the main between-subject experiment, we modified the manipulations of media and information richness at the experimental Samsung Fun Club website, which we will describe in detail in section 4.6.1.1.

\subsection{Main between-subject experimental design}

To test our hypotheses, we finally conducted a web-based experiment in which two levels of media richness (low vs. high), two levels of information richness (low vs. high) and the motivation to gather information (search vs. browse) were manipulated employing a $2{ }^{*}{ }^{*} 2$ between-subjects factorial design with real members of the Samsung Fun Club.

\subsubsection{Experimental design}

Based on the results of the qualitative and quantitative pre-test of our experimental design we modified our experimental design before we conducted the main between-subject experimental design. 


\subsubsection{Manipulation media and information richness}

The results of the website manipulation check in the quantitative pre-test of the experiment demonstrated that there was no significant difference in the grading of the website of participants that visited one of the four different versions of the website. Consequently, we modified the manipulations of the website by adapting the low information richness situations by providing even more incorrect, irrelevant and incomplete information. For instance, we exchanged the information of particular types of mobile phones, provided information about the weather etc. Furthermore, we modified the low media richness situations by providing even less pictures and clickable links.

In addition, we included in the high media richness situations a virtual personality in order to enhance website visitors' perceptions of media richness (see figure 4-4). Website visitors could ask this virtual personality questions via normal sentences so not via search terms or key words. The virtual personality immediately provided answers in written text and was able to answer one question at a time, representing synchronicity. Thus, the virtual personality did not simply refer to another part of the website. If a website visitor asked for example: "Which Samsung mobile phone has a photo-camera?" The virtual personality answered: "With one of the following mobile phones with photo-camera, you can make everywhere the most beautiful pictures: e310, e810, e820, e300, z105, e800, d410, x600 and e700. Click on one of these phones if you would like to have more information about one of these specific mobile phones with photo-camera".

Moreover, we varied the content of the dialog script of the virtual personality for situations either low or high in information richness. In the low information richness situation the virtual personality provided wrong, irrelevant, incomprehensible or incomplete answers. For instance, if a website visitor asked "Which Samsung mobile phones have a low weight? The virtual personality answered: "I am as light as a feather, because I am virtual". The answer of the virtual personality to the similar question in the high information situation was "The Samsung mobile phones are extremely light because of recent innovations. The following phones are really lightweights as they weight less than 100 grams; e310, e810, e820, e300, e800, e100, x600 and e700". 


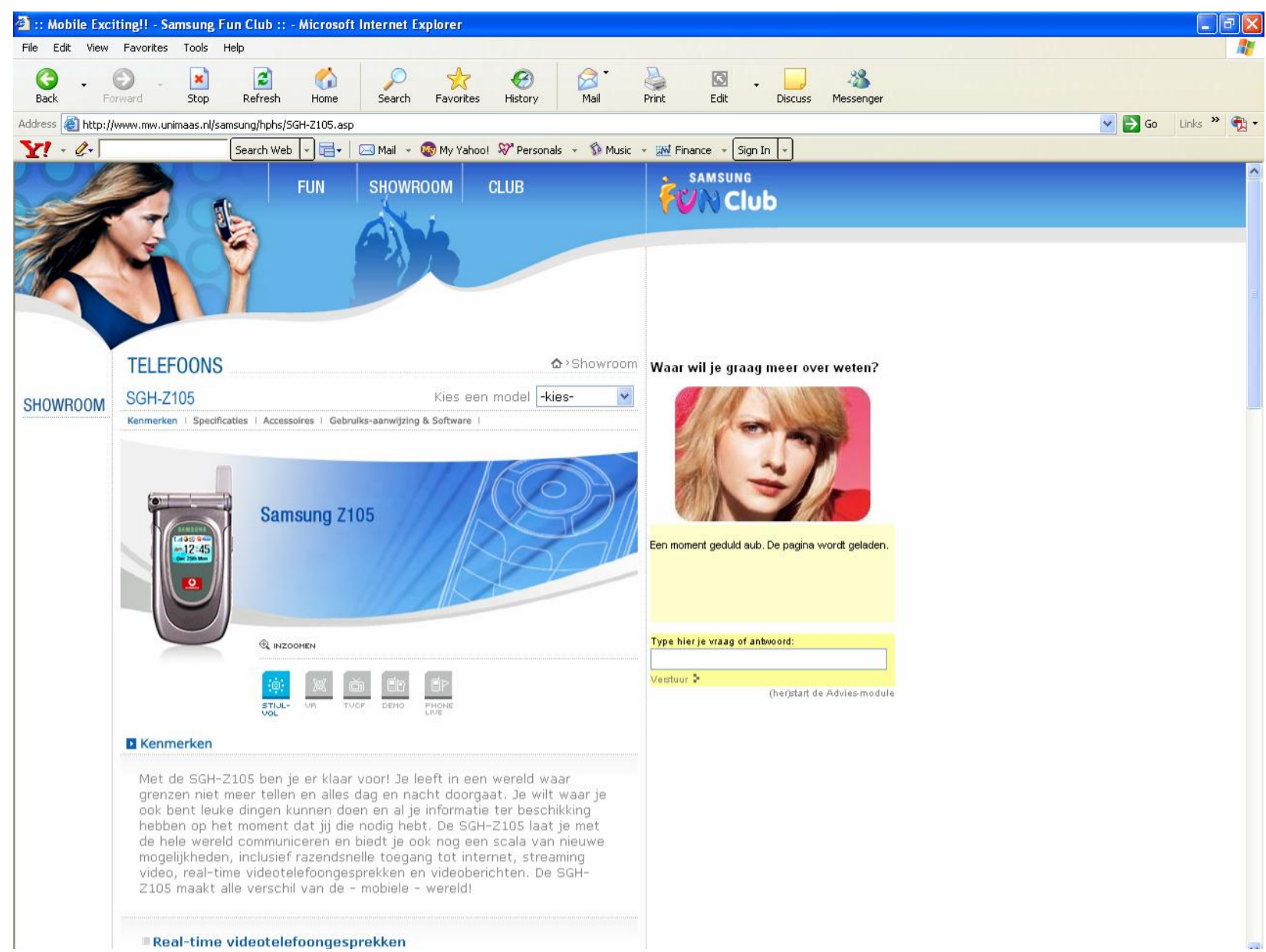

Figure 4-4: High media richness website with virtual personality

\subsubsection{Manipulation purposeful behavior}

As the results of the qualitative and quantitative pre-test indicated that the manipulations of purposeful behavior were unambiguous, we did not make any changes in the descriptions of the search or browse task. We incorporated Hitbox, a web analytics tool, in our experimental design. HitBox (HBX) is a comprehensive web analytics tool that delivers insight into visitors' behavior at a website. To be more specific, HBX provides detailed information about how website visitors are navigating and what content and products they are interested in at the website. We applied this web analytics tool to check whether visitors' actual behavior at the website indeed differed for participants that had a task either to search or to browse. This information about website visitors' actual online behavior was supplementary to the information about website visitors' purposeful behavior retrieved from the manipulation checks in the questionnaire. 


\subsubsection{Procedure}

The procedure was comparable to that employed in the pre-test. Via a newsletter, e-mail registered visitors (i.e., members) of the Samsung Fun Club were invited to participate in this online research. In addition, a banner at Samsung's Fun Club homepage invited website visitors to participate (see figure 4-5). Subjects could participate by simply clicking on a link to the starting page of the research (see figure 4-6). However, they were asked to register first to be eligible for the Samsung Fun Club credits that they could earn with their participation in the online research.

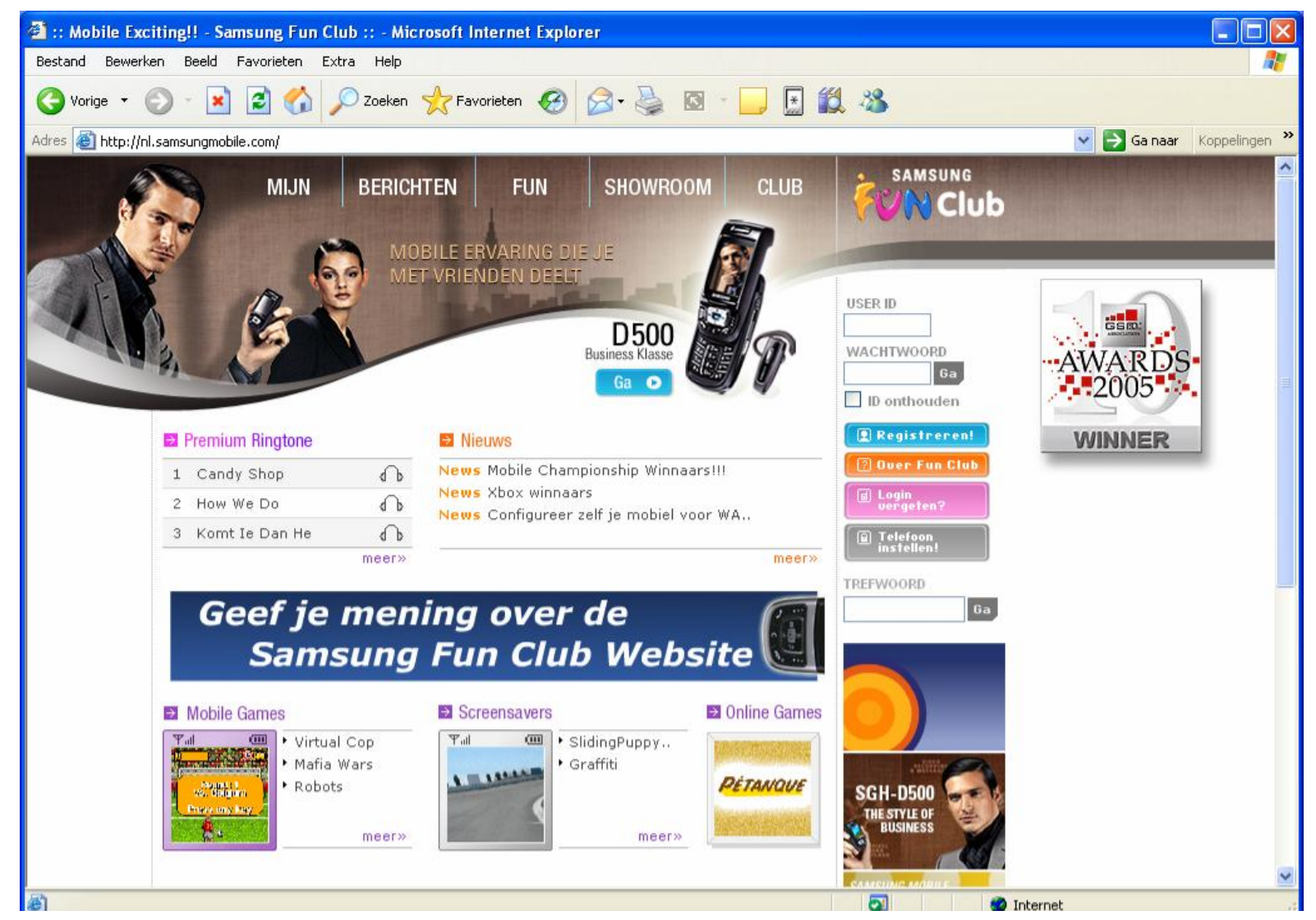

Figure 4-5: Banner invitation to the research 


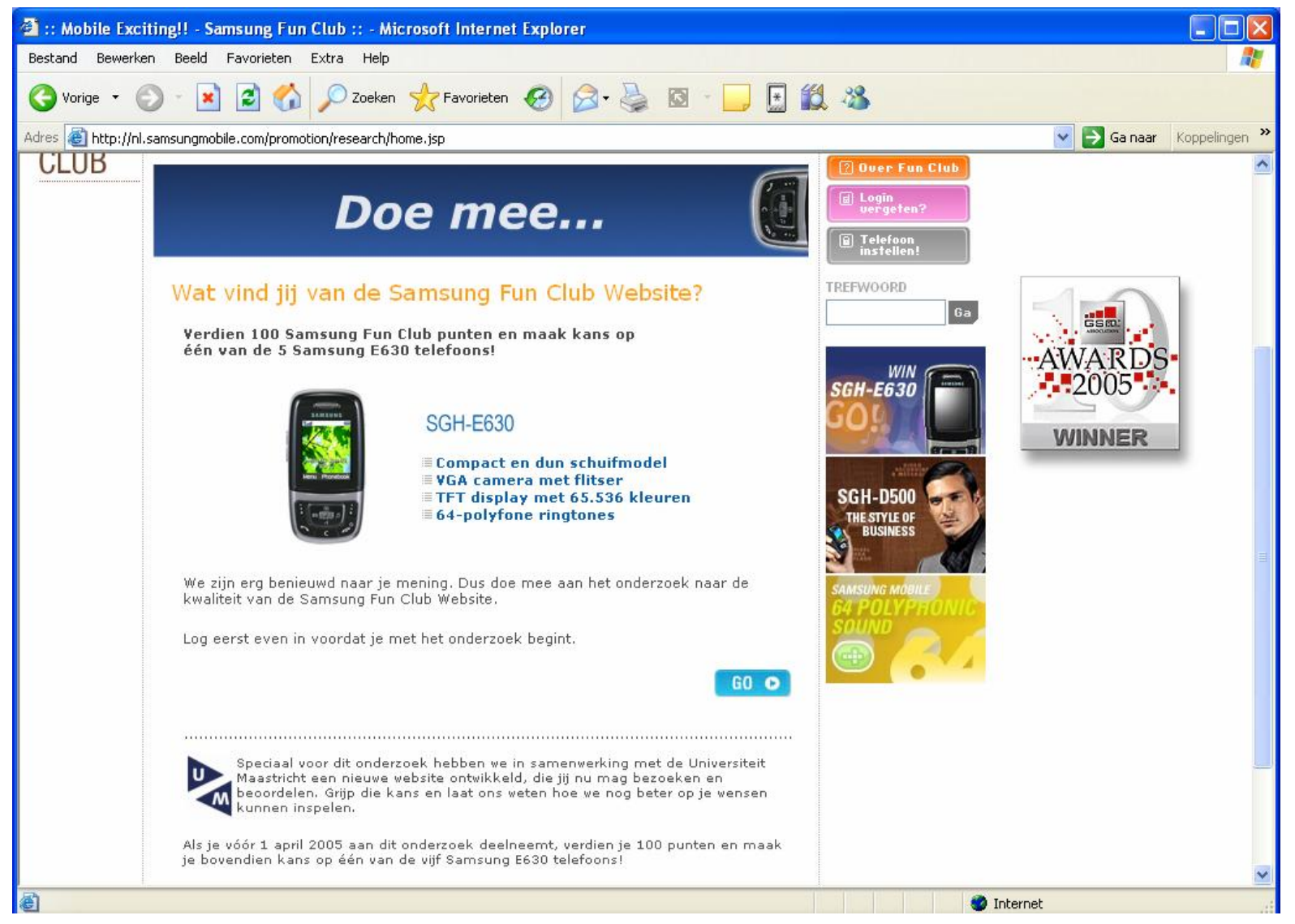

Figure 4-6: Invitation to the research

All participants began the experiment by reading an online document that described the purpose of the research and some general instructions (see figure 4-7). After clicking on an embedded URL link at the bottom of the introduction page, participants were asked to complete the first part of the questionnaire which measured subject-related factors and demographics. Subject-related factors were measured before presenting the scenarios to reduce possible bias. Apart from questions about demographics, questions of a 7-point Likert-type, each containing a statement and an answer option ranging from "1 = strongly disagree" to "7 = strongly agree", were used. When respondents submitted the first part of the questionnaire, they were randomly assigned to one of the two scenarios describing the task (search or browse) for visiting the manipulated Samsung's Fun Club website. Then participants visited one of the four experimentally manipulated Samsung's Fun Club websites and the click stream data of their website visit was gathered.

After their visit to one of the eight experimental conditions (see figure 4-3), respondents were asked to complete an online survey measuring their value perceptions of the online experience and their loyalty towards the website (e-loyalty). Among this set of measures were also the realism check and the manipulation checks for media and information features and purposeful behavior. Besides the realism check, respondents were also asked which of the ten telephones presented at the experimental website they would prefer in order to 
further add realism to the experimental task. All measures used a seven-point Likert scale, each containing a statement with "strongly disagree" and "strongly agree" as the anchors. In order to increase the response rate, 5 mobile phones were raffled and each respondent that completed all parts of the research received 100 Samsung Fun Club credits, which could be exchanged for ring tones, wallpapers or mobile games. The experimental website was left open for a period of three weeks and, within this period, 583 respondents participated, which resulted in a usable response of 547.

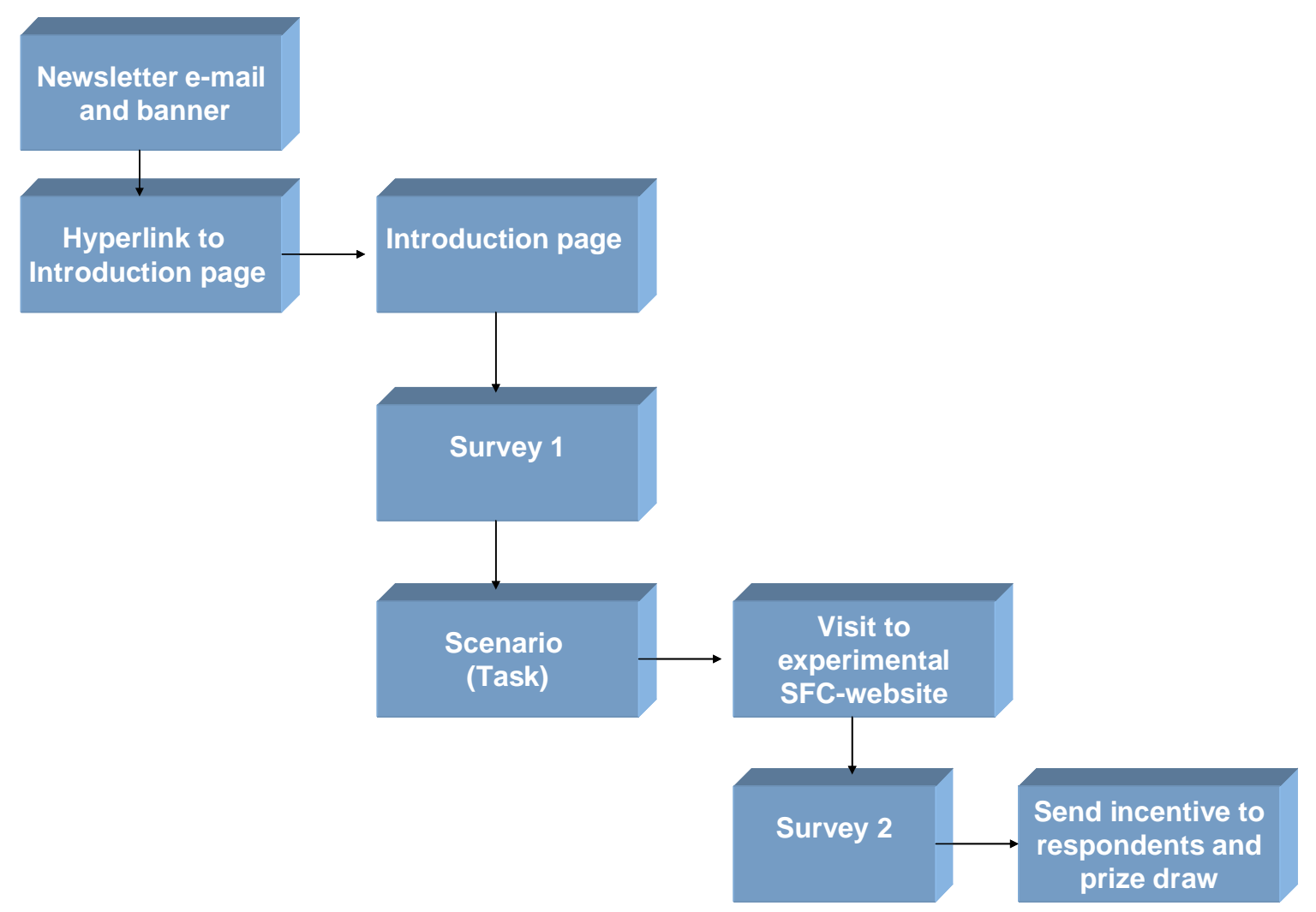

Figure 4-7: Procedure experiment

\subsubsection{Measures outcome variables}

In the current study, we use the experiential value scale of Mathwick, Malhotra and Rigdon (2001) to measure subjects' utilitarian and hedonic value perceptions in an online context. As we empirically assessed in section 3.3.6.2., their experiential value construct represents a higher-order model that consists of two underlying dimensions, utilitarian and hedonic value. Similar to our study in an online Books and CD context, we have used PLS in this study to test the higher-order model of experiential value (Mathwick et al. 2001). PLS path modeling allows for the conceptualization of higher-order factors through the repeated use of manifest variables (Guinot et al. 2001; Lohmöller 1989; Tenenhaus et al. 2005; Wold 1982). A higherorder factor can thus be created by specifying a latent variable that represents all the 
manifest variables of the underlying lower-order factors. As a result, the third-order construct, hedonic and utilitarian value, contained all manifest variables of the first-order constructs. The loadings of the first-order factors and the second-order factors exceed 0.80 (aesthetics: 0.96 [visual appeal] and 0.93 [entertainment]; playfulness: 0.93 [escapism] and 0.81 [enjoyment]; CROI: 0.93 [efficiency] and 0.93 [economic value]). Similarly, the loadings of the second-order factors on the third-order factors are equal to or exceed 0.80 . The loadings on hedonic value of aesthetics and playfulness are respectively 0.94 and 0.91 and the loadings of $\mathrm{CROI}$ and excellence on utilitarian value are 0.97 and 0.89 , in support of the third-order model of online experiential value. Moreover, our results indicate that all loadings are significant at $\alpha=0.05$. These results are in line with the findings of our empirical examination of a fourth-order model of experiential value in a previous study with a sample of 190 visitors to online book and CD retailer as described in section 3.3.6.2 (see table 4-3).

Table 4-3: Higher-order model experiential value for mobile phone context

\begin{tabular}{|c|c|c|c|c|}
\hline \multicolumn{5}{|c|}{ Second-Order Model } \\
\hline & Aesthetics & Playfulness & $\begin{array}{l}\text { Service } \\
\text { Excellence }^{b}\end{array}$ & Customer ROI \\
\hline $\begin{array}{l}\text { CR } \\
A V E\end{array}$ & $\begin{array}{l}0.97 \\
0.94\end{array}$ & $\begin{array}{l}0.92 \\
0.85\end{array}$ & $\begin{array}{l}\text { n.a. } \\
\text { n.a. }\end{array}$ & $\begin{array}{l}0.97 \\
0.94\end{array}$ \\
\hline $\begin{array}{l}\text { Visual appeal } \\
\text { Entertainment } \\
\text { Escapism } \\
\text { Enjoyment } \\
\text { Efficiency } \\
\text { Economic value }\end{array}$ & $\begin{array}{l}0.96^{\star *} \\
0.93^{\star *}\end{array}$ & $\begin{array}{l}0.93^{* *} \\
0.81^{* *}\end{array}$ & $\begin{array}{l}\text { n.a. } \\
\text { n.a. } \\
\text { n.a. } \\
\text { n.a. } \\
\text { n.a. } \\
\text { n.a. }\end{array}$ & $\begin{array}{l}0.93^{\star *} \\
0.93^{\star *}\end{array}$ \\
\hline \multicolumn{5}{|c|}{ Third-Order Model } \\
\hline & $\begin{array}{l}\text { Hedonic } \\
\text { Value }\end{array}$ & $\begin{array}{l}\text { Utilitarian } \\
\text { Value }\end{array}$ & & \\
\hline $\begin{array}{l}\text { CR } \\
A V E\end{array}$ & $\begin{array}{l}0.96 \\
0.92\end{array}$ & $\begin{array}{l}0.93 \\
0.87\end{array}$ & & \\
\hline $\begin{array}{l}\text { Aesthetics } \\
\text { Playfulness } \\
\text { Excellence } \\
\text { Customer return } \\
\text { on investment }\end{array}$ & $\begin{array}{l}0.94^{* *} \\
0.91^{* *}\end{array}$ & $\begin{array}{l}0.88^{\star \star} \\
0.97^{\star \star}\end{array}$ & & \\
\hline $\begin{array}{l}{ }^{* *} \mathrm{p}<0.01 \\
\text { bervice excellence is } \\
\text { excellence constitutes sec }\end{array}$ & $\begin{array}{l}\text { cified as a firs } \\
\text {-order factor. }\end{array}$ & or in the $n$ & & hical $n$ \\
\hline
\end{tabular}


For the e-loyalty measure, we retrieved 14 items from several existing loyalty scales (Mathwick et al. 2001; Srinivasan et al. 2002; Zeithaml et al. 1996). In addition, some questions measuring demographics were included. The questions were mixed to overcome halo effects.

\subsubsection{Manipulation checks}

The manipulation checks were similar to those employed in the quantitative pre-test. The scenarios were considered highly realistic as the realism check items had a rating of 6.3 on a scale of 1 to 7 . Moreover, the manipulation check for purposeful behavior at the website showed a significant difference $(p=.000)$ for respondents that either had a task to search $(\mu=$ $4.70, N=292)$ or to browse $(\mu=3.9, N=245)$. Our results indicated that respondents with a task to search also searched more for information than respondents with a task to browse. In addition, the manipulation checks for media and information features reported significant different grades for the websites with high and low information richness $(p=.000)$ and high and low media richness $(p=.000)$. This indicated that the information and media richness manipulations had the intended effect.

\subsubsection{Sample profile}

Five hundred forty-seven members of the Samsung Fun Club participated in the experiment (see table $4-4$ ). The sample consisted of $51.7 \%$ females and $47.5 \%$ males. With respect to age, $26.3 \%$ were younger than 21 years old, $30.7 \%$ were aged between $21-30,21 \%$ between $31-40$ and $21.2 \%$ were older than 40 . Concerning profession, $50.8 \%$ of the respondents were employees, $31.8 \%$ students, $4.9 \%$ employers, $6.9 \%$ housewife/men and $4.9 \%$ unemployed. A majority of the respondents used the Internet several times a day $(73.5 \%)$ and $18.1 \%$ on average once a day. Most of the respondents (62.9\%) reported that they spent on average more than an hour online, $22.1 \%$ between $31-60$ minutes, $11.7 \% 16-30$ and $2.6 \%$ less than 15 minutes. Moreover, most of the respondents visited the Samsung Fun Club website a few times per month (49.4\%), $17.6 \%$ less than once a month, $18.5 \%$ several times a week, $3.1 \%$ almost never and $4.9 \%$ at least once a day. Concerning time spent at the Samsung Fun Club website, $51.6 \%$ of the respondents reported that they spent on average 5-15 minutes per visit at this website, $30.3 \% 16-30$ minutes and $6.2 \%$ between 31 minutes and an hour. 
Table 4-4: Sample profile: main between-subjects experimental design

$\mathrm{N}=547$

Gender

Age

Education

Profession

Frequency of Internet use

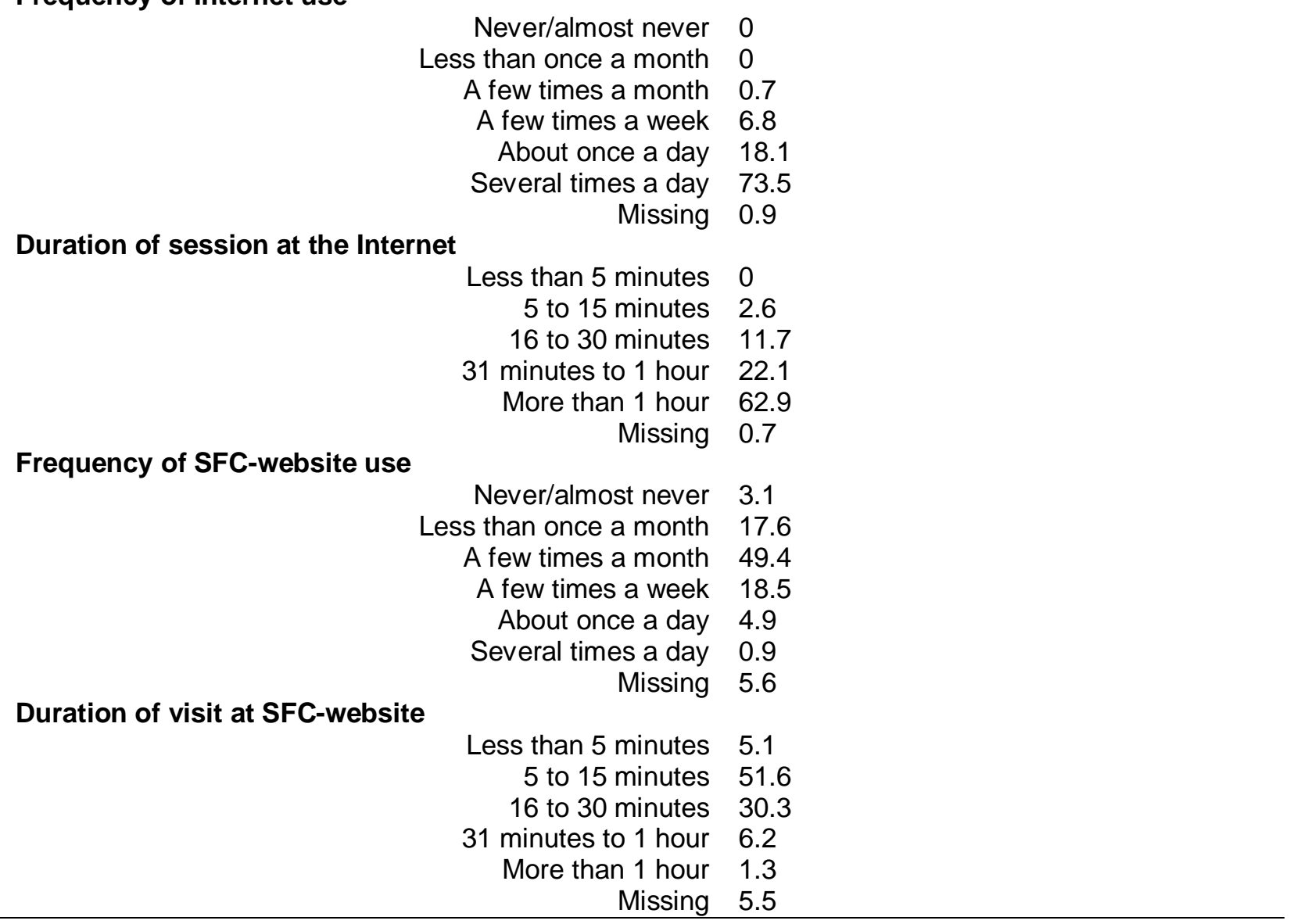

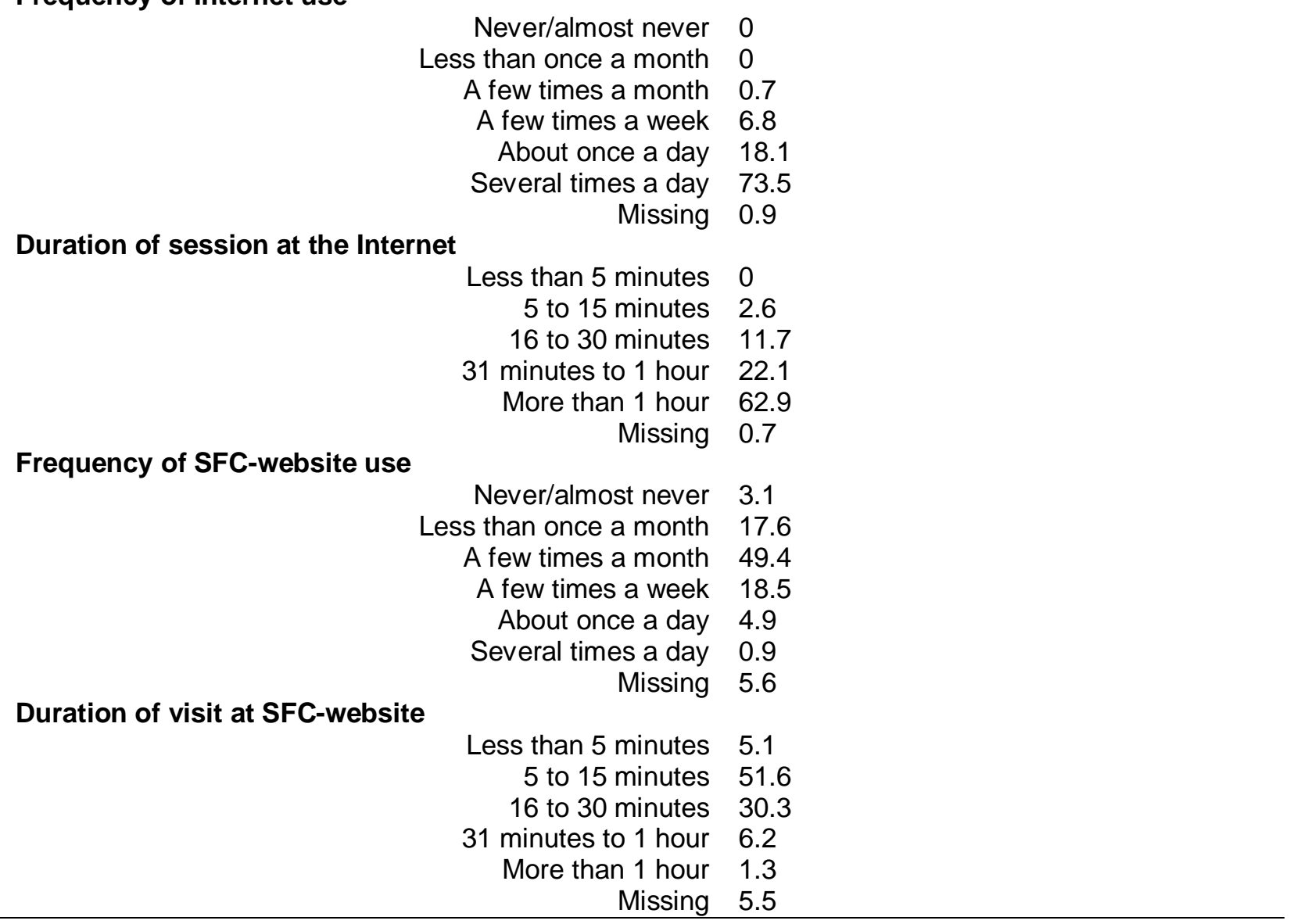

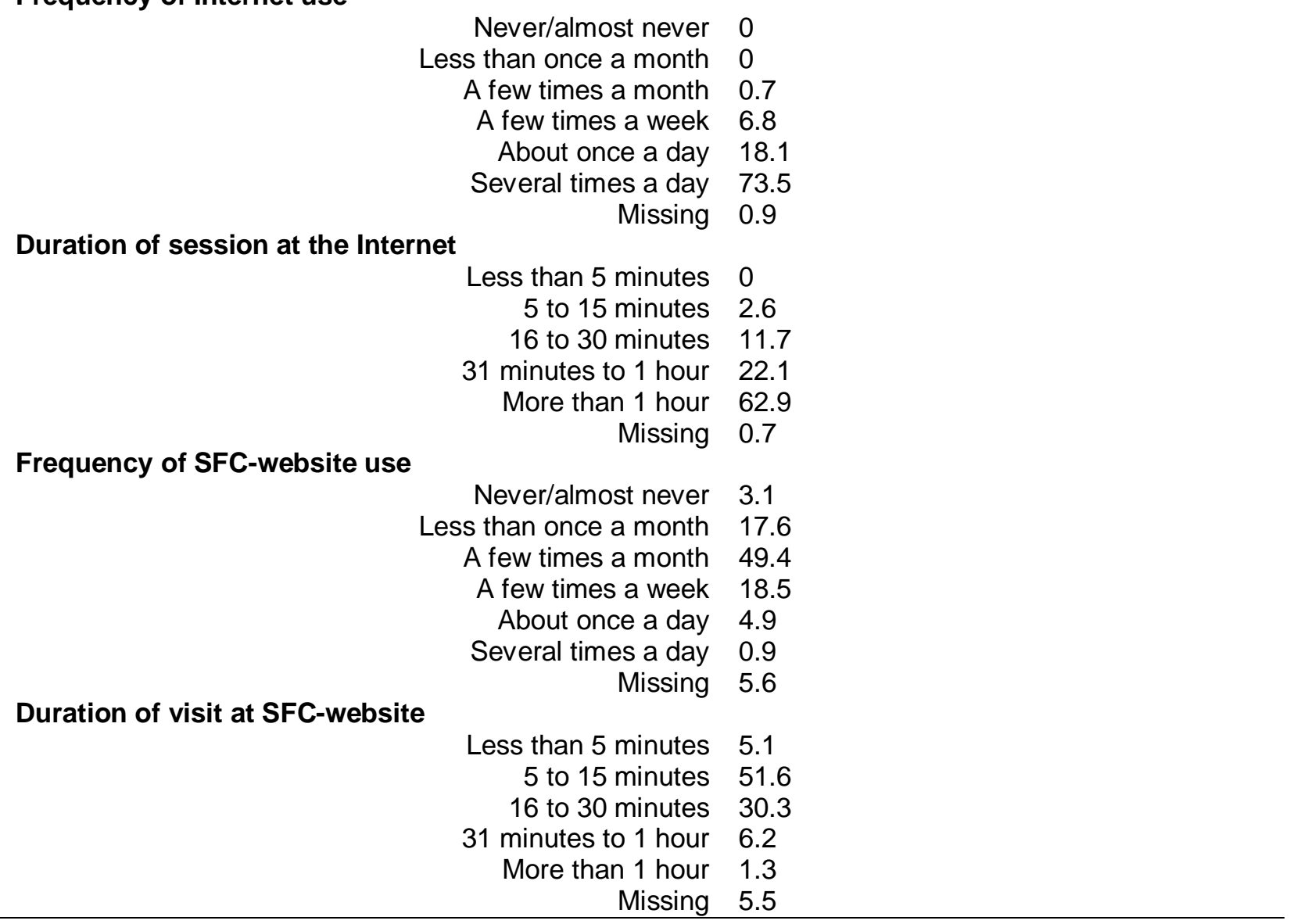

Percentage (\%)

$\begin{aligned} \text { Male } & 47.5 \\ \text { Female } & 51.7 \\ \text { Missing } & 0.8\end{aligned}$

$<21$ years 26.3

21-30 years old 30.7

$31-40$ years old 21.0

$>40$ years 21.2

Missing 0.8

Primary school 7.5

Secondary school $\quad 35.5$

Intermediate vocational education 35.1

Higher vocational education 16.6

University 3.1

other 1.6

Missing 0.6

Students 31.8

Employee 50.8

Employer 4.9

Housewife/men 6.9

Unemployed 4.9

Missing $\quad 0.7$ ss than once a month 0

A few times a month 0.7

few times a week 6.8

About once a day 18.1

s a day 73.5

s than 5 minutes

5 to 15 minutes 2.6

16 to 30 minutes 11.7

minutes to 1 hour 22.1

1 hour 62.9

Missing 0.7

shan once

once a day

Missing 5.6

than 5 minu

5 to 15 minutes 51.6

Missing 5.5 


\subsubsection{Website visitors' actual behavior at the website}

In addition to the quantitative data collection, we also gathered data on website visitors' real behavior at the website with HitBox a web analytics tool. We used the active segmentation option of HitBox to segment the website visitors in accordance with the experimental condition they participated in. Subsequently, in order to identify differences in the online behavior of website visitors in different experimental conditions, we examined how many pages participants looked at during their visit at the experimental Samsung Fun Club website. However, we limited ourselves to examine only the number of visitors that visited a range from one to ten pages of the experimental website. Table 4-5 illustrates for each experimental condition how many pages were visited by research participants during their website visit.

Table 4-5: Website visitors' actual behavior

\begin{tabular}{|c|c|c|c|c|c|c|c|c|}
\hline \multirow[b]{2}{*}{$\begin{array}{l}\text { Number } \\
\text { of pages } \\
\text { visited }\end{array}$} & \multicolumn{8}{|c|}{ Number of visitors per experimental condition } \\
\hline & LLS* $^{*}$ & LLB & LHS & LHB & HLS & HLB & HHS & HHB \\
\hline 1. & 10 & 1 & & 1 & 0 & 7 & 1 & 1 \\
\hline 2. & 7 & 0 & & 0 & 0 & 0 & 2 & 0 \\
\hline 3. & 3 & 1 & & 0 & 1 & 1 & 1 & 1 \\
\hline 4. & 2 & 3 & & 0 & 2 & 3 & 1 & 0 \\
\hline 5. & 0 & 4 & & 4 & 1 & 5 & 1 & 5 \\
\hline 6. & 3 & 7 & & 7 & 6 & 17 & 3 & 15 \\
\hline 7. & 4 & 12 & & 10 & 6 & 4 & 15 & 6 \\
\hline 8. & 2 & 5 & & 6 & 9 & 8 & 6 & 4 \\
\hline 9. & 5 & 5 & & 1 & 6 & 4 & 11 & 4 \\
\hline 10. & 7 & 3 & & 3 & 6 & 5 & 2 & 2 \\
\hline $\begin{array}{l}\text { LLS }=\text { low } m \\
\text { LLB }=\text { media } \\
\text { HLS =high } m \\
\text { HHS }=\text { high } m\end{array}$ & rmatic & les & ich & $\begin{array}{l}=\text { low media } \\
=\text { low media } \\
\text { high media } \\
\text { =high medi }\end{array}$ & $\begin{array}{l}\text { chness, hig } \\
\text { ichness, hic } \\
\text { ichness, lov } \\
\text { ichness, hi }\end{array}$ & $\begin{array}{l}\text { informatio } \\
\text { informatio } \\
\text { informatior } \\
\text { informatic }\end{array}$ & $\begin{array}{l}\text { chness, s } \\
\text { ichness, b } \\
\text { chness, br } \\
\text { ichness, }\end{array}$ & $\begin{array}{l}\text { reh } \\
\text { wse } \\
\text { sse } \\
\text { owse }\end{array}$ \\
\hline
\end{tabular}

The results indicate that in the low media/low information richness situation ten searchers visit only one page and 7 searchers only two pages. While only one browser visited just one page and most browsers visited 6 or 7 pages. Moreover, in the high media richness/high information richness situation most searchers visit 7, 8 or 9 pages. In contrast, 15 browsers visit 6 pages and the number of browsers that visit 7, 8, or 9 pages is much lower than for searchers. In addition, if we compare the number of pages visited by searchers in the high media richness/high information richness situation (HHS) with the low media richness/low information richness situation (LLS), we see that the number of searchers that visit more pages is higher in the rich environment. However, for browsers there is not such clear 
difference between the numbers of pages visited in the high versus low media/information richness environment.

Although we did not empirically test these differences between searchers and browsers for the number of pages visited, we can identify differences between them. These findings indicate that searchers visit fewer pages than browsers when the website is low in media richness and information richness. Searchers want to fulfill their specific information needs at the website and consequently we assume that they have a more critical attitude towards the website than browsers. Consequently, due to their critical attitude, searchers identify probably faster that media and information richness are low at the website and as a result they will quit their website visit already after visiting one or two pages. In contrast, browsers still continue their navigation through the pages. However, if respondents visit a website that is rich in media and information features, they visited relatively more pages than browsers. Hence, these findings support our results of the manipulation checks that browsers and searchers behave differently at a website.

\subsection{Data analyses}

We used Partial Least Square (PLS-GRAPH v 3.00) to estimate the measurement properties of our research model instead of ANOVA, because PLS allows us to examine the experimental design with multiple causal relationships. Another reason for using PLS is that we aim to predict the dependent endogenous variables (Chin 1998; Fornell and Bookstein 1982).

We first assessed convergent validity by examining the factor loadings of construct indicators. All factor loadings were equal to or exceeded 0.89 , which indicated convergent validity (Hulland 1999). Second, we evaluated composite reliability to assess construct reliability (Fornell and Larcker 1981). Composite reliabilities were equal to or higher than 0.95 and exceeded the cut-off value of 0.7 (Nunnally and Bernstein 1994). Third, we calculated the average variances extracted, which were above the recommended cut-off value of 0.50 (Fornell and Larcker 1981). Subsequently, we found that all constructs showed discriminant validity as the square root of the average variance extracted exceeded the correlations of the construct with other constructs (Fornell and Larcker 1981).

\subsubsection{Results main effects}

The first hypotheses predict that website visitors perceive higher levels of utilitarian and hedonic value when visiting websites high in media richness. Our results support both hypotheses $1 \mathrm{a}$ and $1 \mathrm{~b}$ as website visitors' perceptions of utilitarian $(\beta=0.131, p<0.01)$ and hedonic $(\beta=0.133, p<0.01)$ value are both positively influenced by high perceived levels of media richness $(-1=$ low media richness, $1=$ high media richness $)$. We also found support 
for hypotheses $2 a$ and $2 b$ indicating that website visitors' perceptions of utilitarian $(\beta=0.162$, $\mathrm{t}=\mathrm{p}<0.01)$ and hedonic $(\beta=0.107, \mathrm{p}<0.01)$ value are higher when website visitors perceive higher levels of information richness (information richness, $-1=$ low and $1=$ high). Hypothesis 3a predicts that searchers perceive higher levels of utilitarian value than browsers when visiting a website. In contrast, hypothesis $3 \mathrm{~b}$ predicts that browsers perceive higher levels of hedonic value when visiting a website than searchers. Our results show that searchers' and browsers' perceived levels of utilitarian value $(\beta=0.070, p>0.05)$ are not significantly different. Nevertheless, we found that browsers perceive significantly different levels of hedonic value $(\beta=0.136, p<0.01)$ than searchers when visiting a website. The results are shown in table 4-6.

\subsubsection{Results interaction effects}

Hypothesis 4 proposes that in situations of low media richness, websites high (versus low) in information richness have stronger influences on hedonic value, whereas in situations of high media richness, the impact of high and low information richness is equal. Our results provide evidence for this hypothesis, by showing a significant effect of the interaction term (media richness*information richness) on hedonic value $(\beta=-0.092, p<0.05)$ (see figure 4-8). Furthermore, we found support for hypothesis $5(\beta=-0.147, p<0.01)$, as our results show that in situations of low information richness, the impact of websites high in media richness on utilitarian value is stronger than for websites low in media richness, while the impact of websites high versus low media richness is equal in situations of high information richness (see figure 4-9). Hypotheses 6 predicted the influence of the interaction terms related to purposeful behavior on utilitarian and hedonic value. We found that the interaction terms related to purposeful behavior have no significant influence on both utilitarian and hedonic value. Hence, we rejected hypothesis 6 . A summary of the results and the $R^{2}$ for the endogenous constructs are provided in table 4-6. 
Table 4-6: Results research model I

\begin{tabular}{|c|c|c|c|c|}
\hline Hypothesis & Relationship & $\begin{array}{l}\text { Hypothesized } \\
\text { direction }\end{array}$ & $\begin{array}{l}\text { Standardized } \\
\text { Coefficient } \\
(\beta)\end{array}$ & Results \\
\hline H1a & MR-Utvalue & Positive & $0.131^{\star *}$ & Supported \\
\hline H1b & MR-Hedvalue & Positive & $0.133^{\star \star}$ & Supported \\
\hline H2a & INFOR-Utvalue & Positive & $0.162^{\star *}$ & Supported \\
\hline $\mathrm{H} 2 \mathrm{~b}$ & INFOR-Hedvalue & Positive & $0.107^{* *}$ & Supported \\
\hline H3a & P-Utvalue & Positive & 0.070 & n.s. \\
\hline H3b & P-Hedvalue & Positive & $0.136^{* *}$ & Supported \\
\hline H4 & MR*INFOR-Hedvalue & Negative & $-0.092^{*}$ & Supported \\
\hline H5 & MR*INFOR-Utvalue & Negative & $-0.147^{* *}$ & Supported \\
\hline $\mathrm{H} 6 \mathbf{a}$ & MR*P-Utvalue & Positive & -0.016 & n.s. \\
\hline H6b & INFOR ${ }^{*} \mathrm{P}-$ Utvalue & Positive & -0.048 & n.s. \\
\hline H6c & $\mathrm{MR}^{*}$ INFOR*P-Utvalue & Positive & -0.052 & n.s. \\
\hline H6d & MR ${ }^{*}$ - -Hedvalue & Negative & -0.012 & n.s. \\
\hline H6e & INFOR*P-Hedvalue & Negative & -0.069 & n.s. \\
\hline H6f & $\mathrm{MR}^{*} \mid \mathrm{NFOR}{ }^{*} \mathrm{P}-$-Hedvalue & Negative & -0.053 & n.s. \\
\hline $\mathrm{H} 10 \mathrm{a}$ & Utvalue-Eloy & Positive & $0.518^{\star *}$ & Supported \\
\hline $\mathrm{H} 10 \mathrm{~b}$ & Hedvalue-Eloy & Positive & $0.366^{\star *}$ & Supported \\
\hline $\begin{array}{l}\text { Construct } \\
\mathbf{R}^{2}\end{array}$ & $\begin{array}{c}\text { Utilitarian value } \\
0.069\end{array}$ & $\begin{array}{c}\text { Hedonic value } \\
0.059\end{array}$ & $\begin{array}{c}\text { E-loyalty } \\
0.719\end{array}$ & \\
\hline
\end{tabular}

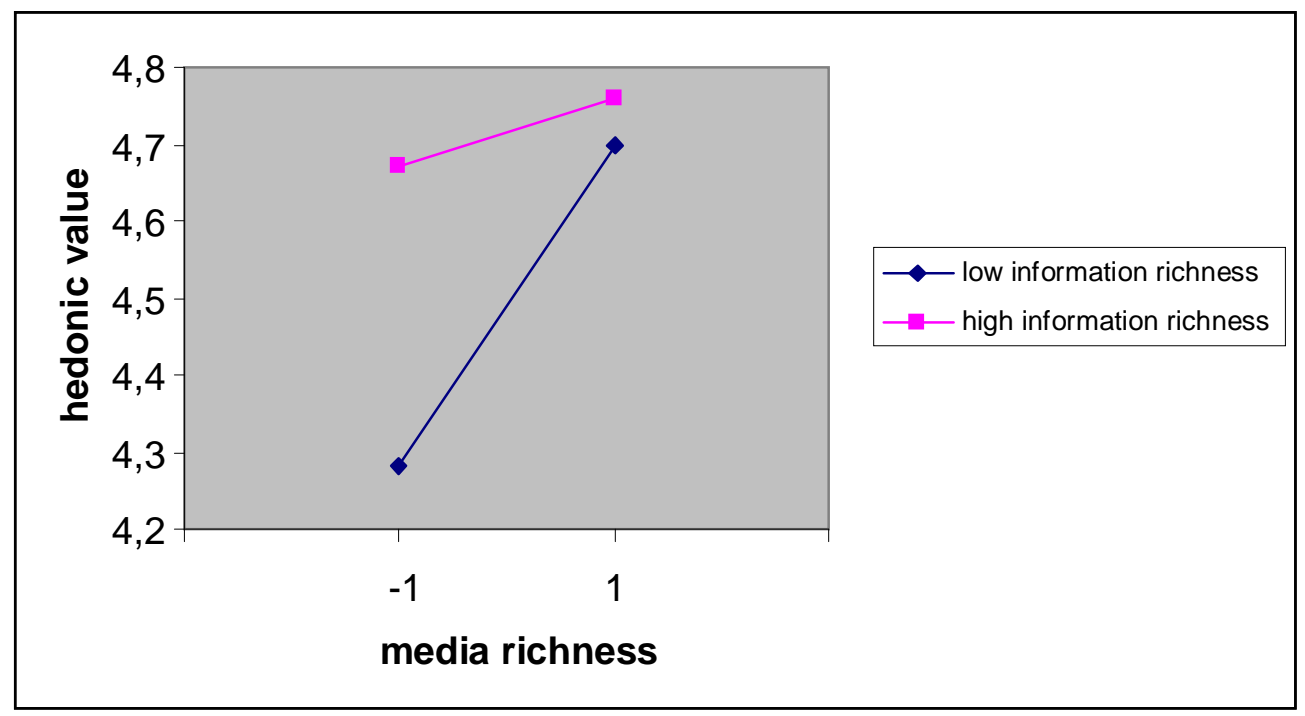

Figure 4-8: Interaction effect media and information richness on hedonic value 


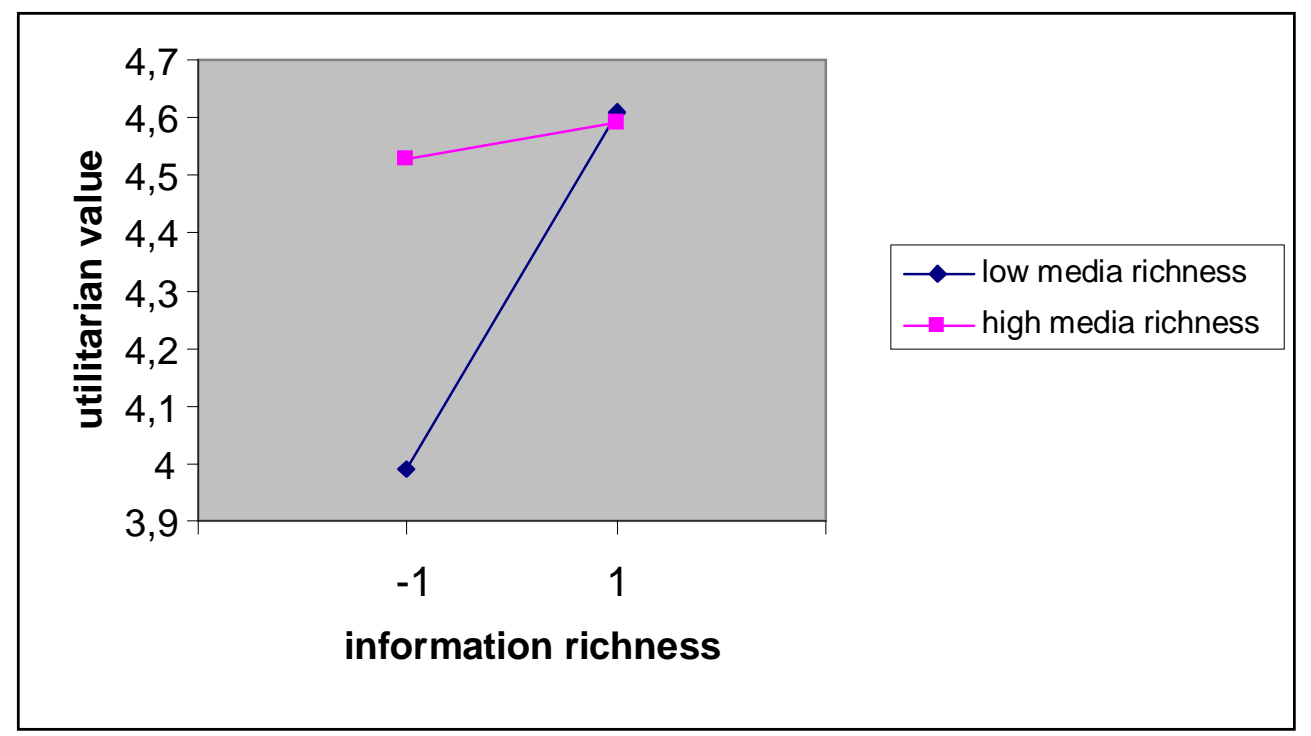

Figure 4-9: Interaction effect media and information richness on utilitarian value

\subsection{Conclusion}

In the experimental design, we emphasized the impact of two distinct but interrelated dimensions of interactional richness on outcomes of the interaction experience. The empirical findings will be discussed in section 4.8.1. Our results do provide strong theoretical and managerial implications which will be discussed in section 4.8 .2 and 4.8 .3 respectively.

\subsubsection{Discussion}

Our results show that websites with high levels of media richness have a positive influence on website visitors' perceptions of both utilitarian $(\mathrm{H} 1 \mathrm{a})$ and hedonic value $(\mathrm{H} 1 \mathrm{~b})$. These findings demonstrate that media richness in terms of synchronicity, multiplicity of cues and control, does not only lead to a pleasurable website visit (De Wulf et al. 2006), but also adds to visitors' perception of goal attainment.

Second, we also find a direct positive influence of information richness on visitors' perceptions of both utilitarian $(\mathrm{H} 2 \mathrm{a})$ and hedonic value $(\mathrm{H} 2 \mathrm{~b})$. In line with our expectations we find that the direct impact of information richness on website visitors' perceptions of utilitarian value is strongest as rich information content provided at a website reduces visitors' effort to find appropriate information and consequently enhances their task fulfillment. Nevertheless, the positive significant impact of information richness on hedonic value cannot be neglected. In addition to the main effects, we also investigated interaction effects of media richness and information richness. These effects are as proposed and show that in case the perceived level of media richness is low at a website a high level of information richness compensates this deficiency and still leads to hedonic value. However, if the perceived level of media 
richness is high at a website, website visitors need information richness to a lesser extent to perceive hedonic value $(\mathrm{H} 4)$.

Also, in line with our hypothesis, our empirical findings show that a low level of perceived information richness at a website can be compensated by high levels of media richness and enhance website visitors' perceptions of utilitarian value. Whereas for high informative websites, visitors need media richness cues to a lesser extent to perceive utilitarian value (H5). In addition, the highest levels of both utilitarian and hedonic value are reached when media richness and information richness are both high.

In terms of consumer-related motivations, our experimental design demonstrated, in line with our expectations, that browsers perceive higher levels of hedonic value than searchers (H3b). However, contrary to our expectations, searchers did not perceive higher levels of utilitarian value when visiting a website than browsers ( $\mathrm{H3a}$ ). A possible explanation for this unexpected finding is that not only searchers but also website visitors who visit a website out of curiosity or interest (browsers) may perceive utilitarian value, not because they can accomplish their tasks but simply because they value the services offered at the website. Fifth, our research investigates the combined effect of media or information richness and purposeful behavior in a two-way interaction effect. Our results illustrated that both two-way interaction effects did not have a significant impact on website visitors' perceptions of both utilitarian and hedonic value (H6a,b,d,e). In a similar vein, the three-way interaction effect between media richness and information richness and purposeful behavior did also not have a significant influence on both utilitarian and hedonic value (H6c,f). In a previous study, Schlosser (2003) demonstrated that the congruency between site design and purposeful behavior did have an effect on website visitors' attitude. Based on her study, we would expect that the interaction effects of media richness and information richness and purposeful behavior would have an impact on perceived value. However, our findings imply that the positive impact of the interaction effects of both website features media and information richness on both value perceptions was existing, while the interaction effect of one of the website features (either media or information richness) and purposeful behavior could not be found.

Finally, our study provides empirical support for the value-loyalty hypotheses. As we predicted, utilitarian ( $\mathrm{H} 10 \mathrm{a})$ and hedonic $(\mathrm{H} 10 \mathrm{~b})$ value both have a strong positive impact on consumers' loyalty towards the website.

\subsubsection{Theoretical implications}

This study focused on domination structures of the duality of structure model and examined how website visitors draw on asymmetries in website features (media and information richness) to fulfill their goals (hedonic and utilitarian value). Our experimental research 
contributes to contemporary research on online interactive marketing (Stewart and Pavlou 2002; Yadav and Varadarajan 2005b) and information systems literature (McKinney et al. 2002; Muylle et al. 2004; Negash et al. 2003) by demonstrating that consumers' value perceptions of the online interaction experience are influenced by the joined impact (interaction effect) of the richness of the website design (media richness) and the richness of the information content provided at the website (information richness) on both hedonic and utilitarian value. These findings provide empirical evidence for existing assumptions that differences in media richness cues determine the role website visitors attach to information richness (Dennis and Kinney, 1998). Moreover, Ranganathan and Ganapathy (2002) claimed that the design of the website is as important as its content and Huizingh (2000) argued that a website's presentations style facilitates the interpretation of the information. While these studies assessed the performance of different types of websites on both dimensions, we advance their insights by providing empirical evidence for the complementary effect of media and information richness.

In terms of knowledge on search and browse behavior online, our study provides empirical support for existing propositions (Babin et al. 1994; Lee et al. 2006) that browsers simply visit a website for the experience or out of curiosity and are therefore more likely to perceive higher levels of hedonic value than searchers who visit a website primarily to accomplish their goals and consequently pay less attention to the pleasantness of the online experience. The link between value and loyalty is relatively well established in existing literature claiming that website visitors' perceptions of both utilitarian and hedonic value are important in influencing their loyalty towards a website (Childers et al. 2001; Fiore et al. 2005). However, the differential impact of utilitarian and hedonic value on e-loyalty is largely neglected. Therefore, our study moves the available knowledge forward by demonstrating that in creating online loyalty in this online mobile phone setting, the impact of utilitarian value is stronger than the impact of hedonic value. In other words, in a mobile phone setting, the accomplishment of a task (e.g., finding information about a particular mobile phone) has a stronger impact on someone's willingness to return to the site than the perceived fun of visiting the site. Summarizing, our results on the link between value and loyalty provide empirical evidence for the recently launched principle of dual creation of value in the customer relationship management literature. This premise of dual creation of value, stresses that the creation of value for customers simultaneously creates value for companies in terms of the resulting customer loyalty (Boulding et al. 2005; Payne and Frow 2005).

\subsubsection{Managerial implications}

From a managerial perspective, our results suggest that website designers have to acknowledge the crucial role of accurate, comprehensive, comprehensible, and relevant 
information in creating both hedonic and utilitarian value. Our empirical findings demonstrate that information richness can be considered as a prerequisite for a rewarding website visit. On the other hand, our findings imply that companies cannot neglect the design of media richness elements irrespective of the nature of the context. So even if the context is considered to be mainly utilitarian in nature (e.g., national tax website, insurances, and educational institutions), it is worthwhile to carefully develop media richness cues at the website.

However, the interplay of information and media richness has the strongest implications for business practice. It is no longer sufficient to focus on either information content or media richness as both elements of a website have a joined impact on consumers' appreciation of the online experience. From a company perspective, we strongly recommend the cooperation of employees responsible for information content and people mastering the technical expertise to exploit media features as the combination of both will most likely lead to a valuable online experience for website visitors. 


\section{Chapter 5: The Impact of Interactional Richness on Customer Evaluations of Online Experiences}

\subsection{Introduction}

In the final research phase, we focus on legitimation structures, which are the result of domination structures and bring about evaluative criteria (value) to justify behavior (e-loyalty). More specifically, we investigate the impact of visitors' perceptions of the website (interactional richness) on their value perceptions and ultimately their e-loyalty, simultaneously taking into consideration the idiosyncratic characteristics of website visitors such as their competence and reflexivity. In the experimental research (chapter 4 ) we found a complementary effect of media richness and information richness on website visitors' perceptions of hedonic and utilitarian value. Hence, in order to comprehensively capture the full range of aspects involved in visitors' perceptions of an interaction with a website, we apply in the current survey research our higher-order construct of interactional richness with its underlying dimensions media and information richness and we will empirically assess its higher-order structure (section 5.6.2).

First, we briefly describe the research setting (section 5.2) and the data collection method (section 5.3). Next, we provide an overview of the measures incorporated in our research (section 5.4) and the sample profile (section 5.5). In section 5.6, we present the results of our data analyses. Finally, we conclude this chapter in section 5.7 .

\subsection{Research setting: career websites}

In order to empirically test our hypotheses, we conducted a quantitative study in an online career context. We opted for this specific research context because the use of career websites to search for a job has grown tremendously in recent years (Dineen et al. 2002; Williamson et al. 2003). The advances in technology have not only changed the way people search for jobs, but have also made the career websites more sophisticate (Cober et al. 2000; Cober et al. 2003). Previous research already suggested that, customers' perceptions of career websites may be based on both the content of information provided and the characteristics of the website (Cober et al. 2003). However, little is known about customers' value perceptions of career websites and their reactions towards these websites. Although it seems that career websites are more utilitarian than hedonic in nature as they enhance the effectiveness of a job search, the different services offered on these websites might also deliver hedonic value to customers. 


\subsection{Data collection}

Our research population consisted of people who were orientating themselves on the labor market. First, we recruited respondents through links and pop-ups at various national career websites e.g. studentenbaan.nl, Randstad.nl and one of the largest Dutch career website for confidentiality reasons called X. Second, students of a Dutch University and a Higher Vocational Education Institution which were either in the final stage of their program or recently finished their studies were invited to participate via a link on their organizations' websites (see figure 5-1).

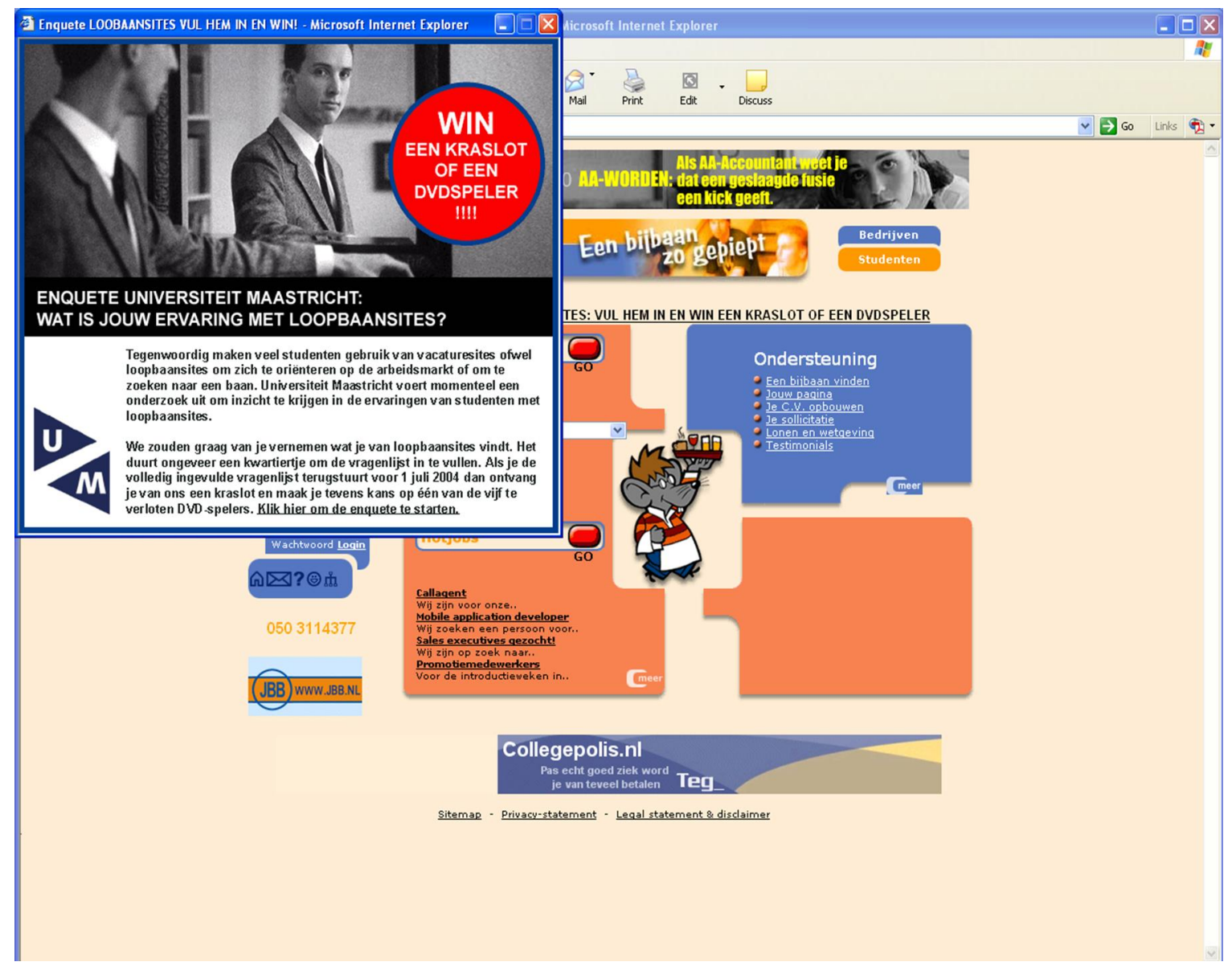

Figure 5-1: Invitation to participate in the research on career websites

To motivate participation, a scratch ticket was offered to all participants that completed the questionnaire. Moreover, the respondents also had a chance to win one of five DVD-players. The questionnaire was online for three weeks. On the webpage of the questionnaire, the purpose of the research was explained to participants and encouraged potential respondents to participate in order to help to improve the quality of the services offered via the career websites. The original English questionnaire was translated into Dutch by a qualified 
professional translator as it was administered via national Dutch career websites. Respondents could choose whether they completed the English or Dutch questionnaire.

Participants were first asked which career websites they knew. Next, respondents were asked which career website they visited most often and when they had visited it the last time. Respondents were asked to fill out the answers that best described their experiences with the career website they visited most often. Via the link on the national career websites, 233 people participated in the survey research. Via the link on the university and higher vocational education institutions websites 70 people participated. In total, we received 288 usable responses. To avoid double entries, we checked the date and time of completion and the unique IP-address. As we do not know how many people read the invitations at the career, university, and higher vocational education websites to participate in our online survey, but decided not to respond, we cannot estimate a precise response rate.

\subsection{Measures}

In order to empirically assess website visitors' perceptions of the online interaction process, we incorporated in this research the multi-item measures which we developed and refined in study 1 (chapter 3). First of all, to assess visitors' perceptions of the website we included our newly developed multi-item interactional richness scale in the survey. Next, we measured website visitors' perceptions of value with our utilitarian and hedonic value scales, which we retrieved from the experiential value scale of Mathwick et al. (2001) after we provided empirical evidence for the higher-order structure of this construct. Moreover, we evaluated website visitors' loyalty towards the website (e-loyalty) with our 14 item purified e-loyalty scale reflecting the cognitive, affective and conative stages of e-loyalty. Furthermore, we assessed website visitors' reflexivity regarding their own online information search process with our refined 3 item reflexivity scale expressing a visitor's critical evaluation and monitoring of his/her own information search online. In addition, we measured website visitors' competence referring to their search capabilities online with a 3 item scale that we adopted from previous work (Mathwick and Rigdon 2004). Finally, the questionnaire also included some demographic questions. Items of the various constructs were mixed to reduce possible halo effects. An overview of the measures included in our questionnaire is provided in appendix $\mathrm{H}$.

\subsection{Sample profile}

The 288 respondents in our analysis are predominantly younger than 40 years (89\%), with $56 \%$ female and $44 \%$ male respondents (see table $5-1$ ). Most of the respondents completed secondary school (25\%), higher vocational education (29\%), or university (37\%). Moreover, $40 \%$ of the respondents are student, $37 \%$ are employee, and $18 \%$ are unemployed. 
Respondents visit the career websites mostly a few times a week $(30 \%)$ or a month $(31 \%)$, while they visit the internet primarily several times a day (77\%).

Table 5-1: Sample profile career websites

\begin{tabular}{|c|c|}
\hline $\mathrm{N}=\mathbf{2 8 8}$ & Percentage (\%) \\
\hline \multicolumn{2}{|l|}{ Gender } \\
\hline Male & 43.8 \\
\hline Female & 55.9 \\
\hline Missing & 0.3 \\
\hline \multicolumn{2}{|l|}{ Age } \\
\hline$<25$ & 46.6 \\
\hline $25-40$ & 42.0 \\
\hline $41-55$ & 9.0 \\
\hline Missing & 2.4 \\
\hline \multicolumn{2}{|l|}{ Education } \\
\hline Primary school & 0.7 \\
\hline Secondary school & 25.3 \\
\hline Intermediate vocational education & 7.3 \\
\hline Higher vocational education & 28.5 \\
\hline University & 36.5 \\
\hline other & 1.7 \\
\hline \multicolumn{2}{|l|}{ Profession } \\
\hline Student & 40.3 \\
\hline Employee & 36.5 \\
\hline Employer & 3.1 \\
\hline Housewife/men & 0.3 \\
\hline Unemployed & 18.4 \\
\hline \multirow{2}{*}{\multicolumn{2}{|c|}{ Frequency of Internet use }} \\
\hline & \\
\hline Never/almost never & 0.3 \\
\hline Less than once a month & 0.3 \\
\hline A few times a month & 1.0 \\
\hline A few times a week & 7.3 \\
\hline About once a day & 13.9 \\
\hline Several times a day & 77.2 \\
\hline \multicolumn{2}{|l|}{ Duration of online session at the Internet } \\
\hline Less than 5 minutes & 0.7 \\
\hline 5 to 15 minutes & 8.7 \\
\hline 16 to 30 minutes & 16.0 \\
\hline 31 minutes to 1 hour & 29.2 \\
\hline More than 1 hour & 45.4 \\
\hline
\end{tabular}

\subsection{Results}

\subsubsection{Measurement model}

We used Partial Least Squares (PLS, PLS GRAPH v 3.00) to estimate the measurement properties. In PLS, the reliability and validity of the measurement model can be assessed by examining the factor loadings of the construct indicators, composite scale reliability $(\mathrm{CR})$, 
average variance extracted (AVE), and discriminant validity (Fornell and Larcker 1981). All factor loadings are higher than 0.5 (Hulland 1999), which supports convergent validity. The CRs are equal to or greater than 0.91 and AVEs are greater than 0.73 which compellingly exceed the cut-off values of CR 0.70 and AVE 0.5 as proposed by Fornell and Larcker (1981). In addition, we found support for discriminant validity as the square root of the AVE exceeds the intercorrelations of the latent variables in the model (Fornell and Larcker 1981). Table 5-2 shows composite reliabilities, average variance extracted, and the intercorrelations between the constructs.

Table 5-2: Composite reliability, average variance extracted, and correlations

\begin{tabular}{lcccccc}
\hline & CR & AVE & $\begin{array}{c}\text { Interactional } \\
\text { richness }\end{array}$ & $\begin{array}{c}\text { Utilitarian } \\
\text { value }\end{array}$ & $\begin{array}{c}\text { Hedonic } \\
\text { value }\end{array}$ & E-loyalty \\
Interactional richness & $\mathbf{0 . 9 3}$ & $\mathbf{0 . 8 7}$ & $\mathbf{0 . 9 3 3 ^ { * }}$ & & & \\
Utilitarian value & $\mathbf{0 . 9 2}$ & $\mathbf{0 . 8 6}$ & 0.761 & $\mathbf{0 . 9 2 7}$ & & \\
Hedonic value & $\mathbf{0 . 9 3}$ & $\mathbf{0 . 8 6}$ & 0.556 & 0.419 & $\mathbf{0 . 9 2 7}$ & \\
E-loyalty & $\mathbf{0 . 9 1}$ & $\mathbf{0 . 7 3}$ & 0.730 & 0.819 & 0.481 & $\mathbf{0 . 8 5 4}$ \\
\hline
\end{tabular}

*Numbers shown in bold on the diagonal denote the square root of the AVE

\subsubsection{Higher-order model interactional richness}

Our results of the experiment indicated that we should consider the effects of media and information richness simultaneously. Consequently, we empirically tested the existence of a third-order model of interactional richness with the underlying dimensions media and information richness. We used PLS to test the higher-order construct of interactional richness as it allows for the conceptualization of the higher-order construct through the repeated use of the manifest variables of the first-order constructs (Guinot et al. 2001; Lohmöller 1989; Tenenhaus et al. 2005; Wold 1982). Consequently, the third-order construct, interactional richness enclosed all manifest variables of the first-order construct. Our results indicate that the loadings of the first-order factors on the second-order factors are equal to or exceed 0.7 (information richness: 0.89 [relevance], 0.87 [accuracy], 0.85 [comprehensibility], 0.83 [comprehensiveness]; media richness: 0.83 [synchronicity], 0.81 [multiplicity of cues], 0.71 [control]) (see table 5-3). In addition, the loading of information richness on interactional richness equals 0.94 and the loading of media richness equals 0.83 . Moreover, all loadings are significant at $\alpha=0.05$. These results support our conceptual ideas and indicate that website visitors' perceptions of a website are represented by interactional richness, which consists of the underlying dimensions media and information richness. 
Table 5-3: Higher-order model interactional richness

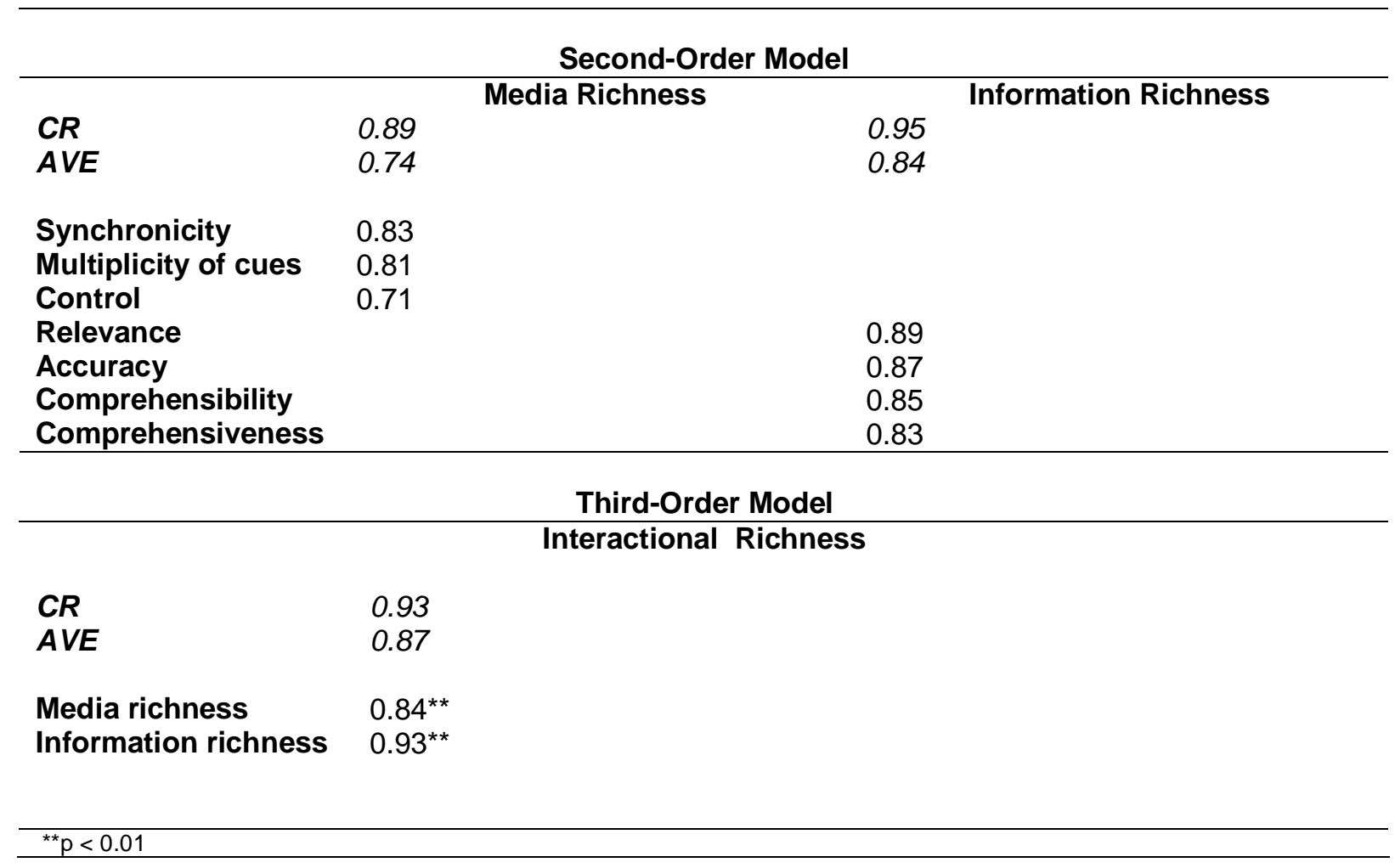

\subsubsection{Structural model}

In testing the hypotheses of the direct effects model, we find support for all six hypotheses (see Table 5-4). We found empirical evidence for the first set of hypotheses predicting a positive influence of interactional richness on both utilitarian $\left(\mathrm{H}_{7 \mathrm{a}}: \beta=0.776, p<0.01\right)$ and hedonic value $\left(\mathrm{H}_{7 \mathrm{~b}}: \beta=0.569, p<0.01\right)$. Moreover, we also found a positive impact of interactional richness on reflexivity $\left(\mathrm{H}_{8 \mathrm{a}}: \beta=0.185, p<0.01\right)$ and competence $\left(\mathrm{H}_{9 \mathrm{a}}: \beta=\right.$ 0.282, $p<0.01$ ). Hypotheses $10 \mathrm{a}$ and $10 \mathrm{~b}$, assuming a positive relationship between utilitarian value and e-loyalty and hedonic value and e-loyalty, are also supported $\left(\mathrm{H}_{10 \mathrm{a}}: \beta=\right.$ $\left.0.749, p<0.01 ; \mathrm{H}_{10 \mathrm{~b}}: \beta=0.167, p<0.01\right)$. The variance explained by the model in terms of $\mathrm{R}^{2}$ is 0.580 for utilitarian value, 0.329 for hedonic value, and 0.694 for e-loyalty. According to Cohen (1988) these effects can be classified as large. Moreover, these $\mathrm{R}^{2}$ values of the endogenous constructs can be used to assess model fit, as PLS does not provide proper single goodness-of-fit measures, such as $X^{2}$ (Chin 1998; Tenenhaus et al. 2005).

\subsubsection{Moderating effects}

We tested the moderating effects of the idiosyncratic characteristics of website visitors, reflexivity and competence, with a two-step score construction method in PLS (Chin et al. 2003). The first step comprised the estimation of latent variables (LV) scores and saving these standardized LV scores (Tenenhaus et al. 2005). The second step involved the 
calculation of the interaction terms and the inclusion of these interaction terms in our model. With this two-step score construction method we are able to test a relatively large number of interaction effects and can simultaneously correct for measurement error (Chin et al. 2003). Next, parameter estimates were obtained from PLS and (nonparametric) bootstrapping with 500 resamples provided the standard errors of the estimates and the accompanying $t$ statistics. Moreover, to test our hypotheses we used a hierarchical approach which implied that we first estimated a model with the main effects only and subsequently added the interaction effects (Chin et al. 2003).

Our results indicated that the positive relationship between interactional richness and utilitarian value is strengthened for people who highly reflect upon their information search process $\left(\mathrm{H}_{8 \mathrm{~b}}\right)$ (see Table 5-4). However, the moderating effect of reflexivity on the positive relationship between interactional richness and hedonic value is not significant $\left(\mathrm{H}_{8 \mathrm{c}}\right)$. Furthermore, we found that competence strengthens the relationships between interactional richness and hedonic value $\left(\mathrm{H}_{9 \mathrm{c}}\right)$. In addition, we found a significant moderating effect of competence on the positive relationship between interactional richness and utilitarian value in the opposite direction of the hypothesized effect $\left(\mathrm{H}_{9 b}\right)$. The $\mathrm{R}^{2}$ in the final model (including both main and interaction effects) is for utilitarian value 0.588 , for hedonic value 0.331 , and for e-loyalty 0.694 .

Table 5-4: Results research model II

\begin{tabular}{|c|c|c|c|c|}
\hline Hypothesis & Relationship & $\begin{array}{l}\text { Hypothesized } \\
\text { direction }\end{array}$ & $\begin{array}{l}\text { Standardized } \\
\text { Coefficient }(\beta)\end{array}$ & Results \\
\hline H7a & IR-Utvalue & Positive & $0.776^{* *}$ & Supported \\
\hline H7b & IR-Hedvalue & Positive & $0.569^{* *}$ & Supported \\
\hline $\mathrm{H} 8 \mathrm{a}$ & IR-Reflex & Positive & $0.185^{\star *}$ & Supported \\
\hline H8b & IR*Reflex - Utvalue & Positive (strengthened) & $0.106^{* *}$ & Supported \\
\hline H8c & IR*Reflex - Hedvalue & "equal" & -0.033 & n.s. \\
\hline $\mathrm{H9a}$ & IR-Comp & Positive & $0.282^{* *}$ & Supported \\
\hline $\mathrm{H} 9 \mathrm{~b}$ & $\mathrm{IR}^{*}$ Comp - Utvalue & Positive (strengthened) & $-0.060^{*}$ & Rejected \\
\hline H9c & IR*Comp - Hedvalue & Positive (strengthened) & $0.054^{*}$ & Supported \\
\hline $\mathrm{H} 10 \mathrm{a}$ & Utvalue-Eloy & Positive & $0.749^{* *}$ & Supported \\
\hline $\mathrm{H} 10 \mathrm{~b}$ & Hedvalue-Eloy & Positive & $0.167^{* *}$ & Supported \\
\hline $\begin{array}{l}\text { Construct } \\
\mathbf{R}^{2}\end{array}$ & $\begin{array}{c}\text { Utilitarian value } \\
0.588\end{array}$ & $\begin{array}{c}\text { Hedonic value } \\
0.331\end{array}$ & $\begin{array}{c}\text { E-loyalty } \\
0.694\end{array}$ & \\
\hline
\end{tabular}

\subsection{Conclusion}

In chapter 3, we developed a measure for interactional richness. Subsequently, we investigated the separate and joint impact of its underlying dimensions, media and information richness, in our experimental research (chapter 4). In this experimental research, we found empirical evidence for the complementary effects of media and information 
richness on website visitors' value perceptions. These findings justified our assumption that interactional richness can be depicted as a higher-order construct consisting of both media and information richness dimensions. Hence, building on the results of our previous studies, in this chapter, we empirically assessed the higher-order structure of interactional richness and its impact on website visitors' perceptions of the online interaction process by means of a survey research.

\subsubsection{Discussion}

First, our empirical results provide strong support for the third-order latent model that integrates the media richness and information richness components into the overall concept of interactional richness. We defined interactional richness as consumers' perceptions of the extent to which the website at a given point in time provides relevant, accurate, comprehensible, and comprehensive information presented in multiple ways, facilitating user control, and two-way communication in real-time.

Second, our study provides empirical evidence for the strong positive impact of interactional richness on website visitors' perceptions of both utilitarian and hedonic value ( $\mathrm{H} 7 \mathrm{a}, \mathrm{h} 7 \mathrm{~b})$. In extant literature in an offline marketing context, quality, and costs such as price or effort are often put forward as important antecedents of value (Cronin et al. 2000). In a similar vein, Chen and Dubinsky (2003) confirm in an online e-commerce context that valence of experience, perceived quality, perceived risk, and price are important predictors of perceived value. However, as a result of the growing importance of interactivity in an online context (Yadav and Varadarajan 2005b), we argue that it is no longer sufficient to focus only on traditional drivers of value such as quality or price. We demonstrated that interactional richness is a crucial and innovative driver of perceived value ultimately resulting in loyalty.

Third, while website visitors' perceptions of utilitarian value have a very strong positive influence on e-loyalty ( $\mathrm{H} 10 \mathrm{a})$, website visitors' perceptions of hedonic value also have a positive impact on e-loyalty $(\mathrm{H} 10 \mathrm{~b})$. These findings are fundamental because they demonstrate that even in the online functional services context of career websites, hedonic value has a positive influence on website visitors' loyalty on top of the evident impact of utilitarian value on visitors' e-loyalty.

Fourth, in line with trait-activation theory (Tett and Guterman 2000) our results show that interactional richness triggers website visitors' reflexivity $(\mathrm{H} 8 \mathrm{a})$, which reveals the impact of a website (structure) on its visitors (actors) in the duality of structure model. Moreover, in line with our hypothesis, the survey results indicate that website visitors' reflexivity attenuates the relationship between visitors' perceptions of interactional richness and resulting perceptions of utilitarian value $(\mathrm{H} 8 \mathrm{~b})$. This finding supports the idea that website visitors (actors) also influence the effect of a website (structure) in the duality of structure model. 
However, in line with our hypothesis, the moderating effect of website visitors' reflexivity on the relationship between interactional richness and hedonic value is not significant (H8c). This is not surprising as website visitors' reflexivity refers to an individual's critical evaluation of his/her own information search process which plays a dominant role when website visitors intend to accomplish their information needs effectively but is irrelevant when they visit the website just for fun.

Finally, our results show that interactional richness has a positive influence on website visitors' competence (H9a). This result provides empirical evidence for an existing proposition ( $\mathrm{Yi}$ and Hwang 2003) that consumers perceive challenges as a chance to develop competence. However, in contrast to our expectations we found a negative effect of website visitors' competence on the relationship between interactional richness on utilitarian value (H9b). A possible explanation might be that competent website visitors find the website too simplistic and are consequently not encouraged to fulfill their tasks. However, in line with our expectations, our empirical results show that competence strengthens the relationship between interactional richness and hedonic value $(\mathrm{H} 9 \mathrm{c})$. This finding implies that while competent website visitors are not encouraged to fulfill their tasks online they may still perceive the visit to an interactional rich website as an enjoyable escape.

\subsubsection{Theoretical implications}

The previously described empirical results offer several interesting theoretical implications. In 2005b, Yadav and Varadarajan already recognized that research on online interactivity has to be advanced and consequently they conceptualized a multi-dimensional interactivity construct ranging from low to high. Advancing their suggestion, our construct of interactional richness goes beyond mere interactivity by also including information content components. Also, we demonstrate that website visitors evaluate the entire website as the sum of its underlying elements. Previous studies merely focused on the evaluation of individual website dimensions (media richness or information richness) (Muylle et al. 2004) or on separate website features (e.g. accuracy or relevance) rather than acknowledging the overall picture of a website. Hence, the third-order model of interactional richness reveals an important innovative driver of utilitarian and hedonic value.

Previous research already demonstrated the impact of both utilitarian and hedonic value in an online retail context (e.g. Childers et al. 2001; Fiore et al. 2005). Our survey results substantiate the existing findings in a more functional services context. In our experimental design, which was conducted in the experiential services context of a mobile phone website, we found similar results, which support the robustness of our research findings.

From a structuration perspective, both structure (website) and actor (website visitor) play a dominant role in the online interaction process. Therefore, our study referred to the micro 
change perspective, focusing on differences between individuals and their resulting online attitudes and behaviors, stressing the important role of the actor. We investigated the impact of website visitors' reflexivity and competence on the relationship between interactional richness and their perceptions of utilitarian and hedonic value. Our results on the link between interactional rich websites and visitors' reflexivity extend prior assertions in a marketing education context to an online context. In the marketing education context, studies demonstrated that students' reflexivity can be stimulated if a course instructor develops a course in such a way that students become challenged and are consequently aware of their own thinking process (Peltier et al. 2005). Our empirical findings show that an interactional rich website triggers website visitors' reflexivity, making them aware of their own information search process. Moreover, our results also demonstrate that website visitors' reflexivity attenuates the relationship between visitors' perceptions of interactional richness and resulting perceptions of utilitarian value. Thereby, we provide empirical support for existing propositions in an online marketing education context that reflexivity engages students to appraise their experiences and subsequently identify new solutions to problems (Peltier et al. 2006). Our findings also demonstrate that competence, the next idiosyncratic characteristic suggested by structuration theory, plays a prevailing role in an online context. Our results clearly show the impact of interactional richness on perceived competence, but also the moderating role of competence in strengthening the relationship between interactional richness and hedonic value. These findings advance existing theory by displaying the applicability of the duality of structure model to an online context.

Thus, the key contribution of this survey research is that it does not only focus on the impact of structural features of the website on the interaction process, but also stresses the important role of the website visitor in creating an online experience.

\subsubsection{Managerial implications}

From a managerial perspective, our results provide empirical support for a comprehensive construct of interactional richness that enables managers to assess visitors' perceptions of the entire website. Business practice can benefit from this finding by aiming at a positive overall website evaluation, using the underlying elements to achieve this objective. In the 21 st century it is no longer sufficient to focus on a few elements only, because website visitors expect an attractive and informative website they can rely on. In addition, the impact of interactional richness on value demonstrates visitors' current need to experience an interactive website visit. This finding is possibly geared by the disappearance of offline possibilities for human interactions with companies (e.g., atm's at banks) and the traditional impersonal online contact possibilities (e.g., booking a flight online without the option to consult a salesperson). Therefore, website designers can benefit from our insights resulting 
in advanced options (e.g., virtual agents, 3D visualizations of products, blogs) to offer interactional rich website visits to potential customers. Moreover, by developing an interactional rich website managers can challenge their website visitors and consequently stimulate them to critically evaluate their own information search process. Reflexive website visitors are more aware of the interactional rich cues at the websites and consequently identify new cues or sources to fulfill their information needs.

We strongly recommend website designers to develop interactional rich websites, as it may not only stimulate visitors' reflexivity but even create an enjoyable escape for competent visitors that find the website not appropriate to fulfill their tasks. 
"It's not about simply moving your marketing efforts to the Internet. It's about how well your company dialogs."

(Newell 2000)

\section{Chapter 6: Discussion}

\subsection{Introduction}

As the above quote illustrates, Newell (2000) stresses that simply being present online is not enough, companies should engage their customers in online interactions and simultaneously recognize the power customers have in creating a valuable online experience. Traditionally, companies have focused on gaining understanding in what customers value and subsequently create customer value by delivering this value to their customers in return for their loyalty (Flint 2006). However, nowadays attention is shifting towards facilitating or empowering customers in creating their own value (Vargo and Lusch 2004).

The research in this dissertation is driven by the importance of reciprocal interactions between websites and their visitors and the attainment of both customer and company goals in terms of respectively creating a valuable online experience for customers and ultimately creating customer loyalty towards the website. As the success of companies' online presence depends on their online interaction process with their customers, empirical evidence is needed to examine the reciprocal interaction process between websites and their visitors. Therefore, the focus in this dissertation has been on the interactional richness of websites and customers' evaluations of their online interaction experiences with these websites and subsequently their responses to these websites.

In chapter 1, we stated that the overall purpose of this dissertation was to apply structuration theory in an online context to create a comprehensive understanding of the reciprocal interaction process between websites and their visitors. Based on this overall purpose we developed more specific objectives. Our first objective was to introduce, conceptualize and empirically assess a higher-order construct of interactional richness to comprehensively assess visitors' perceptions of a website. Second, in addition to interactional richness we aimed to develop and refine several multi-item measures to comprehensively assess the online interaction process between websites and their visitors. Third, we aimed to establish how website visitors' perceptions of the interactional richness of websites influence their perceptions of utilitarian and hedonic value and ultimately their loyalty towards the website. Our fourth goal, examined how the relationship between visitors' perceptions of interactional richness and their perceptions of utilitarian and hedonic value are contingent upon the idiosyncratic characteristics of website visitors such as reflexivity, purposeful behavior and 
competence. Finally, our fifth objective was to assess the robustness of our research findings across different methods, samples and online services contexts.

In this concluding chapter, we will first present, in section 6.2, the contributions of the different studies in relation to our objectives. Next, in section 6.3, we will discuss the implications of our findings from a managerial perspective. Subsequently, we will describe the limitations of our research and suggestions for further research in section 6.4. We conclude this dissertation with a final thought in section 6.5.

\subsection{Theoretical discussion}

\subsubsection{A structuration perspective on the online interaction process}

The overall contribution of this dissertation to the online interactive marketing literature is the application of structuration theory in an online context and consequently providing a more complete understanding of the reciprocal interaction process between websites and their visitors.

In their seminal work on the new dominant logic for marketing, Vargo and Lusch (2004) introduce a service-centered view of marketing. In this view with its inherent focus on the customer and the relationship, interactivity and the corresponding evolving structures between the organization and the customer, are key issues. Inspired by their work, in this study we used structuration theory (Giddens 1979) as a theoretical lens to investigate the interactions between websites and their visitors. We demonstrated the applicability of structuration theory, a "meta-theory" that provides general guidance for the theoretical development and empirical investigation of the online interaction process between websites and their visitors. Structuration theory online has recently been applied to an online interactive marketing context (van Dolen et al. 2007; Stewart and Pavlou 2002). However, the existing studies have not explicitly applied the duality of structure model nor introduced constructs representing this duality of structure model in an online context. Therefore, a major contribution of this dissertation is that we examined the online reciprocal interaction process between websites and their visitors along the lines of the duality of structure model inherent in structuration theory. The duality of structure model offers a conceptualization of the reciprocal and mediated relationships between websites and interactions with website visitors (actors) (see figure 6-1). 


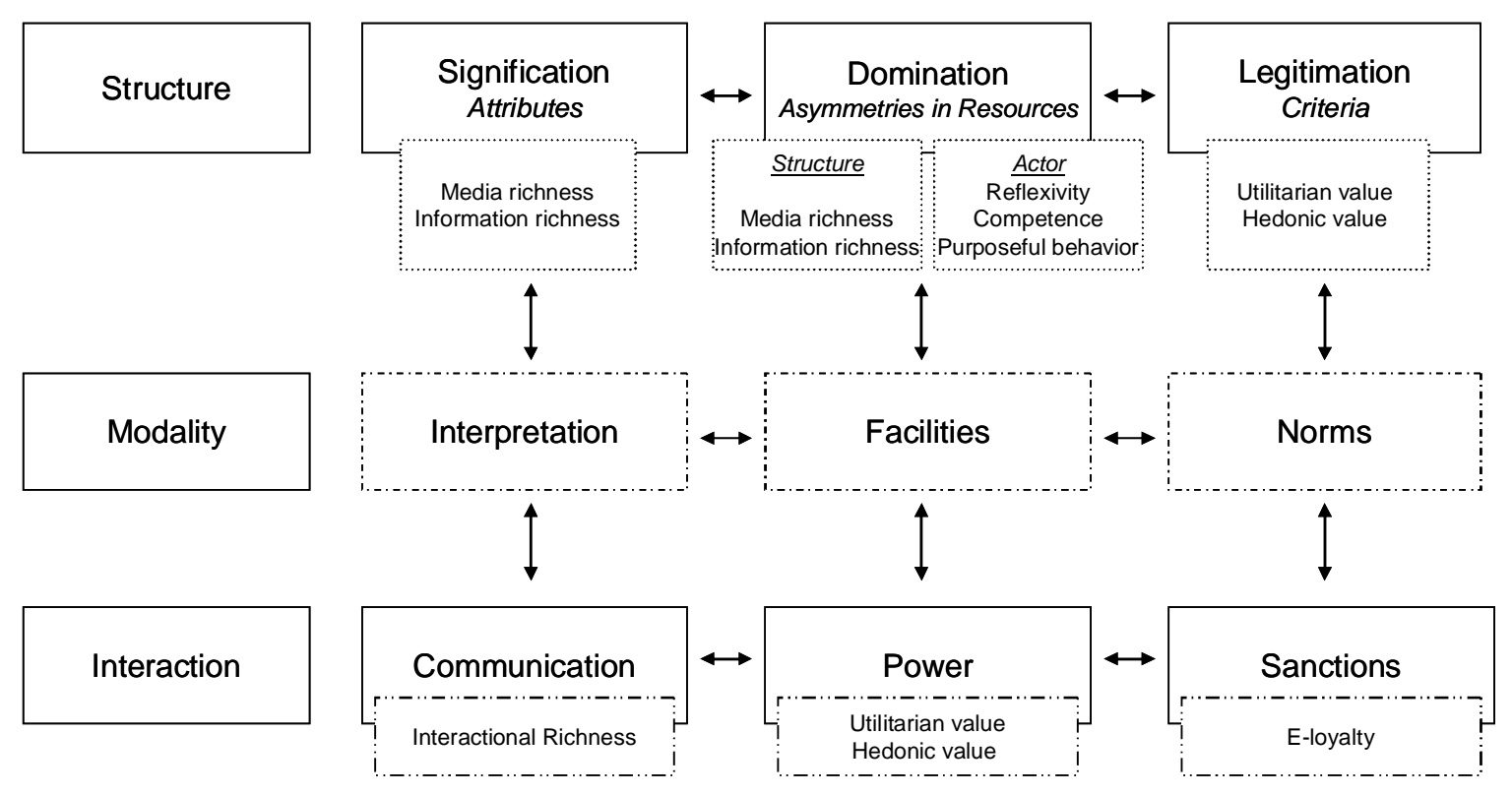

Figure 6-1: The duality of structure model applied to an online interaction process

The first phase of the duality of structure model, signification structures, focuses on visitors' perceptions of a website, which we capture in the construct interactional richness. We argue that signification structures refer to the characteristics of a website that can be interpreted by a visitor. This interpretation shapes the communication between website and visitor (figure 61). The second phase of the duality of structure model, domination structures, focuses on asymmetries in resources such as website features and idiosyncratic characteristics of the website visitor. These resources are facilities that empower the website visitors to attain their goals, which we define as utilitarian and hedonic value. The third phase of the duality of structure model, legitimation structures, focuses on evaluative criteria or norms. We consider the perceived value as a norm that website visitors can apply to legitimate their (non-) sanction behavior. We position e-loyalty as a non-sanction (or reward) in return for the perceived hedonic and/or utilitarian value and switching as a sanction resulting from a lack of perceived value. Apart from our effort to define constructs that represent the duality of structure model in an online interactive marketing context, we also strongly emphasize the interdependencies between interactional richness and both value components as well as the interdependencies between both value components and e-loyalty. Despite the fact that the duality of structure model proposes these interdependencies, visually represented by the horizontal arrows in figure 6-1, the scarce literature that applied structuration theory in an online interactive marketing context (van Dolen et al. 2007; Stewart and Pavlou 2002) has not yet explicitly incorporated these interdependencies. In 2005, Yadav and Vardarajan indicated that researchers could draw on structuration theory for their study of online marketing interactions. Because of its high level of abstraction, structuration theory offers a 
broad range of opportunities that can be used by researchers to enlarge the body of knowledge on interactivity online. From a scientific perspective our use of structuration theory to understand online marketing interactions therefore is a major step forward. Due to fast technological developments, websites and the nature of the interaction with their visitors change quickly (Evans and Brooks 2005). These changes resulted in a strong need for a framework that enables researchers to capture the interdependencies between websites and their visitors. Hence, our effort to use the duality of structure model as a promising framework to investigate online interactions advances the existing research.

\subsubsection{Interactional richness}

Building on previous research (Stewart and Pavlou 2002), the first contribution of our study is the introduction and development of a conceptualization of interactional richness that draws a distinction between media richness and information richness as an important driver of online customer value and loyalty. It is increasingly important to gain a better understanding of customers' perceptions of the online interaction as the process of value creation is rapidly changing from a company centric approach to personalized consumer experiences (Prahalad and Ramaswamy 2004). In both managerial (Pine and Gilmore 1999) and academic (Mathwick et al. 2001) literature the importance of creating valuable perceptions of online interactions for consumers has been stressed (Mathwick and Rigdon 2004). However, to the best of our knowledge there was not one single construct available to assess customers' overall perceptions of the online interface (Yadav and Varadarajan 2005b). So far, existing measures of the online interaction mainly focused on the responses and behavior of website visitors, while there was no measure available that focused on consumers' perceptions of the multi-dimensional nature of the online interaction itself (Stewart and Pavlou 2002). The higher-order construct of interactional richness as we introduce, conceptualize and empirically test in this dissertation, does assess the extent to which subjects' perceive that the website at a given point in time provides relevant, accurate, comprehensible and comprehensive information (information richness), presented in multiple ways, facilitating user control and two-way communication in real time (media richness).

\subsubsection{Assessing customers' evaluations of the online interaction experience}

So far, available studies about online marketing interactions have been valuable in their efforts to apply existing offline constructs to an online setting (e.g. Srinivasan et al. 2002; Szymanski and Hise 2000). Despite their valuable contributions, the choice of constructs investigated concurrently is arbitrary rather than structured. We believe that this lack of structure is related to the lack of an overall framework to guide researchers in this online setting. We advance existing research by using the duality of structure model as a promising 
framework to investigate online interactions and subsequently follow a more structured approach of developing conceptual frameworks which fully capture online experiences. Consequently, our second contribution refers to the development and refinement of constructs that represent the reciprocal interaction process between websites and their visitors along the lines of the duality of structure model (see figure 6-1). As described in section 6.2.2 we first developed interactional richness, which represents the signification structure in the duality of structure model. To examine the impact of website visitors' perceptions of interactional richness on their value perceptions representing the domination structure, we developed an appropriate measure to assess the utilitarian and hedonic value dimensions of concurrently. Finally, the legitimation structure is captured in the construct of e-loyalty. We purified a measure for e-loyalty explicating the distinctions between cognition, affect and conation as these underlying representations of e-loyalty contribute to the overall perceived loyalty towards a website. In addition, we refined a measure for website visitors' reflexivity as their critical evaluation of their online interaction process possibly results in different perceptions of the online interaction experience.

\subsubsection{Interactional richness: a key predictor}

From a structuration view there is a recursive, reinforcing relationship between websites and visitors' actions or behaviors (Lewis and Suchan 2003) that is driven simultaneously by consumers' and companies' goals (cfr. Payne and Frow 2005). However, the online interaction itself is not the critical issue, but whether the online interaction helps to accomplish consumers' and companies' goals (Stewart and Pavlou 2002). Consequently, our third contribution is the investigation of the impact of interactional richness on value and eloyalty, respectively consumers' and companies' goals.

Previous research already suggested that value should be assessed upon the total customer experience (Chen and Dubinsky 2003; Woodruff 1997). In this dissertation we introduced interactional richness as a measure of subjects' perceptions of a website and tested whether these perceptions influenced subjects' overall value perceptions of the online interaction experience. In line with the experiential perspective of consumption (e.g. Belk 1987; Bourdeau et al. 2002) our results demonstrate that consumers are likely to find a website more valuable (in terms of both utilitarian and hedonic value) when this website is interactional rich. Websites that include cognitive stimulations will have an opportunity to create utilitarian value and if they also offer exciting and enjoying aspects they will simultaneously create hedonic value for their visitors.

In existing marketing literature, perceived customer value is the key determinant of loyalty (Parasuraman and Grewal 2000). Also, in Payne and Frow's (2005) framework, the creation of customer value is seen as a crucial antecedent of loyalty. In an online context, Lin, Wu 
and Tsai (2005) argue that website visitors who do not perceive the online interaction experience as valuable, are not likely to return. Hence, we consider online loyalty as the value companies receive from customers in return for delivering a valuable online experience, which was created by an interaction rich website. Our empirical findings support the idea that even in the cognitively dominated functional service context (e.g. career websites), both the utilitarian and the hedonic value components add to evolving customer loyalty online.

\subsubsection{The role of website visitors' idiosyncratic characteristics}

In an online interactive marketing context, Stewart and Pavlou (2002) argue that the interaction process is not only determined by the structural features of the medium but also by the actors involved. In a similar vein, Poole and DeSanctis (2004) argue that structuration theory concerns the development of structure over time as a result of the ongoing interaction process with actors. However, so far existing research (e.g. Ranganathan and Ganapathy 2002; Srinivasan et al. 2002) mainly focused at the role of structural features, e.g. website designs, security, on the online interaction process rather than taking actor-related variables into consideration. Nevertheless, Das, Echambadi and McCardle (2003) acknowledge that a variety of website features and multi-dimensional uses of websites engage website visitors with different characteristics and personality traits. Consequently, we advance research on structuration theory and online interactive marketing by empirically showing the dominating role of customers (actors) in their reciprocal interaction process with websites at a micro level. One of the principles of structuration theory is that actors are viewed as reflexive, purposeful and competent individuals (Sarason et al. 2006). Our empirical results demonstrate that website visitors' reflexivity and competence are activated by an interactional rich website, whereas reflexivity and competence act as a moderator on the impact of interactional richness on utilitarian and hedonic value. We also found that website visitors' value perceptions differed as a result of their purposeful vs. non-purposeful behavior. These empirical findings clearly demonstrate the indispensable role of visitors' idiosyncratic characteristics.

\subsubsection{Robustness of the research results}

In this dissertation, in line with a recent trend in structuration methodology, we employed a multi-method approach to test our conceptual model from a macro change perspective and applied it to different samples in various online services contexts. Summarizing, in study one, we developed a scale for interactional richness and conducted two pilot tests with students in an information services context, respectively travel and newspaper websites. Based on our newly developed conceptualization of interactional richness, in study two, we designed an 
experimental setting in an experiential services context (mobile phone websites) and manipulated the two assumed underlying dimensions of interactional richness, media and information richness. In contrast to study one, we did not use a student sample but invited visitors of the Samsung Fun Club website to participate in our research. Our results showed that not only the direct effects of media and information richness but also their interaction effect positively influenced participants' perceptions of utilitarian and hedonic value. Consequently, in our third study, a survey research in a functional services context (career websites) focused on interactional richness as a whole, encompassing both media and information richness dimensions. Our sample consisted of people who were orientating themselves at the labor market. We employed the survey data to empirically assess the higher-order structure of interactional richness with its underlying dimensions media and information richness. In addition, our results showed that interactional richness has a positive impact on both utilitarian and hedonic value which is in line with our findings in study two. According to Wood, Daily, Miller and Roper (1999), research findings are likely to be robust when they are constant across multi-method phases with diverse samples in a variety of contexts as the results are less likely to be biased due to poor design or sample bias. In line with this, we argue that our results are robust as our findings were similar across the diverse research contexts. As illustrated in table 6-1, we found on the one hand that in an experiential services context, the interaction effect of the two underlying dimensions of interactional richness had a positive impact on utilitarian and hedonic value and on the other hand that in a functional services context, interactional richness as a whole had a positive influence on both utilitarian and hedonic value. In addition, we found across these two services contexts that both utilitarian and hedonic value had a positive impact on e-loyalty. However, we have to mention that the positive relationship between utilitarian value and eloyalty is stronger in a functional services context than in an experiential services context. Meanwhile, the positive influence of hedonic value on e-loyalty is stronger in an experiential services context than in a functional services context. In addition, we also see that the difference between the impact of utilitarian and hedonic value is larger in the functional services context than in the experiential services context. These findings are in line with our expectations that in a functional services context, website visitors' perceptions of utilitarian value play a predominant role in creating e-loyalty, as consumers in such a context are more goal-oriented, while hedonic value is more important for creating e-loyalty in an experiential services context. 
Table 6-1: Robustness of the research results

\begin{tabular}{lccc}
\hline & \multicolumn{2}{c}{ Online services context } \\
& Experiential & Functional \\
\hline Constructs & & E-loyalty & \\
Utilitarian value & 0.518 & & 0.749 \\
Hedonic value & 0.316 & & 0.167 \\
$\mathbf{R}^{2}$ & 0.719 & 0.694 \\
\hline
\end{tabular}

\subsection{Managerial implications}

From a managerial perspective, applying the duality of structure model to the highly interactive online environment offers several benefits. First, our approach helps business practice to acknowledge the strong interdependencies between websites and their visitors. So far, business practice recognized the importance of developing a sophisticated website. However, the role of the website visitor in creating their own online experience has not yet received adequate managerial attention (e.g. Vargo and Lusch 2004). To facilitate customers in creating their own online experience, companies could offer website visitors the possibility to create their own personal website with customized products or services. The company Nike already offers their customers the possibilities to customize their shoes online. However, companies could also go one step further and offer their customers the possibility to engage in co-creation to develop new products.

Second, the duality of structure model offers a useful guide for developing websites that will be perceived as interactional rich. Our findings demonstrate that interactional rich websites deliver a valuable online experience ultimately resulting in visitors' loyalty towards the website. Especially, since industry practice demonstrates that companies heavily invest in creating impressive websites, thereby often neglecting the role and the importance of the provided information. Based on the results of our research, we stress that rather than focusing on media or information features, practitioners have to take the complementary roles of media and information features of a website into consideration. For instance, in a functional services context such as career websites companies should recognize that medium and information features create both hedonic and utilitarian value vice versa. On the one hand, customers might perceive their information search at a career website for a job and related information as very effective and functional. On the other hand, they might enjoy visiting a career website for its own sake, as they can participate in a discussion forum and watch movies of companies to get an impression of their potential future employer.

Third, the duality of structure model helps practitioners as well as website visitors to realize their respective goals. Companies with an online presence usually strive for loyal website visitors as this drives the website's continuity. Visitors on the other hand want to experience 
a valuable online interaction. By applying the duality of structure model, website managers gain vital insights in the dual development of customer and company goals. Through assessing visitors' perceptions of the interactional richness of websites and its impact on their value perceptions, mangers can identify the strengths and weaknesses of their website in relation to visitors' perceived utilitarian and hedonic value. Based on these insights managers can constantly improve the content of their websites in order to enhance website visitors' perceptions of the online experience and ultimately their loyalty towards the company's website.

Fourth, the duality of structure model enables practitioners to identify different customer segments based on website visitors' idiosyncratic characteristics. A better insight into these subject-related characteristics of website visitors such as reflexivity, competence and purposeful behavior enables companies to improve their customer segmentation and adapt the online interface to segment specific needs. For instance, companies could develop different websites for either high or low competent website visitors or they could offer their low competent visitors assistance through a virtual agent.

Summarizing, in order to create a superior online interaction experience, companies should understand customers' needs and assess how they perceive the different aspects of the online interaction experience. Our interactional richness construct can be used by managers for assessing customers' perceptions of the website. Our research might provide companies with an increased understanding of why some websites are perceived more valuable and attractive to customers than others. Based on the empirical results of our research, we suggest that companies should deliver a rich online interactive experience to their customers to enable website visitors to accomplish their task and enjoy the online experience itself, which both have a significant impact on customers' loyalty towards the website. Moreover, our results indicate that it is important for managers to gain a better understanding of customer differences as these significantly influence the relationship between customers' value perceptions of the online experience and their loyalty towards the website.

\subsection{Limitations and suggestions for further research}

In this dissertation, we only assessed the interactional richness of one communication channel, websites, while it might also be very interesting to assess the level of interactional richness across channels. Future research could apply our research framework in a multichannel context incorporating both offline and online channels as most companies nowadays interact with their customers through various channels. Applying our research framework in a multi-channel context would be especially interesting as different channels vary in their potential of interactional richness. Moreover, it would also be interesting to apply our research framework to different online channels such as communities and blogs where 
customers highly interact with each other, and to virtual worlds, e.g. second life.com, where customers and companies create their own virtual identity for their online interaction.

From a structuration perspective, we employed a multi-method approach to capture and understand the reciprocal interactions and co-evolution between websites and their visitors over time. Although the multi-method approach already provided us with crucial insights into the strong interdependencies and co-evolution of websites and their visitors over time, a longitudinal approach can further advance our findings. In addition, research on the reciprocal interaction process between websites and their visitors would also benefit from gathering clickstream data over time, representing visitors' actual behavior at a website, as this data would provide us more in depth information how structures (websites) are produced and reproduced over time due to actors' (visitors') actions.

In our experimental design we manipulated the extremes of website visitors' purposeful behavior, search versus browse behavior, in order to assess the separate influence of these two types of purposeful behavior. However, we acknowledge that a customer can exhibit a combination of both types of purposeful behavior during a website visit. Future research could investigate a mixture of these two types of purposeful behavior.

In line with structuration theory, we examined the impact of three idiosyncratic characteristics of website visitors, reflexivity, competence and purposeful behavior, on website visitors' perceptions of the online interaction experience. However, other idiosyncratic characteristics of website visitors such as need for cognition or need for affect may also influence website visitors perceptions of their online interaction experience. Hence, additional research should be devoted to examining the role of different idiosyncratic characteristics in website visitors' evaluation of the online interaction process. Moreover, it would also be interesting to identify and develop different typologies of website visitors based on these characteristics.

\subsection{A final thought}

Our study is entitled "From Rags to Richness", a variation on the well-known theme "Rags to Riches". In this very final section we would like to take the opportunity to briefly philosophize about this major theme. In the world around us, many stories (e.g. Cinderella), movies (e.g. Rocky), reality television shows (e.g. Idols), and even songs (e.g. Rags to riches by Tony Bennett) feature a Rags to Riches theme. This theme basically refers to any situation in which an object rises from the unknown to fame or from poverty to wealth, providing hope to the poor that they can rise to fame and wealth.

In a similar vein, our study "gives hope" to online companies by demonstrating that the mere online presence is too poor to create a valuable online experience. Website designers have to acknowledge that a website should offer opportunities for rich interactions with website visitors. Only then, website visitors will become inclined to return to the site and to share their 
valuable online experiences with others. Our study also "gives hope" to website visitors as they ultimately benefit from the enriched online interactions, possibly resulting in customized websites contributing to their approval of the online experience.

So, by acknowledging the dominant role of interactional richness online companies and their website visitors will live happily ever after and evolve from rags to richness. 
Appendices

\section{Appendix A: Method qualitative pre-test measure development interactional} richness

\begin{tabular}{|c|c|c|c|c|c|c|}
\hline Relevance & Accuracy & Synchronicity & Comprehensibility & $\begin{array}{l}\text { Multiplicity of } \\
\text { Presentation }\end{array}$ & Control & Completeness \\
\hline $\begin{array}{l}\text { The extent } \\
\text { to which the } \\
\text { user } \\
\text { perceives } \\
\text { the } \\
\text { information } \\
\text { on the } \\
\text { website to } \\
\text { meet his } \\
\text { needs }\end{array}$ & $\begin{array}{l}\text { The extent } \\
\text { to which the } \\
\text { user } \\
\text { perceives } \\
\text { the } \\
\text { information } \\
\text { on the } \\
\text { website to } \\
\text { be correct }\end{array}$ & $\begin{array}{l}\text { The extent to } \\
\text { which the user } \\
\text { perceives that } \\
\text { the website } \\
\text { facilitates } \\
\text { two-way } \\
\text { communication } \\
\text { between the } \\
\text { organization's } \\
\text { website and } \\
\text { users and/or } \\
\text { across users in } \\
\text { real time }\end{array}$ & $\begin{array}{l}\text { The extent to which } \\
\text { the user perceives } \\
\text { the information on } \\
\text { the website to be } \\
\text { easy to decode and } \\
\text { to understand }\end{array}$ & $\begin{array}{l}\text { The extent to } \\
\text { which the user } \\
\text { perceives that the } \\
\text { website uses } \\
\text { multiple cues to } \\
\text { present the } \\
\text { information } \\
\text { (e.g. text, } \\
\text { pictures, symbols, } \\
\text { written and } \\
\text { spoken language } \\
\text { and language with } \\
\text { a personal tone) }\end{array}$ & $\begin{array}{l}\text { The extent } \\
\text { to which the } \\
\text { user } \\
\text { perceives } \\
\text { that the } \\
\text { website } \\
\text { enables him } \\
\text { to create his } \\
\text { own } \\
\text { experiences } \\
\text { at the } \\
\text { website }\end{array}$ & $\begin{array}{l}\text { The extent to } \\
\text { which the user } \\
\text { perceives the } \\
\text { information on } \\
\text { the website to } \\
\text { be complete }\end{array}$ \\
\hline
\end{tabular}




\section{Appendix A: continued}

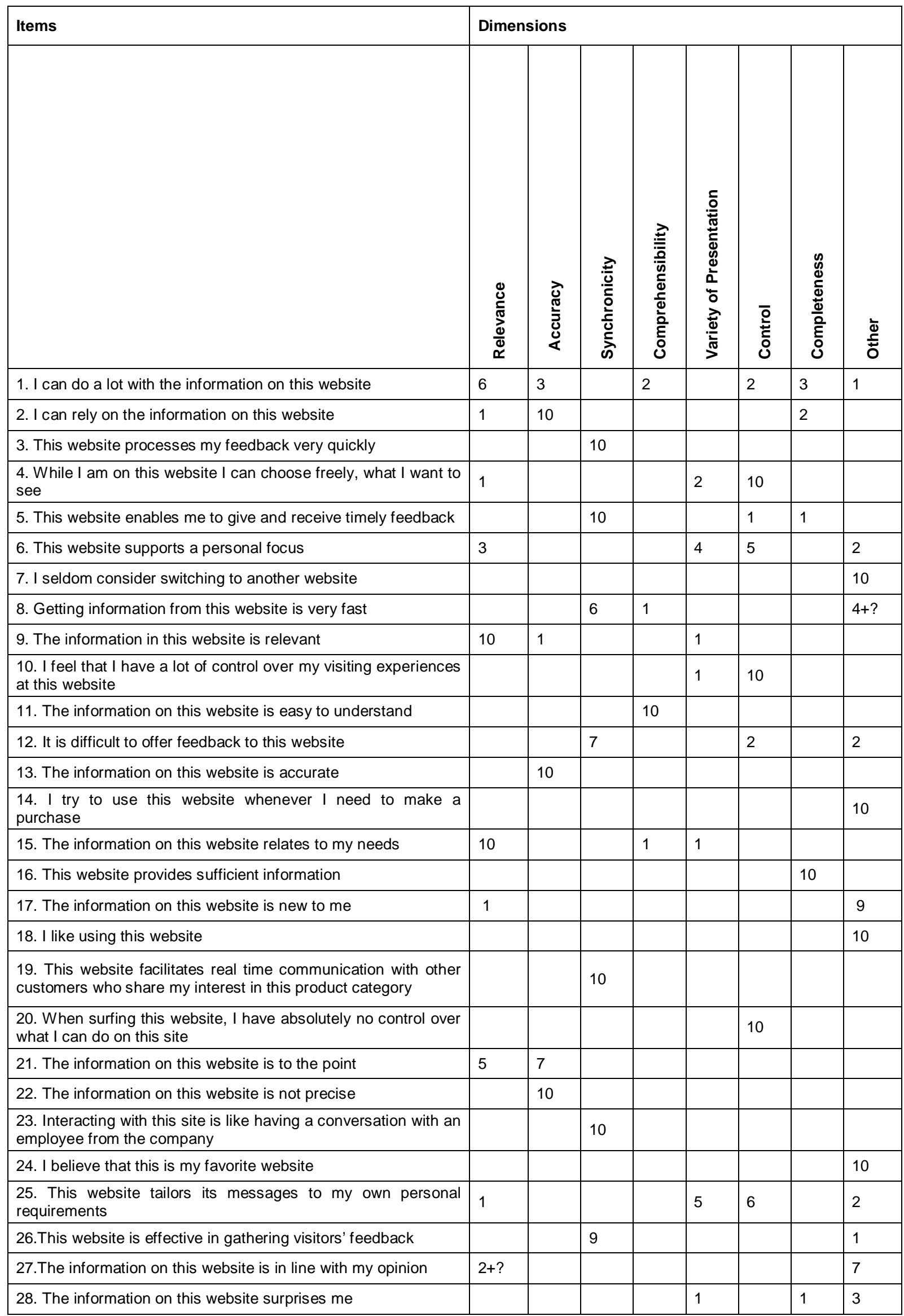


29. This site has the ability to respond to my specific questions quickly

30. This website uses appropriate cues such as words and text to present the information

31. I am able to obtain information I want from this website without any delay

32. The information on this website is clear to me

33. I feel as if this website talks back to me while I am navigating

34. This website adds meaning to what it wants to say by using appropriate cues (pictures, symbols, numbers, text etc.)

35. This website enables me to ask questions and obtain answers as they arise

36. To me this website is the best website to do business with

37. This website does not at all encourage visitors to talk back

38. This website makes me feel it wants to listen to its visitors

39. As long as the present service continues, I doubt that I would switch websites

40. This website communicates a variety of different cues (such as emotional tone, attitude, or formality) in its messages

41. When I need to make a purchase, this website is my firs choice

42. The information on this website is complete

43. When I clicked on the links, I felt that I was getting instantaneously information

44. Via this website I can communicate with the organization directly for further questions about the organization or its products if I want to

45. The information on this website is presented clearly

46. This website was slow in responding to my requests

47. While surfing this website my actions decided the kind of experiences I got

48. The information on this website does not help me at all

49. The information on this website is sufficiently detailed

50 . This website uses rich and varied language in its messages

51. The information on this website reflects the reality

52. The information on this website is not presented in an adequate way

53. This website gives visitors the opportunity to talk back in real time

54. The information on this website is unambiguous

55. This website facilitates immediate two-way communication between the visitors and the site

56. The information on this website is recent to me

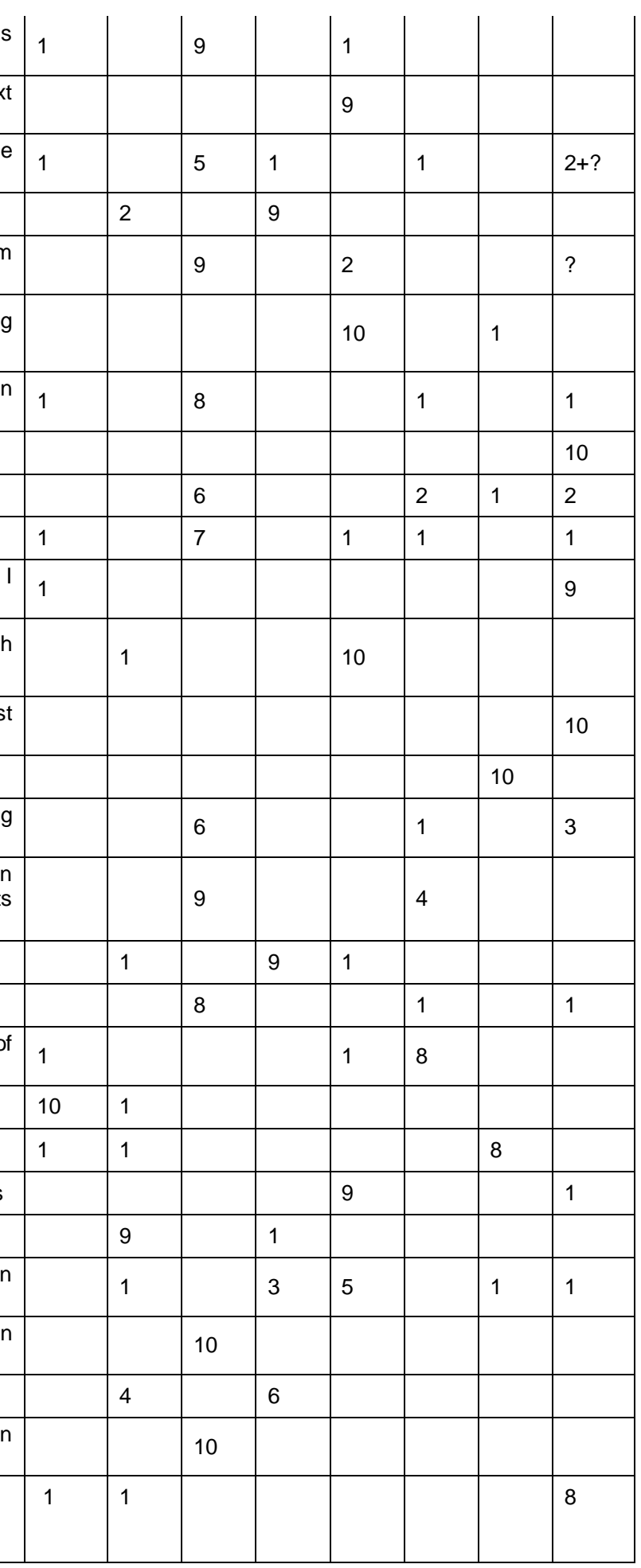




\section{Appendix B: Results qualitative pre-test measure development interactional} richness

\begin{tabular}{|c|c|c|}
\hline Original item & Adapted item & $\begin{array}{l}\text { Delete } \\
?\end{array}$ \\
\hline \multicolumn{3}{|c|}{ Accuracy } \\
\hline \multicolumn{3}{|l|}{ Information Accuracy (Muylle et al., 2003) } \\
\hline The information in the website is accurate & on this website & No (10) \\
\hline The information in the website is not precise ${ }^{*}$ & on this website & No (10) \\
\hline I can rely on the information in this website & on this website & No (10) \\
\hline \multicolumn{3}{|l|}{ Information credibility (adapted from Moenaert et al., 1996) } \\
\hline The information in the website reflects the reality & on this website & No (9) \\
\hline The information in the website is unambiguous & on this website & $?$ \\
\hline \multicolumn{3}{|c|}{ Comprehensibility } \\
\hline \multicolumn{3}{|l|}{ Information Comprehensibility (Muylle et al., 2003 ) } \\
\hline The information in the website is easy to understand & on this website & No (10) \\
\hline The information in the website is clear to me & on this website & No (9) \\
\hline The information in the website is presented clearly & on this website & No (9) \\
\hline $\begin{array}{l}\text { The information in the website is not presented in an } \\
\text { adequate way * }\end{array}$ & on this website & ?? \\
\hline \multicolumn{3}{|c|}{ Comprehensiveness } \\
\hline Information Comprehensiveness (Muylle et al., 2003) & Completeness & \\
\hline The website provides sufficient information & No changes & No (10) \\
\hline The information in the website is complete & on this website & No (10) \\
\hline The information in the website is sufficiently detailed & on this website & No $(8)$ \\
\hline \multicolumn{3}{|c|}{ Relevance } \\
\hline \multicolumn{3}{|l|}{ Information Relevancy (Muylle et al., 2003) } \\
\hline The information in the website is relevant & on this website & No (10) \\
\hline The information in the website is to the point & on this website & $?$ \\
\hline The information in the website does not help me at all* & On this website & No (10) \\
\hline \multicolumn{3}{|l|}{$\begin{array}{l}\text { Information Relevance (adapted from Moenaert et al., } \\
\text { 1996) }\end{array}$} \\
\hline The information in the website relates to my needs & On this website & No (10) \\
\hline I can do a lot with the information in the website & On this website & Yes \\
\hline
\end{tabular}




\begin{tabular}{|c|c|c|}
\hline \multicolumn{2}{|c|}{ Synchronicity } & \multirow[b]{2}{*}{$\begin{array}{l}\text { Delete } \\
?\end{array}$} \\
\hline Original item & Adapted item & \\
\hline \multicolumn{3}{|l|}{ Synchronicity (Liu, 2002) } \\
\hline The website processed my input very quickly & This website processes my feedback very quickly & No \\
\hline Getting information from the Website is very fast & this website & Yes \\
\hline $\begin{array}{l}\text { When I clicked on the links, I felt I was getting instantaneous } \\
\text { information }\end{array}$ & $\begin{array}{l}\text { When I click on the links, I get instantaneously } \\
\text { information }\end{array}$ & $?$ \\
\hline The website was very slow in responding to my request * & This website is slow in responding to my request & No $(8)$ \\
\hline I was able to obtain information I want without any delay & $\begin{array}{l}\text { I am able to obtain information I want from this } \\
\text { website without any delay }\end{array}$ & $?$ \\
\hline \multicolumn{3}{|l|}{ Media Richness (Carlson and Z Zmud, 1999) } \\
\hline $\begin{array}{l}\text { This website allows me and my communication partner to } \\
\text { give and receive timely feedback }\end{array}$ & $\begin{array}{l}\text { This website enables me to give and receive timely } \\
\text { feedback }\end{array}$ & No $(10)$ \\
\hline \multicolumn{3}{|l|}{ Media Richness ( D'Ambra, Rice and Connor, 1998) } \\
\hline $\begin{array}{l}\text { This website allows communicators to ask questions and } \\
\text { obtain answers as they arise }\end{array}$ & $\begin{array}{l}\text { This website enables me to ask questions and obtain } \\
\text { answers as they arise }\end{array}$ & No (8) \\
\hline \multicolumn{3}{|l|}{ Perceived interactivity,(Jee and Lee, 2002) } \\
\hline $\begin{array}{l}\text { I could communicate in real time with other customers who } \\
\text { shared my interest in this product category }\end{array}$ & $\begin{array}{l}\text { This website facilitates real time communication with } \\
\text { other customers who share my interest in this product } \\
\text { category }\end{array}$ & No $(10)$ \\
\hline $\begin{array}{l}\text { I could communicate with the company directly for further } \\
\text { questions about the company or its products if I wanted to }\end{array}$ & $\begin{array}{l}\text { Via this website I can communicate with the } \\
\text { organization directly for further questions about the } \\
\text { organization or its products if I want to }\end{array}$ & No $(9)$ \\
\hline $\begin{array}{l}\text { Interacting with this site is like having a conversation with a } \\
\text { sociable, knowledgeable employee from the company }\end{array}$ & $\begin{array}{l}\text { Interacting with this site is like having a conversation } \\
\text { with an employee from the company }\end{array}$ & No (10) \\
\hline I felt as if this Website talked back to me while I was navigating & $\begin{array}{l}\text { I feel as if this website talks back to me while I am } \\
\text { navigating }\end{array}$ & No $(9)$ \\
\hline $\begin{array}{l}\text { The site had the ability to respond to my specific questions } \\
\text { quickly and efficiently }\end{array}$ & $\begin{array}{l}\text { This site has the ability to respond to my specific } \\
\text { questions quickly }\end{array}$ & No $(9)$ \\
\hline \multicolumn{3}{|l|}{ 2-way communication, (Liu, 2002) } \\
\hline This website is effective in gathering visitors' feedback & No changes & No $(9)$ \\
\hline $\begin{array}{l}\text { This website facilitates two-way communication between the } \\
\text { visitor and the site }\end{array}$ & $\begin{array}{l}\text { This website facilitates immediate two -way } \\
\text { communication between the visitors and the site }\end{array}$ & No (10) \\
\hline It is difficult to offer feedback to the website* & This website & $?$ \\
\hline This website makes me feel it wants to listen to its visitors & No changes & $?$ \\
\hline This website does not at all encourage visitors to talk back* & No changes & $?$ \\
\hline This website gives visitors the opportunity to talk back & No changes & No $(10)$ \\
\hline
\end{tabular}




\begin{tabular}{|c|c|c|}
\hline \multicolumn{2}{|c|}{ Synchronicity (continued) } & \multirow[b]{2}{*}{ Delete? } \\
\hline Original item & Adapted item & \\
\hline \multicolumn{3}{|l|}{ Media Richness (Carlson and Zmud, 1999) } \\
\hline $\begin{array}{l}\text { This website allows me and my communication partner to tailor } \\
\text { our messages to our own personal requirements }\end{array}$ & $\begin{array}{l}\text { This website tailors its messages to my own personal } \\
\text { requirements }\end{array}$ & $?$ \\
\hline $\begin{array}{l}\text { This website allows my communication partner and me to } \\
\text { communicate a variety of different cues (such as emotional tone, } \\
\text { attitude, or formality) in our messages }\end{array}$ & $\begin{array}{l}\text { This website communicates a variety of different cues } \\
\text { (such as emotional tone, attitude, or formality) in its } \\
\text { messages }\end{array}$ & $\begin{array}{l}\text { No } \\
(10)\end{array}$ \\
\hline $\begin{array}{l}\text { This website allows my communication partner and me to use } \\
\text { rich and varied language in our messages }\end{array}$ & $\begin{array}{l}\text { This website uses rich and varied language in its } \\
\text { messages }\end{array}$ & No (9) \\
\hline \multicolumn{3}{|c|}{ Multiplicity of Cues } \\
\hline \multicolumn{3}{|l|}{ Media Richness (D'Ambra, Rice and Connor, 1998) } \\
\hline $\begin{array}{l}\text { This website allows communicators to add meaning to what they } \\
\text { want to say by using as many cues (pictures, symbols, numbers, } \\
\text { text etc.) as possible. }\end{array}$ & $\begin{array}{l}\text { This website adds meaning to what it wants to say by } \\
\text { using multiple cues (pictures, symbols, numbers, text etc.) }\end{array}$ & No (9) \\
\hline $\begin{array}{l}\text { This website allow communicators to be flexible with the way } \\
\text { words and text are used in order to increase understanding. }\end{array}$ & $\begin{array}{l}\text { This website uses various cues such as pictures and text } \\
\text { to present the information }\end{array}$ & No (9) \\
\hline \multicolumn{3}{|c|}{ Control } \\
\hline \multicolumn{3}{|l|}{ Active control (Liu, 2002) } \\
\hline $\begin{array}{l}\text { I felt that I had a lot of control over my visiting experiences at this } \\
\text { Web site }\end{array}$ & $\begin{array}{l}\text { I feel that I have a lot of control over my visiting } \\
\text { experiences at this website }\end{array}$ & No (10) \\
\hline $\begin{array}{l}\text { While I was on the Website, I could choose freely what I wanted } \\
\text { to see }\end{array}$ & $\begin{array}{l}\text { When I am on this website, I can choose freely what I want } \\
\text { to see }\end{array}$ & No (10) \\
\hline $\begin{array}{l}\text { While surfing the Website, I had absolutely no control over what } \\
\text { I can do on the site }\end{array}$ & $\begin{array}{l}\text { When surfing this website, I have absolutely no control } \\
\text { over what I can do on this site }\end{array}$ & No (10) \\
\hline $\begin{array}{l}\text { While surfing the Website, my actions decided the kind of } \\
\text { experiences I got }\end{array}$ & $\begin{array}{l}\text { When surfing this website, my actions determine the kind } \\
\text { of experiences I get }\end{array}$ & No (8) \\
\hline \multicolumn{2}{|c|}{ Other } & Delete? \\
\hline This website supports a personal focus & & Yes \\
\hline I seldom consider switching to another website & & Yes \\
\hline I try to use this website whenever I need to make a purchase & & Yes \\
\hline The information on this website is new to me & & Yes \\
\hline I like using this website & & Yes \\
\hline I believe that this is my favorite website & & Yes \\
\hline The information on this website is in line with my opinion & & Yes \\
\hline The information on this website surprises me & & Yes \\
\hline $\begin{array}{l}\text { As long as the present service continues, I doubt that I would } \\
\text { switch websites }\end{array}$ & & Yes \\
\hline When I need to make a purchase, this website is my first choice & & Yes \\
\hline The information on this website is recent to me & & Yes \\
\hline I seldom consider switching to another website & & Yes \\
\hline
\end{tabular}

The last column indicates whether the item should be deleted or not.

No: the items were very clear and did not cause any problems with assigning them to a dimension (nr. assigned to one category)

Yes: the items were deleted

?: items which are assigned to more than one category, not yet deleted

* : reversed scale item 


\section{Appendix C: Questionnaire pilot test 1}

\section{Questionnaire}

This research investigates people's experiences with travel websites. Travel websites are sites where you can search for information about a weekend trip or holiday and/or book such a trip, excluding sites where you can only book flight tickets.

1. Please write down three of your most favorite travel websites

1.

2.

3.

2. Which of your favorite travel websites do you visit most often?

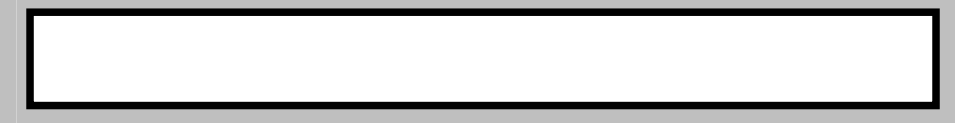

The following questions are about your experience with the travel website you mentioned in the box (question 2). Please read all questions carefully and fill out the answers that best describe your experiences with your favorite travel website. There are no wrong or right answers; we are just interested in your opinion. However, it is extremely important that you answer all the questions. Don't worry about questions that look alike.

\begin{tabular}{|c|c|c|c|c|c|c|c|}
\hline 3. & This website processes my input very quickly & $f$ & $f$ & $f$ & $f$ & $f$ & $f \quad f$ \\
\hline 4. & When I am on this website, I can choose freely what I want to see & $f$ & $f$ & $f$ & $f$ & $f$ & $£ \quad f$ \\
\hline 5. & This website enables me to give and receive immediate feedback & $f$ & $f$ & $f$ & $f$ & $f$ & $f \quad f$ \\
\hline 6. & This website supports a personal focus & $f$ & $f$ & $f$ & $f$ & $f$ & $f \quad f$ \\
\hline 7. & I am very experienced using this website & $f$ & $f$ & $f$ & $f$ & $f$ & $f \quad f$ \\
\hline 8. & Getting information from this website is very fast & $f$ & $f$ & $f$ & $f$ & $f$ & $f \quad f$ \\
\hline 9. & The information on this website is relevant & $f$ & $f$ & $f$ & $f$ & $f$ & $f \quad f$ \\
\hline 10. & I feel that I have a lot of control over my visiting experiences at this website & $f$ & $f$ & $£$ & $f$ & $f$ & $£ \quad f$ \\
\hline 11. & The information on this website is easy to understand & $f$ & $f$ & $f$ & $f$ & $f$ & $f$ \\
\hline 12. & It is difficult to offer feedback to this website & $f$ & $f$ & $f$ & $f$ & $f$ & $£ \quad f$ \\
\hline 13. & The information on this website is accurate & $f$ & $f$ & $f$ & $f$ & $f$ & $f \quad f$ \\
\hline 14. & I feel that this website is easy to use & $f$ & $f$ & $f$ & $f$ & $f$ & $f$ \\
\hline 15. & The information on this website relates to my needs & $f$ & $f$ & $f$ & $f$ & $f$ & $f$ \\
\hline
\end{tabular}


16. This website provides sufficient information

17. The information on this website is new to me

18. I feel competent using this website

19. This website facilitates real time communication with other customers who share my interest in this service

20. When surfing this website, I have absolutely no control over what I can do on this site

21. The information on this website is to the point

22. The information on this website is not precise

23. Interacting with this site is like having a conversation with an employee from the company

24. I understand how to use all the features of this website

25. This website tailors its messages to my own personal requirements

26. This website is effective in gathering visitors' feedback

27. The information on this website is in line with my opinion

28. The information on this website surprises me by its newness

29. This site has the ability to respond to my specific questions quickly

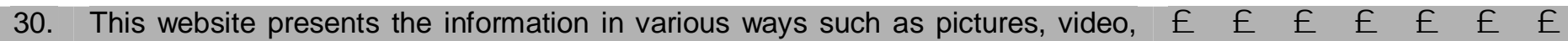
text etc.

31. I am able to obtain information I want from this website without any delay

32. The information on this website is clear to me

33. I feel as if this website talks back to me while I am navigating

34. This website expresses in multiple ways what it wants to say by using pictures, symbols, numbers, text etc.

35. This website enables me to ask questions and obtain answers as they arise

36. I feel comfortable using this website

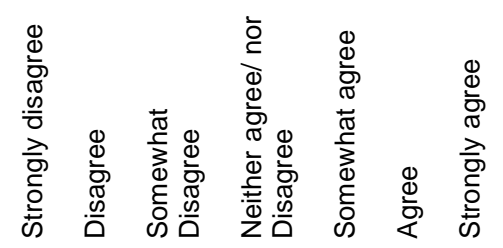

$£ \quad £ \quad f \quad € \quad f \quad f \quad f$

$\begin{array}{lllllll} & f & f & f & f & f & f\end{array}$

$f \quad f \quad f \quad f \quad f \quad f \quad f$

$\begin{array}{lllllll} & f & f & f & f & f & f\end{array}$

$\begin{array}{llllllll} & f & f & f & f & f & f\end{array}$

$\begin{array}{lllllll} & f & f & f & £ & f & \end{array}$

$\begin{array}{llllllll} & f & f & f & f & f & f\end{array}$

$\begin{array}{llllllll} & f & f & f & f & f & f\end{array}$

$f \quad f \quad f \quad f \quad f \quad f \quad f$

$\begin{array}{lllllll} & f & f & f & f & f & \end{array}$

$\begin{array}{lllllll} & f & f & f & f & f & f\end{array}$

$\begin{array}{lllllll} & f & f & f & f & f & f\end{array}$

$\begin{array}{lllllll} & f & f & f & f & f & f\end{array}$

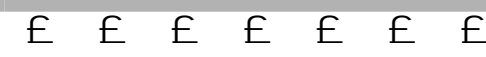

$\begin{array}{lllllll} & f & f & f & f & f & f\end{array}$

$£ \quad f \quad f \quad f \quad f \quad f \quad f$

$\begin{array}{lllllll} & f & f & f & f & f & f\end{array}$

$\begin{array}{lllllll} & f & f & f & f & f\end{array}$

$\begin{array}{lllllll} & f & f & f & £ & £ & f\end{array}$

$\begin{array}{lllllll} & f & f & f & f & f & f\end{array}$ 
37. This website does not at all encourage visitors to talk back

38. This website makes me feel it wants to listen to its visitors

39. I feel that I am a novice using this website

40. This website communicates its information in various ways such as written and spoken language with a personal tone, pictures, symbols etc.

41. I feel that I am experienced with the information provided at this website

42. The information on this website is complete

43. When I click on the links, I instantaneously get information

44. Via this website I can directly communicate with the organization for further information

45. The information on this website is presented clearly

46. This website is slow in responding to my requests

47. While surfing this website my actions determine the kind of experiences I get

48. The information on this website does not help me at all

49. The information on this website is sufficiently detailed

50. This website uses rich and varied language in its messages

51. The information on this website reflects reality

52. The information on this website is not presented in an adequate way

53. This website gives visitors the opportunity to talk back in real time

54. This website is a rich medium because it facilitates user control, two-way communication in real time and uses multiple ways to present the information

55. I perceive the information at this website to be rich because it is relevant, novel, accurate, complete and comprehensible information

56. Overall, this website is a rich medium that provides rich information

57. The information on this website is correct

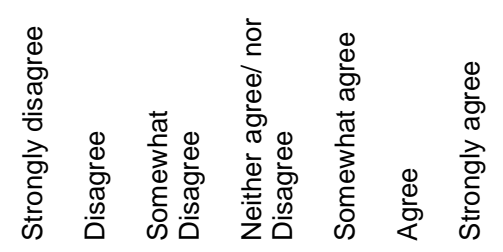

$£ \quad £ \quad f \quad € \quad £ \quad f \quad f$

$\begin{array}{lllllll} & f & f & f & f & f & f\end{array}$

$f \quad f \quad f \quad f \quad f \quad f \quad f$

$\begin{array}{lllllll} & f & f & f & f & & \end{array}$

$\begin{array}{lllllll} & f & f & f & f & f & f\end{array}$

$£ \quad £ \quad f \quad f \quad f \quad f \quad f$

$\begin{array}{lllllll} & f & f & f & f & f & f\end{array}$

$\begin{array}{lllllll} & f & f & £ & £ & £ & f\end{array}$

$\begin{array}{lllllll} & f & f & f & f & f & f\end{array}$

$\begin{array}{lllllll} & f & f & f & f & f & f\end{array}$

$\begin{array}{lllllll} & f & f & f & f & f & f\end{array}$

$\begin{array}{lllllll} & f & f & f & £ & f & f\end{array}$

$\begin{array}{lllllll} & f & f & f & f & f & f\end{array}$

$\begin{array}{lllllll} & f & f & f & f & f & f\end{array}$

$\begin{array}{lllllll} & f & f & f & f & f\end{array}$

$\begin{array}{lllllll} & f & f & f & f & £ & f\end{array}$

$\begin{array}{lllllll} & f & f & f & f & f\end{array}$

$£ \quad £ \quad f \quad f \quad f \quad f \quad f$

$\begin{array}{lllllll} & f & f & f & £ & f\end{array}$

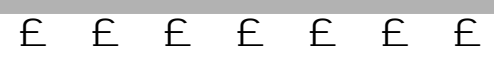

$\begin{array}{lllllll} & f & f & f & f & f & f\end{array}$ 


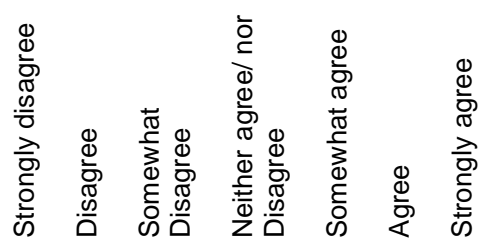

58. This website facilitates immediate two-way communication between the visitors $\quad f \quad f \quad f \quad f \quad f \quad f \quad f$ and the site

59. I perceive the information on this website to be up to date $\begin{array}{lllllllllll} & f & f & f & f & f & f\end{array}$

60. I can do a lot with the information on this website $\begin{array}{lllllllllllll} & f & f & f & f & f & f\end{array}$

61. I do not feel knowledgeable about the information provided at this website $\begin{array}{lllllllllll} & f & f & f & f & f & f\end{array}$

62. I can rely on the information on this website $\begin{array}{lllllllllllllll} & f & f & f & f & f & f\end{array}$

63. I feel that I am familiar with the content of this website $\begin{array}{llllllll} & f & f & f & f & f & f\end{array}$

64. This website is in general a lean medium that provides poor information $\begin{array}{lllllllllllll} & f & f & f & f & f & f\end{array}$

65. A new idea with evaluating people's experiences with websites is Interactional Richness, which can be defined as the extent to which an interaction at a given point in time provides rich information facilitated by a rich medium

Please indicate your level of agreement with the following statement.

Overall, I consider this website to be Interactionally Rich

66. On average, how often do you use this website?

f Never/ Almost Never

$f$ Less than once a month

f A few times a month

$f$ A few times a week

f About once a day

f Several times a day

68. What is your gender?

$f$ male $f$ female

70. Please indicate your age range

$f$ younger than 18

$f$ from 18 until 23

$f$ from 23 until 28

$£$ from 28 and older
67. On average, how often do you use the Internet?

f Never/ Almost Never

$£$ Less than once a month

$f$ A few times a month

f A few times a week

$f$ About once a day

$f$ Several times a day

69. What is your nationality?

71. Please indicate your education level

$f 3^{\text {rd }}$ year Graduate

$f 4^{\text {th }}$ year Graduate

$f 2^{\text {nd }}$ year Bachelor

f $3^{\text {rd }}$ year Bachelor

$f$ Master

$£$ Other

\section{Many thanks for your cooperation!!!}




\section{Appendix D: Questionnaire pilot test 2}

\section{Customers' experiences with online newspaper websites}

This research investigates people's experiences with online newspaper websites.

If you complete this questionnaire, you have the chance of winning one of 25 vouchers of $€ 10$ each.

1. Please write down three online newspaper websites you know

1.

2.

3.

2. Which of these online newspaper websites do you visit most often?

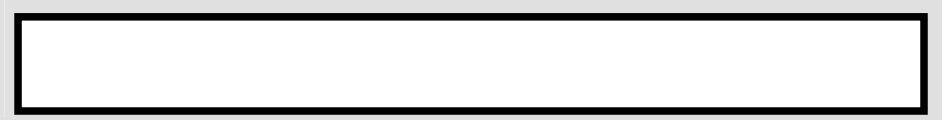

The following questions are about your experience with the online newspaper website you mentioned in the box (question 2). Please read all questions carefully and fill out the answers that best describe your experiences with the online newspaper website you visit most often. There are no wrong or right answers; we are just interested in your opinion. However, it is extremely important that you answer all the questions. Don't worry about questions that look alike.

\section{The information on this website is easy to understand}

4. I believe that this is my favorite online newspaper website

5. The information on this website is relevant

6. It is always a pleasant experience to visit this website, that is why I continue to visit it

7. This website enables me to ask questions and obtain answers as they arise

8. I am a loyal visitor to this website

9. This website communicates its information in various ways such as text, pictures, symbols etc.

10. I say positive things about this website to other people

11. I feel that I have a lot of control over what happens when I visit this website

12. I seldom consider switching to another website

13. I can rely on the information on this website

14. I like using this website

15. This website provides sufficient information on news events

16. Via this website I can directly communicate with the underlying organization for further information

17. To me this website is the best online newspaper website to visit

18. I remain a visitor of this website, because I feel a strong attachment to this website

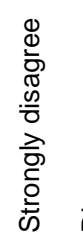

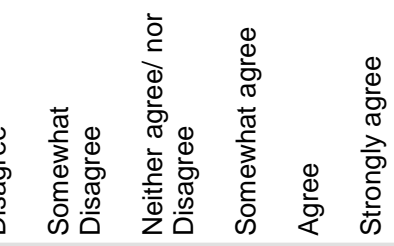

$\begin{array}{lllllll} & f & f & f & f & f & f\end{array}$

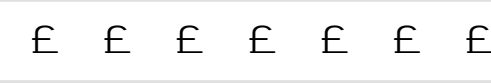

$f \quad f \quad f \quad f \quad f \quad f \quad f$

$f \quad f \quad f \quad f \quad f \quad f \quad f$

$f \quad f \quad f \quad f \quad f \quad f \quad f$

$\begin{array}{lllllll} & \ddagger & \ddagger & \ddagger & \ddagger\end{array}$

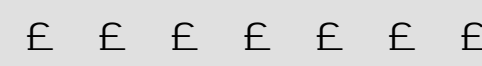

$£ \quad £ \quad £ \quad £ \quad f \quad f$

$£ \quad £ \quad f \quad f \quad f \quad f \quad f$

$\begin{array}{lllllll} & \ddagger & \ddagger & \ddagger & & & \end{array}$

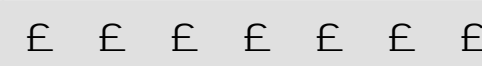

$\begin{array}{lllllll} & \pm & \ddagger & \ddagger & f & \end{array}$

$£ \quad £ \quad f \quad f \quad f \quad f$

$£ \quad £ \quad £ \quad £ \quad f$

$f \quad £ \quad f \quad f \quad f \quad f \quad f$

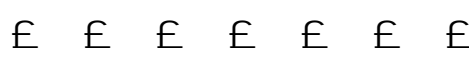




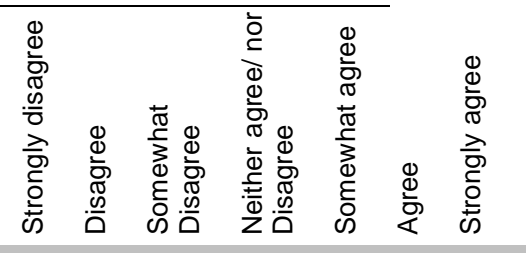

19. This website expresses in multiple ways what it wants to say by using pictures, symbols, numbers, text etc.

20. I intend to visit this website more in the next few years

$\begin{array}{lllllll} & f & \ddagger & \ddagger & \ddagger & f\end{array}$

21. If I had to pay for this online newspaper website, I would stop visiting it

$£ \quad f \quad f \quad f \quad f \quad f \quad f$

22. When I am on this website, I can choose freely what I want to see

$\begin{array}{llllllll} & f & f & f & f & f & f\end{array}$

23. In the future, this website is one of the first places I will look when I want to read
the latest news

24. One of the reasons why I visit this website is because I like it

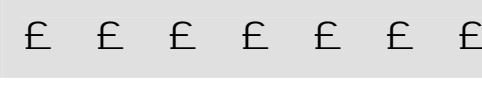

25. The information on this website is to the point

$\begin{array}{lllllll} & f & f & f & f & f & f\end{array}$

26. I do not encourage friends to visit this website

$£ \quad £ \quad £ \quad f \quad f \quad f \quad f$

27. I will visit this website less in the next few years

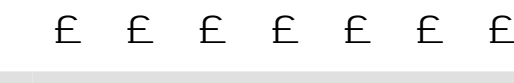

28. The information on this website reflects reality

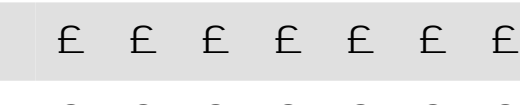

29. I intend to visit this website in the future

30. The information on this website is clear to me

31. I continue visiting this website, because I feel like I am "part of the newspaper's
family"

32. If I had to pay for this online newspaper website, I would pay a higher price at
this website compared to another newspaper website for the similar benefit

33. The information on this website is complete

34. This website is the best online newspaper website to read the latest news

$\begin{array}{llllllllllllll} & f & f & f & f & f & f\end{array}$

35. I feel as if this website talks back to me while I am navigating

36. I hesitate to refer my acquaintances to this website

$£ \quad f \quad f \quad f \quad f \quad £ \quad f$

37. I consider this online newspaper website my first choice to read the news

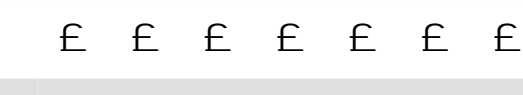

38. This website presents the information in various ways such as pictures, video,
text etc.
39. As long as the present level of service is maintained, I doubt that I would switch websites

40. When surfing this website, I can do what I want

$£ \quad f \quad f \quad f \quad f \quad f \quad f$

$f \quad f \quad f \quad f \quad f \quad f$

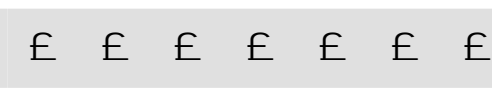

41. I like visiting this website, and want to remain a visitor

42. This website is effective in gathering visitors' feedback

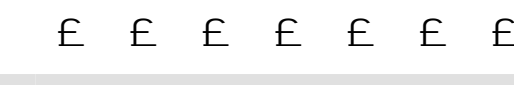

43. When I am searching for information about news events this website is my first
choice
44. I would pay for this website, even if I could visit another online newspaper website for free

$\begin{array}{lllllllllllll} & f & f & f & f & f & f\end{array}$

$\begin{array}{llllllllllllll} & f & f & f & f & f & f\end{array}$

$£ \quad f \quad f \quad f \quad f \quad f \quad f$

45. I recommend this website to anyone who seeks my advice

46. The information on this website relates to my needs

$\begin{array}{lllllll} & f & f & f & f & f & f\end{array}$

$f \quad f \quad f \quad f \quad f \quad f \quad f$

$\begin{array}{lllllll} & f & f & f & f & f & f\end{array}$

$f \quad f \quad f \quad f \quad f \quad f \quad f$

$£ \quad f \quad f \quad f \quad f \quad f \quad f$

$f \quad f \quad f \quad f \quad f \quad f \quad f$

$\begin{array}{lllllll} & f & f & f & f & f & f\end{array}$

$f \quad f \quad f \quad f \quad f \quad f \quad f$

$f \quad f \quad f \quad f \quad f \quad f \quad f$

$f \quad f \quad f \quad f \quad f \quad f \quad f$ 


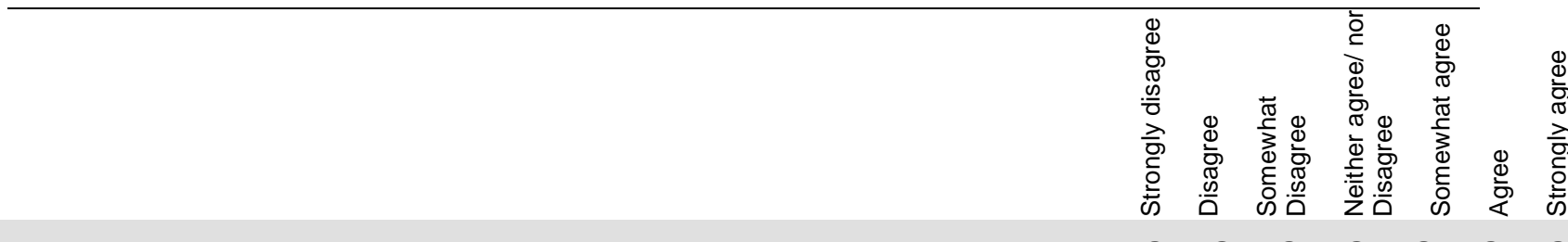

47. When it comes to obtaining the latest news this website is my first preference

48. This website makes me feel it wants to listen to its visitors

49. I want to remain a visitor of this website, because I genuinely enjoy my relationship with it

50. The information on this website is correct

51. If I had to pay for this online newspaper website, I would visit another online newspaper website that offers the service for free

52. The information on this website is presented clearly

53. My decision to remain a customer is based on my attraction to the things the website stands for

54. I try to use this website whenever I want to get the latest news

55. The information on this website is sufficiently detailed

56. I want to remain a customer of this website, because I feel a strong sense of belonging towards this website

57. Before I get to search for information online, I make sure that I have exactly identified my information needs

$£ \quad f \quad f \quad f \quad f \quad f \quad f$

$f \quad f \quad f \quad f \quad f \quad f \quad f$

$\begin{array}{llllllllllllllll} & f & f & f & f & f & f\end{array}$

$\begin{array}{llllllll} & f & f & f & f & f & f\end{array}$

$\begin{array}{llllllllllllllll} & f & f & f & f & f & f\end{array}$

$f \quad f \quad f \quad f \quad f \quad f \quad f$

$\begin{array}{lllllllllllllllll} & f & f & f & f & f & f & f\end{array}$

$\begin{array}{llllllllllllll} & f & f & f & f & f & f\end{array}$

$\begin{array}{llllllllllllll} & f & f & f & f & f & f\end{array}$

$\begin{array}{llllllllllllll} & f & f & f & f & f & f\end{array}$

$\begin{array}{lllllll} & f & f & f & f & f & f\end{array}$

\section{In general, while searching for information online, I....}

58. usually take well-considered decisions

59. Think of different ways in which I can fulfill my information needs

$£ \quad £ \quad f \quad € \quad € \quad €$

60. examine how changes in the environment might influence my information needs

61. Keep in mind what I have learned from past search activities

$£ \quad f \quad f \quad f \quad f \quad f \quad f$

62. Stop to assess whether I am searching for the right information

$£ \quad f \quad f \quad f \quad f \quad f$

63. examine the long-term consequences of my search activities $£ \quad f \quad f \quad f \quad f \quad f \quad f$

64. question my information needs on a regular basis

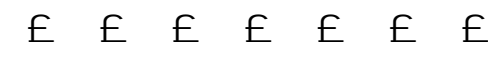

65. evaluate the results of my search actions

$£ \quad £ \quad € \quad € \quad € \quad € \quad €$

66. check whether my search activities produced the expected results

$\begin{array}{lllllllllllll} & f & f & f & f & f & f\end{array}$

67. look at alternatives of how information can be acquired

$\begin{array}{llllllllllllll} & f & f & f & f & f & f\end{array}$

68. evaluate why I did not receive the information I was looking for

$\begin{array}{llllllllllllll} & f & f & f & f & f & f & f\end{array}$

70. evaluate matters after my search activities are completed

$\begin{array}{lllllllllllll} & f & f & f & f & f & f\end{array}$

71. take the time to find the possible cause why I did not get the information which I

needed

72. Think of my information needs only once they have become urgent

$\begin{array}{llllllllllllll} & f & f & f & f & f & f\end{array}$

73. evaluate, as a result of changes in the environment, my online search process

$£ \quad f \quad f \quad f \quad f \quad f \quad f$

$£ \quad f \quad f \quad f \quad f \quad f$

$f \quad f \quad f \quad f \quad f \quad f \quad f$

$£ \quad f \quad f \quad f \quad f \quad f$ 
74. On average, how often do you use this online 175 . On average, how often do you use the Internet? newspaper website?

£ Never/ Almost Never

$f$ Less than once a month

f A few times a month

$f$ A few times a week

f About once a day

$f$ Several times a day

76. On average, how much time do you usually spend on this online newspaper website per visit?

$f$ Less than 5 minutes

f 5 to 15 minutes

f 16 to 30 minutes

£ 31 minutes to 1 hour

$f$ More than 1 hour

78. What is your gender?

$f$ male $\quad £$ female

80. Please indicate your education level

$f 3^{\text {rd }}$ year Graduate

$£ 4^{\text {th }}$ year Graduate

$£ 2^{\text {nd }}$ year Bachelor

f Master

f Other f Never/ Almost Never

$f$ Less than once a month

f A few times a month

f A few times a week

$f$ About once a day

f Several times a day

77. On average, how much time do you usually spend on the Internet per visit?

$f$ Less than 5 minutes

f 5 to 15 minutes

f 16 to 30 minutes

f 31 minutes to 1 hour

f More than 1 hour

79. What is your nationality?

81. If you want to win one of the 25 vouchers of $€ 10$, please write down your email address:

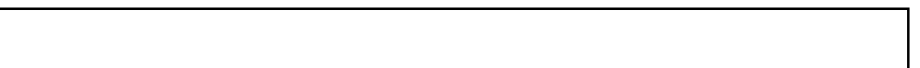




\section{Appendix E: Results qualitative pre-test measure refinement e-loyalty}

\begin{tabular}{|c|c|c|c|c|c|}
\hline Items & 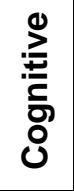 & 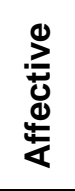 & 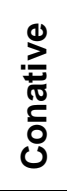 & 응 & 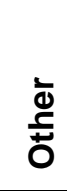 \\
\hline I believe that this is my favorite website & 4 & & & & \\
\hline It is pleasant visiting this website, that's why I continue to visit it & & 4 & & & \\
\hline I am a loyal customer to this website & & & 3 & 1 & \\
\hline I say positive things about this website to other people & & & 3 & 1 & \\
\hline I seldom consider switching to another website & & 1 & 1 & 2 & \\
\hline On average, how often do you use this website? & & & 1 & 1 & 2 \\
\hline I like using this website & & 3 & & & 1 \\
\hline To me this website is the best website to do business with & 1 & 1 & 2 & & \\
\hline $\begin{array}{l}\text { I remain a customer of this website, because I feel a strong attachment to } \\
\text { this website }\end{array}$ & & & 3 & & ? \\
\hline I intend to use this website more in the next few years & & & 2 & 1 & 1 \\
\hline $\begin{array}{l}\text { I will stop doing business with this website if its competitors' prices } \\
\text { decrease somewhat }\end{array}$ & 1 & & 2 & 1 & \\
\hline $\begin{array}{l}\text { In the future, this website is one of the first places I will look when I need to } \\
\text { find certain types of information }\end{array}$ & 3 & & 1 & & \\
\hline One of the reasons I prefer being a customer is because I like this website & 1 & 3 & & & \\
\hline I do not encourage friends to visit this website & & & 3 & 1 & \\
\hline I will use this website less in the next few years & & & 2 & 1 & 1 \\
\hline I intend to visit this website in the future & 1 & & 2 & & 1 \\
\hline $\begin{array}{l}\text { I continue visiting this website, because I feel like I am "part of the website's } \\
\text { family }\end{array}$ & & 1 & 2 & 1 & \\
\hline $\begin{array}{l}\text { I will pay a higher price at this website relative to the competition for the } \\
\text { same benefit }\end{array}$ & 1 & & 3 & & \\
\hline This Internet site is the best site to search for information & 4 & & & & \\
\hline I hesitate to refer my acquaintances to this website & & & 4 & & \\
\hline I consider this website my first choice to search for information & 3 & 1 & & & \\
\hline $\begin{array}{l}\text { As long as the present service continues, I doubt that I would switch } \\
\text { websites }\end{array}$ & & 1 & 2 & 1 & \\
\hline I like visiting this website, and want to remain a customer & & 4 & & & \\
\hline When I need to search for information this website is my first choice & 3 & 1 & & & \\
\hline $\begin{array}{l}\text { I will continue to do business with this website if its prices increase } \\
\text { somewhat }\end{array}$ & & & 4 & & \\
\hline I recommend this website to anyone who seeks my advice & & & 3 & 1 & \\
\hline Typically, How much time do you usually spend on this website? & & & 1 & & 3 \\
\hline When it comes to searching information this website is my first preference & 3 & 1 & & & \\
\hline $\begin{array}{l}\text { I want to remain a member of this website's network, because I genuinely } \\
\text { enjoy my relationship with it }\end{array}$ & & 1 & 3 & & \\
\hline I will take some of my business to a competitor that offers better prices & & & 4 & & \\
\hline $\begin{array}{l}\text { My decision to remain a customer is based on my attraction to the things } \\
\text { the website stands for }\end{array}$ & 1 & 2 & & 1 & \\
\hline I try to use this website whenever I need to search for information & 4 & & & & \\
\hline $\begin{array}{l}\text { I want to remain a customer of this website, because I feel a strong sense } \\
\text { of belonging with this website }\end{array}$ & & 1 & 3 & & \\
\hline
\end{tabular}




\section{Appendix F: Results qualitative pre-test measure refinement reflexivity}

\begin{tabular}{|c|c|}
\hline $\begin{array}{lcc}\text { Original } & \text { Team } & \text { reflexivity } \\
\text { (evaluation/learning) } & \end{array}$ & Individual Reflexivity Scale \\
\hline $\begin{array}{l}\text { Before we get to work, we make sure everyone on } \\
\text { the team has the same problem definition }\end{array}$ & $\begin{array}{l}\text { Before I get to search for information online, I } \\
\text { make sure that I have exactly identified my } \\
\text { information needs }\end{array}$ \\
\hline & While searching for information online I.... \\
\hline $\begin{array}{l}\text { As a team we usually take well-considered } \\
\text { decisions }\end{array}$ & usually take well-considered decisions \\
\hline $\begin{array}{l}\text { We review our methods of working as a result of } \\
\text { changes in the environment }\end{array}$ & $\begin{array}{l}\text { evaluate, as a result of changes in the } \\
\text { environment, } \\
\text { my online search process }\end{array}$ \\
\hline $\begin{array}{l}\text { We talk about different ways in which we reach our } \\
\text { objectives }\end{array}$ & $\begin{array}{l}\text { think of different ways in which I can fulfill my } \\
\text { information needs }\end{array}$ \\
\hline $\begin{array}{l}\text { Problems are discussed only once they have } \\
\text { become critical }\end{array}$ & $\begin{array}{l}\text { think of my information needs only once they } \\
\text { have become urgent }\end{array}$ \\
\hline $\begin{array}{l}\text { We examine the implications that changes in the } \\
\text { environment may have for the aims of the team }\end{array}$ & $\begin{array}{l}\text { examine how changes in the environment } \\
\text { might influence my information needs }\end{array}$ \\
\hline We work out what we can learn from past activities & $\begin{array}{l}\text { keep in mind what I learned from past search } \\
\text { activities }\end{array}$ \\
\hline $\begin{array}{l}\text { During task execution, we stop to assess whether } \\
\text { the team is on the right track }\end{array}$ & $\begin{array}{l}\text { stop to assess whether I am searching for the } \\
\text { right information }\end{array}$ \\
\hline $\begin{array}{l}\text { If a team member discovers a problem, he or she } \\
\text { will talk about it with other team members }\end{array}$ & $\begin{array}{l}\text { will discuss the problems I discover with other } \\
\text { people }\end{array}$ \\
\hline $\begin{array}{l}\text { We examine the long-term consequences of certain } \\
\text { activities }\end{array}$ & $\begin{array}{l}\text { examine the long-term consequences of my } \\
\text { search activities }\end{array}$ \\
\hline We questions our objectives on a regular basis & $\begin{array}{l}\text { question my information needs on a regular } \\
\text { basis }\end{array}$ \\
\hline $\begin{array}{l}\text { Problems are looked at from different points of view } \\
\text { in this team }\end{array}$ & $\begin{array}{l}\text { look at alternatives of how information can be } \\
\text { acquired }\end{array}$ \\
\hline $\begin{array}{l}\text { We check whether our activities produced the } \\
\text { expected results }\end{array}$ & $\begin{array}{l}\text { check whether my search activities produced } \\
\text { the expected results }\end{array}$ \\
\hline In this team the results of actions are evaluated & evaluate the results of my search actions \\
\hline $\begin{array}{l}\text { We reflect on the question of whether a pattern can } \\
\text { be discerned in events }\end{array}$ & $\begin{array}{l}\text { reflect on the question of whether a pattern can } \\
\text { be discerned in events }\end{array}$ \\
\hline We evaluate things that don't work out as planned & $\begin{array}{l}\text { evaluate why I did not receive the information I } \\
\text { was looking for }\end{array}$ \\
\hline $\begin{array}{l}\text { After certain activities are completed, we evaluate } \\
\text { matters }\end{array}$ & $\begin{array}{l}\text { evaluate matters after my search activities are } \\
\text { completed }\end{array}$ \\
\hline $\begin{array}{l}\text { If things don't work out as they should, we take the } \\
\text { time as a team to find the possible cause of the } \\
\text { problem }\end{array}$ & $\begin{array}{l}\text { take the time to find the possible cause why I } \\
\text { did not get the information which I needed }\end{array}$ \\
\hline
\end{tabular}




\section{Appendix G : Scenario's : manipulation purposeful behavior}

\section{Search}

Although, you might have already a mobile phone, we would like to ask you to please read the description below carefully and try to imagine yourself in the following situation.

So, please imagine yourself in the following situation.

Imagine that you walked a couple of days ago through town. Your phone rang! When you wanted to pick your phone out of your bag to answer it, it fell on the flour and it was broken. Your phone is already 2,5 years old, its heavy and the battery is very quick low.

So, it is time for a new mobile phone.

Imagine that you are searching for a light Samsung mobile phone with a high standby time, a photo camera and a TFT-color screen.

You decide to search for a new mobile phone at the Samsung Fun Club website which fits the four above described requirements.

\section{What should you do?}

Click on the link below to visit the Samsung Fun Club website and search for a new mobile phone that fits the four above described requirements. When you are done with searching, please click on the link to the questionnaire and complete it carefully.

\section{Browse}

Please read the description below carefully and try to imagine yourself in the following situation.

Last weekend you met one of your best friends in town. You started a conversation and he told you that he had the intention to buy a new Samsung mobile phone with several features. Your friend is always informed about the latest developments regarding mobile phones and you wonder where he gets all this information from. He told you that he visits the Samsung Fun Club website on a regular basis to stay informed about the latest developments about new mobile phones, new ring tones, games and other interesting things.

You also want to stay informed about the latest developments regarding mobile phones and your friend has made you a bit curious. You decide to have a look at the Samsung Fun Club website and to browse at the website just for fun.

\section{What should you do?}

Click on the link below to visit the Samsung Fun Club website. Look at the things you find interesting and enjoyable. When you quit your visit at the website, please click on the link to the questionnaire and complete it carefully. 
Appendix H: Measurement scales included in survey research

\begin{tabular}{|c|c|c|c|}
\hline CONSTRUCT & ORIGINAL SCALE ITEM & ADJUSTED SCALE ITEM & $\begin{array}{l}\text { ADJUSTED SCALE ITEM } \\
\text { DUTCH }\end{array}$ \\
\hline \multirow[t]{4}{*}{$\begin{array}{l}\text { Interactional } \\
\text { Richness } \\
\text { Media Richness }\end{array}$} & $\begin{array}{l}\text { This website enables me to ask } \\
\text { questions and obtain answers as } \\
\text { they arise }\end{array}$ & $\begin{array}{l}\text { This career website provides an } \\
\text { opportunity to ask questions and } \\
\text { obtain answers as they arise }\end{array}$ & $\begin{array}{l}\text { Deze loopbaansite biedt de } \\
\text { mogelijkheid om vragen te } \\
\text { stellen en antwoord te krijgen } \\
\text { indien nodig }\end{array}$ \\
\hline & $\begin{array}{l}\text { I feel as if this website talks back } \\
\text { to me while I am navigating }\end{array}$ & $\begin{array}{l}\text { I feel as if this career website } \\
\text { reacts to me while I am navigating }\end{array}$ & $\begin{array}{l}\text { Ik heb het gevoel dat deze } \\
\text { loopbaansite reageert terwijl ik } \\
\text { surf }\end{array}$ \\
\hline & $\begin{array}{l}\text { This website is effective in } \\
\text { gathering visitor's feedback }\end{array}$ & $\begin{array}{l}\text { This career website is effective in } \\
\text { gathering visitor's feedback }\end{array}$ & $\begin{array}{l}\text { Deze loopbaansite is effectief } \\
\text { in het verzamelen van } \\
\text { feedback van bezoekers }\end{array}$ \\
\hline & $\begin{array}{l}\text { This website makes me feel it } \\
\text { wants to listen to its visitors }\end{array}$ & $\begin{array}{l}\text { This career website makes me } \\
\text { feel it wants to listen to its visitors }\end{array}$ & $\begin{array}{l}\text { Ik heb het gevoel dat deze } \\
\text { loopbaansite naar zijn } \\
\text { bezoekers luistert }\end{array}$ \\
\hline \multirow[t]{3}{*}{ Multiplicity of cues } & $\begin{array}{l}\text { This website communicates its } \\
\text { information in various ways such } \\
\text { as (written and spoken) text, } \\
\text { pictures, symbols etc. }\end{array}$ & $\begin{array}{l}\text { This career website presents its } \\
\text { information in various ways such } \\
\text { as text, pictures, symbols etc. }\end{array}$ & $\begin{array}{l}\text { Deze loopbaansite presenteert } \\
\text { informatie op verschillende } \\
\text { manieren zoals tekst, plaatjes, } \\
\text { symbolen enz. }\end{array}$ \\
\hline & $\begin{array}{l}\text { This website expresses in } \\
\text { multiple ways what it wants to } \\
\text { say by using pictures, symbols, } \\
\text { numbers, text etc. }\end{array}$ & $\begin{array}{l}\text { This career website expresses in } \\
\text { multiple ways what it wants to say } \\
\text { by using pictures, symbols, } \\
\text { numbers, text etc. }\end{array}$ & $\begin{array}{l}\text { Deze loopbaansite geeft } \\
\text { informatie op verschillende } \\
\text { manieren weer, door middel } \\
\text { van plaatjes, symbolen, cijfers, } \\
\text { tekst enz. }\end{array}$ \\
\hline & $\begin{array}{l}\text { This website presents the } \\
\text { information in various ways such } \\
\text { as pictures, video, text etc. }\end{array}$ & $\begin{array}{l}\text { This career website presents } \\
\text { information in various ways such } \\
\text { as pictures, video, text etc. }\end{array}$ & $\begin{array}{l}\text { Deze loopbaansite geeft } \\
\text { informatie op verschillende } \\
\text { manieren weer zoals plaatjes, } \\
\text { video, tekst enz. }\end{array}$ \\
\hline \multirow[t]{4}{*}{ Control } & $\begin{array}{l}\text { User controls order or sequence } \\
\text { of information access }\end{array}$ & $\begin{array}{l}\text { While surfing this career website, I } \\
\text { can control the sequence of my } \\
\text { information search }\end{array}$ & $\begin{array}{l}\text { Terwijl ik op deze loopbaansite } \\
\text { surf, kan ik de volgorde van } \\
\text { mijn zoektocht naar informatie } \\
\text { zelf bepalen }\end{array}$ \\
\hline & $\begin{array}{l}\text { User controls opportunities for } \\
\text { interaction }\end{array}$ & $\begin{array}{l}\text { While surfing the career website, I } \\
\text { can control my interactions with } \\
\text { the site }\end{array}$ & $\begin{array}{l}\text { Wanneer ik op deze } \\
\text { loopbaansite surf, kan ik mijn } \\
\text { interacties met deze site zelf } \\
\text { bepalen }\end{array}$ \\
\hline & $\begin{array}{l}\text { When I am on this website, I can } \\
\text { choose freely what I want to see }\end{array}$ & $\begin{array}{l}\text { While surfing this career website, I } \\
\text { can click what I want }\end{array}$ & $\begin{array}{l}\text { Wanneer ik deze website } \\
\text { bezoek, kan ik aanklikken wat } \\
\text { ik wens }\end{array}$ \\
\hline & $\begin{array}{l}\text { While surfing this website, I can } \\
\text { do what I want }\end{array}$ & $\begin{array}{l}\text { While surfing this career website, I } \\
\text { can do what I want }\end{array}$ & $\begin{array}{l}\text { Als ik op deze loopbaansite } \\
\text { surf, kan ik doen wat ik wil }\end{array}$ \\
\hline \multirow{3}{*}{$\begin{array}{l}\text { Information Richness } \\
\text { Relevance }\end{array}$} & $\begin{array}{l}\text { The information on this website } \\
\text { is relevant }\end{array}$ & $\begin{array}{l}\text { The information on this career } \\
\text { website is relevant }\end{array}$ & $\begin{array}{l}\text { De informatie op deze } \\
\text { loopbaansite is relevant }\end{array}$ \\
\hline & $\begin{array}{l}\text { The information on this website } \\
\text { is to the point }\end{array}$ & $\begin{array}{l}\text { The information on this career } \\
\text { website is to-the-point }\end{array}$ & $\begin{array}{l}\text { De informatie op deze } \\
\text { loopbaansite is 'to-the-point' }\end{array}$ \\
\hline & $\begin{array}{l}\text { The information on this website } \\
\text { relates to my needs }\end{array}$ & $\begin{array}{l}\text { The information on this career } \\
\text { website relates to my needs }\end{array}$ & $\begin{array}{l}\text { De informatie op deze } \\
\text { loopbaansite sluit aan bij mijn } \\
\text { behoeften }\end{array}$ \\
\hline \multirow[t]{3}{*}{ Accuracy } & $\begin{array}{l}\text { I can rely on the information on } \\
\text { this website }\end{array}$ & $\begin{array}{l}\text { I can rely on the information on } \\
\text { this career website }\end{array}$ & $\begin{array}{l}\text { Ik kan de informatie op deze } \\
\text { loopbaansite vertrouwen }\end{array}$ \\
\hline & $\begin{array}{l}\text { The information on this website } \\
\text { reflects reality }\end{array}$ & $\begin{array}{l}\text { The information on this career } \\
\text { website reflects reality }\end{array}$ & $\begin{array}{lrr}\text { De informatie op deze } \\
\text { loopbaansite geeft } & \text { de } \\
\text { werkelijkheid weer } & \end{array}$ \\
\hline & $\begin{array}{l}\text { The information on this website } \\
\text { is correct }\end{array}$ & $\begin{array}{l}\text { The information on this career } \\
\text { website is correct }\end{array}$ & $\begin{array}{l}\text { De informatie op deze } \\
\text { loopbaansite is juist }\end{array}$ \\
\hline Comprel & $\begin{array}{l}\text { The information on this website } \\
\text { is easy to understand }\end{array}$ & $\begin{array}{l}\text { The information on this career } \\
\text { website is easy to understand }\end{array}$ & $\begin{array}{l}\text { De informatie op deze } \\
\text { loopbaansite is makkelijk te } \\
\text { begrijpen }\end{array}$ \\
\hline
\end{tabular}




\begin{tabular}{|c|c|c|c|}
\hline CONSTRUCT & ORIGINAL SCALE ITEM & ADJUSTED SCALE ITEM & $\begin{array}{l}\text { ADJUSTED SCALE ITEM } \\
\text { DUTCH }\end{array}$ \\
\hline & $\begin{array}{l}\text { The information on this website } \\
\text { is clear to me }\end{array}$ & $\begin{array}{l}\text { The information on this career } \\
\text { website is clear to me }\end{array}$ & $\begin{array}{l}\text { De informatie op deze } \\
\text { loopbaansite is voor mij } \\
\text { duidelijk }\end{array}$ \\
\hline & $\begin{array}{l}\text { The information on this website } \\
\text { is presented clearly }\end{array}$ & $\begin{array}{l}\text { The information on this career } \\
\text { website is presented clearly }\end{array}$ & $\begin{array}{l}\text { De informatie op deze } \\
\text { loopbaansite is duidelijk } \\
\text { weergegeven }\end{array}$ \\
\hline \multirow[t]{3}{*}{ Comprehensiveness } & $\begin{array}{l}\text { This website provides sufficient } \\
\text { information on news events }\end{array}$ & $\begin{array}{l}\text { This career website provides } \\
\text { sufficient information to orientate } \\
\text { myself on the labor market }\end{array}$ & $\begin{array}{l}\text { Deze loopbaansite bidet } \\
\text { voldoende informatie om me } \\
\text { op de arbeidsmarkt te } \\
\text { oriënteren }\end{array}$ \\
\hline & $\begin{array}{l}\text { The information on this website } \\
\text { is complete }\end{array}$ & $\begin{array}{l}\text { The information on this career } \\
\text { website is complete }\end{array}$ & $\begin{array}{l}\text { De informatie op deze } \\
\text { loopbaansite is volledig }\end{array}$ \\
\hline & $\begin{array}{l}\text { The information on this website } \\
\text { is sufficiently detailed }\end{array}$ & $\begin{array}{l}\text { The information on this career } \\
\text { website is sufficiently detailed }\end{array}$ & $\begin{array}{l}\text { De informatie op deze } \\
\text { loopbaansite is voldoende } \\
\text { gedetailleerd }\end{array}$ \\
\hline \multirow{4}{*}{$\begin{array}{l}\text { E-loyalty } \\
\text { Cognitive loyalty }\end{array}$} & $\begin{array}{l}\text { When I need to make a } \\
\text { purchase this website is my first } \\
\text { choice }\end{array}$ & $\begin{array}{l}\text { When I am searching for a job and } \\
\text { related information, this career } \\
\text { website is my first choice }\end{array}$ & $\begin{array}{l}\text { Als ik naar een baan en } \\
\text { aanverwante informatie op } \\
\text { zoek ben, heeft deze } \\
\text { loopbaansite mijn eerste keus }\end{array}$ \\
\hline & $\begin{array}{l}\text { Consider XYZ your first choice } \\
\text { to buy services }\end{array}$ & $\begin{array}{l}\text { I consider this career website my } \\
\text { first choice to search for a job and } \\
\text { related information }\end{array}$ & $\begin{array}{l}\text { Ik beschouw deze } \\
\text { loopbaansite als mijn eerste } \\
\text { keuze voor het zoeken naar } \\
\text { een baan en aanverwante } \\
\text { informatie }\end{array}$ \\
\hline & $\begin{array}{l}\text { When it comes to shopping } X Y Z \\
\text { is my first preference }\end{array}$ & $\begin{array}{l}\text { When it comes to orientating } \\
\text { myself on the labor market, this } \\
\text { career website has my first } \\
\text { preference }\end{array}$ & $\begin{array}{l}\text { Als ik mij op de arbeidsmarkt } \\
\text { moet oriënteren, heeft deze } \\
\text { loopbaansite mijn voorkeur }\end{array}$ \\
\hline & $\begin{array}{l}\text { In the future, XYZ's Internet Site } \\
\text { is one of the first places I will } \\
\text { look when I need to find certain } \\
\text { kinds of merchandise }\end{array}$ & $\begin{array}{l}\text { In the future, this career website is } \\
\text { one of the first places I will search } \\
\text { when I want to orientate myself on } \\
\text { the labor market }\end{array}$ & $\begin{array}{l}\text { In de toekomst is deze } \\
\text { loopbaansite een van de } \\
\text { eerste plaatsen waar ik } \\
\text { informatie zal zoeken wanneer } \\
\text { ik me op de arbeidsmarkt wil } \\
\text { oriënteren }\end{array}$ \\
\hline \multirow[t]{3}{*}{ Affective loyalty } & $\begin{array}{l}\text { It is pleasant working with (the } \\
\text { supplier); that's why we continue } \\
\text { to represent them }\end{array}$ & $\begin{array}{l}\text { It is always a pleasant experience } \\
\text { to visit this career website, that is } \\
\text { why I continue to visit it }\end{array}$ & $\begin{array}{l}\text { Het is altijd een prettige } \\
\text { ervaring om deze loopbaansite } \\
\text { te bezoeken, daarom blijf ik } \\
\text { deze bezoeken }\end{array}$ \\
\hline & $\begin{array}{l}\text { One of the reasons we prefer } \\
\text { being a (supplier) dealer is } \\
\text { because we like (the supplier) as } \\
\text { a company }\end{array}$ & $\begin{array}{l}\text { One of the reasons why I visit this } \\
\text { career website is because I like it }\end{array}$ & $\begin{array}{l}\text { Een van de redenen waarom ik } \\
\text { deze loopbaansite bezoek, is } \\
\text { omdat ik het leuk vind }\end{array}$ \\
\hline & $\begin{array}{l}\text { We like working with (the } \\
\text { supplier), and want to remain a } \\
\text { (supplier) dealer }\end{array}$ & $\begin{array}{l}\text { I like visiting this career website, } \\
\text { and want to remain a visitor }\end{array}$ & $\begin{array}{l}\text { Ik bezoek deze loopbaansite } \\
\text { graag en wil een bezoeker } \\
\text { blijven }\end{array}$ \\
\hline \multirow[t]{4}{*}{ Word of Mouth } & $\begin{array}{l}\text { I say positive things about this } \\
\text { website to other people }\end{array}$ & $\begin{array}{l}\text { I say positive things about this } \\
\text { career website to other people }\end{array}$ & $\begin{array}{l}\text { Ik zeg positieve dingen over } \\
\text { deze loopbaansite tegen } \\
\text { andere mensen }\end{array}$ \\
\hline & $\begin{array}{l}\text { I recommend this website to } \\
\text { anyone who seeks my advice }\end{array}$ & $\begin{array}{l}\text { I recommend this career website } \\
\text { to anyone who seeks my advice }\end{array}$ & $\begin{array}{l}\text { ledereen die mij om advies } \\
\text { vraagt, raad ik deze } \\
\text { loopbaansite aan }\end{array}$ \\
\hline & $\begin{array}{l}\text { I do not encourage friends to do } \\
\text { business with this website* }\end{array}$ & $\begin{array}{l}\text { I encourage friends to visit this } \\
\text { career website }\end{array}$ & $\begin{array}{l}\text { Ik moedig mijn vrienden aan } \\
\text { om deze loopbaansite te } \\
\text { bezoeken }\end{array}$ \\
\hline & $\begin{array}{l}\text { I hesitate to refer my } \\
\text { acquaintances to this website }{ }^{*}\end{array}$ & $\begin{array}{l}\text { I refer my acquaintances to this } \\
\text { career website }\end{array}$ & $\begin{array}{l}\text { Ik verwijs mijn kennissen naar } \\
\text { deze loopbaansite }\end{array}$ \\
\hline \multirow[t]{2}{*}{ Visit Intention } & $\begin{array}{l}\text { Do more business with } X Y Z \text { in } \\
\text { the next few months }\end{array}$ & $\begin{array}{l}\text { I intend to visit this career website } \\
\text { more in the next months }\end{array}$ & $\begin{array}{l}\text { Ik ben van plan deze } \\
\text { loopbaansite in de komende } \\
\text { maanden te bezoeken }\end{array}$ \\
\hline & $\begin{array}{l}\text { Do less business with } X Y Z \text { in the } \\
\text { next few years* }\end{array}$ & $\begin{array}{l}\text { I will visit this career website less } \\
\text { in the next months* }\end{array}$ & $\begin{array}{l}\text { Ik zal deze loopbaansite de } \\
\text { komende maanden minder } \\
\text { bezoeken* }\end{array}$ \\
\hline
\end{tabular}




\begin{tabular}{|c|c|c|c|}
\hline CONSTRUCT & ORIGINAL SCALE ITEM & ADJUSTED SCALE ITEM & $\begin{array}{l}\text { ADJUSTED SCALE ITEM } \\
\text { DUTCH }\end{array}$ \\
\hline & $\begin{array}{l}\text { I intend to shop from } X Y Z \text { 's } \\
\text { Internet Site in the future }\end{array}$ & $\begin{array}{l}\text { I intend to visit this career website } \\
\text { in the future }\end{array}$ & $\begin{array}{l}\text { Ik ben van plan deze } \\
\text { loopbaansite in de toekomst te } \\
\text { bezoeken }\end{array}$ \\
\hline \multirow[t]{3}{*}{ Experiential Value } & $\begin{array}{l}\text { I think XYZ's products are a } \\
\text { good economic value }\end{array}$ & $\begin{array}{l}\text { The services offered by this career } \\
\text { website are of great value to me }\end{array}$ & $\begin{array}{l}\text { De diensten die deze } \\
\text { loopbaansite aanbiedt, zijn } \\
\text { voor mij van grote waarde }\end{array}$ \\
\hline & $\begin{array}{l}\text { Overall, I am happy with XYZ's } \\
\text { prices }\end{array}$ & $\begin{array}{l}\text { Overall, the services offered by } \\
\text { this career website are valuable } \\
\text { for me }\end{array}$ & $\begin{array}{l}\text { In het algemeen zijn de } \\
\text { diensten die deze loopbaansite } \\
\text { aanbiedt, waardevol voor mij }\end{array}$ \\
\hline & $\begin{array}{l}\text { The prices of the product(s) I } \\
\text { purchased from XYZ's Internet } \\
\text { Site are too high, given the } \\
\text { quality of the merchandise* }\end{array}$ & $\begin{array}{l}\text { The effort I have to make for using } \\
\text { the services of this career website } \\
\text { is too high, considering the quality } \\
\text { of the services offered* }\end{array}$ & $\begin{array}{l}\text { Gezien de kwaliteit van de } \\
\text { aangeboden diensten van } \\
\text { deze loopbaansite, moet ik } \\
\text { teveel moeite doen om deze } \\
\text { diensten te gebruiken* }\end{array}$ \\
\hline \multirow[t]{3}{*}{ Efficiency } & $\begin{array}{l}\text { Shopping from } X Y Z \text { is and } \\
\text { efficient way to manage my time }\end{array}$ & $\begin{array}{l}\text { Using the services offered by this } \\
\text { career website is an efficient way } \\
\text { to manage my time }\end{array}$ & $\begin{array}{l}\text { Door gebruik te maken van de } \\
\text { diensten die deze loopbaansite } \\
\text { aanbiedt, kan ik mijn tijd op } \\
\text { een efficiënte manier beheren }\end{array}$ \\
\hline & $\begin{array}{l}\text { Shopping from XYZ's Internet } \\
\text { Site make my life easier }\end{array}$ & $\begin{array}{l}\text { Using the services offered by this } \\
\text { career website make my life easier }\end{array}$ & $\begin{array}{l}\text { Door gebruik te maken van de } \\
\text { diensten die door deze } \\
\text { loopbaansite worden } \\
\text { aangeboden, wordt mijn leven } \\
\text { makkelijker gemaakt }\end{array}$ \\
\hline & $\begin{array}{l}\text { Shopping from XYZ's Internet } \\
\text { Site fits my schedule }\end{array}$ & $\begin{array}{l}\text { Using the services of this career } \\
\text { website fits my schedule }\end{array}$ & $\begin{array}{l}\text { Het gebruik van de diensten } \\
\text { van deze loopbaansite past in } \\
\text { mijn planning }\end{array}$ \\
\hline \multirow[t]{2}{*}{ Enjoyment } & $\begin{array}{l}\text { I shop from XYZ's Internet Site } \\
\text { for the pure enjoyment of it }\end{array}$ & $\begin{array}{l}\text { I visit this career website for the } \\
\text { pure enjoyment of it }\end{array}$ & $\begin{array}{l}\text { Ik bezoek deze loopbaansite } \\
\text { puur om er plezier aan te } \\
\text { beleven }\end{array}$ \\
\hline & $\begin{array}{l}\text { I enjoy shopping from XYZ's } \\
\text { Internet Site for its own sake, not } \\
\text { just for the items I may purchase }\end{array}$ & $\begin{array}{l}\text { I enjoy visiting this career website } \\
\text { for its own sake, not just for the } \\
\text { services I may want to use }\end{array}$ & $\begin{array}{l}\text { Ik vind het gewoon leuk om } \\
\text { deze loopbaansite te } \\
\text { bezoeken, niet alleen vanwege } \\
\text { de diensten die ik zou kunnen } \\
\text { gebruiken }\end{array}$ \\
\hline \multirow[t]{3}{*}{ Escapism } & $\begin{array}{l}\text { Shopping from XYZ's Internet } \\
\text { Site "gets me away from it all" }\end{array}$ & $\begin{array}{l}\text { Using the services from this career } \\
\text { website "gets me away from it all" }\end{array}$ & $\begin{array}{l}\text { Wanneer ik de diensten van } \\
\text { deze loopbaansite gebruik, kan } \\
\text { ik alles om me heen vergeten }\end{array}$ \\
\hline & $\begin{array}{l}\text { Shopping from XYZ makes me } \\
\text { feel like I am in another world }\end{array}$ & $\begin{array}{l}\text { Using the services offered by this } \\
\text { career website makes me feel like } \\
\text { I am in another world }\end{array}$ & $\begin{array}{l}\text { Als ik de diensten van deze } \\
\text { loopbaansite gebruik, lijkt het } \\
\text { alsof ik in een andere wereld } \\
\text { ben }\end{array}$ \\
\hline & $\begin{array}{l}\text { I get so involved when I shop } \\
\text { from } X Y Z \text { that I forget everything } \\
\text { else }\end{array}$ & $\begin{array}{l}\text { I get so involved when I use the } \\
\text { services offered by this career } \\
\text { website, that I forget everything } \\
\text { else }\end{array}$ & $\begin{array}{l}\text { Als ik de diensten van deze } \\
\text { loopbaansite gebruik, word ik } \\
\text { zodanig meegesleept, dat ik } \\
\text { alles om mij heen vergeet }\end{array}$ \\
\hline \multirow[t]{2}{*}{ Service Excellence } & $\begin{array}{l}\text { When I think of } X Y Z \text {, I think of } \\
\text { excellence }\end{array}$ & $\begin{array}{l}\text { When I think of this career } \\
\text { website, I think of excellence }\end{array}$ & $\begin{array}{l}\text { Wanneer ik over deze } \\
\text { loopbaansite nadenk, vind ik } \\
\text { deze uitstekend }\end{array}$ \\
\hline & $\begin{array}{l}\text { I think of } X Y Z \text { as an expert in the } \\
\text { merchandise it offers }\end{array}$ & $\begin{array}{l}\text { I think of this career website as an } \\
\text { expert in the services it offers }\end{array}$ & $\begin{array}{l}\text { Ik zie deze loopbaansite als } \\
\text { een expert wat dit soort } \\
\text { diensten betreft }\end{array}$ \\
\hline \multirow[t]{3}{*}{ Visual appeal } & $\begin{array}{l}\text { The way } \mathrm{XYZ} \text { displays its } \\
\text { products is attractive }\end{array}$ & $\begin{array}{l}\text { The way this career website } \\
\text { displays its services is attractive }\end{array}$ & $\begin{array}{l}\text { De manier waarop deze } \\
\text { loopbaansite haar diensten } \\
\text { toont, is aantrekkelijk }\end{array}$ \\
\hline & $\begin{array}{l}\text { XYZ's Internet Site is } \\
\text { aesthetically appealing }\end{array}$ & $\begin{array}{l}\text { This career website is nice to look } \\
\text { at }\end{array}$ & $\begin{array}{l}\text { Deze loopbaansite is leuk om } \\
\text { naar te kijken }\end{array}$ \\
\hline & $\begin{array}{l}\text { I like the way XYZ's Internet Site } \\
\text { looks }\end{array}$ & $\begin{array}{l}\text { I like the way this career website } \\
\text { looks }\end{array}$ & $\begin{array}{l}\text { Hoe deze loopbaansite er } \\
\text { uitziet, vind ik leuk }\end{array}$ \\
\hline & & & \\
\hline
\end{tabular}




\begin{tabular}{|c|c|c|c|}
\hline CONSTRUCT & ORIGINAL SCALE ITEM & ADJUSTED SCALE ITEM & $\begin{array}{l}\text { ADJUSTED SCALE ITEM } \\
\text { DUTCH }\end{array}$ \\
\hline \multirow[t]{3}{*}{ Entertainment } & $\begin{array}{l}\text { I think XYZ's Internet Site is very } \\
\text { entertaining }\end{array}$ & $\begin{array}{l}\text { I think this career website is very } \\
\text { entertaining }\end{array}$ & $\begin{array}{l}\text { Ik denk dat deze loopbaansite } \\
\text { zeer vermakelijk is }\end{array}$ \\
\hline & $\begin{array}{l}\text { The enthusiasm of XYZ's } \\
\text { Internet Site is catching, it picks } \\
\text { me up }\end{array}$ & $\begin{array}{l}\text { This career website is catching, it } \\
\text { picks me up }\end{array}$ & $\begin{array}{l}\text { Deze loopbaansite weet mij te } \\
\text { boeien }\end{array}$ \\
\hline & $\begin{array}{l}\text { XYZ doesn't just sell products it } \\
\text { entertains me }\end{array}$ & $\begin{array}{l}\text { This career website does not just } \\
\text { offer services, it entertains me }\end{array}$ & $\begin{array}{l}\text { Deze loopbaansite biedt niet } \\
\text { alleen diensten, maar } \\
\text { vermaakt me ook }\end{array}$ \\
\hline \multirow[t]{4}{*}{ Competence } & & $\begin{array}{l}\text { In general, while searching for } \\
\text { information online, I... }\end{array}$ & $\begin{array}{l}\text { In het algemeen, wanneer ik } \\
\text { online naar informatie zoek. }\end{array}$ \\
\hline & $\begin{array}{l}\text { I am extremely skilled at using } \\
\text { the web }\end{array}$ & $\begin{array}{l}\text { Am extremely skilled at using the } \\
\text { Internet }\end{array}$ & $\begin{array}{l}\text { Ben ik uitermate ervaren in het } \\
\text { gebruik van Internet }\end{array}$ \\
\hline & $\begin{array}{l}\text { I consider myself knowledgeable } \\
\text { about good search techniques } \\
\text { on the web }\end{array}$ & $\begin{array}{l}\text { Consider myself knowledgeable } \\
\text { about search techniques on the } \\
\text { Internet }\end{array}$ & $\begin{array}{l}\text { Vind ik dat ik verstand heb van } \\
\text { zoektechnieken op het Internet }\end{array}$ \\
\hline & $\begin{array}{l}\text { I know how to find what I am } \\
\text { looking for on the web }\end{array}$ & $\begin{array}{l}\text { Know how to find what I am } \\
\text { looking for on the Internet }\end{array}$ & $\begin{array}{l}\text { Weet ik, hoe ik op het Internet } \\
\text { dat moet vinden wat ik zoek }\end{array}$ \\
\hline \multirow[t]{4}{*}{ Reflexivity } & & $\begin{array}{l}\text { In general, while searching for } \\
\text { information online, I... }\end{array}$ & $\begin{array}{l}\text { In het algemeen, wanneer ik } \\
\text { online naar informatie zoek. }\end{array}$ \\
\hline & $\begin{array}{l}\text { During task execution, we stop } \\
\text { to assess whether the team is } \\
\text { on the right track }\end{array}$ & $\begin{array}{l}\text { Stop for a moment to assess } \\
\text { whether I am searching for the } \\
\text { right information }\end{array}$ & $\begin{array}{l}\text { Stop ik even om vast te stellen } \\
\text { of ik wel naar de juiste } \\
\text { informatie aan het zoeken ben }\end{array}$ \\
\hline & $\begin{array}{l}\text { We examine the long-term } \\
\text { consequences of certain } \\
\text { activities }\end{array}$ & $\begin{array}{l}\text { Examine the long-term } \\
\text { consequences of my search } \\
\text { activities }\end{array}$ & 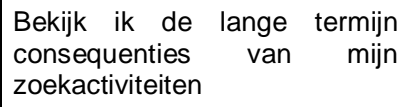 \\
\hline & $\begin{array}{l}\text { We question our objectives on a } \\
\text { regular basis }\end{array}$ & $\begin{array}{l}\text { Question my information needs on } \\
\text { a regular basis }\end{array}$ & $\begin{array}{l}\text { Vraag ik me regelmatig af } \\
\text { welke informatie ik nodig heb }\end{array}$ \\
\hline
\end{tabular}




\section{References}

Addis, Michela and Morris B. Holbrook (2001), "On the Conceptual Link between Mass Customization and Experiential Consumption: An Explosion of Subjectivity," Journal of Consumer Behaviour, 1 (1), 50-66.

Anderson, Rolph E. and Srini S. Srinivasan (2003), "E-Satisfaction and E-Loyalty: A Contingency Framework," Psychology \& Marketing, 20 (2), 123-38.

Babin, Barry J. and Jill S. Attaway (2000), "Atmospheric Affect as a Tool for Creating Value and Gaining Share of Customer," Journal of Business Research, 49, 91-99.

Babin, Barry J., Jean-Charles Chebat, and Richard Michon (2004), "Perceived Appropriateness and its Effect on Quality, Affect and Behavior," Journal of Retailing and Services, 11 (5), 287-98.

Babin, Barry J., William R. Darden, and Mitch Griffin (1994), "Work and/or Fun: Measuring Hedonic and Utilitarian Shopping Value," Journal of Consumer Research, 20 (4), 644-56.

Backström, Kristina and Ulf Johansson (2006), "Creating and Consuming Experiences in Retail Store Enviroments: Comparing Retailer and Consumer Perspectives," Journal of Retailing and Consumer Services, 13 (6), 417-30.

Ballantine, Paul W. (2005), "Effects of Interactivity and Product Information on Consumer Satisfaction in an Online Retail Setting," International Journal of Retail \& Distribuion Management, 33 (6), 461-71.

Bandura, Albert (1986), Social Foundations of Thought and Action. New Jersey: PrenticeHall.

Barry, Bruce and J. Michael Crant (2000), "Dyadic Communication Relationships in Organizations: An Attribution/Expectancy Approach," Organization Science, 11 (6), 648-64.

Baumgartner, Hans H., Thomas Falk, and Maik Hammerschmidt (2006), "eTransQual: A Transaction Process-Based Approach for Capturing Service Quality in Online Shopping," Journal of Business Research, 59 (7), 866-75.

Belk, R.W. (1987), "A Child's Christmas in America: Santa Claus as Deity, Consumption as Religion," Journal of American Culture, 10, 87-100.

Bellenger, Danny, N. and Pradeep Korgaonker, K. (1980), "Profiling the Recreational Shopper," Journal of Retailing, 56 (Fall), 77-92.

Bolton, Ruth N. and Tina Bronkhorst, M (1995), "The Relationship Between Customer Complaints to the Firm and Subsequent Exit Behavior," Advances in Consumer Research, $22(1), 94-100$.

Bolton, Ruth N. and James H. Drew (1991), "A Multistage Model of Customers' Assessments of Service Quality and Value," Journal of Consumer Research, 17 (4), 375-84.

Boulding, William, Richard Staelin, Michael Ehret, and Wesley J. Johnston (2005), "A Customer Relationship Management Roadmap: What Is Known, Potential Pitfalls, and Where to Go," Journal of Marketing, 69 (October), 155-56. 
Bourdeau, Laurent, Jean-Charles Chebat, and Christian Couturier (2002), "Internet Consumer Value of University Students: E-mail- vs.-Web Users," Journal of Retailing and Consumer Services, 9 (2), 61-69.

Brady, Michael K. and Christopher J. Robertson (1999), "An Exploratory Study of Service Value in the USA and Ecuador," International Journal of Service Industry Management, 10 (5), 469-86.

Burroughs, James E. and David G. Mick (2004), "Exploring Antecedents and Consequences of Consumer Creativity in a Problem-Solving Context," Journal of Consumer Research, 31 (2), 402-11.

Carlson, John R. and Robert W. Zmud (1999), "Channel Expansion Theory and the Experiential Nature of Media Richness Perceptions," Academy of Management Journal, 42 (2), 153-70.

Chen, Lei-Da and Justin Tan (2004), "Technology Adaptation in E-Commerce: Key Determinants of Virtual Store Acceptance," European Journal of Management, 22 (1), 74-86.

Chen, Qimei, Sandra J. Clifford, and William D. Wells (2002), "Attitude Toward the Site II: New Information " Journal of Advertising Research, 42 (2), 33-45.

Chen, Zhan and Alan J. Dubinsky (2003), "A Conceptual Model of Perceived Customer Value in E-Commerce: A Preliminary Investigation," Psychology \& Marketing, 20 (4), 323-47.

Childers, Terry L., Christopher L. Carr, Joann Peck, and Stephen Carson (2001), "Hedonic and Utilitarian Motivations for Online Retail Shopping Behavior," Journal of Retailing, 77 (4), 511-35.

Chin, Wynne W (2001), PLS-Graph User's Guide Version 3.0. Houston, TX: C.T. Bauer College of Business.

Chin, Wynne W. (1998), "The Partial Least Squares Approach to Structural Equation Modeling," Modern Business Research Methods, 295-336.

Chin, Wynne W., Barbara L. Marcolin, and Peter R. Newsted (2003), "A Partial Least Squares Latent Variable Modeling Approach for Measuring Interaction Effects: Results from a Monte Carlo Simulation Study and Voice Mail Emotion/Adoption Study," Information Systems Research, 14 (2), 189-218.

Chiou, Jyh-Shen (2004), "The Antecedents of Consumers' Loyalty toward Internet Service Providers," Information and Management, 2004 (41), 685-95.

Chiu, Hung-Chang, Yi-Ching Hsieh, Yu-Chuan Li, and Monte Lee (2004), "Relationship Marketing and Consumer Switching Behavior," Journal of Business Research, in press.

Churchill, Gilbert A. JR. (1979), "A Paradigm for Developing Better Measures of Marketing Constructs," Journal of Marketing Research, 16 (1), 64-73.

Cober, Richard T., Douglas J. Brown, Alana J. Blumental, Dennis Doverspike, and Paul Levy (2000), "The Quest for the Qualified Job Surfer: It's Time the Public Sector Catches the Wave," Public Personnel Management, 29, 479-96. 
Cober, Richard T., Douglas J. Brown, Paul Levy, Alana B. Cober, and Lisa M. Keeping (2003), "Organizational Web Sites: Web Site Content and Style as Determinants of Organizational Attraction," International Journal of Selection and Assessment, 11 (2/3), 15869.

Cotte, June, Tilottama G. Chowdhury, S. Rathneswar, and Lisa M. Ricci (2006), "Pleasure or Utility? Time Planning Style and Web Usage Behaviors," Journal of Interactive Marketing, 20 (1), 45-57.

Cronin, J.Joseph Jr., Michael K. Brady, and G.Tomas. M. Hult (2000), "Assessing the Effect of Quality, Value and Customer Satisfaction on Consumer Behavioral Intentions in Service Environments," Journal of Retailing, 76 (2), 193-218.

D'Ambra, John, Ronald E. Rice, and Marcus O'Conner (1998), "Computer-Mediated Communication and Media Preference: an Investigation of the Dimensionality of Perceived Task Equivocality and Media Richness," Behaviour and Information Technology, 17 (3), 16474.

Dabholkar, Pratibha A. and Richard P. Bagozzi (2002), "An Attitudinal Model of TechnologyBased Self-Service: Moderating Effects of Consumer Traits and Situational Factors," Journal of the Academy of Marketing Science, 30 (3), 184-201.

Daft, Richard, L. and Robert Lengel, H. (1986), "Organizational Information Requirements, Media Richness and Structural Design," Management Science, 32 (5), 554-71.

Das, Samar, Raj Echambadi, and Michael McCardle (2003), "The Effect of Interpersonal Trust, Need for Cognition, and Social Loneliness on Shopping, Information Seeking and Surfing on the Web," Marketing Letters, 14 (3), 185-202.

Dawson, Scott, Peter Bloch, H., and M. Ridgway (1990), "Shopping Motives, Emotional States, and Retail Outcomes," Journal of Retailing, 66 (Winter), 408-27.

De Wulf, Kristof and Gaby Odekerken-Schröder (2003), "Assessing the Impact of a Retailer's Relationship Efforts on Consumers' Attitudes and Behavior," Journal of Retailing and Consumer Services, 10 (2), 95-108.

De Wulf, Kristof, Gaby Odekerken-Schröder, and Dawn lacobucci (2001), "Investments in Consumer Relationships: A Cross-Country and Cross-Industry Exploration," Journal of Marketing, 65 (October), 33-50.

De Wulf, Kristof, Niels Schillewaert, Steve Muylle, and Deva Rangarajan (2006), "The Role of Pleasure in Web Site Success," Information and Management, 43 (4), 434-46.

DeLone, William H. and Ephraim R. McLean (2004), "Measuring e-Commerce Success: Applying the DeLone \& McLean Information Systems Success Model," Internation Journal of Electronic Commerce, 9 (1), 31-47.

Dennis, Alan R. and Joseph S. Valacich (1999), "Rethinking Media Richness: Towards a Theory of Media Synchronicity," 32nd Hawaii International Conference on System Sciences.

Dennis, Allan, R. and Susan Kinney, T. (1998), "Testing Media Richness Theory in the New Media: The Effects of Cues, Feedback, and Task Equivocality," Information Systems Research, 9 (3), 256-74. 
Dholakia, Ruby Roy, Miao Zhao, Nikhilesh Dholakia, and David R. Fortin (2000), "Interactivity and Revisits to Websites: A Theoretical Framework," Kingston, Research Institute for Telecommunications and Information Marketing (RITIM), working paper.

Dick, Alan S. and Kunal Basu (1994), "Customer Loyalty: Toward an Integrated Conceptual Framework," Journal of the Academy of Marketing Science, 22 (2), 99-113.

Dineen, Brian R., Steven R. Ash, and Raymond A. Noe (2002), "A Web of Applicant Attraction: Person-Organization Fit in the Context of Web-Based Recruitment," Journal of Applied Psychology, 87 (4), 723-34.

van Dolen, Willemijn, M., Pratibha A. Dabholkar, and Ko de Ruyter (2007), "Satisfaction with Online Commercial Group Chat: the Influence of Technology Attributes, Chat Group Characteristics, and Advisor Communication Style," Journal of Retailing, in press.

Edwards, Jeffrey R. (2001), "Multidimensional Constructs in Organizational Behavior Research: An Integrative Analytical Framework," Organizational Research Methods, 4 (2), 144-92.

Eroglu, Sevgin A., Karen A. Machleit, and Lenita M. Davis (2003), "Empirical Testing of a Model of Online Store Atmospherics and Shopper Responses," Psychology \& Marketing, 20 (2), 139-50.

Evans, James and Laurence Brooks (2005), "Understanding Collaboration Using New Technologies: A Structural Perspective," The Information Society, 20 (3), 215-20.

Fallows, Deborah (2004), "The Internet and Daily Life," available online at www.pewinternet.org/reports.

Fiore, Ann Marie, Jihyun Kim, and Hyun-Hwa Lee (2005), "Effect of Image Interactivity Technology on Consumer Responses toward the Online Retailer," Journal of Interactive Marketing, 19 (3), 38-53.

Fiore, Ann Marie, Hyun-Jeong Jin, and Jihyun Kim (2005b), "For Fun and Profit: Hedonic Value from Image Interactivity and Responses toward an Online Store," Psychology \& Marketing, 22 (8), 669-94.

Flint, Daniel J. (2006), "Innovation, Symbolic Interaction and Customer Valuing: Thoughts Stemming from a Service-Dominant Logic of Marketing," Marketing Theory, 6 (3), 349-62.

Fornell, Claes and Fred L. Bookstein (1982), "Two Structural Equations Models: LISREL and PLS applied to Consumer Exit-Voice Theory," Journal of Marketing Research 19 (4), 440-52.

Fornell, Claes and David F. Larcker (1981), "Evaluating Structural Equation Models with Unobservable Variables and Measurement Error," Journal of Marketing Research, 18 (3), 3950 .

Forsythe, Sandra, Liu Chuanlan, David Shannon, and Liu Chun Gardner (2006), "Development of a Scale to Measure the Perceived Benefits and Risks of Online Shopping," Journal of Interactive Marketing, 20 (2), 55-75.

Fortin, David R., Ruby Roy Dholakia, and Nikhilesh Dholakia (2002), "Emerging Issues in Electronic Marketing: Thinking Outside the Square," Journal of Business Research, 55 (8), 623-27. 
Gefen, Karahanna D. and D.W. Straub (2003), "Inexperience and Experience with Online Stores: The Importance of TAM and Trust," IEEE Transactions on Engineering Management, 50 (3), 307-21.

Giddens, Anthony (1979), Central Problems in Social Theory: Action, Structure, and Contradiction in Social Analysis. Berkley CA: University of California Press.

---- (1984), The Constitution of Society: Outline of the Theory of Structuration. Cambridge UK: Polity Press.

Grewal, Dhruv, Joan Lindsey-Mullikin, and Jeanne Munger (2003), "Loyalty in E-Tailing: A Conceptual Framework," Journal of Relationship Marketing, 2 (3-4), 31-49.

Griffith, David, A., Robert Krampf, F., and Jonathan W. Palmer (2001), "The Role of Interface in Electronic Commerce: Consumer Involvement with Print Versus On-Line Catalogs," International Journal of Electronic Commerce, 5 (4), 135-53.

Guinot, Christiane, Julie Latreille, and Michel Tenenhaus (2001), "PLS Path Modeling and Multiple Table Analyses. Application to the Cosmetic Habits of Women in Ile-de-France," Chemometrics and Intelligent Laboratory Systems, 58, 247-59.

Hammond, Kathy, Gil McWilliam, and Andrea Narholz Diaz (1998), "Fun and Work on the Web: Differences in Attitudes between Novices and Experience Users," Advances in Consumer Research, 25, 372-78.

Hampton-Sosa, William and Marios Koufaris (2005), "The Effect of Web Site Perceptions on Initial Trust in the Owner Company," International Journal of Electronic Commerce, 10 (1), 55-81.

Hanisch, Kathy A., Charles L. Hulin, and Mary Roznowski (1998), "The Importance of Individuals' Repertoires of Behaviors: The Scientific Appropriateness of Studying Multiple Behaviors and General Attitudes," Journal of Organizational Behavior, 19 (5), 463-80.

Harris, Lloyd C. and Mark M.H. Goode (2004), "The Four Levels of Loyalty and the Pivotal Role of Trust: A Study of Online Service Dynamics," Journal of Retailing, 80 (2), 139-58.

Hoegl, Martin and K. Praveen Parboteeah (2006), "Team Reflexivity in Innovative Projects," R\&D Management, 36 (2), 113-25.

Hoffman, Donna L. and Thomas P. Novak (1996), "Marketing in Hypermedia ComputerMediated Environments: Conceptual Foundations," Journal of Marketing 60 (3), 50-68.

Hoffman, Donna L., Thomas P. Novak, and Patrali Chatterjee (2000), "Commercial Scenarios for the Web: Opportunities and Challenges," Journal of Computer-Mediated Communication, 1 (3).

Holbrook, Morris B. (1986), "Emotions in the Consumption Experience: Toward a New Model of Consumer Behavior.," in The Role of Affect in Consumer Behavior: Emerging Theories and Applications, R. A. Peterson and W. D. Hoyer and W.R. Wilson, Eds. Heath: Lexington.

---- (1994), "The Nature of Customer Value: An Axiology of Services in the Consumption Experience," Service Quality: New Directions in Theory and Practice, 21-77. 
Holbrook, Morris B. and Elizabeth C. Hirschman (1982), "The Experiential Aspects of Consumption: Consumer Fantasies, Feelings and Fun," Journal of Consumer Research, 9 (2), 132-40.

Hong, Weiying, James Thong, Y.L., and Kar Yan Tam (2004), "The Effects of Information Format and Shopping Task on Consumers' Online Shopping Behavior: A Cognitive Fit Perspective," Journal of Management Information Systems, 21 (3), 149-84.

Huang, Ming-Hui (2000), "Information Load: it's Relationship to Online Exploratory and Shopping Behavior," International Journal of Information Management, 20 (5), 337-47.

Huizingh, Eelko K.R.E. (2000), "The Content and Design of Web Sites: An Empirical Study," Information and Management, 37 (3), 123-34.

Hulland, J. (1999), "Use of Partial Least Squares (PLS) in Strategic Management Research: A Review of Four Recent Studies," Strategic Management Journal, 20 (2), 195-204.

Joseph, George (2006), "Understanding Developments in the Management Information Value Chain from a Structuration Theory Framework," International Journal of Accounting Information Systems, 7, 319-41.

Kaltcheva, Velitchka D. and Barton A. Weitz (2006), "When Should a Retailer Create an Exciting Store Environment?," Journal of Marketing, 70 (January), 107-18.

Keaveney, Susan M. and Madhavan Parthasarathy (2001), "Customer Switching Behavior in Online Services: An Exploratory Study of the Role of Selected Attitudinal, Behavioral and Demographic Factors," Journal of the Academy of Marketing Science, 29 (4), 374-90.

Kim, Jihyun, Ann Marie Fiore, and Hyun-Hwa Lee (2007), "Influences of Online Store Perception, Shopping Enjoyment, and Shopping Involvement on Consumer Patronage Behavior towards an Online Retailer," Journal of Retailing and Consumer Services, 14 (2), 95-107.

Kim, S. and L. Stoel (2004), "Dimensional Hierarchy of Retail Website Quality," Information and Management, 41, 619-33.

Koufaris, Marios (2002), "Applying the Technology Acceptance Model and Flow Theory to Online Consumer Behavior," Information Systems Research, 13 (2), 205-23.

Kuo, Feng-Yang, Tsai-Hsin Chu, Meng-Hsiang Hsu, and Hong Ssu Hsieh (2004), "An Investigation on Effort-Accuracy Trade-Off and the Impact of Self-Efficacy on Web Searching Behaviors," Decision Support Systems, 37 (3), 331-42.

Kwak, Hyokjin, Richard J. Fox, and George M. Zinkhan (2002), "What Products Can Be Successfully Promoted and Sold via the Internet?," Journal of Advertising Research, 42 (1), 23-38.

Lee, Hyun-Hwa, Ann Marie Fiore, and Jihyun Kim (2006), "The Role of the Technology Acceptance Model in Explaining Effects of Image Interactivity Technology on Consumer Responses," International Journal of Retail and Distribution Management, 34 (8), 621-44.

Lehto, Xinran Y., Dae-Young Kim, and Alastair M. Morrison (2006), "The Effect of Prior Destination Experience on Online Information Search Behavior," Tourism and Hospitality Research, 6 (2), 160-78. 
Lewis, Ira and Jim Suchan (2003), "Structuration Theory: Its Potential Impact on Logistics Research," International Journal of Physical Distribution and Logistics Management, 33 (4), 296-315.

Liang, Ting-Peng and Hung-Jen Lai (2002), "Effect of Store Design on Consumer Purchases: An Empirical Study of On-line Bookstores," Information and Management, 39 (6), 431-44.

Lin, Cathy S., Sheng Wu, and Ray J. Tsai (2005), "Integrating Perceived Playfulness into Expectation-Confirmation Model for Web Portal Context," Information and Management, 42 (5), 683-93.

Liu, Chang and Kirk P. Arnett (2000), "Exploring The Factors Associated with Web Site Success in the Context of Electronic Commerce," Information and Management, 38, 23-33.

Liu, Yuping (2002), "Not All Consumers are Ready to Interact Online: Conceptualization and Research Issues (Interaction Readiness)," Submitted to the 2003 Winter SCP Conference.

Liu, Yuping and L.J. Shrum (2002), "What Is Interactivity and Is It Always Such a Good Thing? Implications of Definition, Person, and Situation for the Influence of Interactivity on Advertising Effectiveness," Journal of Advertising, 31 (4), 53-64.

Lohmöller, Jan-Berndt (1989), Latent Variable Path Modeling with Partial Least Squares. Heidelberg, Germany: Physica-Verlag.

Macintosh, Norman B. and Robert W. Scapens (1990), "Structuration Theory in Management Accounting," Accounting Organization and Society, 15 (5), 455-77.

Mano, Haim and Richard Oliver (1993), "Assessing the Dimensionality and Structure of the Consumption Experience: Evaluation, Feeling and Satisfaction," Journal of Consumer Research, 20 (3), 451-66.

Marsh, Herbert, W and David Hocevar (1985), "The Application of Confirmatory Factor Analysis to the Study of the Self-Concept: First and Higher Order Factor Structures and their Invariance across Age Groups," Psychological Bulletin, 97, 562-82.

Marsico De, Maria and Stefano Levialdi (2004), "Evaluating Web Sites; Exploiting User's Expectations," International Journal of Human-Computer Studies, 60, 318-416.

Mathwick, Charla, Naresh K. Malhotra, and Edward Rigdon (2002), "The Effect of Dynamic Retail Experiences on Experiential Perceptions of Value: An Internet and Catalog Comparison," Journal of Retailing, 78 (1), 51-60.

Mathwick, Charla, Naresh Malhotra, and Edward Rigdon (2001), "Experiential Value: Conceptualization, Measurement and Application in the Catalog and Internet Shopping Environment," Journal of Retailing, 77 (1), 39-56.

Mathwick, Charla and Edward Rigdon (2004), "Play, Flow and the Online Search Experience," Journal of Consumer Research, 31 (September), 324-32.

McKinney, Vicki, Kanghyun Yoon, and Fatemeh Mariam Zahedi (2002), "The Measurement of Web-Customer Satisfaction: An Expectation and Disconfirmation Approach," Information Systems Research, 13 (3), 296-315.

Menon, Satya and Barbara Kahn (2002), "Cross-category Effects of Induced Arousal and Pleasure on the Internet Shopping Experience," Journal of Retailing, 78 (1), 31-40. 
Mummalameni, Venkatapparao (2005), "An Empirical Investigation of Web Site Characteristics, Consumer Emotional States and On-line Shopping Behaviors," Journal of Business Research, 58, 526-32.

Muylle, Steve, Rudy Moenaert, and Marc Despontin (2004), "The Conceptualization and Empirical Validation of Web Site User Satisfaction," Information and Management, 41 (5), 543-60.

Negash, Solomon, Terry Ryan, and Magid Igbaria (2003), "Quality and Effectiveness in Webbased Customer Support Systems," Information and Management, 40 (8), 757-68.

Neuberger, Christoph, Jan Tonnemacher, Matthias Biebl, and Andre Duck (1998), "Onlinethe Future of Newspapers? German's Dailies on the World Wide Web," Journal of Computer Mediated Communication, 4 (1).

Newell, Frederick (2000), Loyalty.com. New York: McGraw-Hill.

Novak, Thomas P., Donna L. Hoffman, and Yiu-Fai Yung (2000), "Measuring the Customer Experience in Online Environments: A Structural Modeling Approach," Marketing Science, 19 (1), 22-42.

Nunnally, Jum C. and Ira H. Bernstein (1994), Psychometric Theory. New York: McGraw-Hill.

Oliver, Richard L. (1997), Satisfaction. A Behavioral Perspective on the Consumer. New York: McGraw-Hill.

---- (1999), "Whence Consumer Loyalty?," Journal of Marketing, 63 (Special Issue), 33-44.

Orlikowski, Wanda J. (2000), "Using Technology and Constituting Structures: A Practice Lens for Studying Technology in Organizations," Organization Science, 11 (4), 404-28.

Overby, Jeffrey W. and Eun-Ju Lee (2006), "The Effects of Utilitarian and Hedonic Online Shopping Value on Consumer Preference and Intentions," Journal of Business Research, 59 (10-11), 1160-66.

Palmer, Jonathan W. (2002), "Web Site Usability, Design, and Performance Metrics," Information Systems Research, 13 (2), 151-67.

Parasuraman, A. and Drew Grewal (2000), "The Impact of Technology on the Quality-ValueLoyalty Chain: A Research Agenda," Journal of the Academy of Marketing Science, 28 (1), 168-74.

Payne, Adrian and Pennie Frow (2005), "A Strategic Framework for Customer Relationship Management," Journal of Marketing, 69 (October), 167-76.

Peltier, James W., Amanda Hay, and William Drago (2005), "The Reflective Learning Continuum: Reflecting on Reflection," Journal of Marketing Education, 27 (3), 250-63.

--- (2006), "Reflecting on Reflection: Scale Extension and a Comparison of Undergraduate Business Students in the United States and the United Kingdom," Journal of Marketing Education, 28 (1), 5-16. 
Peters, Linda D. (2006), "Conceptualizing Computer-Mediated Communication Technology and Its Use in Organizations," International Journal of Information Management, 26 (2), 14252 .

Pine, Joseph and James Gilmore (1999), The Experience Economy. Boston: Harvard Business School Press.

Poole, Marshall Scott and Gerardine DeSanctis (2004), "Structuration Theory in Information Systems Research: Methods and Controversies," in The Handbook of Information Systems Research, Michael E. Whitman and Amy B. Woszcynski, Eds: London: Idea Group Inc.

Poole, Marshall Scott and van de Ven, Andrew H. (1989), "Using Paradox to Build Management and Organization Theories," Academy of Management Review, 14 (4), 562-78.

Pozzebon, Marlei (2004), "The Influence of a Structuration View on Strategic Management Research," Journal of Management Studies, 41 (2), 247-72.

Pozzebon, Marlei and Alain Pinsonneault (2001), "Structuration Theory in the IS Field: An Assessment of Research Strategies," in The 9th European Conference on Information Systems Bled, Slovenia.

Prahalad, C.K. and Venkat Ramaswamy (2004), "Co-Creation Experiences: The Next Practice in Value Creation," Journal of Interactive Marketing, 18 (3), 5-14.

Ranganathan, C. and Shobha Ganapathy (2002), "Key Dimensions of Business-toConsumer Web Sites," Information and Management, 39 (6), 457-65.

Rayport, Jeffrey F., Bernard J. Jaworski, and Ellie J. Kyung (2005), "Best Face Forward: Improving Companies' Service Interfaces with Customers," Journal of Interactive Marketing, $19(4), 67-80$.

Reichheld, Frederick F. and William Sasser, E. Jr. (1990), "Zero Defects: Quality Comes to Service " Harvard Business Review (September-October), 105-11.

Reynolds, Kristy, E. and Sharon Beatty, E. (1999), "A Relationship Customer Typology," Journal of Retailing, 75 (Winter), 509-23.

Rindskopf, David and Ted Rose (1988), "Second Order Factor Analysis: Some Theory and Applications," Multivariate Behavioral Research, 23, 51-67.

Rose, Jeremy (1998), "Evaluating the Contribution of Structuration Theory of the Information Systems Discipline," in European Conference on Information Systems Aix-en-Provence.

Sarason, Yolanda, Tom Dean, and Jesse F. Dillard (2006), "Entrepreneurship as the Nexus of Individual and Opportunity: A Structuration View," Journal of Business Venturing, 21 (3), 286-305.

Schippers, Michaela C. (2003), "Reflexivity in Teams," Vrije Universiteit Amsterdam.

Schlossberg, Edwin (1998), Interactive Excellence: Defining and Developing New Standards for the 21st Century. New York: The Ballantine Publishing Group.

Schlosser, Ann E. (2003), "Experiencing Products in the Virtual World: The Role of Goal and Imagery in Influencing Attitudes versus Purchase Intentions," Journal of Consumer Research, 30 (2), 184-98. 
Schultz, Tanjev (1999), "Interactive Options in Online Journalism: A Content Analysis of 100 U.S. Newspapers," Journal of Computer Mediated Communication, 5 (1), 1-21.

Shankar, Venkatesh, Amy K. Smith, and Arvind Rangaswamy (2003), "Customer Satisfaction and Loyalty in Online and Offline Environments," International Journal of Research in Marketing, 20 (2), 153-75.

---- (2000), "Customer Satisfaction and Loyalty in Online and Offline Environments."

Shankar, Venkatesh, Fareena Sultan, and Glen L. Urban (2002), "Online Trust and eBusiness Strategy: Concepts, Implications, and Future Directions."

Shih, Chuan-Fong (1998), "Conceptualizing Consumer Experiences in Cyberspace," European Journal of Marketing, 32 (7/8), 655-63.

Srinivasan, Srini S. , Rolph Anderson, and Kishore Ponnavolu (2002), "Customer Loyalty in E-commerce: An Exploration of its Antecedents and Consequences," Journal of Retailing, 78, 41-50.

Stewart, David W. (2005), "Traditional Ad Research Overlooks Interaction," in Marketing News.

Stewart, David W. and Paul A. Pavlou (2002), "From Consumer Response to Active Consumer: Measuring the Effectiveness of Interactive Media," Journal of the Academy of Marketing Science, 30 (4), 376-96.

Szymanski, David M and Richard T. Hise (2000), "E-Satisfaction: An Initial Examination," Journal of Retailing, 76 (3), 309-22.

Tenenhaus, Michel, Vincenzo E. Vinzi, Ives-Marie Chatelin, and Carlo Lauro (2005), "PLS Path Modeling," Computational Statistics \& Data Analyses, 48, 159-205.

Tett, Robert, P. and Dawn Burnett, D. (2003), "A Personality Trait-Based Interactionist Model of Job Performance," Journal of Applied Psychology, 88 (3), 500-17.

Tett, Robert, P. and Hal. A. Guterman (2000), "Situation Trait Relevance, Trait Expression, and Cross-Situational Consistency: Testing a Principle of Trait Activation," Journal of Research in Personality, 34 (4), 397-423.

Van der Heijden, H. (2004), "User Acceptance of Hedonic Information Systems," MIS Quarterly, 28 (4), 695-704.

Vargo, Stephen L. and Robert F. Lusch (2004), "Evolving to a New Dominant Logic for Marketing," Journal of Marketing, 68 (January), 1-17.

Westbrook, Robert, A. and William Black, C. (1985), "A Motivation-Based Shopper Technology," Journal of Retailing, 61 (Spring), 78-103.

Williamson, lan O, David P. Lepak, and James King (2003), "The Effect of Company Recruitment Web Site Orientation on Individuals' Perceptions of Organizational Attractiveness," Journal of Vocational Behavior, 63, 242-63. 
Wold, Herman (1982), "Soft Modeling: The Basic Design and Some Extensions," in Systems under Indirect Observations: Causality, Structure, Prediction, K.G. Jöreskog and H. Wold, Eds. Vol. 2. Amsterdam.

Wolfinbarger, Mary and Mary C. Gilly (2001), "Shopping Online for Freedom, Control and Fun," California Management Review, 43 (2), 34-55.

Wood, Murray, John Daly, James Miller, and Marc Roper (1999), "Multi-method Research: an Empirical Investigation of Object-Oriented Technology," The Journal of Systems and Software, 48, 13-26.

Woodruff, Robert, B. (1997), "Customer Value: The Next Source for Competitive Advantage," Journal of the Academy of Marketing Science, 25 (Spring), 139-53.

---- (2005a), "Understanding Product Migration to the Electronic Marketplace: A Conceptual Framework," Journal of Retailing, 81 (2), 125.

Yadav, Manjit S. and Rajan Varadarajan (2005b), "Interactivity in the Electronic Marketplace: An Exposition of the Concept and Implications for Research," Journal of the Academy of Marketing Science, 33 (4), 585-603.

Yi, Mun Y. and Yujong Hwang (2003), "Predicting the Use of Web-Based Information Systems: Self-Efficacy, Enjoyment, Learning Goal Orientation, and the Technology Acceptance Model," International Journal of Human-Computer Studies, 59 (4), 431-49.

Zeithaml, Valerie A., Leonard L. Berry, and Arvind Parasuraman (1996), "The Behavioral Consequences of Service Quality," Journal of Marketing, 60 (2), 31-46.

Zeithaml, Valerie A., A. Parasuraman, and Arvind Malhotra (2000), "A Conceptual Framework for Understanding E-Service Quality: Implications for Future Research and Managerial Practice," Marketing Science Institute, 1-46.

Zhang, Ping and Gisela M. von Dran (2001), "User Expectations and Rankings of Quality Factors in Different Web Site Domains," International Journal of Electronic Commerce, 6 (2), 9-33.

Zhou, Zheng (2002), "Users' Attitudes toward Web Advertising: Effects of Internet Motivation and Internet Ability," Advances in Consumer Research, 29, 71-78. 


\section{Nederlandse samenvatting}

\section{Inleiding}

De introductie van het Internet heeft de manier waarop mensen communiceren en naar informatie zoeken drastisch veranderd. Een van de belangrijkste kenmerken van het Internet is interactiviteit, een kenmerk dat niet alleen bepalend is voor het ontwerp van de website, maar ook voor de wijze waarop bezoekers de website ervaren. Door de toenemende interactiviteit van het Internet, biedt het Internet de mogelijkheid om offline ervaringen te benaderen en virtuele omgevingen te creëren waarin gebruikers deel uit maken van een andere wereld zoals in Secondlife.com. Tegenwoordig gebruiken de meeste organisaties hun websites dan ook als een volwaardig communicatiekanaal naast de al bestaande kanalen. Het communicatieproces tussen bedrijven en hun klanten is enorm veranderd door de komst van het Internet en verandert nog steeds als gevolg van recente technologische ontwikkelingen, die elkaar in een hoog tempo opvolgen. Deze recente technologische ontwikkelingen zijn een stuwende kracht achter een substantiële toename van interactieve kenmerken op websites zoals, virtuele persoonlijkheden, chat, drie-dimensionele virtuele rondleidingen, communities en interactieve spelletjes. Gezien deze ontwikkelingen is het voor organisaties zeer interessant om meer inzicht te krijgen in de invloed van diverse website kenmerken op de ervaringen van hun website bezoekers.

Gedreven door praktische en theoretische ontwikkelingen, is het hoofddoel van deze dissertatie om het wederzijdse interactie proces tussen websites en hun bezoekers te onderzoeken aan de hand van structuratie theorie.

Teneinde dit doel te bereiken, formuleren we de volgende sub-doelen:

1. Het introduceren en ontwikkelen van het construct interactie rijkheid om zo een compleet beeld te krijgen van wat klanten van websites vinden.

2. Het ontwikkelen en verfijnen van geschikte maatstaven voor de bestudering van het online interactie proces tussen websites en hun bezoekers.

3. Het vaststellen van het causale verband tussen interactie rijkheid, hedonische en functionele waarde en uiteindelijk loyaliteit ten opzichte van de website met behulp van meerdere studies.

4. Het bestuderen van de invloed van kenmerken van het individu zoals reflectie, competentie en doelgericht gedrag op het causale verband tussen interactie rijkheid, waarde en loyaliteit.

5. Het vaststellen van de robuustheid van onze onderzoeksresultaten. 
Deze dissertatie is verdeeld in drie delen: theoretisch raamwerk (hoofdstuk 2), empirische toepassing (hoofdstukken 3, 4 en 5) en conclusies (hoofdstuk 6).

\section{Structuratie theorie in een online context}

In hoofdstuk 2 wordt het theoretische raamwerk van het onderzoek naar de relatie tussen websites en hun bezoekers geschetst. De structuratie theorie van de socioloog Anthony Giddens wordt gebruikt om de wederzijdse interacties tussen websites en hun bezoekers te verklaren. Allereerst wordt het model van de dualiteit van structuur beschreven. Dit model berust op het principe dat structuur en actoren onlosmakelijk met elkaar verbonden zijn en elkaar wederzijds beïnvloeden. Binnen het model van dualiteit van structuur kunnen drie gelijkwaardige componenten van structuur onderscheiden worden; een zingevings-, dominantie- en een legitimatiecomponent. Uit deze structuur componenten putten actoren de interpretatiekaders, de hulpmiddelen of bronnen en de normen aan de hand waarvan de communicatie, machtsbeïnvloeding en normatieve sanctionering plaatsvindt. De actoren worden binnen deze theorie gezien als reflexieve en competente personen die doelgericht gedrag kunnen vertonen en door hun handelen de structuren telkens reproduceren.

Vervolgens wordt deze theorie toegepast op het interactie proces tussen websites en hun bezoekers. We richten ons eerst op de zingevende structuur componenten, die refereren aan de website kenmerken, zoals media rijkheid en informatie rijkheid, die het interpretatiekader voor de website bezoekers vormen. De dominantie structuur componenten verwijzen enerzijds naar de specifieke eigenschappen van de website bezoekers zoals de mate waarin zij doelgericht handelen, hun reflectie en competentie en anderzijds verwijzen ze naar de verschillende niveaus van media en informatie rijkheid van de website. Deze dominantie structuur componenten faciliteren website bezoekers om hun doelen in termen van zowel functionele als hedonische waarden te bereiken. Tot slot, verwijzen de legitimatie structuur componenten naar de normen en criteria, in dit geval de waargenomen functionele en hedonische waarden, die website bezoekers gebruiken om hun niet-loyaal versus loyaal gedrag te rechtvaardigen.

Dit theoretische raamwerk wordt vanuit het macro-veranderingsperspectief met behulp van meerdere empirische studies bestudeerd omdat een combinatie van meerdere complementaire empirische methoden bijdraagt aan een beter begrip van het wederzijdse interactie proces, de hoge afhankelijkheid en de gelijktijdige beïnvloeding van websites en hun bezoekers gedurende de tijd.

\section{Maatstaven voor de evaluatie van de online ervaring van consumenten}

In hoofdstuk 3 ontwikkelen we diverse instrumenten om de ervaringen van consumenten met een website vast te stellen. Allereerst ontwikkelen we een meetschaal voor het construct 
interactie rijkheid dat we in hoofdstuk 2 geïntroduceerd hebben. Interactie rijkheid geeft het beeld weer dat de bezoeker van de website heeft en omvat zowel de mate waarin de website gezien wordt als een rijk medium en als een drager van rijke informatie. Teneinde deze meetschaal voor interactie rijkheid te ontwikkelen voeren we eerst twee kwalitatieve studies en vervolgens twee kwantitatieve studies met bezoekers van websites van reisorganisaties en dagbladen uit. De ontwikkeling van de meetschaal voor interactie rijkheid resulteert in een multi-dimensioneel construct dat het beeld weergeeft dat de website bezoekers hebben van de veelzijdige kenmerken van de website.

Vervolgens voeren we een kwantitatieve studie uit met bezoekers van boeken en cd websites. Hiermee kunnen we geschikte instrumenten ontwikkelen waarmee we het beeld, dat website bezoekers hebben van zowel de hedonische als de functionele waarden van de online ervaring, kunnen vaststellen.

Daarnaast ontwikkelen we een instrument voor online loyaliteit dat verschillende fasen van loyaliteit aan een website weergeeft, te weten cognitieve loyaliteit, affectieve loyaliteit en intenties zoals mond-tot-mond reclame en de intentie om opnieuw de website te bezoeken. Tevens verfijnen we een bestaande meetschaal voor reflectie binnen teams tot een instrument waarmee we de mate waarin individuen reflecteren op hun eigen informatie zoekproces in een online omgeving kunnen vaststellen.

\section{Media rijkheid en informatie rijkheid: twee aanvullende dimensies}

In hoofdstuk 4 onderzoeken we middels een experimentele opzet het effect van media rijkheid en informatie rijkheid op de waarde perceptie van website bezoekers en uiteindelijk hun loyaliteit aan de website. Daartoe manipuleren we de media rijkheid en informatie rijkheid van de Samsung Fun Club website (hoog versus laag) en het doelgericht gedrag van de website bezoekers (zoeken versus surfen). De resultaten van het experiment, waaraan 547 Samsung Fun Club leden deelnamen, laten zien dat media rijkheid en informatie rijkheid niet alleen een direct positief effect hebben op functionele en hedonische waarden, maar dat er ook een interactie-effect bestaat tussen media rijkheid, informatie rijkheid en de functionele en de hedonische waarden. In overeenstemming met de verwachtingen tonen deze effecten dat wanneer het waargenomen niveau van media rijkheid laag is een hoog niveau van informatie rijkheid dit gebrek kan compenseren en nog steeds tot hedonische waarde leidt. Echter wanneer het waargenomen niveau van media rijkheid hoog is, hebben website bezoekers in mindere mate rijke informatie nodig om hedonische waarde te ervaren. Daarnaast tonen onze resultaten dat wanneer het waargenomen niveau van informatie rijkheid laag is, dit gecompenseerd kan worden door een hoog niveau van media rijkheid om zo functionele waarde te creëren. Echter wanneer bezoekers hoge niveaus van informatie 
rijkheid waarnemen, hebben ze in mindere mate behoefte aan media rijkheid teneinde functionele waarde te ervaren.

Tevens laten onze resultaten zien dat niet-doelgerichte website bezoekers (surfers) hogere niveaus van hedonische waarden ervaren dan website bezoekers die doelgericht zoeken.

\section{De invloed van interactie rijkheid op de evaluatie van de online ervaring van consumenten}

In hoofdstuk 5 onderzoeken we het effect van interactie rijkheid in zijn geheel op de ervaringen van bezoekers met de website en hun loyaliteit ten opzichte van de website. Daarbij wordt ook de rol van kenmerken van de website bezoeker zoals hun reflectie en competentie onderzocht. De resultaten van het empirische onderzoek, waarbij 288 bezoekers van loopbaan websites een online vragenlijst invulden, tonen aan dat zowel media rijkheid als informatie rijkheid belangrijke componenten van interactie rijkheid zijn. Uit de onderzoeksresultaten blijkt dat het totale concept van interactie rijkheid een sterke positieve invloed heeft op de ervaring van zowel functionele als hedonische waarde. Daarnaast blijkt dat interactie rijkheid website bezoekers aanspoort hun eigen informatie zoekproces kritisch te evalueren (reflecteren) en tevens een positieve invloed heeft op de vaardigheden van een individu wat betreft het zoeken naar informatie online (competentie). De invloed van interactie rijkheid op de ervaring van functionele waarde wordt versterkt wanneer website bezoekers hun eigen zoekproces naar informatie kritisch evalueren. Echter reflectie heeft geen modererend effect op de relatie tussen interactie rijkheid en ervaring van hedonische waarde. Tegen de verwachtingen in, wordt het effect van interactie rijkheid op de ervaring van functionele waarde afgezwakt wanneer website bezoekers competent zijn. Daarentegen wordt het effect van interactie rijkheid op de ervaring van hedonische waarde wel versterkt wanneer de website bezoekers competent zijn. Tot slot heeft de ervaring van zowel hedonische als functionele waarde een positief effect op de loyaliteit van bezoekers ten opzichte van de website.

\section{Conclusie}

Dit proefschrift verschaft met behulp van structuratie theorie inzicht in het wederzijdse interactie proces tussen websites en hun bezoekers en de invloed hiervan op de ervaringen van website bezoekers en hun loyaliteit ten opzichte van de website. Daarnaast introduceren en ontwikkelen we het construct interactie rijkheid ten einde de percepties van website bezoekers vast te stellen. De ontwikkeling van het construct interactie rijkheid is belangrijk omdat het gezien wordt als een construct dat inzicht verschaft in de percepties van website bezoekers van zowel de rijkheid van het medium als de rijkheid van de informatie. Interactie rijkheid heeft een positieve invloed op de ervaring van zowel de hedonische als de 
functionele waarde en uiteindelijk de loyaliteit van bezoekers ten opzichte van de website. Daarnaast stimuleert interactie rijkheid de reflectie en competentie van website bezoekers wat betreft hun zoekproces naar informatie online. Tevens modereren de reflectie en competentie van website bezoekers de relatie tussen interactie rijkheid en de ervaren waarde. De waarde die website bezoekers ervaren verschilt ook als gevolg van hun doelgericht gedrag. Tot slot blijken de resultaten van ons onderzoek robuust te zijn in verschillende contexten met verschillende steekproeven.

\section{Implicaties voor managers}

Vanuit een praktisch oogpunt biedt het toepassen van het model van dualiteit van structuur voor het onderzoeken van het interactieproces tussen websites en hun bezoekers diverse voordelen. Allereerst, verschaft onze aanpak managers inzicht in de sterke wederzijdse afhankelijkheid tussen websites en hun bezoekers. Daarnaast biedt het model een richtlijn voor de ontwikkeling van interactie rijke websites. Op basis van de resultaten van deze dissertatie benadrukken we dat managers bij het ontwikkelen van een website niet alleen moeten focussen op de rijkheid van het medium of de rijkheid van de informatie van de website, maar dat ze zich op zowel media rijkheid als informatie rijkheid moeten richten omdat dit twee complementaire factoren zijn. Tevens biedt het model inzicht in de doelen van zowel de website bezoeker in termen van waarde van de ervaring als de doelen van de organisatie in termen van loyaliteit. Daarnaast stelt het model managers in staat om op basis van de persoonlijkheidskenmerken van consumenten hun website bezoekers te segmenteren.

\section{Beperkingen en suggesties voor verder onderzoek}

Een van de beperkingen van dit onderzoek is dat we alleen de interactie rijkheid van websites onderzocht hebben, terwijl het zeer interessant kan zijn om de interactie rijkheid van verschillende communicatiekanalen te onderzoeken. Zeker omdat we in de praktijk zien dat de meeste bedrijven via meerdere kanalen zowel offline als online met hun klanten communiceren. Hoewel we in het kader van de structuratie theorie verschillende methoden gebruiken om inzicht te verkrijgen in het macro-veranderingsperspectief, kan het verrichten van longitudinaal onderzoek nog waardevolle inzichten in deze materie verschaffen. Tevens zouden we naast de drie kenmerken van website bezoekers die we in dit onderzoek onderzocht hebben ook nog de invloed van andere persoonlijkheidskenmerken kunnen bestuderen en aan de hand van deze kenmerken de bezoekers aan de website kunnen segmenteren. 


\section{Slotgedachte}

De titel van het proefschrift "From Rags to Richness" is afgeleid van het engelse gezegde "Rags to Riches". In dit laatste deel van het proefschrift maken we van de gelegenheid gebruik om kort over dit thema te filosoferen. Tegenwoordig zijn er verschillende sprookjes (bijv. Assepoester), films (bijv. Rocky), televisieprogramma's (bijv. Idols) en zelfs liedjes (bijv. Rags to Riches door Tony Benett) die op het Rags to Riches thema gebaseerd zijn. Dit thema verwijst in principe naar iedere situatie waarin een onbekend of arm individu beroemd of rijk wordt en geeft de armen hoop dat ze beroemd of rijk kunnen worden.

Op dezelfde wijze geeft dit proefschrift bedrijven "hoop" door aan te tonen dat alleen hun aanwezigheid online niet voldoende is om een waardevolle online ervaring voor hun klanten te creëren. Website ontwerpers moeten bezoekers van websites rijke interacties bieden. Alleen dan zullen website bezoekers overwegen om de website opnieuw te bezoeken en hun waardevolle ervaringen met anderen te delen. Dit proefschrift geeft ook "hoop" aan website bezoekers omdat zij uiteindelijk profiteren van de verrijkte online interacties waardoor ze mogelijkerwijs de online ervaring waarderen.

Wanneer bedrijven die online actief zijn de dominante rol van interactie rijkheid erkennen zullen ze samen met hun website bezoekers nog lang en gelukkig leven en zich ontwikkelen van rags to richness. 


\section{Curriculum Vitae}

Claudia van Oppen was born on the 10th of June 1977 in Meerssen, the Netherlands. After completing secondary school at 'Stella Maris College' in Meerssen (1989-1995), she studied Business Economics at the Faculty of Economics and Business Administration at Maastricht University (the Netherlands). During her studies, she specialized in Organization Science and Marketing. In 1999, she spent one semester at the Norwegian School of Management BI, Sandvika (Norway). Subsequently, she did an internship of 6 months on Lead Management at TNT Post Group - Hoofddorp (the Netherlands). Her final thesis concerned an empirical research for the Carlson Marketing Group investigating the influence of characteristics of loyalty programs on the attitude and behavior of Dutch and Belgian consumers towards loyalty programs. Her master thesis was nominated for the DMSA Carel Rog award 2000. In September 2000, she obtained her Master's Degree and she immediately started her career as a junior lecturer and research fellow at the Department of Marketing of Maastricht University. During this period she was involved in several research projects e.g. The Loyalty Monitor of the Carlson Marketing Group in cooperation with the Vlerick Leuven Gent Management School. In September 2002, she became a PhD candidate at the Department of Marketing of Maastricht University. During her time as a PhD candidate she supervised several students with their master thesis and coordinated several marketing courses e.g. e-commerce. For her $\mathrm{PhD}$ research she closely cooperated with various organizations such as Samsung, Adversitement and Elitech. Her main research interests are in the area of online consumer behavior, relationship marketing and services marketing. She has presented her work at various international conferences. Furthermore, her work has been published in Journal of Relationship Marketing and in the book Principes van Marketing of Philip Kotler. In addition, her work has been reported in the commercial press, such as Tijdschrift voor Marketing and Adfodirect. In February 2006, she gave birth to her son Dries and after her maternity leave she continued her work as a PhD candidate. As of February 2007, she is the manager of the Small and Medium Sized Enterprises (SME) Portal of Maastricht University (the Netherlands) responsible for facilitating, coordinating and managing the knowledge transfer between University Maastricht and entrepreneurs in the (eu)region. 